PNWD-3035

BNFL-RPT-027 Rev. 0

\title{
Combined Entrained Solids and Sr/TRU Removal from AN-107 Diluted Feed
}

\author{
R. T. Hallen \\ P. R. Bredt \\ K. P. Brooks \\ L. K. Jagoda
}

August 2000

Prepared for

BNFL, Inc.

under Contract W375-LC-98-4168

Battelle, Pacific Northwest Division

Richland, Washington 99352 
-

-

• 


\section{DISCLAIMER}

This report was prepared as an account of work sponsored by an agency of the United States Government. Neither the United States Government nor any agency thereof, nor any of their employees, make any warranty, express or implied, or assumes any legal liability or responsibility for the accuracy, completeness, or usefulness of any information, apparatus, product, or process disclosed, or represents that its use would not infringe privately owned rights. Reference herein to any specific commercial product, process, or service by trade name, trademark, manufacturer, or otherwise does not necessarily constitute or imply its endorsement, recommendation, or favoring by the United States Government or any agency thereof. The views and opinions of authors expressed herein do not necessarily state or reflect those of the United States Government or any agency thereof. 


\section{DISCLAIMER}

Portions of this document may be illegible in electronic image products. Images are produced from the best available original document. 


\section{SUMMARY}

Waste from Hanford underground storage tank 241-AN-107 is a candidate low-activity waste (LAW) for Envelope C. Envelope C wastes require pretreatment to remove radioactive Sr and TRU (along with cesium and technetium) before immobilization. The baseline pretreatment process planned for $\mathrm{Sr}$ /TRU removal was precipitation with added strontium and iron. However, studies have shown that the $\mathrm{Sr} / \mathrm{Fe}$ precipitates were very difficult to filter. An alternative treatment being evaluated uses permanganate instead of iron. Permanganate treatment has been shown to be effective for decontaminating waste from Hanford Tank SY-101.

Battelle conducted small-scale experiments with archived AN-107 waste over a period of about three months to determine the effectiveness of the permanganate treatment process. These tests showed that permanganate treatment alone would provide adequate TRU removal, however, permanganate alone would not provide adequate $\mathrm{Sr}$ removal. The preferred Sr/TRU removal process involved addition of strontium and permanganate. Test conditions that provided adequate $\mathrm{Sr} / \mathrm{TRU}$ decontamination were identified. These test conditions were further evaluated with a 1-L batch of archived AN-107, which provided a large enough volume of waste to conduct crossflow filtration studies. These tests showed that Sr/TRU removal could be accomplished by addition of a strontium solution followed by permanganate solution. The resulting precipitate could be removed effectively by crossflow filtration.

The original target sodium concentration for $\mathrm{AN}-107$ diluted feed was 7.7M. The waste was further diluted and additional caustic added before Sr/TRU precipitation. The target concentrations for the treated waste were $6.0 \mathrm{M}$ sodium, $1.0 \mathrm{M}$ free hydroxide, $0.075 \mathrm{M}$ strontium, and $0.05 \mathrm{M}$ permanganate. Approximately 1.4-L of AN-107 diluted feed were treated. Decontamination of strontium-90 and TRU (Am-241) in the supernatant was greater than needed to meet the immobilized low-activity waste (ILAW) requirements (less than $100 \mathrm{nCi} / \mathrm{g}$ TRU and less than $20 \mathrm{Ci} / \mathrm{m}^{3} \mathrm{Sr}-90$ in the final ILAW). The stronium-90 decontamination factor (DF) was consistently greater than 50 and the Am-241 DF greater than 25. The target DFs were 10 for Sr-90 and 5 for Am-241. These DFs include the contribution from the removal of the entrained solids although this was relatively small. The removal of the entrained solids accounted for about $8 \%$ of the DF for $\mathrm{Sr}-90$ and about $17 \%$ of the DF for the alpha emitters.

Crossflow filtration tests with archived AN-107 showed that the entrained solids could not be readily removed from $\mathrm{AN}-107$ waste prior to $\mathrm{Sr} / \mathrm{TRU}$ treatment. However, the filterability, as determined by filter flux rate, increased by an order of magnitude after the treatment process. For AN-107 diluted feed, crossflow filtration tests were conducted in the Cell Unit Filter (CUF) system with the Sr/TRU precipitated waste only. Results showed that the treated waste could be effectively filtered by crossflow filtration. A parametric study was conducted with relatively low, $1.9 \mathrm{wt} \%$, initial solids loading of the treated waste. At target transmembrane pressure (TMP) of 50 psi and crossflow velocity of $12.2 \mathrm{ft} / \mathrm{sec}$, the average flux rate was $0.03 \mathrm{gpm} / \mathrm{ft}^{2}$ or $1.75 \mathrm{~m}^{3} / \mathrm{m}^{2} /$ day and the permeability was $0.53 \mathrm{~m} /$ day $/ \mathrm{bar}$. The treated waste slurry was dewatered in the CUF to approximately $4 \mathrm{wt} \%$. Additional dewatering in the CUF was not possible because the minimum operating volume of the CUF was reached. Solids' washing was not conducted in the CUF because of the low solid loading in the dewatered slurry. Additional filtration tests will need to be conducted to determine maximum solids loading. 


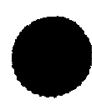

○

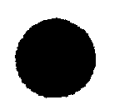




\section{TERMS AND ABBREVIATIONS}

AEA

BNFL

DF

DI water

EQL

GEA

ICP

MDL

MRQ

RPD

SAL alpha energy analysis

BNFL, Inc; subsidiary of British Nuclear Fuels, Ltd.

decontamination factor

deionized water

estimated quantitation level

gamma energy analysis

inductively coupled plasma/atomic emission

spectrometry

method detection limit

minimum reportable quantity

relative percent difference

Shielded Analytical Laboratory 


\section{UNITS}

${ }^{\circ} \mathrm{C}$
$\mathrm{ft} / \mathrm{s}$
$\mathrm{g}$
$\mathrm{g} / \mathrm{mL}$
$\mu \mathrm{g} / \mathrm{g}-\mu \mathrm{g} / \mathrm{mL}$
$\mu \mathrm{Ci} / \mathrm{g}-\mu \mathrm{Ci} / \mathrm{mL}$
$\mathrm{M}$
$\mathrm{mL}$
$\mathrm{mmole} / \mathrm{mL}$
$\mathrm{nCi} / \mathrm{g}$
$\mathrm{pCi} / \mathrm{g}$
$\mathrm{Vol} \%$
$\mathrm{Wt} \%$

${ }^{\circ} \mathrm{C}$

$\mathrm{ft}$

$\mathrm{g} / \mathrm{mL}$

$\mu \mathrm{g} / \mathrm{g}-\mu \mathrm{g} / \mathrm{mL}$

$\mu \mathrm{Ci} / \mathrm{g}-\mu \mathrm{Ci} / \mathrm{mL}$

$\mathrm{mmole} / \mathrm{mL}$

$\mathrm{nCi} / \mathrm{g}$

Vol\%

$\mathrm{Wt} \%$ degrees Centigrade

feet per second

gram

gram per milliliter

microgram per gram / microgram per milliliter

microcurie per gram / microcurie per milliliter

mole/liter

milliliter

millimole per milliliter

nanocurie per gram

picocurie per gram

volume percent

weight percent 


\section{CONTENTS}

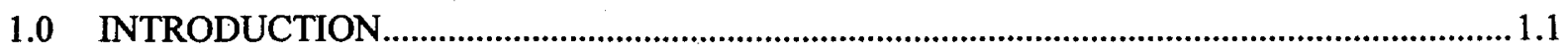

2.0 TEST CONDITIONS AND EXPERIMENTAL PROCEDURES .................................................

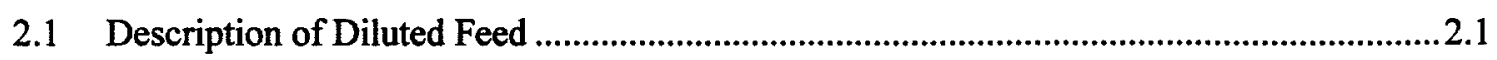

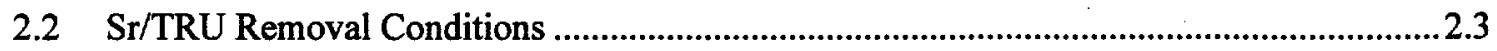

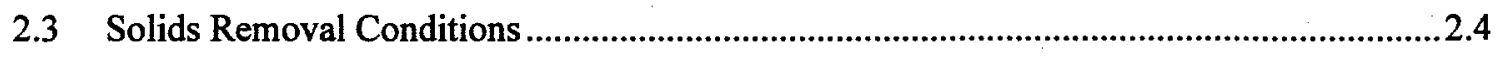

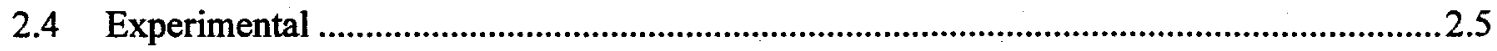

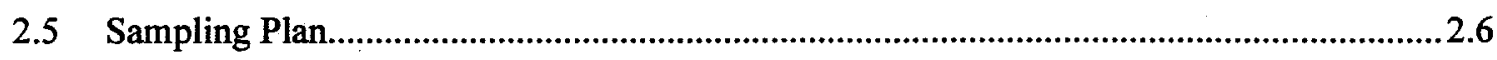

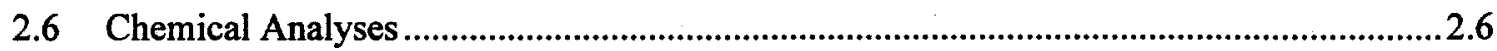

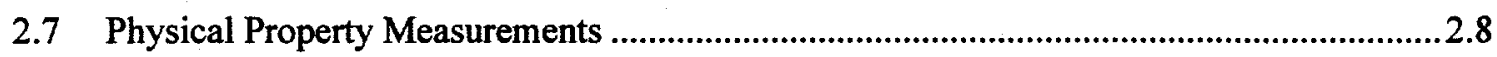

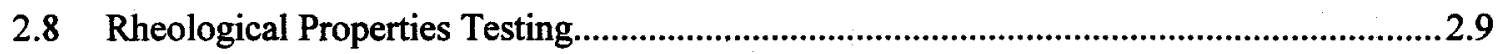

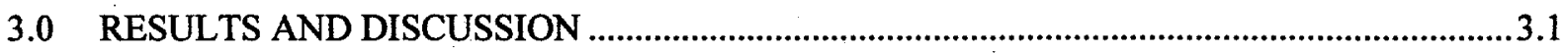

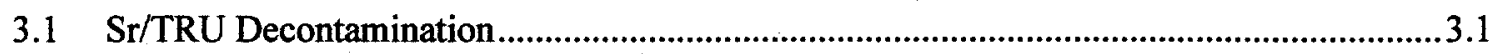

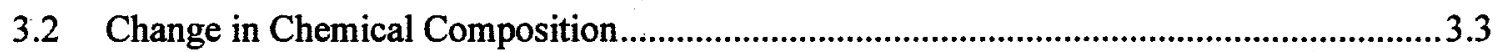

3.3 Composition of Wash Solutions and Washed Solids ......................................................... 3.5

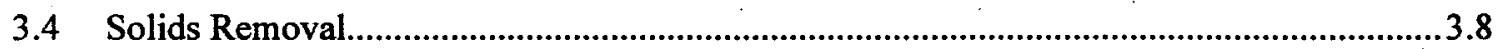

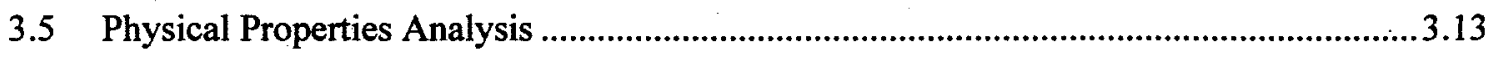

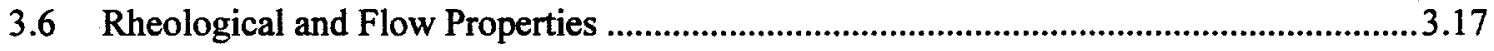

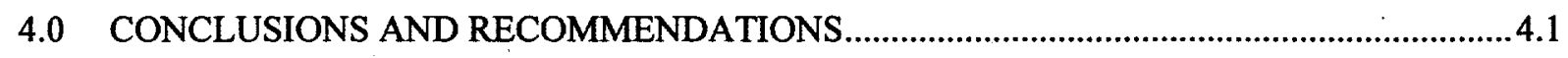

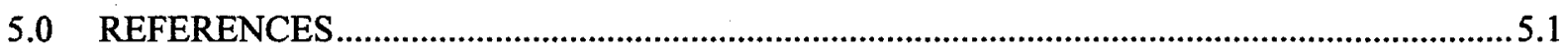

APPENDIX A: TEST INSTRUCTION AND DATA SHEETS …....................................................

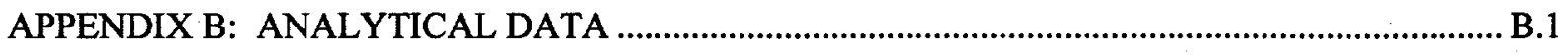

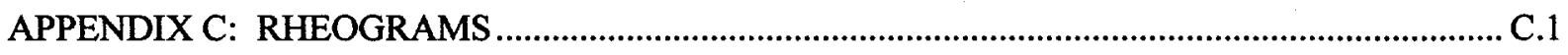

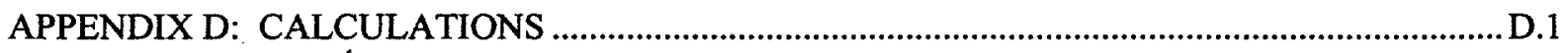

APPENDIX E: STAFF AND ROLE/RESPONSIBILITY …........................................................... E.1 


\section{FIGURES}

Figure 1.1. Comparison the Filtrate Flux for Entrained Solids Removal and Sr/TRU Precipitated Archived AN-107 Waste at $55 \mathrm{psi}$ TMP and $12.2 \mathrm{ft} / \mathrm{s}$ Crossflow Velocity

Figure 3.1. CUF Data for Test Number 1 of the Test Matrix, 49 psi Transmembrane Pressure and $4.0 \mathrm{gpm}$ Total Flow (crossflow velocity of $12 \mathrm{ft} / \mathrm{s}$ )

Figure 3.2. CUF Data for Test Number 6, Repeat of Test Number 1 ...............................................

Figure 3.3. Flux Rate During Dewatering in the CUF Unit

Figure 3.4. Comparison of Flux Data from Sr/TRU Precipitated Archived AN-107 and AN-107 Diluted Feed

Figure 3.5. Comparison of Flux Rates at Different Slurry Concentrations with Test Number 1 Conditions

Figure 3.6. Filtrate Flux Rates with Frequent Backpulsing

Figure 3.7. Initial AN-107 Diluted Feed: Sample 1

Figure 3.8. AN-107 Sr/TRU Precipitated Slurry: Sample 1 Analysis 1

\section{TABLES}

Table 2.1. Calculated Composition of AN-107 Diluted Feed Before Treatment.............................2.2

Table 2.2. $\quad$ Sr/TRU Precipitate Filtration Tests Conditions .............................................................2.4

Table 2.3. Chemical Additions to AN-107 Diluted Feed ...............................................................2.5

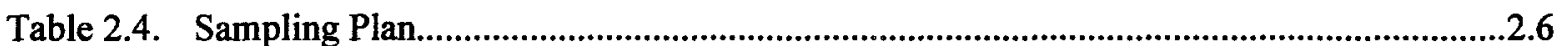

Table 2.5. Analytical Requirements for Washed Solids, Filtrate, and Wash Solutions ....................2.7

Table 2.6. Identification of Samples that were Analyzed ${ }^{1}$..........................................................2.8

Table 3.1. Samples and Mass Dilution for Calculating Decontamination Factors............................3.1

Table 3.2. Strontium, Am, and Cm Decontamination Factors for Samples DF-01 to DF-11 and the Composition of CUF Filtrate (DF-11) ..................................................................2

Table 3.3. Radioactive Element Decontamination Factors for Samples DF-14, DF-20 and DF-21 and Average Composition of Composite Filtrate.

Table 3.4. Percent Removal of ICP Metals from samples DF-01 to DF-11 and Composition of the CUF Filtrate (DF-11)

Table 3.5. Composition Change, Reported as Percent Removed, on Treatment and Dilution of the Slurry and Final Composite Filtrate .............................................................................3.4

Table 3.6. Sodium Concentration in DF-01 to DF-21 Samples .......................................................

Table 3.7. Percent Removal of Carbon and Composition of the Composite Filtrate Samples...........3.5

Table 3.8. Percent Removal of Anions and Composition of the Composite Filtrate Samples...........3.5

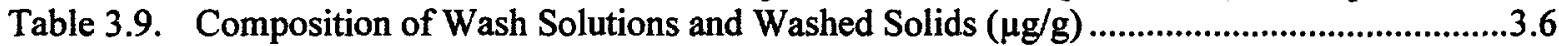

Table 3.10. Average Filtrate Flux as a Function of Test Number and Conditions..............................3.8

Table 3.11. CUF Test Results for the Diluted Slurry .......................................................................3.12

Table 3.12. Density Measurements for Samples of AN-107 Diluted Feed (AN-107 PT), Sr/TRU Precipitated Slurry (DF-05 and DF-06), and Diluted Slurry (DF-13)

Table 3.13. Weight Percent and Volume Percent Solids measurements for samples of AN-107 Diluted Feed (AN-107 PT), Sr/TRU Precipitated Slurry (DF-05 and DF-06), and Diluted Slurry (DF-13)

Table 3.14. Results of Wt\% Residual Solids and Undissolved Solids Calculation Following Drying at $105^{\circ} \mathrm{C}$ for 24 Hours for Samples of AN-107 Diluted Feed (AN-107 PT), Sr/TRU Precipitated Slurry (DF-05 and DF-06), and Diluted Slurry (DF-13) 


\subsection{INTRODUCTION}

BNFL Inc. was awarded the Privatization Contract for treatment of Hanford underground storage tank wastes as part of the River Protection Project-Waste Treatment Plant (RPP-WTP). In Part B-1, Battelle is conducting technology development and demonstration of process flowsheet steps. Three candidate low-activity waste types have been identified, Envelope A, Envelope B and Envelope C. Treatment and disposal of the liquid (supernatant) fraction of Envelope $C$ wastes, such as tank 241AN-107, requires that transuranics (TRU) and radioactive strontium be removed. Because of the high concentration of organic complexants in this waste (Complexant Concentrate waste), conventional separation processes (e.g., ion exchange) are not effective.

During Part A-1 of privatization, Savannah River Technology Center (SRTC) developed a Sr/TRU removal process which involved isotopic dilution and precipitation with added strontium and iron (SRTC 1997a-d). While this treatment process provided the necessary supernatant decontamination, the resulting precipitate could not be filtered. The search began for an alternate treatment process. Battelle proposed permanganate be examined as an alternative, because it had been demonstrated to work with waste from Hanford tank SY-101, which also contained high levels of organic complexants (Orth et al. 1995).

Permanganate has been examined as an oxidant (decomplexing waste (Orth et al. 1995), solubilizing chromium (Rapko et al. 1995, Rapko 1998), and oxidation of technetium species to pertechnetate (Schroeder)) for treating tank wastes. Permanganate was found to oxidize chromium first, then organic carbon, and lastly nitrite. For wastes such as Tank SY-101, the chromium in the sludge consumes as much as half the permanganate. Orth et al. recommended permanganate doses of $0.1 \mathrm{M}$ for decomplexing SY-101 type wastes. At this level of permanganate, decontamination factors (DF) of $>143$ were obtained for $\mathrm{Sr}$ and 28.5 for $\mathrm{Pu}$. AN-107 does not have the high chromium values in the sludge so permanganate is expected to be effective at lower concentrations.

Permanganate is also used as a precursor to $\mathrm{MnO}_{2}$ and/or $\mathrm{Mn}(\mathrm{OH})_{2}$ coprecipitants via the "Method of Appearing Reagents" (Krot et al. 1996). The method of appearing reagents requires the addition of a reductant to the waste to be treated. However, for Hanford wastes this is not necessary because reductants are already present in the waste. The resulting solids are effective coprecipitants for $\mathrm{Pu}$ and other TRU elements but generally not as effective as iron precipitates. Decontamination factors of greater 100 have been reported for various simulated waste streams.

The treatment scheme for $\mathrm{Sr} / \mathrm{TRU}$ removal was developed from tests conducted at Battelle with waste simulants and actual waste (Hallen et al. 2000a). The final test conditions were defined by BNFL in a Test Specification (Townson 1999) document based on previous results. This test specification was used to prepare a general test plan for Sr/TRU removal tests. A test instruction was prepared which detailed the specifics for conducting this test with $\mathrm{AN}-107$ diluted feed. The test instruction was used to record the specific details of the test, and is attached in Appendix A.

The proposed pretreatment flowsheet shows entrained solids are removed from the double-shell tank wastes. The entrained solids may be returned to BNFL as HLW for vitrification or as LAW for pretreatment depending on composition. Battelle used a Cell Unit Filtration System (CUF) equipped with a $0.1-\mu \mathrm{m}$ filter element (Brooks et al. 1999) to conduct filtration tests with an archived AN-107 waste sample. These tests demonstrated that the entrained solids present in this waste could not easily be removed by crossflow filtration (Hallen et al. 2000b). For entrained solids removal, the initial flux dropped in less than a minute to $0.023 \mathrm{gpm} / \mathrm{ft}^{2}$ and within 5 minutes had dropped to $0.0074 \mathrm{gpm} / \mathrm{ft}^{2}$ at 55 -psid transmembrane pressure (TMP) and $12.2 \mathrm{ft} / \mathrm{s}$ crossflow velocity. To prevent further 
plugging of the filter, no further testing was conducted at this condition. An attempt was made to collect sufficient filtrate to backpulse (clean) the filter. Only a small quantity of material could be collected in the backpulse chamber and two short backpulses were performed. A second condition was then tested at $70 \mathrm{psi}$ and $9.3 \mathrm{ft} / \mathrm{s}$. In this case, after 1 min the filtrate flux was $0.0079 \mathrm{gpm} / \mathrm{ft}^{2}$. Testing was stopped at this point and entrained solids removal was determined to be not feasible for AN-107 waste.

The waste was drained from the CUF and Sr/TRU precipitation conducted on the waste with the entrained solids present. Approximately $75 \mathrm{~mL}$ of $1 \mathrm{M} \mathrm{Sr}\left(\mathrm{NO}_{3}\right)_{2}$ and $50 \mathrm{~mL}$ of $1 \mathrm{M} \mathrm{NaMnO}_{4}$ were added to $882 \mathrm{~mL}$ of the caustic adjusted (1M) waste drained from the CUF. The precipitated waste was digested at $50^{\circ} \mathrm{C}$ for 4 hours. The resulting slurry was cooled and transferred back to the CUF and filtration tests conducted. Figure 1.1 shows filtrate flux data for entrained solids removal and $\mathrm{Sr} / \mathrm{TRU}$ precipitate removal from archived $\mathrm{AN}-107$ at $55 \mathrm{psi}$ TMP and $12.2 \mathrm{ft} / \mathrm{s}$ crossflow velocity. The filtrate flux was an order of magnitude higher for the treated waste, $0.11 \mathrm{gpm} / \mathrm{ft}^{2}$ averaged over the hour of testing.

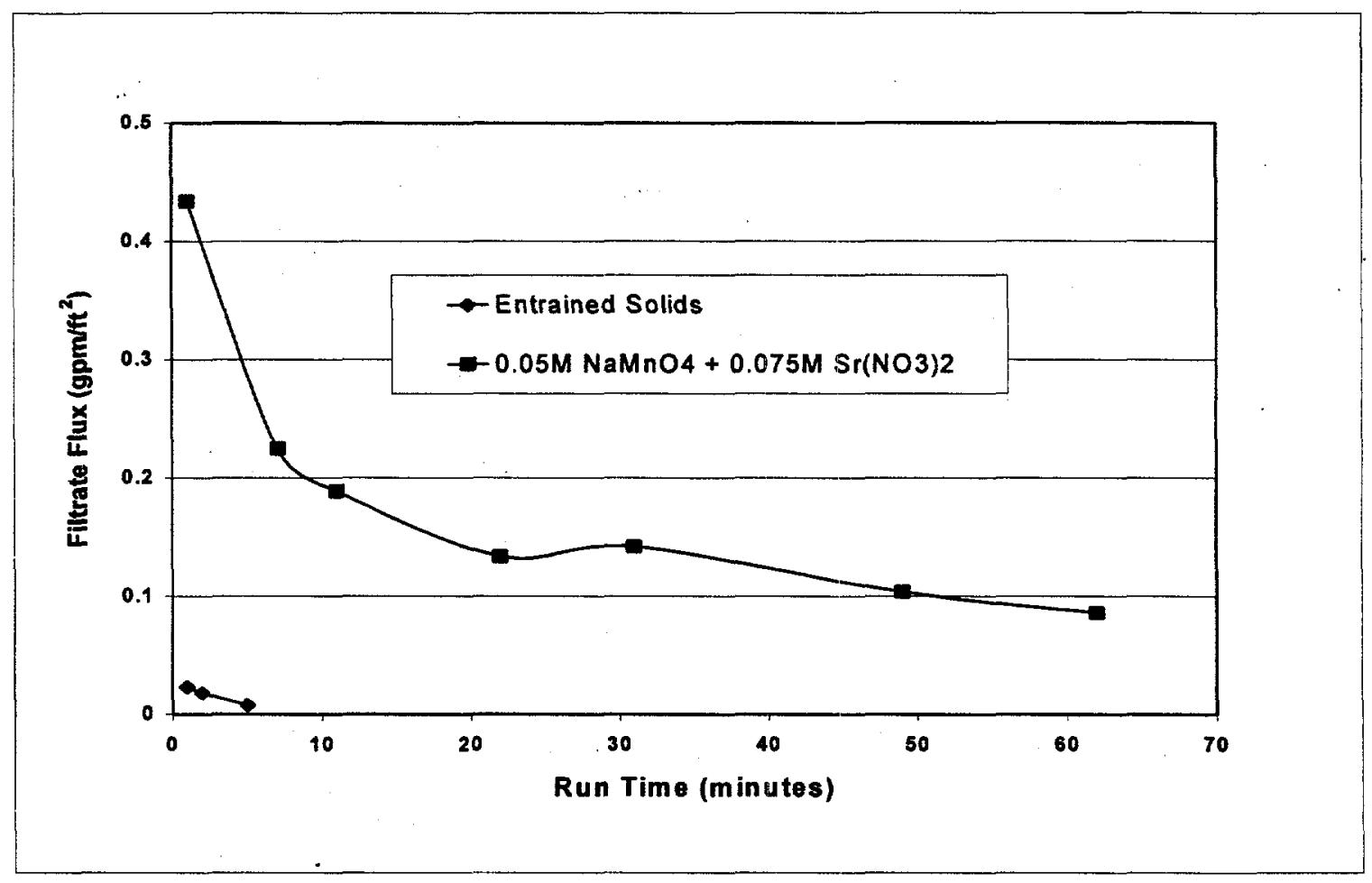

Figure 1.1. Comparison the Filtrate Flux for Entrained Solids Removal and Sr/TRU Precipitated Archived AN-107 Waste at 55 psi TMP and $12.2 \mathrm{ft} / \mathrm{s}$ Crossflow Velocity 
Entrained solids removal from AN-107 diluted feed is expected to be even more difficult than from the archived waste. The archived waste was more dilute, suspended solids had been removed by settling, and the waste had been run through a cesium ion exchange column (Hendrickson 1997). Since the Sr/TRU precipitated waste with entrained solids are filterable and the entrained solids alone are not, the two filtration steps were combined. Furthermore, analysis of the entrained solids in the AN-107 diluted feed showed that they would be classified as HLW similar to the Sr/TRU precipitate and thus need not be sent back to the DOE for HLW storage prior to vitrification.

This report contains the results of Sr/TRU removal testing conducted at Battelle with AN-107 diluted feed. Test conditions and experimental procedures are described in Section 2.0. Results from waste treated with added $\mathrm{Sr}$ and permanganate are described in regards to $\mathrm{Sr} / \mathrm{TRU}$ decontamination, chemical composition, solids removal, and physical and rheological properties of the waste in Section 3.0. The major conclusion and recommendations that evolved from this work are given in Section 4.0. The appendices contain the test instruction, data sheets, logbook entries, analytical data, rheograms, calculation, and staff role/responsibilities for this work. 


\subsection{TEST CONDITIONS AND EXPERIMENTAL PROCEDURES}

The conditions for conducting the Sr/TRU removal tests were detailed in Sr/TRU Precipitation and Ultrafiltration Test Specification (Townson 1999) issued by BNFL. The Test Specification was used to prepare a Test Plan (TP 29953-013) that described the general requirements for the Sr/TRU removal tests to be conducted at Battelle. The actual test was conducted in accordance with Test Instruction-29953-052, which was specific to the Sr/TRU Removal test described in this report for AN-107 diluted feed. No deviations from the test instruction were necessary.

\subsection{Description of Diluted Feed}

A total of 17 samples from Tank AN-107 were received from Hanford's 222-S Laboratory between September 14 and 25, 1998. These samples were then composited and homogenized in a 4-L, glass kettle. The homogenized waste was sampled and characterized to represent the waste, as it exists in Tank AN-107 (Urie et al. 1999a). The composite waste was diluted to represent process flowsheet conditions, i.e., diluted feed. The diluted feed target sodium concentration was $7.7 \mathrm{M}$ and the free hydroxide was $1.1 \mathrm{M}$. These compositing and dilution activities were conducted under Test Plan 29953-1.

The amount of sodium in the $\mathrm{AN}-107$ diluted feed sample from the original, as-received waste is needed to determine the waste loading in the ILAW. The sodium concentration in the as-received AN- 107 was $9.26 \mathrm{M}$. The as-received waste $(1.57-\mathrm{L})$ was combined with $0.16-\mathrm{L}$ of decanted supernatant $(9.0 \mathrm{M} \mathrm{Na})$ to give $1.73-\mathrm{L}$ of waste with a sodium concentration of $9.2 \mathrm{M}$. The diluted feed was prepared by adding $0.13-\mathrm{L}$ of $19 \mathrm{M} \mathrm{NaOH}$ and $0.44-\mathrm{L} \mathrm{of} 0.1 \mathrm{M} \mathrm{NaOH}$ to the $1.73-\mathrm{L}$ of waste. The AN-107 diluted feed had a calculated sodium concentration of $8.04 \mathrm{M}$ and 86.4 mole or weight percent of the sodium was from the as-received waste. The diluted feed was 75 -volume percent as-received waste.

The AN-107 diluted feed was characterized as two individual components, supernatant and centrifuged solids (Urie et al. 1999b). The data from each component was used to calculate the starting composition of the diluted feed. The data from the individual samples were averaged, and the density was used for the supernatant, along with the percent centrifuged solids data to calculate the initial composition of the diluted feed. The calculated composition of the starting AN-107 diluted feed is shown in Table 2.1. The sodium concentration reported for the supernatant fraction, $7.5 \mathrm{M}$, appears much lower than the expected $8.04 \mathrm{M}$. However, the analyses conducted on the treated waste samples, reported in Section 3.0 of this report, also suggest the sodium concentration reported in Table 2.1 is too low. The sodium concentration of the diluted feed should therefore be close to the calculated sodium concentration of $8.04 \mathrm{M}$. 
Table 2.1. Calculated Composition of AN-107 Diluted Feed Before Treatment

\begin{tabular}{|l|c|c|c|}
\hline BNFL ICP Analyte List & $\begin{array}{c}\text { Supernatant } \\
\text { Average } \\
(\mu \mathrm{g} / \mathrm{mL})\end{array}$ & $\begin{array}{c}\text { Solids } \\
\text { Average } \\
(\mu \mathrm{g} / \mathrm{g})\end{array}$ & $\begin{array}{c}\text { Calculated } \\
\text { Composition } \\
(\mu \mathrm{g} / \mathrm{g})\end{array}$ \\
\hline $\mathrm{Al}$ & 3930 & 7450 & 3120 \\
\hline $\mathrm{Ba}$ & 4 & 46 & 5 \\
\hline $\mathrm{Ca}$ & 439 & 368 & 323 \\
\hline $\mathrm{Cd}$ & 47 & 34 & 35 \\
\hline $\mathrm{Cr}$ & 146 & 716 & 138 \\
\hline $\mathrm{Cu}$ & 21 & 20 & 16 \\
\hline $\mathrm{Fe}$ & 1140 & 8900 & 1250 \\
\hline $\mathrm{K}$ & 1270 & 659 & 1240 \\
\hline $\mathrm{La}$ & 23 & 110 & 22 \\
\hline $\mathrm{Mg}$ & - & 30 & 2 \\
\hline $\mathrm{Mn}$ & 107 & 4990 & 329 \\
\hline $\mathrm{Na}$ & 173500 & 136500 & 128000 \\
\hline $\mathrm{Ni}$ & 392 & 277 & 288 \\
\hline $\mathrm{Pb}$ & 256 & 770 & 218 \\
\hline $\mathrm{Zn}$ & 19 & 64 & 17 \\
\hline $\mathrm{Zr}$ & 43 & 202 & 40 \\
\hline
\end{tabular}

\begin{tabular}{|l|c|c|c|}
\hline Other ICP Analytes & $\begin{array}{c}\text { Supernate } \\
\text { Average } \\
(\mu \mathrm{g} / \mathbf{m L})\end{array}$ & $\begin{array}{c}\text { Solids } \\
\text { Average } \\
(\mu \mathrm{g} / \mathrm{g})\end{array}$ & $\begin{array}{c}\text { Calculated } \\
\text { Composition } \\
(\mu \mathrm{g} / \mathrm{g})\end{array}$ \\
\hline $\mathrm{As}$ & 95.5 & 80 & 70.72 \\
\hline $\mathrm{Ce}$ & 27 & 215.5 & 29.83 \\
\hline $\mathrm{Nd}$ & 70.5 & 318.5 & 65.44 \\
\hline $\mathrm{P}$ & 496.5 & 427 & 368.23 \\
\hline $\mathrm{Sr}$ & 2.6 & 6.3 & 2.79 \\
\hline $\mathrm{Y}$ & 11 & 31.5 & 9.28 \\
\hline
\end{tabular}

\begin{tabular}{|l|c|c|c|}
\hline $\begin{array}{l}\text { Rad. Chem. } \\
\text { Analytes }\end{array}$ & $\begin{array}{c}\text { Supernatant } \\
\text { Average } \\
(\mu \mathrm{Ci} / \mathrm{mL})\end{array}$ & $\begin{array}{c}\text { Solids } \\
\text { Average } \\
(\mu \mathrm{Ci} / \mathrm{g})\end{array}$ & $\begin{array}{c}\text { Calculated } \\
\text { Composition } \\
(\mu \mathrm{Ci} / \mathrm{g})\end{array}$ \\
\hline Co-60 (GEA) & 0.113 & $<$ & $7.89 \mathrm{E}-02$ \\
\hline Sr-90 & 75.9 & 191.5 & $6.27 \mathrm{E}+01$ \\
\hline $\mathrm{Cs}-137$ (GEA) & 255.5 & 165 & $1.87 \mathrm{E}+02$ \\
\hline Eu-154(GEA) & 0.6115 & 1.305 & $4.93 \mathrm{E}-01$ \\
\hline Eu-155(GEA) & 0.3555 & 0.818 & $2.90 \mathrm{E}-01$ \\
\hline Pu-238 & 0.00769. & 0.0438 & $7.60 \mathrm{E}-03$ \\
\hline Pu-239+Pu-240 & 0.0314 & 0.1505 & $2.96 \mathrm{E}-02$ \\
\hline Am-241 (GEA) & 0.398 & 2.085 & $3.84 \mathrm{E}-01$ \\
\hline Am-241 (AEA) & 0.3785 & 1.47 & $3.39 \mathrm{E}-01$ \\
\hline $\mathrm{Cm}-242$ & 0.00144 & 0.00421 & $1.22 \mathrm{E}-03$ \\
\hline
\end{tabular}




\begin{tabular}{|l|c|c|c|}
\hline Cm-243+Cm-244 & 0.01225 & 0.03095 & $1.01 \mathrm{E}-02$ \\
\hline Total Beta & 450 & 514.5 & $3.40 \mathrm{E}+02$ \\
\hline Total Alpha & 0.4465 & 1.83 & $4.05 \mathrm{E}-01$ \\
\hline Alpha Sum & 0.432 & 1.7 & $3.88 \mathrm{E}-01$ \\
\hline & $(\mu \mathrm{g} / \mathrm{mL})$ & $(\mu \mathrm{g} / \mathrm{g})$ & $(\mu \mathrm{g} / \mathrm{g})$ \\
\hline Total Cs & 12 & 7.675 & $\mathbf{8 . 7 6 \mathrm { E } + 0 0}$ \\
\hline Total U & 73.1 & 103 & $5.63 \mathrm{E}+01$ \\
\hline
\end{tabular}

\begin{tabular}{|l|c|c|c|}
\hline Analyte & $\begin{array}{c}\text { Supernatant } \\
\text { Average } \\
(\mu \mathrm{g} / \mathbf{m L})\end{array}$ & $\begin{array}{c}\text { Solids } \\
\text { Average } \\
(\boldsymbol{\mu g} / \mathbf{g})\end{array}$ & $\begin{array}{c}\text { Calculated } \\
\text { Composition } \\
(\mu \mathrm{g} / \mathrm{g})\end{array}$ \\
\hline Tc-99(ICP/MS) & 4.315 & 3.77 & 3.20 \\
\hline TIC & 16300 & 17850 & 12000 \\
\hline TOC & 29900 & 32000 & 22500 \\
\hline TC (sum) & 46200 & 50800 & 34800 \\
\hline Fluoride & 6350 & 4400 & 4660 \\
\hline Chloride & 1400 & $<1200$ & 980 \\
\hline Nitrite & 51350 & 31050 & 37400 \\
\hline Bromide & $<490$ & $<1200$ & - \\
\hline Nitrate & 161000 & 111000 & 118000 \\
\hline Phosphate & 3000 & $<2400$ & 2100 \\
\hline Sulfate & 7650 & 7000 & 5700 \\
\hline Oxalate & 1300 & 32100 & 2500 \\
\hline & $\mathbf{m m o l e} / \mathbf{m L}$ & $\mathbf{m m o l e} / \mathbf{g}$ & $\mathbf{m m o l e} / \mathbf{g}$ \\
\hline Hydroxide & 0.717 & - & 0.500 \\
\hline & $\mathbf{p H}$ & $\mathbf{p H}$ & \\
\hline pH & 13.32 & - & - \\
\hline
\end{tabular}

\subsection{Sr/TRU Removal Conditions}

Supernatant from Envelope $\mathrm{C}$ waste contains levels of Sr-90 and TRU too high to meet immobilized low-activity waste (ILAW) requirements. The BNFL targets for ILAW are less than $100 \mathrm{nCi} / \mathrm{g}$ TRU and less than $20 \mathrm{Ci} / \mathrm{m}^{3} \mathrm{Sr}-90$ in the final ILAW. For $\mathrm{AN}-107$ waste, this translates to required decontamination factors (DF) of approximately 10 for strontium ( $90 \%$ removal) and 5 for TRU ( $80 \%$ removal). Since over $90 \%$ of the TRU in AN-107 is due to Am-241, a decontamination factor of 5 was established for Am-241.

Experimental conditions for $\mathrm{Sr} / \mathrm{TRU}$ removal were determined from small- and large-scale batch experiments with archived AN-107 waste (Hallen et al. 2000a,b). These experiments suggested that hydroxide could be as low as $0.5 \mathrm{M}$ and the reagent addition could be as low as $0.05 \mathrm{M}$ strontium and $0.03 \mathrm{M}$ permanganate for $\mathrm{AN}-107$. But because the $\mathrm{AN}-107$ diluted feed was more concentrated and contained entrained solids that were not present in the archived $\mathrm{AN}-107$ sample, the conditions used were $1 \mathrm{M}$ hydroxide and reagent addition of $0.075 \mathrm{M}$ for strontium and $0.05 \mathrm{M}$ for permanganate. The target sodium concentration was also reduced to $6.0 \mathrm{M}$, since all previous studies with archived AN-107 had been conducted with more dilute waste. This concentration required an additional dilution/adjustment to the diluted feed with sodium hydroxide solution. The target concentrations for 
the final treated waste after all chemical additions were set at $6.0 \mathrm{M}$ sodium, $1.0 \mathrm{M}$ hydroxide, $0.075 \mathrm{M}$ strontium, and $0.05 \mathrm{M}$ permanganate. The $\mathrm{Sr} / \mathrm{TRU}$ removal process added additional sodium to the as-received waste giving 79.2 mole or weight percent of the sodium from the original, as-received waste.

\subsection{Solids Removal Conditions}

A test matrix was developed for conducting crossflow filtration tests using the single element, Cell Unit Filtration (CUF) test stand (Brooks et al. 1999). The test conditions were focused on higher pressure and crossflow velocities of the test matrix for AW-101 based on results from earlier CUF tests. The CUF test conditions are given in Table 2.2. Conditions 9 to 14 could not be tested because the minimum operating volume of the CUF was too large $(\sim 700-\mathrm{mL})$, and the original solids loading $(\sim 2 \%)$ were too low to reach $20 \mathrm{wt} \%$ solids. Approximately $7-\mathrm{L}$ of treated waste would be required to reach the target solids loading of $20 \mathrm{wt} \%$ solids.

Table 2.2. Sr/TRU Precipitate Filtration Tests Conditions

\begin{tabular}{|c|c|c|c|}
\hline Test Number & Sample & $\begin{array}{c}\text { Transmembrane pressure } \\
\text { (psi) }\end{array}$ & $\begin{array}{c}\text { Crossflow } \\
\text { Velocity }(\mathrm{ft} / \mathrm{s})\end{array}$ \\
\hline$\overline{0}$ & DI water & $10,20,30$ & 12.2 \\
\hline 1 & Feed & 50 & 12.2 \\
\hline 2 & Feed & 30 & 12.2 \\
\hline 3 & Feed & 70 & 12.2 \\
\hline 4 & Feed & Optimum from $2.1-2.3$ & 9.1 \\
\hline 5 & Feed & Optimum from $2.1-2.3$ & 15.2 \\
\hline$\overline{6}$ & Feed & 50 & 12.2 \\
\hline 7 & Feed & Optimum from $2.1-2.7$ & $\begin{array}{l}\text { Optimum from } \\
2.1-2.7\end{array}$ \\
\hline 8 & De-watering & Optimum from $2.1-2.7$ & $\begin{array}{l}\text { Optimum from } \\
2.1-2.7\end{array}$ \\
\hline 9 & $>20 \%$ wt solids & 30 & 12.2 \\
\hline 10 & $>20 \%$ wt solids & 50 & 12.2 \\
\hline 11 & $>20 \%$ wt solids & 70 & 12.2 \\
\hline 12 & $>20 \%$ wt solids & Optimum from $2.9-2.11$ & 9.1 \\
\hline 13 & $>20 \%$ wt solids & Optimum from $2.9-2.11$ & 15.2 \\
\hline 14 & $>20 \%$ wt solids & 50 & 12.2 \\
\hline \multicolumn{4}{|l|}{ CUF Cleaning } \\
\hline 15 & $\begin{array}{l}\text { Water/permeate } \\
\text { cleaning }\end{array}$ & $\bar{N} / \bar{A}$ & N/A \\
\hline 16 & DI water & 20 & 12.2 \\
\hline 17 & $\begin{array}{l}1 \mathrm{M} \text { nitric acid } \\
\text { cleaning (if } \\
\text { needed) }\end{array}$ & N/A & N/A \\
\hline 18 & DI water & $10,20,30$ & 12.2 \\
\hline
\end{tabular}


After the C-104 filtration tests (Brooks et al. 2000) and prior to the Sr/TRU removal tests, the filter element was cleaned by backpulsing and recirculating 1-L of $1 \mathrm{M} \mathrm{HNO}$ through the CUF. The acid was drained from the CUF and found to be very dark in color, so an additional $1-\mathrm{L}$ of $\mathrm{HNO}_{3}$ was used to clean the filter element. The second acid wash was considerably cleaner. The CUF system was rinsed until a neutral $\mathrm{pH}$ was obtained. The clean water flux of the filter element was determined at 20,10 , and 30 psid (test 0 ) to evaluate the relative cleanliness of the CUF and filter element. The respective flux rates were $1.38,0.84$, and $1.77 \mathrm{gpm} / \mathrm{ft}^{2}$ averaged over 20 minutes. These values were 12 to $25 \%$ lower than at the start of the C-104 testing. The clean water flux remained relatively constant over the $20 \mathrm{~min}$ and the CUF was judged to be clean enough to conduct filtration tests.

After Sr/TRU removal tests, the filter element was cleaned with 1-L of a combination of nitric acid $(1 \mathrm{M})$ and citric acid $(0.1 \mathrm{M})$. The manganese precipitate, hydrated manganese dioxide, does not dissolve in $1 \mathrm{M}$ nitric acid normally used to clean the filter element/CUF system. An alpha-hydroxy carboxylic acid such as citric acid will reduce Mn(IV) to Mn(II), which is soluble in nitric acid. The manganese solids remaining in the CUF and filter element can be dissolved and removed. This chemical treatment, followed by recirculation through an external cartridge filter (Brooks et al. 2000), has been shown to be effective for restoring clean water flux to the filtration unit in earlier tests.

\subsection{Experimental}

All Sr/TRU and solids removal tests were performed in the High-Level Radiochemical Facility (HLRF) shielded process cells located in the 300 area at Hanford. Approximately $1.8-\mathrm{L}$ of AN-107 diluted feed had been prepared as part of waste characterization. The target composition for the diluted feed was $7.7 \mathrm{M}$ sodium and $1.1 \mathrm{M}$ hydroxide. The Sr/TRU removal process was demonstrated on 1.4-L of the diluted feed and 0.4-L was saved for future studies. The target values for chemical adjustment and reagent addition are shown in Table 2.3. Stock solutions of the reagents were prepared outside the hot cells for addition to the waste. Sodium hydroxide solution, $3.52 \mathrm{M}$, was added to adjust the sodium and hydroxide concentrations. The strontium solution was made up as the nitrate salt in $1 \mathrm{M}$ concentration. The experiment used $1 \mathrm{M}$ sodium permanganate. The data show that the final treated waste contained $75 \mathrm{vol} \%$ of the diluted feed or $79.2 \mathrm{wt} \%$ of the original, as-received waste sodium.

Table 2.3. Chemical Additions to AN-107 Diluted Feed

\begin{tabular}{|l|c|c|c|c|c|c|}
\hline & $\begin{array}{c}\text { Target } \\
\text { Concentration } \\
(\mathbf{M})\end{array}$ & $\begin{array}{c}\text { Actual } \\
\text { Concentration } \\
(\mathbf{M})\end{array}$ & $\begin{array}{c}\text { Density } \\
(\mathbf{g} / \mathbf{m L})\end{array}$ & $\begin{array}{c}\text { Target } \\
\text { Volume } \\
(\mathbf{L})\end{array}$ & $\begin{array}{c}\text { Actual } \\
\text { Volume } \\
(\mathbf{L})\end{array}$ & $\begin{array}{c}\text { Sodium from } \\
\text { As-Received Waste } \\
(\mathbf{w t} \%)\end{array}$ \\
\hline initial waste & - & - & 1.32 & 1.40 & 1.398 & 86.4 \\
\hline $\mathrm{NaOH}$ & 3.52 & 3.51 & 1.123 & 0.265 & 0.264 & - \\
\hline $\mathrm{Sr}\left(\mathrm{NO}_{3}\right)_{2}$ & 1.00 & 0.999 & 1.159 & 0.143 & 0.143 & - \\
\hline $\mathrm{NaMnO}$ & 1.00 & 1.001 & 1.094 & 0.097 & 0.096 & - \\
\hline final waste & - & - & 1.298 & 1.90 & 1.86 & 79.2 \\
\hline
\end{tabular}

AN-107 diluted feed was transferred from four, 1-pint storage jars to a 4-L Erlenmeyer flask. The waste was mixed with a magnetic stir bar while reagents were slowly added in the order shown in Table 2.3. The waste was thoroughly mixed between each reagent addition. After the permanganate addition, the waste was mixed for $30 \mathrm{~min}$ at ambient temperature, and then heated for 4 hours at $50^{\circ} \mathrm{C}$. The treated waste was cooled and transferred to the CUF feed reservoir for filtration tests. The 
test matrix was run; the slurry diluted by approximately $20 \%$, and CUF tests repeated at a lower slurry concentration to determine the impact on filtration performance. The dilution did not add additional sodium to the waste so 79.2 mole or weight percent of the sodium in the final treated waste was from the original, as-received waste.

\subsection{Sampling Plan}

A sampling plan (Table 2.4) was prepared before the Sr/TRU removal test was performed. The sampling plan was based on the Test Specification, comments received from external reviewers (need for duplicates), and past experience (collect additional samples during tests). Not all of the samples were analyzed. The samples that were not needed for analytical were recombined at the end of the test with the CUF slurry to maximize the amount of supernatant for downstream processing. Chemical analyses also included the radioactive elements.

Table 2.4. Sampling Plan

\begin{tabular}{|l|c|c|c|c|}
\hline \multicolumn{1}{|c|}{ Sampling Step } & $\begin{array}{c}\text { Number of } \\
\text { Samples }\end{array}$ & $\begin{array}{c}\text { Sample } \\
\text { Type }\end{array}$ & Process Step & Analysis \\
\hline Precipitated Feed & 2 & Slurry & After Precipitation & Chemical Analyses \\
\hline $\begin{array}{l}\text { Digested } \\
\text { Precipitate }\end{array}$ & 2 & Slurry & After Digestion & Chemical Analyses \\
\hline Recycled Slurry & 2 & Slurry & CUF slurry sample & Physical Properties \\
\hline Recycled Slurry & 2 & Slurry & CUF Slurry Sample & Rheology \\
\hline CUF Test Matrix & 4 & Filtrate & CUF Filtrate sample & Chemical Analyses \\
\hline $\begin{array}{l}\text { Middle De-water } \\
\text { Step }\end{array}$ & 1 & Filtrate & During Condition 8 & Chemical Analyses \\
\hline $\begin{array}{l}\text { Diluted CUF } \\
\text { Slurry }\end{array}$ & 1 & Slurry & Diluted CUF slurry sample & Physical Properties \\
\hline $\begin{array}{l}\text { Diluted CUF } \\
\text { Slurry }\end{array}$ & 1 & Filtrate & Diluted CUF Filtrate & Chemical Analyses \\
\hline Filtrate Composite & 2 & Filtrate & $\begin{array}{c}\text { Combined CUF \& } \\
\text { Deadend Filtrates }\end{array}$ & Chemical Analyses \\
\hline Four Washes & 1 each & Wash & After Each Wash & Chemical Analyses \\
\hline Wash Composite & 1 & Wash & After All Washes & Chemical Analyses \\
\hline Washed Solids & 2 & Wet Solids & Final Solids & Chemical Analyses \\
\hline
\end{tabular}

\subsection{Chemical Analyses}

All of the chemical analyses were conducted at Battelle. BNFL designated the analytes of interest and minimum reportable quantity in the test specification (Table 2.5). Table 2.6 lists the samples that were analyzed and analyses conducted on each sample. The samples were transferred from the HLRF to the Shielded Analytical Laboratory (SAL) for sample preparation and analyses. The samples were analyzed as soon as possible, but for some samples this was up to two weeks later. The data discussed in Section 3.0 shows that the samples that were taken as slurries, continued to react during sample storage. 
Table 2.5. Analytical Requirements for Washed Solids, Filtrate, and Wash Solutions

\begin{tabular}{|c|c|c|}
\hline Analyte & $\begin{array}{c}\text { Washed Solids } \\
\text { Minimum Reportable } \\
\text { Quantity (MRQ) } \mu \mathrm{Ci} / \mathrm{g} \\
\end{array}$ & $\begin{array}{l}\text { Filtrate and Wash Solutions } \\
\text { Minimum Reportable Quantity } \\
(\mathrm{MRQ}) \mu \mathrm{Ci} / \mathrm{mL}\end{array}$ \\
\hline Cesium-137 & $6.0 \mathrm{E}-02$ & $9.0 \mathrm{E}+00$ \\
\hline Strontium-90 & $7.01 \mathrm{E}+01$ & $1.5 \mathrm{E}-01$ \\
\hline Technetium-99 & $6 \mathrm{E}+00 \mu \mathrm{g} / \mathrm{g}$ & $1.5 \mathrm{E}-03$ \\
\hline Americium-241 & $1.2 \mathrm{E}-03$ & $7.2 \mathrm{E}-04$ \\
\hline Europium-154 & $6.0 \mathrm{E}-02$ & $2.0 \mathrm{E}-03$ \\
\hline Europium-155 & $6.0 \mathrm{E}-02$ & $9.0 \mathrm{E}-02$ \\
\hline Plutonium-239/240 & $6.0 \mathrm{E}+00 \mu \mathrm{g} / \mathrm{g}$ & $9.6 \mathrm{E}-03$ \\
\hline Total Alpha & $1.0 \mathrm{E}-03$ & $2.3 \mathrm{E}-01$ \\
\hline & $\mu \mathrm{g} / \mathrm{g}$ & $\boldsymbol{\mu g} / \mathbf{m L}$ \\
\hline $\mathrm{Al}$ & $3.3 \mathrm{E}+02$ & $7.5 \mathrm{E}+01$ \\
\hline$\overline{\mathrm{Ba}}$ & $6.0 \mathrm{E}+02$ & $7.8 \mathrm{E}+01$ \\
\hline $\mathrm{Ca}$ & $1.8 \mathrm{E}+02$ & $1.5 \mathrm{E}+02$ \\
\hline$\overline{\mathrm{Cd}}$ & $1.1 \mathrm{E}+01$ & $7.5 \mathrm{E}+00$ \\
\hline Co & $3.0 \mathrm{E}+00$ & $3.0 \mathrm{E}+01$ \\
\hline $\mathrm{Cr}$ & $1.2 \mathrm{E}+02$ & $1.5 \mathrm{E}+01$ \\
\hline $\mathrm{Cu}$ & $1.8 \mathrm{E}+01$ & $1.7 \mathrm{E}+01$ \\
\hline$\overline{\mathrm{Fe}}$ & $1.4 \mathrm{E}+02$ & $1.5 \mathrm{E}+02$ \\
\hline $\mathrm{K}$ & $1.5 \mathrm{E}+03$ & $7.5 \mathrm{E}+01$ \\
\hline$\overline{\mathrm{La}}$ & $6.0 \mathrm{E}+01$ & $3.5 \mathrm{E}+01$ \\
\hline$\overline{\mathrm{Mg}}$ & $5.4 \mathrm{E}+02$ & $1.5 \mathrm{E}+02$ \\
\hline Mn & $3.0 \mathrm{E}+02$ & $1.5 \mathrm{E}+02$ \\
\hline Mo & $6.0 \mathrm{E}+00$ & $9.0 \mathrm{E}+01$ \\
\hline $\mathrm{Na}$ & $1.5 \mathrm{E}+02$ & $7.5 \mathrm{E}+01$ \\
\hline$\overline{\mathrm{Ni}}$ & $1.6 \mathrm{E}+02$ & $3.0 \mathrm{E}+01$ \\
\hline $\mathrm{Pb}$ & $6.0 \mathrm{E}+02$ & $3.0 \mathrm{E}+02$ \\
\hline $\mathrm{Si}$ & $3.0 \mathrm{E}+03$ & $1.7 \mathrm{E}+02$ \\
\hline $\mathrm{Sr}$ & $3.0 \mathrm{E}+02$ & $8.7 \mathrm{E}+01$ \\
\hline $\mathrm{Ti}$ & $1.5 \mathrm{E}+02$ & $1.7 \mathrm{E}+01$ \\
\hline $\mathrm{U}$ & $6.0 \mathrm{E}+02$ & $6.0 \mathrm{E}+02$ \\
\hline Zn & $6.0 \mathrm{E}+00$ & $1.65 \mathrm{E}+01$ \\
\hline TOC & $6.0 \mathrm{E}+01$ & $1.5 \mathrm{E}+03$ \\
\hline TIC & $3.0 \mathrm{E}+01$ & $1.5 \mathrm{E}+02$ \\
\hline $\mathrm{Cl}$ & $2.3 E+02$ & $3.0 \mathrm{E}+00$ \\
\hline$\overline{\mathrm{F}}$ & $7.5 \mathrm{E}+03$ & $1.5 \mathrm{E}+02$ \\
\hline NO3 & $4.5 \mathrm{E}+02$ & $3.0 \overline{\mathrm{E}}+03$ \\
\hline SO4 & $1.2 \mathrm{E}+03$ (as S) & $2.3 \mathrm{E}+03$ \\
\hline$\overline{\mathrm{PO} 4}$ & $6.0 \mathrm{E}+02$ (as $\mathrm{P}$ ) & $2.5 \mathrm{E}+03$ \\
\hline
\end{tabular}


Table 2.6. Identification of Samples that were Analyzed ${ }^{1}$

\begin{tabular}{|c|c|c|}
\hline $\begin{array}{c}\text { Sample } \\
\text { Number }\end{array}$ & Type & Comments \\
\hline$\overline{\mathrm{DF}-01}$ & filtrate & Analyze for ${ }^{90} \mathrm{Sr},{ }^{241} \mathrm{Am}$, and $\mathrm{Na}$ (and all ICP elements) \\
\hline DF-02 & slurry & filter and analyze for ${ }^{90} \mathrm{Sr},{ }^{241} \mathrm{Am}$, and $\mathrm{Na}$ \\
\hline$\overline{\mathrm{DF}}-03$ & slurry & filter and analyze for ${ }^{90} \mathrm{Sr},{ }^{24} \mathrm{Am}$, and $\mathrm{Na}$ \\
\hline$\overline{\mathrm{DF}-04}$ & slurry & filter and analyze for ${ }^{90} \mathrm{Sr},{ }^{241} \mathrm{Am}$, and $\mathrm{Na}$ \\
\hline DF-05 & slurry & physical properties \\
\hline DF-06 & slurry & physical properties \\
\hline$\overline{\mathrm{DF}}-11$ & CUF filtrate & analyze for ${ }^{90} \mathrm{Sr},{ }^{241} \mathrm{Am}$, and $\mathrm{Na}$ \\
\hline$\overline{\mathrm{DF}-13}$ & dilute slurry & physical properties \\
\hline$\overline{D F}-14$ & dilute slurry & filter and analyze for ${ }^{90} \mathrm{Sr},{ }^{241} \mathrm{Am}$, and $\mathrm{Na}$ \\
\hline DF-20 & composite filtrate & analyze for all analytes, see Table 2.5 \\
\hline DF-21 & composite filtrate & analyze for all analytes \\
\hline $1^{\text {sl }}$ wash & wash & analyze for $\mathrm{Na}$ (and all ICP elements) \\
\hline $2^{\text {nd }}$ wash & wash & analyze for $\mathrm{Na}$ \\
\hline $3^{\mathrm{rd}}$ wash & wash & analyze for $\mathrm{Na}$ \\
\hline $4^{\text {th }}$ wash & wash & analyze for $\mathrm{Na}$ \\
\hline wash composite & combined washes & analyze for all analytes \\
\hline washed solids & damp solids & Dry, digest, analyze for all analytes \\
\hline
\end{tabular}

'See Table 3.1 for description of process conditions corresponding to each sample.

Sample DF-01 was filtered immediately after the sample was collected. The other slurry samples, when specified, were filtered as part of the analytical sample preparation scheme, about 2 weeks after the samples were taken. The slurry samples were filtered with $0.45-\mu \mathrm{m}$ disposable syringe filters. Many of the samples required multiple filter units to filter the necessary volume of waste for analyses. The washed solids were dried for 24 hours at $105^{\circ} \mathrm{C}$, and the weight percent of dry solids was determined. Duplicate samples of the dried solids were dissolved by acid-digestion and analyzed for $\mathrm{Na} / \mathrm{K}$ (and all ICP elements). Duplicate, washed solids samples were also dissolved by potassium hydroxide-fusion and analyzed for all analytes listed in Table 2.5. The wash samples were analyzed separately for sodium (and all ICP elements), and a composite of all four washes made; $5 \mathrm{~mL}$ of each wash combined to make one $20-\mathrm{mL}$ sample. The composite wash was analyzed for all analytes (Table 2.5).

\subsection{Physical Property Measurements}

Physical property measurements were conducted on samples of AN-107 diluted feed before and after treatment. The physical property analyses included supernatant and centrifuged solids density, and weight percent (wt\%) and volume percent (vol\%) solids. 
An AN-107 diluted feed sample (sample identification "AN-107 PT") was collected from the initial diluted tank composite. The diluted feed was homogenized and sampled as described under Test Plan 29953-6. This sampling method was shown under Test Plan 29953-1 to provide samples with representative solids content.

The AN-107 diluted feed was treated for Sr/TRU removal under Test Plan 29953-013 according to Test Instruction 29953-052. Duplicate samples of the Sr/TRU precipitated slurry (DF-05 and DF-06) were collected for physical property analyses. The Sr/TRU precipitated slurry was then diluted by $19.24 \%$ for additional filtration tests, and an additional slurry sample (DF-13) was collected for physical property analysis.

\subsection{Rheological Properties Testing}

The AN-107 initial diluted feed (AN-107 PT) and Sr/TRU precipitated slurry (similar to DF-05 and DF-06) were analyzed for shear stress as a function of shear rate from approximately 0.1 to $300 \mathrm{~s}^{-1}$ or $1000 \mathrm{~s}^{-1}$ according to procedure 29953-010. The AN-107 initial diluted feed was analyzed using the Bohlin CS viscometer modified for glovebox operations. Concentric cylinders with a $25-\mathrm{mm}$ diameter inner cylinder and a "Small Sample Cell" outer cylinder were used as the measuring geometries. The Sr/TRU precipitated slurry was analyzed using a Haake M5 measuring head modified for hot cell operations. An MVI measuring geometry was used on the Haake. Both the initial and $\mathrm{Sr} / \mathrm{TRU}$ precipitated slurries were analyzed in duplicate at $25^{\circ} \mathrm{C}$. A $49.9 \mathrm{cP}$ standard, Brookfield lot 102298, was used to check the calibration of both instruments before samples were analyzed. The Bohlin is the preferred instrument for analyzing the diluted feed as it can quantify lower viscosities than the Haake M5 with comparable concentric cylinder geometries. The Bohlin also requires significantly less sample material, $5 \mathrm{ml}$, compared to $40 \mathrm{ml}$ for the Haake M5. Since the Sr/TRU slurries were analyzed in the hot cell while the filtration tests were being conducted, the Haake M5 was preferred for these analyses. The Haake M5's location in the hot cell allowed for immediate return of sample to the CUF reservoir following analysis, preventing the loss of sample volume from the test.

Analyses of the AN-107 initial diluted feed were conducted up to $300 \mathrm{~s}^{-1}$ as per Test Instruction 29953-11. Following this testing, guidance was provided by BNFL to increase the shear rate analyses to $1000 \mathrm{~s}^{-1}$. Therefore, testing on the Sr/TRU precipitated slurries were conducted up to $1000 \mathrm{~s}^{-1}$ with additional analyses conducted to only $300 \mathrm{~s}^{-1}$ for comparison.

Prior to shear stress as a function of shear rate analysis, the samples were stirred to combine the separated liquid and solid layers. Shear stress data, as a function of shear rate, was obtained by measuring the shear stress produced at a specific shear rate. The shear rate was gradually increased from approximately 0.1 to either $300 \mathrm{~s}^{-1}$ or $1000 \mathrm{~s}^{-1}$, generating the increasing shear rate curve, and then back down to $0.1 \mathrm{~s}^{-1}$, generating the decreasing curve. For analyses conducted with the Haake M5, the increasing and decreasing $300 \mathrm{~s}^{-1}$ curves were collected over a $2 \mathrm{~min}$ period, while the $1000 \mathrm{~s}^{-1}$ curves were collected over a 2- or 4-min time period. For the Sr/TRU precipitated slurry, the shear rate analysis was conducted three times with the same sample still in the instrument. A difference between the first, second, and third analysis of the same sample would indicate potentially unusual behavior in the samples including (but not limited to) settling of the solids within the instrument, the sample being affected by shearing in the instrument or water loss through evaporation. In all cases, the first, second, and third analyses were virtually identical. The sample cup was then cleaned, and a duplicate sample was analyzed using the same parameters. 


\subsection{RESULTS AND DISCUSSION}

The results of the testing and analyses are discussed below for Sr/TRU decontamination, chemical composition, wash solutions and washed solids composition, solids removal, physical properties, and rheological and flow properties.

\subsection{Sr/TRU Decontamination}

Multiple samples were taken during the Sr/TRU removal tests and analyzed to determine the change in waste composition upon treatment. Samples were taken after various stages of treatment, filtration, and again after the slurry was further diluted for additional filtration tests. The radionuclide composition of the treated samples was compared with the starting composition to determine the extent of decontamination. The Decontamination Factor (DF) is defined as the concentration of the component in the untreated waste divided by the concentration after treatment, corrected by the amount of dilution that occurred:

\section{$D F=[A] /\left([A]^{*} M D\right)$}

where $[\mathrm{A}]_{\mathrm{i}}$ is the concentration of component $\mathrm{A}$ per mass in the diluted feed sample, $[\mathrm{A}]$ is the concentration of component $A$ per mass in the treated sample, and MD is the mass dilution, final mass of treated solution divide by the initial mass of solution. The final mass is determined by summing up the mass of initial waste and all dilution, adjustments, and/or reagent additions. Table 3.1 lists the samples analyzed, mass dilution to be used for calculating DFs, and description of the sample. All DFs and mass dilutions are based on the diluted feed.

Table 3.1. Samples and Mass Dilution for Calculating Decontamination Factors

\begin{tabular}{|c|c|l|}
\hline Sample ID & Mass Dilution & \multicolumn{1}{|c|}{ Sample Description } \\
\hline DF-01 & 1.3075 & $\begin{array}{l}\text { sampled after chemical addition, before heating, and } \\
\text { filtered immediately }\end{array}$ \\
\hline DF-02 & 1.3075 & same as DF-01 but left as slurry until sample prep. \\
\hline DF-03 & 1.3075 & sampled after heating, left as slurry until sample prep \\
\hline DF-04 & 1.3075 & duplicate of DF-03 \\
\hline DF-11 & 1.3075 & CUF filtrate \\
\hline DF-14 & 1.556 & diluted CUF slurry, left as slurry until sample prep \\
\hline DF-20 & 1.556 & $\begin{array}{l}\text { composite filtrate from CUF and Deadend filtration, } \\
\text { also Cs ion exchange feed }\end{array}$ \\
\hline DF-21 & 1.556 & duplicate of DF-20, composite filtrate \\
\hline
\end{tabular}


The strontium, americium, and curium decontamination factors for samples DF-01 through DF-11 are shown in Table 3.2. All samples had very high decontamination for $\mathrm{Sr}$ and TRU components, greatly exceeding the requirements for ILAW. The 4-hour digestion had very little effect on the DFs. The higher DFs for samples DF-02, DF-03, and DF-04 most likely resulted from the long contact time of the solids and supernatant (approximately 2 weeks), while the samples were waiting preparation in the analytical laboratory. This suggests that thermodynamic equilibrium was not reached between solution species and solids during the actual waste testing. Sample DF-11 most accurately represents the current technical baseline process for $\mathrm{Sr} / \mathrm{TRU}$ removal because it underwent the entire treatment and filtration process.

Table 3.2. Strontium, Am, and Cm Decontamination Factors for Samples DF-01 to DF-11 and the Composition of CUF Filtrate (DF-11)

\begin{tabular}{|l|c|c|c|c|c|c|}
\hline & DF-01 & DF-02 & DF-03 & DF-04 & DF-11 & $\begin{array}{c}\text { DF-11 } \\
(\mu \mathrm{Ci} / \mathrm{g})\end{array}$ \\
\hline Sr-90 & 48 & 116 & 246 & 122 & 82 & $5.85 \mathrm{E}-01$ \\
\hline Am-241 (AEA) & 26 & 54 & 64 & 56 & 28 & $9.36 \mathrm{E}-03$ \\
\hline $\mathrm{Cm}-242$ & 24 & 39 & 49 & 42 & 22 & $3.89 \mathrm{E}-04$ \\
\hline $\mathrm{Cm}-243+\mathrm{Cm}-244$ & 18 & 37 & 43 & 39 & 20 & $4.17 \mathrm{E}-05$ \\
\hline
\end{tabular}

The original treated waste was diluted by an additional $19 \mathrm{wt} \%$, additional CUF tests performed, and samples collected for analyses. A reduced test matrix was performed and the optimum conditions were used to dewater the slurry in the CUF until the waste volume was reduced to the volume limit of the CUF. Approximately half the slurry was dewatered in the CUF. The CUF was drained and the slurry filtered to dryness in a deadend filtration unit. The final CUF filtrate was combined with filtrate from the final dewatering of the slurry in a deadend filtration unit and sampled in duplicate, DF-20 and DF-21. These samples represent the low activity waste from the Sr/TRU removal process. The composite filtrate is the feed for the subsequent cesium ion exchange process.

Table 3.3 shows the DFs calculated for the total sample (including entrained solids) and for supernatant for various radioactive elements in these samples. Solids removal contributed very little to the DF. The DFs were very high and consistent with the earlier filtrate sample, DF-11. The DF of less-than-1 for Tc-99 means the concentration after treatment was actually higher in the filtrate than the untreated waste. The most significant result was the additional dilution did not impact the decontamination of the waste. 
Table 3.3. Radioactive Element Decontamination Factors for Samples DF-14, DF-20 and DF-21 and Average Composition of Composite Filtrate

\begin{tabular}{|c|c|c|c|c|c|c|c|}
\hline & \multicolumn{3}{|c|}{ Total Sample } & \multicolumn{3}{|c|}{ Supernatant Only } & \multirow{2}{*}{$\begin{array}{c}\text { Average of } \\
\text { DF-20 \& DF-21 } \\
(\mu \mathrm{Ci} / \mathrm{g})\end{array}$} \\
\hline & DF-14 & DF-20 & DF-21 & DF-14 & DF-20 & DF-21 & \\
\hline Co-60 (GEA) & - & 1 & 1 & - & 1 & 1 & $4.99 \mathrm{E}-02$ \\
\hline Sr-90 & 55 & 85 & 84 & 51 & 78 & 77 & $4.77 \mathrm{E}-01$ \\
\hline$\overline{\mathrm{Cs}}-137$ (GEA) & - & 1 & 1 & - & 1 & 1 & $1.23 \mathrm{E}+02$ \\
\hline Eu-154 (GEA) & - & 11 & 12 & - & 10 & 11 & $2.85 \mathrm{E}-02$ \\
\hline $\mathrm{Pu}-238$ & - & 29 & 29 & - & 22 & 23 & $1.67 \mathrm{E}-04$ \\
\hline $\mathrm{Pu}-239+\mathrm{Pu}-240$ & - & 29 & 31 & - & 24 & 25 & $6.32 \mathrm{E}-04$ \\
\hline Am-241 (AEA) & 66 & 45 & 43 & 56 & 38 & 37 & $4.97 \mathrm{E}-03$ \\
\hline $\mathrm{Cm}-242$ & 51 & 35 & 32 & 46 & 32 & 29 & $2.32 \mathrm{E}-05$ \\
\hline $\mathrm{Cm}-243+\mathrm{Cm}-244$ & 50 & 30 & 27 & 46 & 27 & .25 & $2.32 \mathrm{E}-04$ \\
\hline Tc-99 & - & 0.8 & 0.7 & - & - & - & $2.72(\mu \mathrm{g} / \mathrm{g})$ \\
\hline Total Alpha & - & 32 & 34 & - & 27 & 28 & $7.93 \mathrm{E}-03$ \\
\hline
\end{tabular}

\subsection{Change in Chemical Composition}

The Sr/TRU removal process also changed the chemical composition of the waste samples. Table 3.4 shows the compositional change of the supernatant as a percent removed from the untreated waste. These values are corrected by the mass dilution that occurred upon treatment. The most significant and interesting changes are for $\mathrm{Cr}, \mathrm{Fe}, \mathrm{Mn}$, and $\mathrm{Sr}$. The $\mathrm{Cr}$ in solution decreased, which was opposite of the effect observed by Orth et al. The Fe removal was very high, and most likely correlated directly with the high TRU (Am/Cm/Eu) removal. Manganese decreased, which suggests that soluble $\mathrm{Mn}$, likely Mn(II), is oxidized to Mn(IV) by reaction with Mn(VII). The $\mathrm{Sr}$ increased because the original solution was below the saturation level for $\mathrm{Sr}$, and a fraction of the added $\mathrm{Sr}$ remained soluble.

Table 3.4. Percent Removal of ICP Metals from samples DF-01 to DF-11 and Composition of the CUF Filtrate (DF-11)

\begin{tabular}{|l|c|c|c|c|c|c|}
\hline & $\begin{array}{c}\text { DF-01 } \\
(\%)\end{array}$ & $\begin{array}{c}\text { DF-02 } \\
(\%)\end{array}$ & $\begin{array}{c}\text { DF-03 } \\
(\%)\end{array}$ & $\begin{array}{c}\text { DF-04 } \\
(\%)\end{array}$ & $\begin{array}{c}\text { DF-11 } \\
(\%)\end{array}$ & $\begin{array}{c}\text { DF-11 } \\
(\boldsymbol{\mu g} / \mathbf{g})\end{array}$ \\
\hline $\mathrm{Al}$ & 10 & 7 & 7 & 5 & 7 & 2220 \\
\hline $\mathrm{Ca}$ & 32 & 36 & 39 & 38 & 37 & 157 \\
\hline $\mathrm{Cd}$ & 0 & -4 & -3 & -5 & -3 & 27.1 \\
\hline $\mathrm{Cr}$ & 48 & 93 & 94 & 93 & 51 & 51.5 \\
\hline $\mathrm{Fe}$ & 99 & 99 & 99 & 99 & 98 & 15.9 \\
\hline $\mathrm{K}$ & 24 & 23 & 24 & 23 & 23 & 732 \\
\hline $\mathrm{Mn}$ & 99 & 94 & 92 & 93 & 99 & 1.8 \\
\hline $\mathrm{Ni}$ & 2 & -1 & -1 & -3 & -1 & 222 \\
\hline $\mathrm{P}$ & 0 & -4 & -3 & -5 & -4 & 294 \\
\hline $\mathrm{Pb}$ & 65 & 65 & 65 & 64 & 60 & 65.9 \\
\hline $\mathrm{Sr}$ & -7445 & -4132 & -4113 & -4216 & -7070 & 153 \\
\hline $\mathrm{Zr}$ & 52 & 72 & 75 & 72 & 57 & 3.4 \\
\hline
\end{tabular}


The results for the diluted slurry and final composite filtrate are presented in Table 3.5. The results show the composition did not change significantly upon dilution of the slurry and additional CUF testing.

Table 3.5. Composition Change, Reported as Percent Removed, on Treatment and Dilution of the Slurry and Final Composite Filtrate

\begin{tabular}{|l|c|c|c|c|}
\hline & $\begin{array}{c}\text { DF-14 } \\
(\%)\end{array}$ & $\begin{array}{c}\text { DF-20 } \\
(\%)\end{array}$ & $\begin{array}{c}\text { DF-21 } \\
(\%)\end{array}$ & $\begin{array}{c}\text { Ave DF-20 \& 21 } \\
(\mu \mathrm{g} / \mathrm{g})\end{array}$ \\
\hline $\mathrm{Al}$ & 5 & -1 & 3 & 1980 \\
\hline $\mathrm{Ca}$ & 33 & 32 & 37 & 136.5 \\
\hline $\mathrm{Cd}$ & -3 & -7 & -2 & 23.2 \\
\hline $\mathrm{Cr}$ & 85 & 58 & 59 & 37.025 \\
\hline $\mathrm{Fe}$ & 99 & 99 & 99 & 8.9125 \\
\hline $\mathrm{K}$ & 24 & 21 & 23 & 622.5 \\
\hline $\mathrm{Mn}$ & 98 & 99 & 99 & 2.325 \\
\hline $\mathrm{Nd}$ & 80 & 74 & 74 & 2.725 \\
\hline $\mathrm{Ni}$ & -2 & -7 & -1 & 192 \\
\hline $\mathrm{P}$ & -4 & -8 & -4 & 251.5 \\
\hline $\mathrm{Pb}$ & 61 & 60 & 62 & 54.675 \\
\hline $\mathrm{Sr}$ & -5164 & -6341 & -5867 & 111.25 \\
\hline $\mathrm{Zr}$ & 77 & 68 & 70 & 2.05 \\
\hline
\end{tabular}

Table 3.6 shows the results from sodium analyses of the samples and the density of the filtrate. The sodium concentration is important for LAW glass-loading calculations. Here, the sodium values are higher than expected, $6 \mathrm{M}$ for the initial treated waste and $5 \mathrm{M}$ after additional dilution. These values could be caused by dissolution of additional entrained solids on dilution/treatment, but the results are within the expected analytical error $(10 \%)$ for samples that require high dilution before analysis. The densities reported in the table were determined in the hot-cells using volumetric flasks and samples of the filtrate.

Table 3.6. Sodium Concentration in DF-01 to DF-21 Samples

\begin{tabular}{|l|c|c|c|}
\hline Sample ID & $\begin{array}{c}{[\mathbf{N a}]} \\
(\boldsymbol{\mu g} / \mathbf{g})\end{array}$ & $\begin{array}{c}{[\mathbf{N a}]} \\
(\mathbf{M})\end{array}$ & $\begin{array}{c}\text { Density } \\
(\mathrm{g} / \mathbf{m L})\end{array}$ \\
\hline $\mathrm{DF}-1$ & 112000 & 6.27 & \\
\hline $\mathrm{DF}-2$ & 115000 & 6.43 & \\
\hline DF-3 & 116000 & 6.49 & \\
\hline DF-4 & 118000 & 6.60 & \\
\hline DF-11 & 119000 & 6.66 & \\
\hline average & 116000 & 6.49 & 1.286 \\
\hline DF-14 & 105000 & 5.67 & \\
\hline DF-20 & 102000 & 5.51 & \\
\hline DF-20 dup. & 110000 & 5.94 & \\
\hline DF-21 & 91900 & 4.96 & \\
\hline average & 101300 & 5.47 & 1.2414 \\
\hline
\end{tabular}


Carbon analyses were only performed on the composite filtrate, samples DF-20 and 21. Table 3.7 shows that very little of the organic carbon was destroyed by the Sr/TRU removal process, i.e. permanganate oxidation. This is consistent with the initial high organic carbon content of the waste $(>2 \mathrm{M})$ and low level of added permanganate $(0.05 \mathrm{M})$. The decrease in carbonate is expected because the added $\mathrm{Sr}$ precipitates as $\mathrm{SrCO}_{3}$, removing carbonate from solution. Taking into account the carbonate removed by Sr precipitation, the carbonate (reported as TIC) still decreased by $6 \%$. The data indicate very little destruction of organic carbon and give no indication that any was oxidized to carbonate.

Table 3.7. Percent Removal of Carbon and Composition of the Composite Filtrate Samples

\begin{tabular}{|l|c|c|c|c|}
\hline & $\begin{array}{c}\text { DF-20 } \\
(\mathbf{\%})\end{array}$ & $\begin{array}{c}\text { DF-21 } \\
(\mathbf{\%})\end{array}$ & $\begin{array}{c}\text { Average } \\
(\boldsymbol{\mu g} / \mathbf{g})\end{array}$ & $\begin{array}{c}\text { Average } \\
(\mathbf{M})\end{array}$ \\
\hline TIC & 14 & 13 & 6800 & 0.70 \\
\hline TOC & 3 & 9 & 13600 & 1.41 \\
\hline TC & 7 & 10 & 20425 & 2.11 \\
\hline
\end{tabular}

The filtrate composite, DF-20 and DF-21, was analyzed by ion chromatography (IC) for anions. Table 3.8 shows that most anions were below detection level, except for nitrate and nitrite. The $\mathrm{Sr} / \mathrm{TRU}$ removal process reduced the nitrite concentration about the same amount as the nitrate was increased, which suggests that during the removal process some of the nitrite was oxidized to nitrate. Not enough data are available to determine if this is a result of the initial permanganate oxidation, or a result of the digestion process, where various higher valence metals may act as nitrite oxidants (Mn(IV))

Table 3.8. Percent Removal of Anions and Composition of the Composite Filtrate Samples

\begin{tabular}{|l|c|c|c|c|}
\hline & $\begin{array}{c}\text { DF-20 } \\
(\%)\end{array}$ & $\begin{array}{c}\text { DF-21 } \\
(\%)\end{array}$ & $\begin{array}{c}\text { Average } \\
(\boldsymbol{\mu g} / \mathbf{g})\end{array}$ & $\begin{array}{c}\text { Average } \\
(\mathbf{M})\end{array}$ \\
\hline Fluoride & $>33$ & $>33$ & $<2000$ & \\
\hline Chloride & & & $<2000$ & \\
\hline Nitrite & 9 & 10 & 21700 & 0.59 \\
\hline Nitrate & -6 & -8 & 87400 & 1.75 \\
\hline Phosphate & & & $<4000$ & \\
\hline Sulfate & & & $<4000$ & \\
\hline Oxalate & & & $<4000$ & \\
\hline
\end{tabular}

\subsection{Composition of Wash Solutions and Washed Solids}

The combined entrained solids and Sr/TRU removal solids were collected on the deadend filter. The solids were washed on the filter four times with $0.01 \mathrm{M} \mathrm{NaOH}$. The first wash was vacuum filtered, but filtered so fast the solids were not washed very well. Subsequent washes were all done with gravity filtration. The solids were very difficult to wash in the deadend filtration unit. They could not be easily stirred or mixed while washing. The solids were the consistency of wet clay. The four wash solutions were collected and analyzed separately, and a composite of the four wash solutions was analyzed. The wet, washed solids were removed from the filter unit, dried to constant weight, dissolved, and analyzed. The composition of the wash solutions and washed solids are listed in Table 3.9. 
Table 3.9. Composition of Wash Solutions and Washed Solids $(\mu \mathrm{g} / \mathrm{g})$

\begin{tabular}{|l|c|c|c|c|c|c|}
\hline Element & $\begin{array}{c}\mathbf{1}^{\text {st }} \\
\text { Wash* }^{*}\end{array}$ & $\begin{array}{c}\mathbf{2}^{\text {nd }} \\
\text { Wash }\end{array}$ & $\begin{array}{c}\mathbf{3}^{\text {Td }} \\
\text { Wash }\end{array}$ & $\begin{array}{c}4^{\text {in }} \\
\text { Wash }\end{array}$ & $\begin{array}{c}\text { Composite } \\
\text { Wash }\end{array}$ & $\begin{array}{c}\text { Washed } \\
\text { Solids }\end{array}$ \\
\hline $\mathrm{Ag}$ & - & - & - & - & - & 105 \\
\hline $\mathrm{Al}$ & 194 & 487 & 161 & 90.8 & 125.9 & 7915 \\
\hline $\mathrm{Ba}$ & - & - & - & - & - & 358 \\
\hline $\mathrm{Ca}$ & 15.7 & {$[42]$} & 16.6 & {$[10]$} & 13.3 & 5413 \\
\hline $\mathrm{Cd}$ & 1.9 & 5.29 & 1.8 & 1.07 & 1.435 & 33 \\
\hline $\mathrm{Ce}$ & - & - & - & - & - & 1013 \\
\hline $\mathrm{Co}$ & - & - & - & - & - & - \\
\hline $\mathrm{Cr}$ & 1.19 & {$[2.8]$} & 2.52 & 1.77 & 2.145 & 3277 \\
\hline $\mathrm{Cu}$ & 1.38 & {$[3.3]$} & {$[1.1]$} & {$[0.62]$} & 0.86 & 53 \\
\hline $\mathrm{Fe}$ & {$[1.1]$} & {$[1.4]$} & 3.44 & {$[0.44]$} & 1.94 & 47133 \\
\hline $\mathrm{K}$ & {$[73]$} & {$[140]$} & {$[34]$} & {$[14]$} & 24 & - \\
\hline $\mathrm{La}$ & - & - & - & - & - & 723 \\
\hline $\mathrm{Mg}$ & - & - & - & - & - & 195 \\
\hline $\mathrm{Mn}$ & {$[0.52]$} & - & {$[0.52]$} & {$[0.28]$} & {$[0.4]$} & 130000 \\
\hline $\mathrm{Mo}$ & {$[1.2]$} & {$[3.1]$} & {$[1]$} & {$[0.56]$} & {$[0.78]$} & 31 \\
\hline $\mathrm{Na}$ & 12400 & 26500 & 9560 & 6440 & 8000 & 75567 \\
\hline $\mathrm{Nd}$ & - & - & - & - & - & 2117 \\
\hline $\mathrm{Ni}$ & 16.2 & 43.6 & 14.8 & 8.88 & 11.84 & 134 \\
\hline $\mathrm{P}$ & 18 & 61.4 & 11.7 & 11.3 & 11.5 & 749 \\
\hline $\mathrm{Pb}$ & 9.14 & 23.9 & 9.82 & 7.03 & 8.425 & 4770 \\
\hline $\mathrm{Pd}$ & - & - & - & - & - & 987 \\
\hline $\mathrm{Si}$ & 27.2 & {$[18]$} & {$[18]$} & {$[10]$} & 14 & 4322 \\
\hline $\mathrm{Sr}$ & 16.7 & 40 & 16.7 & 12.4 & 14.55 & 272500 \\
\hline $\mathrm{Th}$ & - & - & - & - & - & 1150 \\
\hline $\mathrm{Ti}$ & - & - & - & - & - & 42 \\
\hline $\mathrm{U}$ & - & - & - & - & - & 1780 \\
\hline $\mathrm{Zn}$ & 0.69 & 1.8 & 0.8 & 0.6 & 0.7 & 307 \\
\hline $\mathrm{Zr}$ & - & - & - & - & - & 1958 \\
\hline & & - & - & - & - & \\
\hline
\end{tabular}

* First wash vacuum filtered, all others gravity filtered. Overall error is estimated to be within $\pm 15 \%$.

Values in brackets are within 10-times the detection limit and errors are likely to exceed $\pm 15 \%$. 
Table 3.9. Composition of Wash Solutions and Washed Solids (Con't)

\begin{tabular}{|l|c|c|}
\hline & $\begin{array}{c}\text { Wash Composite } \\
(\mu \mathrm{Ci} / \mathrm{g})\end{array}$ & $\begin{array}{c}\text { Washed Solids } \\
(\mu \mathrm{Ci} / \mathrm{g})\end{array}$ \\
\hline Alpha & $6.67 \mathrm{E}-04$ & $1.35 \mathrm{E}+01$ \\
\hline Sr-90 & $9.79 \mathrm{E}-02$ & $1.10 \mathrm{E}+03$ \\
\hline Pu-239+ Pu-240 & $2.44 \mathrm{E}-05$ & $6.33 \mathrm{E}-01$ \\
\hline Pu-238 & $6.97 \mathrm{E}-06$ & $1.76 \mathrm{E}-01$ \\
\hline Am-241 & $2.89 \mathrm{E}-04$ & $6.24 \mathrm{E}+00$ \\
\hline $\mathrm{Cm}-243+\mathrm{Cm}-244$ & $1.62 \mathrm{E}-05$ & $1.40 \mathrm{E}-01$ \\
\hline $\mathrm{Cm}-242$ & $1.39 \mathrm{E}-06$ & $1.07 \mathrm{E}-02$ \\
\hline & $(\mu \mathrm{g} / \mathrm{g})$ & $(\mu \mathrm{g} / \mathrm{g})$ \\
\hline Tc-99 & 0.29 & 8.6 \\
\hline TIC & 1,025 & 47,750 \\
\hline TOC & 2,400 & 1,625 \\
\hline TC & 3,425 & 49,375 \\
\hline Fluoride & $<125$ & $<250$ \\
\hline Chloride & $<125$ & $<500$ \\
\hline Nitrite & 2800 & 1750 \\
\hline Nitrate & 11150 & 8350 \\
\hline Phosphate & $<250$ & $<500$ \\
\hline Sulfate & 470 & 1200 \\
\hline Oxalate & 3450 & 23300 \\
\hline
\end{tabular}

The moisture content of the washed solids $(92 \mathrm{~g})$ was $63.4 \mathrm{wt} \%$, which yielded $33.7 \mathrm{~g}$ of solids recovered on a dry basis. The Sr/TRU removal treatment was estimated to yield $35 \mathrm{~g}$ of solids, and the initial waste was estimated to contain $11 \mathrm{~g}$ of entrained solids. The loss of solids occurred because complete removal of the dewatered slurry from the CUF is difficult. Additional entrained solids were also expected to dissolve by the additional dilution/treatment, lowering the amount of entrained solids. Using the $\mathrm{Sr}$ concentration of the washed solids $(272,500 \mu \mathrm{g} / \mathrm{g})$ and predicted $\mathrm{Sr}$ concentration for the solids from precipitation $(345,000 \mu \mathrm{g} / \mathrm{g})$, we calculate that $9 \mathrm{~g}$ of entrained solids were present. The solids content of the waste slurry is calculated to be $1.85 \mathrm{wt} \%$ and includes the entrained solids and Sr/TRU precipitate. The calculation suggests the entrained solids are primarily $\mathrm{Na}, \mathrm{Al}, \mathrm{Si}, \mathrm{Fe}$ and $\mathrm{Mn}$, which is consistent with data on entrained solids washing/ dissolution (Lumetta et al. 1999). The IC analysis was performed on a water leach of the solids and TIC/TOC analyses were made directly on the solids. However, the TOC and oxalate results reported in Table 3.10 for the washed solids did not match. With oxalate at $23,300 \mu \mathrm{g} / \mathrm{g}$, the TOC value should have been at least $6350 \mu \mathrm{g} / \mathrm{g}$. It is likely that the oxalate decomposed during the TIC analyses and is reported as TIC not TOC. 
Table 3.10. Average Filtrate Flux as a Function of Test Number and Conditions

\begin{tabular}{|c|c|c|c|c|}
\hline Test \# & $\begin{array}{c}\text { TMP } \\
(\mathbf{p s i})\end{array}$ & $\begin{array}{c}\text { Total Flow } \\
(\mathbf{g p m})\end{array}$ & $\begin{array}{c}\text { Velocity } \\
(\mathbf{f t} / \mathbf{s})\end{array}$ & $\begin{array}{c}\text { Average Flux } \\
\left(\mathbf{g p m} / \mathbf{f t}^{2}\right)\end{array}$ \\
\hline 1 & 49 & 4.0 & 12.0 & 0.030 \\
\hline 2 & 30 & 4.2 & 12.2 & 0.025 \\
\hline 3 & 69 & 3.4 & 9.9 & 0.022 \\
\hline 4 & 50 & 3.1 & 9.0 & 0.019 \\
\hline 5 & 49 & 4.5 & 13.1 & 0.024 \\
\hline 6 & 50 & 4.1 & 11.9 & 0.022 \\
\hline DW & 48 & 3.9 & 11.3 & 0.021 \\
\hline
\end{tabular}

\subsection{Solids Removal}

The CUF was thoroughly cleaned before each test matrix of filtration tests. The flux rate for clean water was used to evaluate the cleanliness of the CUF unit. When the flux rate was high, and remained consistently high for at least $30 \mathrm{~min}$, the CUF was judged clean enough for filtration tests. The Sr/TRU precipitated waste was then transferred to the CUF for testing.

The result from the first test condition, target transmembrane pressure (TMP) of 50 psi and crossflow velocity of $12.2 \mathrm{ft} / \mathrm{s}$, are shown in Figure 3.1, and are indicative of the overall CUF performance for . the Sr/TRU precipitated waste. The high initial flux rate drops within a few minutes to a lower, consistent flux rate that slowly decreases over the 1-hour test period. For comparison of test conditions, the flux rate is averaged over the 1-hour run time except for the initial flux rate data (data taken at less than $10 \mathrm{~min}$ ). Averaging the data from $10 \mathrm{~min}$ until the end of the test conditions, the average flux rate was $0.03 \mathrm{gpm} / \mathrm{ft}^{2}$ or $1.75 \mathrm{~m}^{3} / \mathrm{m}^{2} /$ day and the permeability was $0.53 \mathrm{~m} /$ day $/ \mathrm{bar}$. These flux rates are significantly less than the value of $0.1 \mathrm{gpm} / \mathrm{ft}^{2}$ that was obtained for the $\mathrm{Sr} / \mathrm{TRU}$ precipitated, archived AN-107 under similar conditions. The archived waste did not have entrained solids present and was more dilute. The filter element also had a slightly higher clean water flux, which suggests the filter element and CUF was initially cleaner for the archived AN-107 sample test.

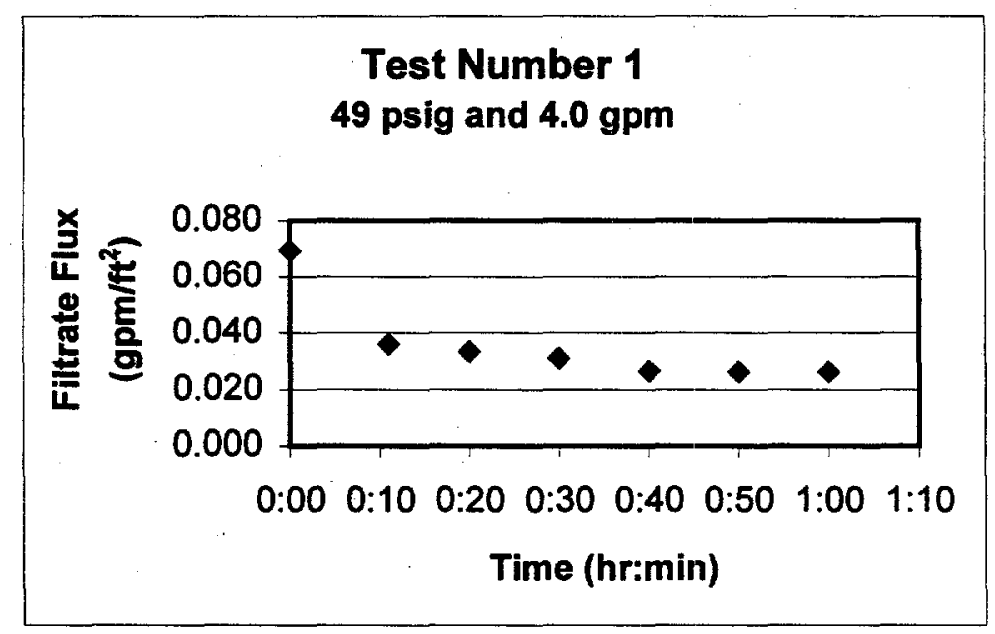

Figure 3.1. CUF Data for Test Number 1 of the Test Matrix, 49 psi Transmembrane Pressure and 4.0 gpm Total Flow (crossflow velocity of $12 \mathrm{ft} / \mathrm{s}$ ) 
Comparing all of the data from the test conditions, Table 3.10, the important operating factor appears to be crossflow velocity. The flux rates appear to drop fairly consistently with increasing run number, which has been observed for other wastes. However, for test condition number 5 , the flux rate increases substantially over the previous two conditions. The decrease in flux rates with run number, or time, can be seen by comparing the results for test number 1 and number 6 (Figure 3.2). The average filtrate flux had decreased from the first test, $0.030 \mathrm{gpm} / \mathrm{ft}^{2}$, to $0.022 \mathrm{gpm} / \mathrm{ft}^{2}$ for test condition 6 . If the decreases in flux rates are estimated for each test, the effect of TMP and velocity can be determined.

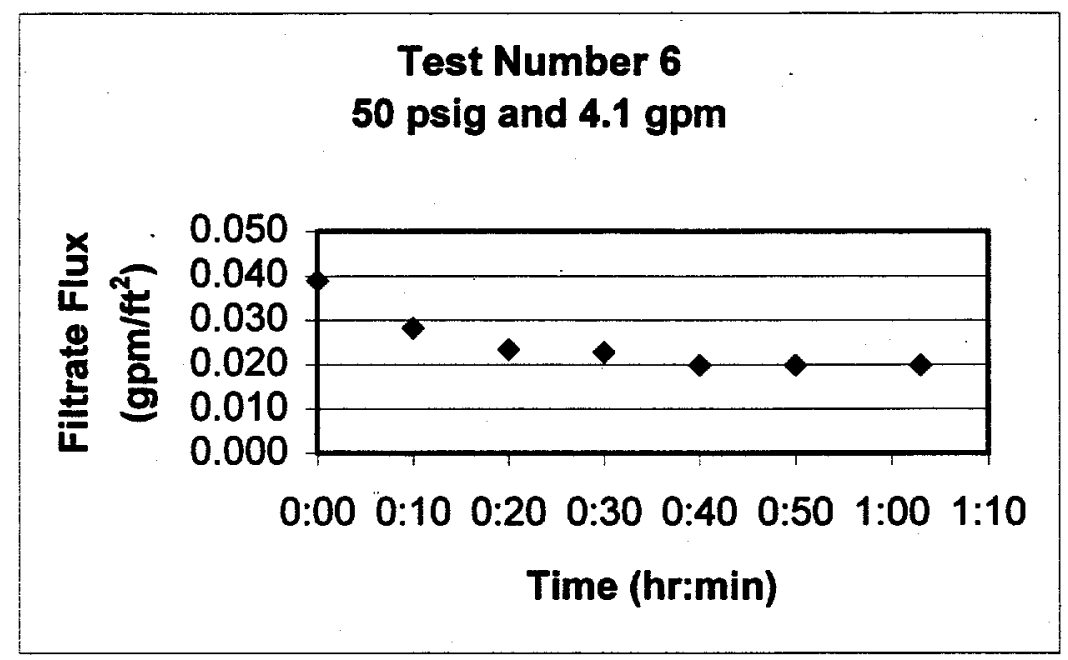

Figure 3.2. CUF Data for Test Number 6, Repeat of Test Number 1

Increasing the TMP from 30 to 50 psi resulted in a $13 \%$ increase in filtrate flux, but increasing the TMP another 20 psi from 50 to $70 \mathrm{psi}$, resulted in only a $2 \%$ increase in filtrate flux. Similarly, increasing crossflow velocity from 9.0 to $11.6 \mathrm{ft} / \mathrm{s}$ resulted in a $31 \%$ increase in flux, but an additional increase from 11.6 to $13.1 \mathrm{ft} / \mathrm{s}$ resulted in only a $2.5 \%$ increase in flux. Unfortunately, because of pump wear, the high pressure and crossflow velocity test conditions could not be reached, 70 psi and $12.2 \mathrm{ft} / \mathrm{s}$, and $50 \mathrm{psi}$ and $15.2 \mathrm{ft} / \mathrm{s}$. However, the results that were obtained suggest these conditions would not have significantly increased filtrate flux compared with $50 \mathrm{psi}$ and $12.2 \mathrm{ft} / \mathrm{s}$.

The conditions for test 1 and 6 were chosen as optimum and used for dewatering the waste in the CUF. The target TMP of $50 \mathrm{psi}$ and total flow of $4.1 \mathrm{gpm}$ could not be sustained during dewatering because of the decreasing slurry volume with time. The waste volume was decreased more than $50 \%$ during dewatering, and the filtrate flux remained quite constant during dewatering, as shown in Figure 3.3. Dewatering was stopped at $38 \mathrm{~min}$ because the volume in the CUF was too low to continue. The average flux rate during dewatering was $0.021 \mathrm{gpm} / \mathrm{ft}^{2}$. 


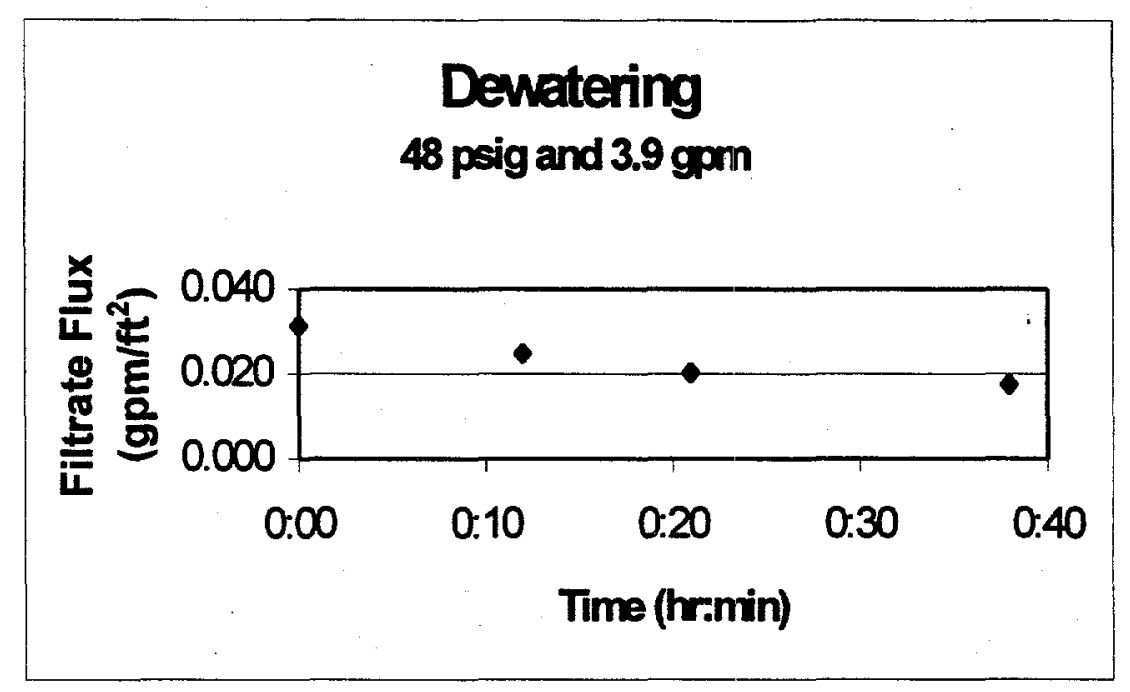

Figure 3.3. Flux Rate During Dewatering in the CUF Unit

The CUF testing was completed and the remaining dewatered slurry removed from the CUF. The CUF was rinsed with DI water and cleaning of the system was initiated. Preliminary evaluation of the filtrate flux data for the Sr/TRU treated AN-107 diluted feed showed a significantly lower filtrate flux than for the treated archived AN-107 sample. Figure 3.4 shows a comparison of the first three test conditions for the treated archived AN-107 sample and the treated AN-107 diluted feed. The large drop in filtrate flux between condition 1 and 2 for the treated, archived AN-107 was thought to be a result of shearing the agglomerated precipitate (solids) into smaller particles. This behavior was not noticed for the treated $\mathrm{AN}-107$ diluted feed.

Additional CUF tests were performed to determine if waste concentration could be a major factor in filter performance. The filtrates, slurry/solids, and samples from the first series of CUF tests were combined to reconstitute the Sr/TRU removal slurry, $\sim 2 \mathrm{wt} \%$ solids. This waste was transferred back to the CUF and filter performance determined using test condition 1 . Then the waste slurry was diluted by 19 wt\% with DI water from the first CUF rinse ( $\sim 1.7$ wt\% solids), and filtration tests repeated: test conditions $1,2,4,6$, and dewatering, plus an additional test to assess the impact of frequent backpulsing every $10 \mathrm{~min}$ of operation (test \#7). Figure 3.5 shows the filtrate flux rates for the starting reconstituted waste and the waste after additional dilution, for similar test conditions, test condition 1 . The reconstituted waste average flux rate was $0.020 \mathrm{gpm} / \mathrm{ft}^{2}$. After dilution it increased to $0.028 \mathrm{gpm} / \mathrm{ft}^{2}$, a $36 \%$ improvement. The dilution of the waste improved the flux rate, but not to the high values obtained for filtration of the treated archived AN-107. 


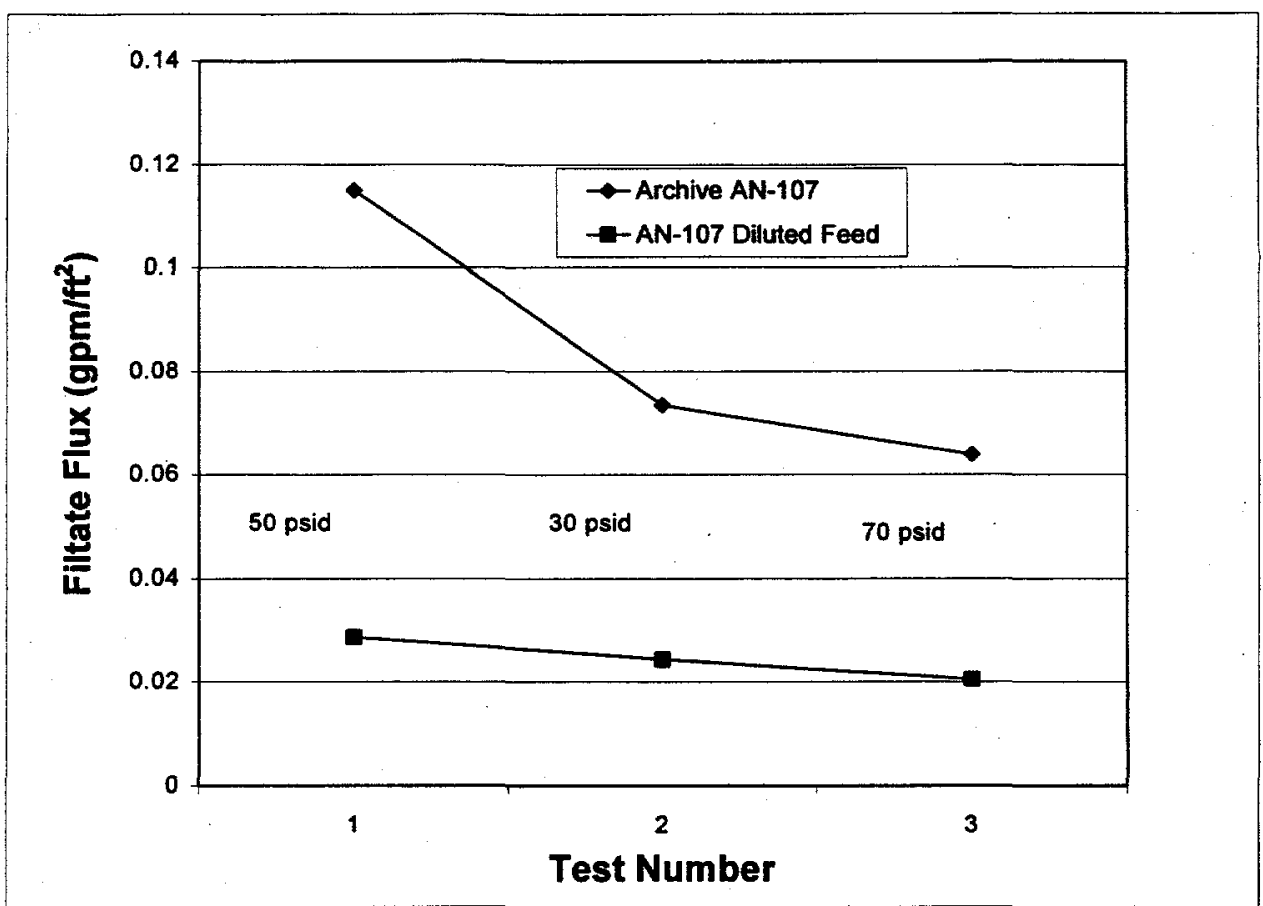

Figure 3.4. Comparison of Flux Data from Sr/TRU Precipitated Archived AN-107 and AN-107 Diluted Feed

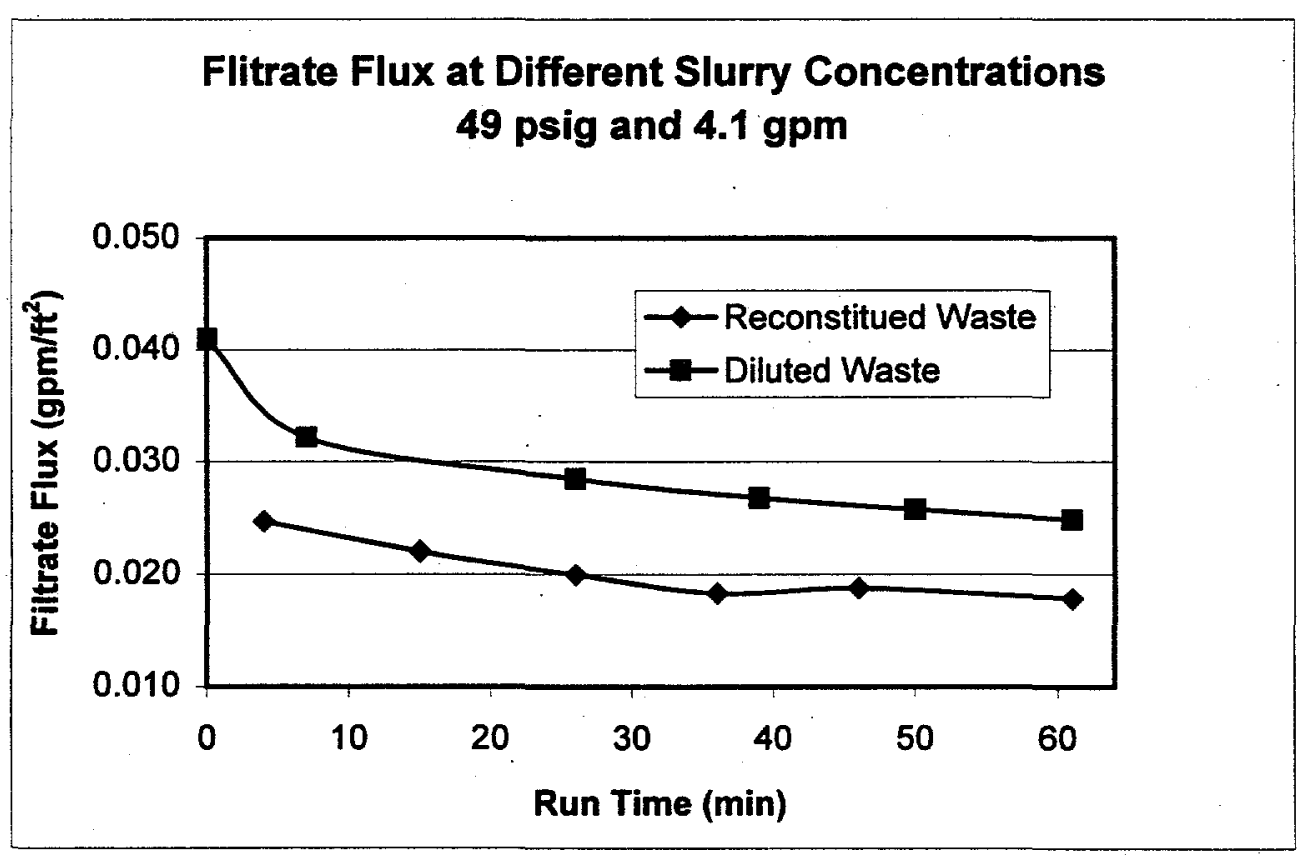

Figure 3.5. Comparison of Flux Rates at Different Slurry Concentrations with Test Number 1 Conditions 
Table 3.11 gives the filtrate flux rates for the diluted slurry at various conditions. The data are consistent with the tests conducted with the more concentrated slurry. Increasing pressure from 28 to $49 \mathrm{psi}$ resulted in a $14 \%$ increase in flux. Increasing crossflow velocity from 9.0 to $11.9 \mathrm{ft} / \mathrm{s}$ resulted in a $27 \%$ increase in flux. The filtrate flux decreased as run number increased, but to a lesser extent than with the more concentrated slurry. Optimum conditions for dewatering were determined to be $50 \mathrm{psi}$ and $12 \mathrm{ft} / \mathrm{s}$ as with the more concentrated slurry. Dewatering the diluted slurry gave very similar results to the more concentrated slurry.

Table 3.11. CUF Test Results for the Diluted Slurry

\begin{tabular}{|c|c|c|c|c|}
\hline Test \# & $\begin{array}{c}\text { TMP } \\
(\mathbf{p s i})\end{array}$ & $\begin{array}{c}\text { Total Flow } \\
(\mathrm{gpm})\end{array}$ & $\begin{array}{c}\text { Velocity } \\
(\mathbf{f t} / \mathbf{s})\end{array}$ & $\begin{array}{c}\text { Average Flux } \\
\left(\mathrm{gpm} / \mathbf{f t}^{2}\right)\end{array}$ \\
\hline 1 & 49 & 4.1 & 11.9 & 0.028 \\
\hline 2 & 28 & 4.2 & 12.2 & 0.024 \\
\hline 4 & 49 & 3.1 & 9.0 & 0.021 \\
\hline 6 & 49 & 4.1 & 11.9 & 0.026 \\
\hline 7 & 49 & 4.1 & 11.9 & 0.029 \\
\hline DW & 48 & 3.9 & 11.3 & 0.022 \\
\hline
\end{tabular}

The average flux value reported for test condition 7 , the frequent backpulse test, excludes the initial flux rate measurements. If the initial flux values are included in the average, the value raises slightly to $0.032 \mathrm{gpm} / \mathrm{ft}^{2}$. The backpulse procedure is described in Brooks et al. (1999). The air pressure to the backpulse chamber was set to 65 psig. A backpulse would take approximately 8 seconds to complete. The number of backpulses was varied from 1 to 2 . The filtrate flux rates and number of backpulses used are shown in Figure 3.6 as a function of filtration time. The initial, time 0 , flux rates should not be used for comparison, because slight delays between back pulse and taking the reading can cause the values to be significantly different as the initial rate is changing rapidly. Comparing the flux rate data taken at approximately $10 \mathrm{~min}$, shows continued degradation of flux rates even with frequent backpulses. Going from 1 backpulse to 2 appeared to stop or temporarily delay the degradation of filter performance, but did not recover lost performance. The significant factor affecting the flux rates with regard to the earlier archived AN-107 data appears to be an overall reduction of filter element/CUF performance with time. The entrained solids present in the AN-107 diluted feed certainly had an effect but probably similar in magnitude to the impact of dilution. 


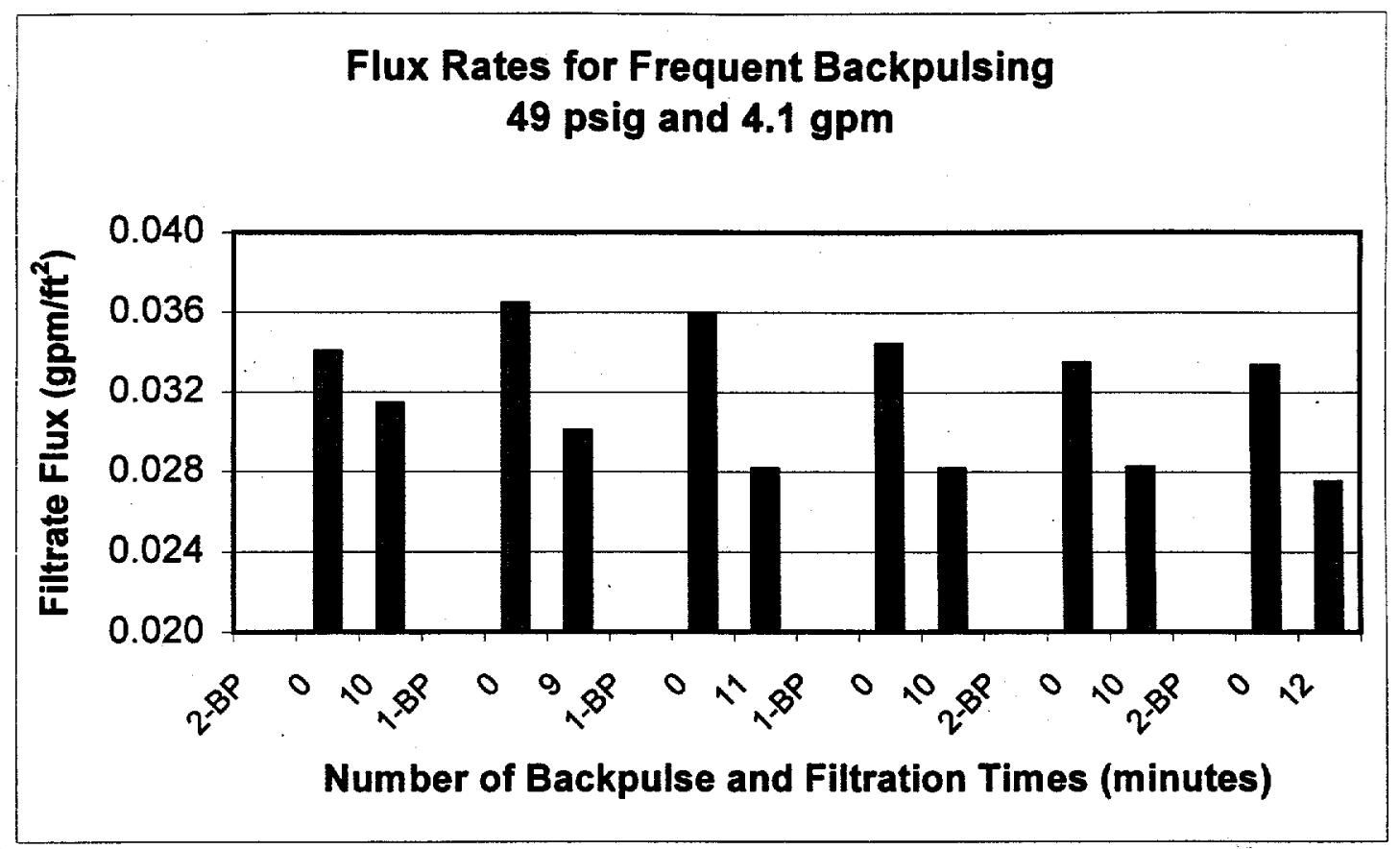

Figure 3.6. Filtrate Flux Rates with Frequent Backpulsing

\subsection{Physical Properties Analysis}

The AN-107 samples (AN-107 Diluted Feed (AN-107 PT), Sr/TRU Precipitated Slurry (DF-05 and DF-06), and Diluted Sr/TRU Precipitated Slurry (DF-13)) were analyzed for density of the bulk slurries, settled solids, supernatant following solids settling, centrifuged solids, and centrifuged supernatant. The density results are listed in Table 3.12. The wt $\%$ and vol $\%$ settled solids, wt $\%$ and vol\% centrifuged solids, and wt $\%$ total solids were measured for these samples as well. The wt $\%$ and vol\% solids results are listed in Table 3.13.

For this testing, a known mass of each slurry was placed in duplicate in volume graduated centrifuge cones. The duplicates were then allowed to settle for 3 days. The total mass $\left(M_{B}\right)$ and volume $\left(V_{B}\right)$ of the settled were recorded, and the density of the bulk slurry was calculated $\left(D_{B}=M_{B} / V_{B}\right)$. In addition, the volume of the settled solids $\left(\mathrm{V}_{\mathrm{ss}}\right)$ and volume of supernatant following solids settling $\left(V_{\mathrm{si}}\right)$ were recorded. The vol\% settled solids were then calculated $\left(\mathrm{Vol}_{\mathrm{ss}}=\mathrm{V}_{\mathrm{ss}} / \mathrm{V}_{\mathrm{B}} \times 100 \%\right)$. A portion of the supernatant following solids settling was then transferred to a graduated cylinder, and its mass $\left(\mathrm{M}_{\mathrm{slb}}\right)$ and volume $\left(\mathrm{V}_{\mathrm{slb}}\right)$ recorded. Using these data, the density of the supernatant following solids settling was calculated $\left(\mathrm{D}_{\mathrm{sl}}=\mathrm{M}_{\mathrm{slb}} / \mathrm{V}_{\mathrm{slb}}\right)$.

Since all of the supernatant following solids settling could not be removed from the centrifuge cone without disturbing the settled solids, the mass of the settled solids $\left(\mathrm{M}_{\mathrm{ss}}\right)$ could not be measured directly. Therefore, the mass of the settled solids was determined by first calculating the mass of the supernatant following solids settling in the centrifuge cone using the measured supernatant density and volume $\left(M_{s l}=D_{s l} \times V_{s l}\right)$, then subtracting this mass for the mass of the bulk slurry to get the mass of the settled solids $\left(\mathrm{M}_{\mathrm{ss}}=\mathrm{M}_{\mathrm{B}}-\mathrm{M}_{\mathrm{sl}}\right)$. The density of the settled solids was then calculated $\left(D_{s s}=M_{s s} / V_{s s}\right)$, as well as the wt $\%$ settled solids $\left(W t \%_{s s}=M_{s s} / M_{B} \times 100 \%\right)$. 
Table 3.12. Density Measurements for Samples of AN-107 Diluted Feed (AN-107 PT), Sr/TRU Precipitated Slurry (DF-05 and DF-06), and Diluted Slurry (DF-13)

\begin{tabular}{|l|c|c|c|c|c|}
\hline & \multicolumn{5}{|c|}{ Density, g/ml } \\
\hline & Slurry & $\begin{array}{c}\text { Settled } \\
\text { Solids }\end{array}$ & $\begin{array}{c}\text { Supernatant } \\
\text { Following } \\
\text { Solids Settling }\end{array}$ & $\begin{array}{c}\text { Centrifuged } \\
\text { Solids }\end{array}$ & $\begin{array}{c}\text { Centrifuged } \\
\text { Supernatant }\end{array}$ \\
\hline AN-107 PT & 1.32 & 1.47 & 1.38 & 1.88 & 1.311 \\
\hline AN-107 PT Duplicate & 1.32 & 1.30 & 1.26 & 1.94 & 1.317 \\
\hline AN-107 PT Average & 1.32 & 1.38 & 1.32 & 1.91 & 1.314 \\
\hline Relative \% Difference & $0 \%$ & $12 \%$ & $9 \%$ & $3 \%$ & $0.4 \%$ \\
\hline DF-5 & 1.25 & 1.23 & 1.28 & 1.36 & 1.290 \\
\hline DF-5 Duplicate & 1.26 & 1.31 & 1.26 & 1.34 & 1.298 \\
\hline DF-5 Average & 1.26 & 1.27 & 1.27 & 1.35 & 1.294 \\
\hline Relative \% Difference & $1 \%$ & $6 \%$ & $2 \%$ & $1 \%$ & $0.6 \%$ \\
\hline DF-6 & 1.26 & 1.37 & 1.29 & 1.42 & 1.291 \\
\hline DF-6 Duplicate & 1.26 & 1.33 & 1.25 & 1.31 & 1.275 \\
\hline 7-DF-6 Average & 1.26 & 1.35 & 1.27 & 1.37 & 1.283 \\
\hline Relative \% Difference & $0 \%$ & $3 \%$ & $3 \%$ & $8 \%$ & $1 \%$ \\
\hline DF-13 & 1.20 & 1.23 & 1.22 & 1.26 & 1.242 \\
\hline DF-13 Duplicate & 1.20 & 1.21 & 1.23 & 1.32 & 1.250 \\
\hline DF-13 Average & 1.20 & 1.22 & 1.22 & 1.29 & 1.246 \\
\hline Relative \% Difference & $0 \%$ & $2 \%$ & $1 \%$ & $5 \%$ & $0.6 \%$ \\
\hline
\end{tabular}

Table 3.13. Weight Percent and Volume Percent Solids measurements for samples of AN-107 Diluted Feed (AN-107 PT), Sr/TRU Precipitated Slurry (DF-05 and DF-06), and Diluted Slurry (DF-13)

\begin{tabular}{|l|c|c|c|c|c|}
\hline & $\begin{array}{c}\text { Wt\% } \\
\text { Settled }^{(\mathbf{1})}\end{array}$ & $\begin{array}{c}\text { Wt\% } \\
\text { Centrifuged }^{(\mathbf{1})}\end{array}$ & $\begin{array}{c}\text { Vol\% } \\
\text { Settled }^{(\mathbf{1})}\end{array}$ & $\begin{array}{c}\text { Vol\% } \\
\text { Centrifuged }^{(\mathbf{1})}\end{array}$ & $\begin{array}{c}\text { Wt\% } \\
\text { Dissolved }^{(\mathbf{1 )}}\end{array}$ \\
\hline AN-107 PT & 7.0 & 4.5 & 6.3 & 3.2 & 41 \\
\hline AN-107 PT Duplicate & 6.6 & 4.6 & 6.7 & 3.1 & 42 \\
\hline AN-107 PT Average & 6.8 & 4.6 & 6.5 & 3.2 & 42.0 \\
\hline Relative \% Difference & $6 \%$ & $2 \%$ & $6 \%$ & $3 \%$ & $2 \%$ \\
\hline DF-5 & 39 & 13 & 39 & 12 & 35 \\
\hline DF-5 Duplicate & 40 & 13 & 39 & 12 & 36 \\
\hline DF-5 Average & 40 & 13 & 39 & 12 & 36 \\
\hline Relative \% Difference & $2 \%$ & $0 \%$ & $0 \%$ & $0 \%$ & $3 \%$ \\
\hline DF-6 & 43 & 15 & 40 & 13 & 43 \\
\hline DF-6 Duplicate & 40 & 13 & 38 & 12 & 39 \\
\hline DF-6 Average & 42 & 14 & 39 & 12 & 41 \\
\hline Relative \% Difference & $7 \%$ & $14 \%$ & $5 \%$ & $\mathbf{8 \%}$ & $10 \%$ \\
\hline DF-13 & 42 & 9.7 & 41 & 9.3 & 30 \\
\hline DF-13 Duplicate & 42 & 9.6 & 41 & $\mathbf{8 . 8}$ & 30 \\
\hline DF-13 Average & 42 & 9.6 & 41 & 9.0 & 30 \\
\hline Relative \% Difference & $0 \%$ & $1 \%$ & $0 \%$ & $6 \%$ & $0 \%$ \\
\hline
\end{tabular}

"Values include interstitial liquid. 
The supernatant following solids settling was then added back to the centrifuge cones and centrifuged at approximately 1000 times the force of gravity for 1 hour. All of the centrifuged supernatant was then transferred to a graduated cylinder and its mass $\left(\mathrm{M}_{\mathrm{cl}}\right)$ and volume $\left(\mathrm{V}_{\mathrm{cl}}\right)$ recorded, and the density was calculated $\left(D_{c l}=M_{c l} / V_{c l}\right)$. The mass $\left(M_{c s}\right)$ and volume $\left(V_{c s}\right)$ of the centrifuged solids were then recorded, and the density was calculated $\left(D_{c s}=M_{c s} / V_{c s}\right)$. In addition, the wt\% centrifuged solids $\left(\mathrm{Wt} \%_{\mathrm{cs}}=\mathrm{M}_{\mathrm{cs}} \mathrm{M}_{\mathrm{B}} \times 100 \%\right)$, and vol\% centrifuged solids $\left(\mathrm{Vol} \%_{\mathrm{cl}}=\mathrm{V}_{\mathrm{cl}} / \mathrm{V}_{\mathrm{B}} \times 100 \%\right)$ were also calculated.

The centrifuged solids and supernatants were then each dried at $105^{\circ} \mathrm{C}$ for 24 hours. The mass of the dried centrifuged supernatant $\left(M_{d c l}\right)$ and dried centrifuged solids $\left(M_{d c s}\right)$ were then measured.

Assuming all mass lost during the drying process is water and not another volatile component, the weight percent total solids in the bulk slurry was calculated $\left(\mathrm{Wt} \%=\left(\mathrm{M}_{\mathrm{dcs}}+\mathrm{M}_{\mathrm{dcl}}\right) /\left(\mathrm{M}_{\mathrm{cs}}+\mathrm{M}_{\mathrm{cl}}\right) \times 100 \%\right)$.

The results in Table 3.12 show the initial density of the diluted feed was $1.32 \mathrm{~g} / \mathrm{mL}$. Following the $\mathrm{Sr} / \mathrm{TRU}$ removal treatment, the density decreased to $1.26 \mathrm{~g} / \mathrm{mL}$. The final diluted slurry, after the additional $19.24 \mathrm{wt} \%$ dilution, had a density of $1.20 \mathrm{~g} / \mathrm{mL}$. This value is very close to that calculated for this amount of dilution, $1.22 \mathrm{~g} / \mathrm{mL}([1.26+0.19] /[1.00+0.19]=1.218)$.

The density of the centrifuged solids in the initial diluted feed was $1.91 \mathrm{~g} / \mathrm{mL}$ (entrained solids). The density of the $\mathrm{Sr} / \mathrm{TRU}$ precipitate and entrained solids decreased to an average of $1.36 \mathrm{~g} / \mathrm{mL}$ for samples DF-05 and DF-06. It then decreased again to $1.29 \mathrm{~g} / \mathrm{mL}$ following the final dilution. The relative percent differences between duplicates were low, with the exception of $8 \%$ for sample DF-06. This drop in density with the final dilution (between DF-05/DF-06 and DF-13) indicates that dilution was inducing a change in the solid species, either decreasing the packing efficiency, dissolving the denser species (entrained solids), or both.

From the data in Table 3.13, there were $4.6 \mathrm{wt} \%$ centrifuged solids (including interstitial liquid) in the initial diluted feed. Following the $\mathrm{Sr} / \mathrm{TRU}$ precipitation, the solids content increased to an average of $14 \mathrm{wt} \%$ for samples DF-05 and DF-06. Following the final dilution, the centrifuged solids content dropped to $9.6 \mathrm{wt} \%$. This decrease to $9.6 \mathrm{wt} \%$ would be anticipated for a $19.24 \%$ dilution $(14 \mathrm{~g} /(126 \mathrm{~g}+19.24 \mathrm{~g}) * 100 \%=9.6 \%)$. The $w t \%$ total solids (including dissolved solids) was $42 \mathrm{wt} \%$ in the initial diluted feed. Following the Sr/TRU precipitation and final dilution this value was $30 \mathrm{wt} \%$. Based on this $30 \mathrm{wt} \%$ value, a value of $44 \mathrm{wt} \%$ would be anticipated for samples DF-05 and DF-06. However, the highest measured value was $43 \%$ with an average of only $39 \mathrm{wt} \%$. It is unclear why the wt $\%$ total solids for samples DF-05 and DF-06 were low, but the relative percent difference between duplicates was high as well, $3 \%$ and $10 \%$, respectively. It is also possible that the value of $30 \mathrm{wt} \%$ for sample DF-13 was high, but both duplicates yielded the same result.

An additional calculation was performed to determine the wt $\%$ solids in the samples excluding all interstitial liquid ( $w t \%$ undissolved solids). The $w t \%$ undissolved solids can be thought of as the solids left if all the supernatant could be removed from the bulk slurry. The following equation was used:

Wt $\%$ undissolved solids $=\left(1-\frac{1-\frac{M_{d s c}}{M_{c s}}}{1-\frac{M_{d c l}}{M_{c l}}}\right) \times \frac{M_{c s}}{M_{B}} \times 100 \%$ 
This calculation assumes 1) that the supernatant and the interstitial liquid have the same composition, and 2) that all mass loss during the drying of the centrifuged solids is water loss from interstitial liquid. The results of this calculation are listed in Table 3.14 along with the $w t \%$ dried residue from the centrifuged solids (Solids Residue $=\mathrm{M}_{\mathrm{cs}} / \mathrm{M}_{\mathrm{dcs}} \times 100 \%$ ), and dried centrifuged supernatant (Supernatant Residue $=\mathrm{M}_{\mathrm{ds}} / \mathrm{M}_{\mathrm{sl}} \times 100 \%$ ).

Table 3.14 shows the wt $\%$ undissolved solids for the duplicate initial diluted feed samples were $0.56 \mathrm{wt} \%$ and $0.67 \mathrm{wt} \%$. This yields an average value of $0.62 \mathrm{wt} \%$ entrained solids in the diluted feed with a relative percent difference of $18 \%$. This relative percent difference of $18 \%$ is not unreasonably high given the low solids content. The duplicates for the final diluted slurry (DF-13) also showed good reproducibility, $1.67 \mathrm{wt} \%$ and $1.58 \mathrm{wt} \%$ with an average of $1.62 \mathrm{wt} \%$ and a relative percent difference of $6 \%$. However, the Sr/TRU precipitated samples, DF-05 and DF-06, showed a great deal of scatter with relative percent differences of $114 \%$ and $180 \%$, respectively. It is possible that the low relative percent difference for the initial and final samples was fortuitous. However, it is more likely that solids inhomogeneity or a subsampling error was the cause of the variability in this analysis. While these are the most likely explanations, the issue is still not clear, since the remaining solids results in Table 3.12 and 3.13 showed reproducibility between the duplicate subsamples.

Given a value of $1.62 \mathrm{wt} \%$ for the final diluted slurry, a value for the initial precipitated slurry of 1.93 $w t \%(1.62 * 1.19=1.93)$ would be anticipated. If we use the initial entrained solids value of $0.62 \mathrm{wt} \%$ and add the expected mass for Sr/TRU precipitate, we estimate $1.94 \mathrm{wt} \%$ solids. This is very close to the $w t \%$ solids predicted earlier based on ICP chemical analysis of the washed solids, $1.85 \mathrm{wt} \%$.

Table 3.14. Results of Wt\% Residual Solids and Undissolved Solids Calculation Following Drying at $105^{\circ} \mathrm{C}$ for 24 Hours for Samples of AN-107 Diluted Feed (AN-107 PT), Sr/TRU Precipitated Slurry

(DF-05 and DF-06), and Diluted Slurry (DF-13)

\begin{tabular}{|l|c|c|c|}
\hline \multicolumn{1}{|c|}{ Sample } & $\begin{array}{c}\text { Wt\% Residual } \\
\text { Centrifuged Solids }\end{array}$ & $\begin{array}{c}\text { Wt\% Residual } \\
\text { Centrifuged } \\
\text { Supernatant }\end{array}$ & $\begin{array}{c}\text { Wt\% } \\
\text { Undissolved } \\
\text { Solids }\end{array}$ \\
\hline AN-107 PT & 50.5 & 43.5 & 0.56 \\
\hline AN-107 PT Duplicate & 51.7 & 43.4 & 0.67 \\
\hline AN-107 PT Average & - & - & 0.62 \\
\hline Relative \% Difference & - & - & $18 \%$ \\
\hline DF-5 & 67.1 & 33.3 & 6.6 \\
\hline DF-5 Duplicate & 44.9 & 36.0 & 1.8 \\
\hline DF-5 Average & - & - & 4.2 \\
\hline Relative\% Difference & - & - & $114 \%$ \\
\hline DF-6 & 43.8 & 43.6 & 0.06 \\
\hline DF-6 Duplicate & 44.6 & 38.9 & 1.21 \\
\hline DF-6 Average & - & - & 0.64 \\
\hline Relative \% Difference & - & - & $180 \%$ \\
\hline DF-13 & 41.6 & 29.6 & 1.67 \\
\hline DF-13 Duplicate & 41.4 & 29.9 & 1.58 \\
\hline DF-13 Average & - & - & 1.62 \\
\hline Relative \% Difference & - & - & $6 \%$ \\
\hline
\end{tabular}




\subsection{Rheological and Flow Properties}

Examples of typical rheograms for the initial AN-107 diluted feed and Sr/TRU precipitated waste are presented in Figures 3.7 and 3.8. All of the rheograms for the standards, samples, and duplicates are included in Appendix C. As seen in these examples, the slurry exhibits Newtonian behavior, as there is a nearly linear relationship between shear stress and shear rate over the shear rate range examined and no detectable yield stress. Since the viscosity is the ratio of the shear stress to the shear rate, the viscosity was nearly constant over the shear rate range examined for all samples. The viscosity of the initial diluted feed was between $10-12 \mathrm{cP}$, and the viscosity of the $\mathrm{Sr} / \mathrm{TRU}$ precipitated slurry was between $7-18 \mathrm{cP}$.

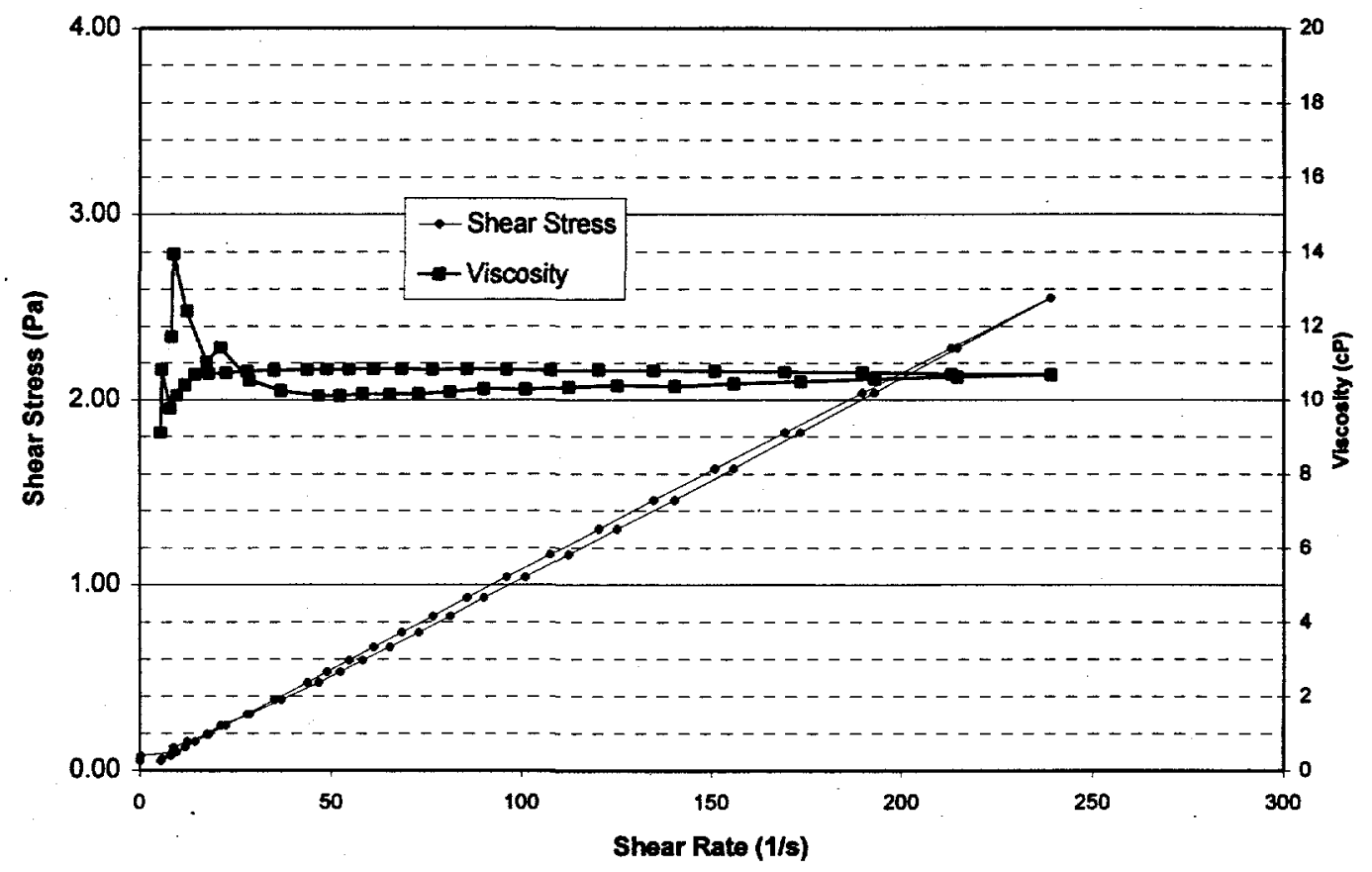

Figure 3.7. Initial AN-107 Diluted Feed: Sample 1 


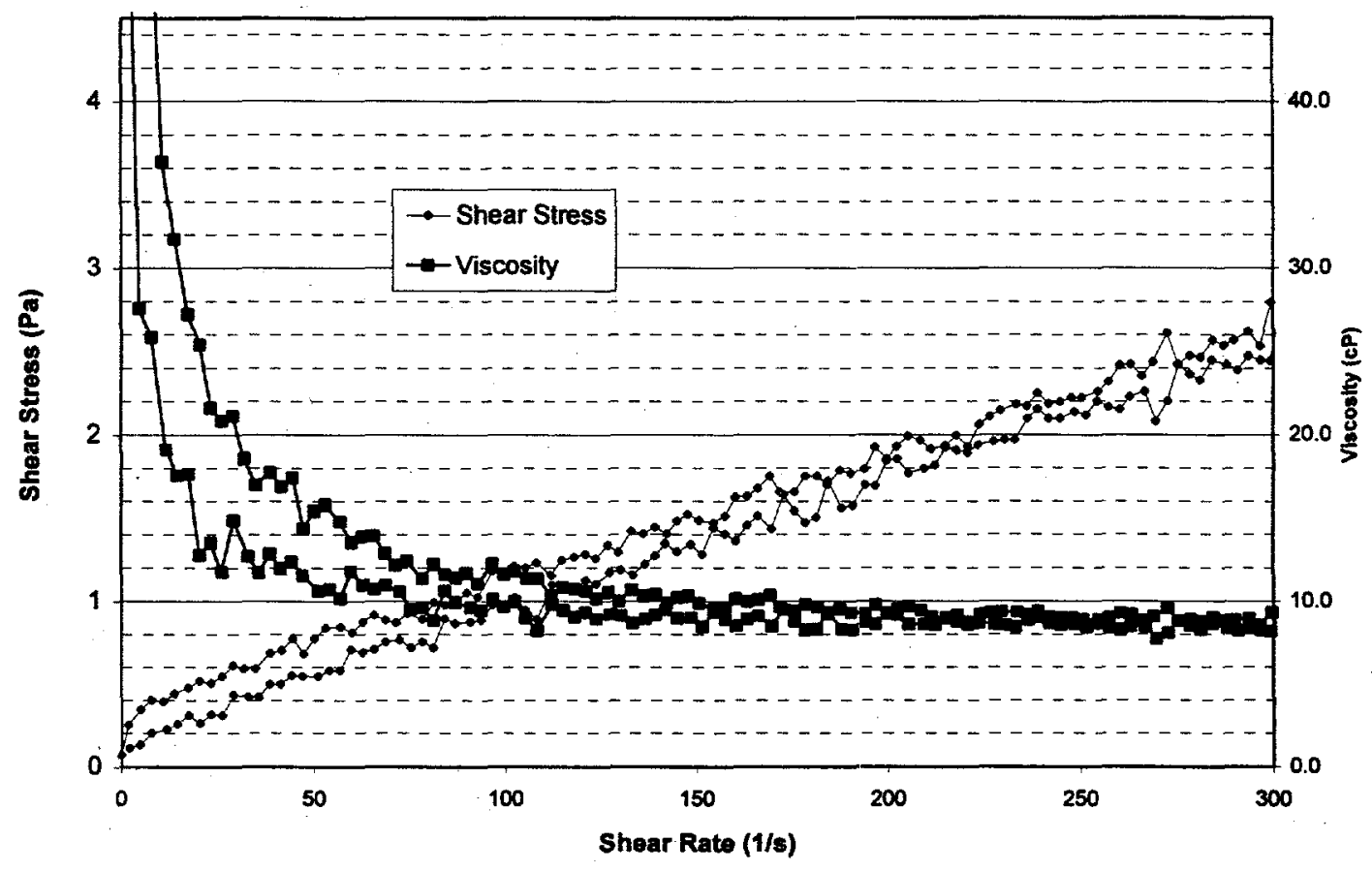

Figure 3.8. AN-107 Sr/TRU Precipitated Slurry: Sample 1 Analysis 1 


\subsection{CONCLUSIONS AND RECOMMENDATIONS}

The new processing scheme for $\mathrm{Sr} / \mathrm{TRU}$ removal involving precipitation by added strontium and permanganate worked well. Very high decontamination of Sr and TRU in AN-107 waste was accomplished with added concentrations of $0.075 \mathrm{M}$ Sr and $0.05 \mathrm{M}$ permanganate. These results support the use of lower concentration of reagent additions than used in this study. Optimization studies should be conducted to examine the reduction in added hydroxide from $1 \mathrm{M}$ to $0.5 \mathrm{M}$, reduction of $\mathrm{Sr}$ from $0.075 \mathrm{M}$ to $0.05 \mathrm{M}$, and reduction in permanganate from $0.05 \mathrm{M}$ to $0.03 \mathrm{M}$. The 4-hour digestion at $50^{\circ} \mathrm{C}$ appears unnecessary to obtain high decontamination of $\mathrm{Sr}$ and TRU using this treatment scheme. Adequate DFs were obtained after addition and thorough mixing of the reagents before the solids were digested. Mixing the precipitate for 1-hour at ambient temperature should be examined in future studies. However, these data indicate that thermodynamic equilibrium with the $\mathrm{Sr} / \mathrm{TRU}$ precipitated solids was not reached during the processing time involved. Longer contact times may be required to allow equilibrium to be reached and reduce the possibility of the formation of solids after the filtration process.

The combined entrained solids and Sr/TRU precipitate was successfully filtered in the single element, crossflow filtration unit. At the preferred operating conditions, transmembrane pressure (TMP) of $50 \mathrm{psid}$ and crossflow velocity of $12.2 \mathrm{ft} / \mathrm{sec}$, the average filtrate flux was $0.03 \mathrm{gpm} / \mathrm{ft}^{2}$ or 1.75 $\mathrm{m}^{3} / \mathrm{m}^{2} /$ day and the permeability was $0.53 \mathrm{~m} /$ day/bar. The filtrate flux was not as high as earlier tests with an archived AN-107 sample $\left(0.11 \mathrm{gpm} / \mathrm{ft}^{2}\right)$, but this result was expected because of the higher concentration and presence of settled solids in the $\mathrm{AN}-107$ diluted feed. The combined entrained and $\mathrm{Sr} / \mathrm{TRU}$ removal solids content of the waste slurry was quite low, $1.9 \mathrm{wt} \%$. The waste could only be dewatered approximately $50 \%$ to a solids content of approximately $4 \mathrm{wt} \%$ because of the large minimum operating volume of the CUF $(\sim 700-\mathrm{mL})$ and the limited amount of solids. The vacuum, air-dried solids were $36.6 \mathrm{wt} \%$ solids ( $63.4 \mathrm{wt} \%$ moisture). It appears that it will be difficult to dewater the combined entrained solids and Sr/TRU precipitate to the target value of $>20 \mathrm{wt} \%$ solids by crossflow filtration. Solids washing in the CUF may allow higher solids levels but would require larger tank samples be treated for the CUF experiment, approximately 7-L samples of waste. Future tests should be conducted with larger tank waste samples to allow the determination of performance of the filter to higher solids content and evaluate the impact of washing in the CUF system.

The viscosity of the Sr/TRU precipitated slurry (1.9 wt\% solids) was between $7-18 \mathrm{cP}$. The slurry showed a nearly linear relationship between shear stress and shear rate over the shear rate range examined and no detectable yield stress, i.e., Newtonian behavior.

The performance of the CUF system degraded with processing time. Frequent backpulsing could help keep average filtrate flux rates higher but could not recover or prevent degradation of filter performance with time. Rinsing and backpulsing the system with clean water was not adequate to restore filter flux. After some period of time, the unit/filter will require chemical cleaning such as the $1 \mathrm{M}$ nitric and $0.2 \mathrm{M}$ citric acid used for these studies. An external filter was also used to reduce the time and volume of water required for the final cleanup up the system. Additional studies need to be conducted to evaluate options for filter element cleaning, and impact to design if nitric/citric acid is required for filter cleaning.

The chemical decontamination of $\mathrm{AN}-107$ waste with added $\mathrm{Sr}$ and permanganate is very rapid and occurs at room temperature in a matter of minutes. The filterability of the waste slurry and potential for post filtration precipitation will likely be the determining factor for the Sr/TRU removal process conditions. The waste as received from the tank is not filterable since the entrained solids rapidly foul the filter element. The Sr/TRU removal treatment results in a waste that can be filtered, the 
permanganate treatment greatly increasing the filterability by crossflow filtration. The filtration is still difficult with lower than expected flux rates, the filter element performance reduces with time, and the level of solids concentration impact of solids washing is unknown. Additional filtration studies need to be conducted and processing schemes involving solids settling/decant, precipitate recycle, and/or alternate dewatering should be considered. 


\subsection{REFERENCES}

Brooks, K. P., P. R. Bredt, G. R. Golcar, S. A. Hartley, M. W. Urie, J. M. Tingey, K. G. Rappe, L.K Jagoda. 1999. Ultrafiltration and Characterization of AW-101 Supernatant and Entrained Solids, PNWD-3000, Battelle, Richland, Washington.

Brooks, K. P., P. R. Bredt, G. R. Golcar, S. A. Hartley, L.K. Jagoda, K. G. Rappe, M. W. Urie. 2000. Characterization, Washing, Leaching, and Filtration of C-104 Sludge, PNWD-3024, Battelle, Richland, Washington.

Hallen, R. T., S. A. Bryan, and F. V. Hoopes. 2000a. Development of an Alternative Treatment Scheme for Sr/TRU Removal: Permanganate Treatment of AN-107 Waste, PNWD-3047, Battelle, Richland, Washington.

Hallen, R. T., K. P. Brooks, and L. K. Jagoda. 2000b. Demonstration of Entrained Solids and Sr/TRU Removal Processes with Archived AN-107 Waste, PNWD-3033, Battelle, Richland, Washington.

Hendrickson, D. W. 1997. Hanford Complexant Concentrate and Salt Cake Cesium Removal Using Superlig $\otimes^{2}$ 644. SESC-EN-RPT-007 Rev. 0, SGN Eurisys Services Corporation, An SGN/Cogema, Inc. Company.

Krot, N. N., V. Shilov, A. Bressonov, N. Budantseva, I. Charushnikova, V. Perminov, and L. N. Astafurova. 1996. Investigation on the Coprecipitation of Elements from Alkaline Solutions by the Method of Appearing Reagents, WHC-EP-0898, Westinghouse Hanford Company, Richland, Washington.

G.J. Lumetta and F.V. Hoopes. 1999. Washing of the AN-107 Entrained Solids, PNWD-2469, Battelle, Richland, Washington.

Orth, R. J., A. H. Zacher, A. J. Schmidt, M. R. Elmore, K. R. Elliott, G. G. Neuenschwander, and S. R. Gano. 1995. Removal of Strontium and Transuranics from Hanford Tank Waste via Addition of Metal Cations and Chemical Oxidant - FY 1995 Test Results, PNL-10766, Pacific Northwest Laboratory, Richland Washington.

Rapko, B.M., G.J. Lumetta, and M.J. Wagner. 1996. Oxidative Dissolution of Chromium from Hanford Tank Sludges Under Alkaline Conditions, PNNL-11233, Pacific Northwest National Laboratory, Richland, Washington.

Rapko, B.M. 1998. Oxidative Alkaline Dissolution of Chromium from Hanford Tank Sludges Results of FY 98 Studies, PNNL-1 1908, Pacific Northwest National Laboratory, Richland, Washington.

River Protection Project Waste Treatment Plant (RPP-WTP) (formerly TWRS) Privatization Contract. 1996. DE-RP06-96RL13308. U.S. Department of.Energy, Richland, Washington.

Schroeder, Norman C., Oxidation, Characterization, and Separation of Non-Pertechnetate Species in Hanford Wastes, TTP Number AL17C321, Los Alamos National Laboratory, Los Alamos, New Mexico.

SRTC 1997a, Hanford Envelope Archive C Tank Waste Precipitation Study, March 20, 1997, SRTC-BNFL-004, revision 0, Savannah River Technology Center, Aiken, South Carolina. 
SRTC. 1997b, Hanford Simulant Tank Waste Precipitation Study, July 8, 1997, SRTC-BNFL-006, revision 1, Savannah River Technology Center, Aiken, South Carolina.

SRTC 1997c, Hanford Envelope C Tank Waste Precipitation Study, August 13, 1997, SRTC-BNFL-005, revision 2, Savannah River Technology Center, Aiken, South Carolina.

SRTC 1997d, Hanford Envelope C Tank Waste Sr/TRU Precipitation Demonstration, November 18, 1997, SRTC-BNFL-024, revision 0, Savannah River Technology Center, Aiken, South Carolina.

Townson, Paul S., 1999, Sr/TRU Precipitation and Ultrafiltration Test Specification, TSP-W375-99-00004 Rev. I, August 17, 1999, BNFL Inc., Richland, Washington.

Urie, MW, J. J. Wagner, L. R. Greenwood, O. T. Farmer, S. K. Fiskum, R. T. Ratner, and C. Z. Soderquist. 1999a. Inorganic and Radiochemical Analysis of AW-101 and AN-107 Tank Waste, PNWD-2462, Battelle, Richland, Washington.

Urie, M. W., J. J. Wagner, L. R. Greenwood, O. T. Farmer, S. K. Fiskum, R. T. Ratner, and C. Z. Soderquist. 1999b. Inorganic and Radiochemical Analysis of $A W-101$ and AN-107 'Diluted Feed' Materials, PNWD-2463, Battelle, Richland, Washington. 


\section{APPENDIX A: TEST INSTRUCTION AND DATA SHEETS}

Sr/TRU Precipitation of AN-107 Diluted Feed and Combined Removal of Entrained Solids and Sr/TRU Precipitate by Crossflow Filtration

Data Sheets

Log Book Entries 
-

○

○

,




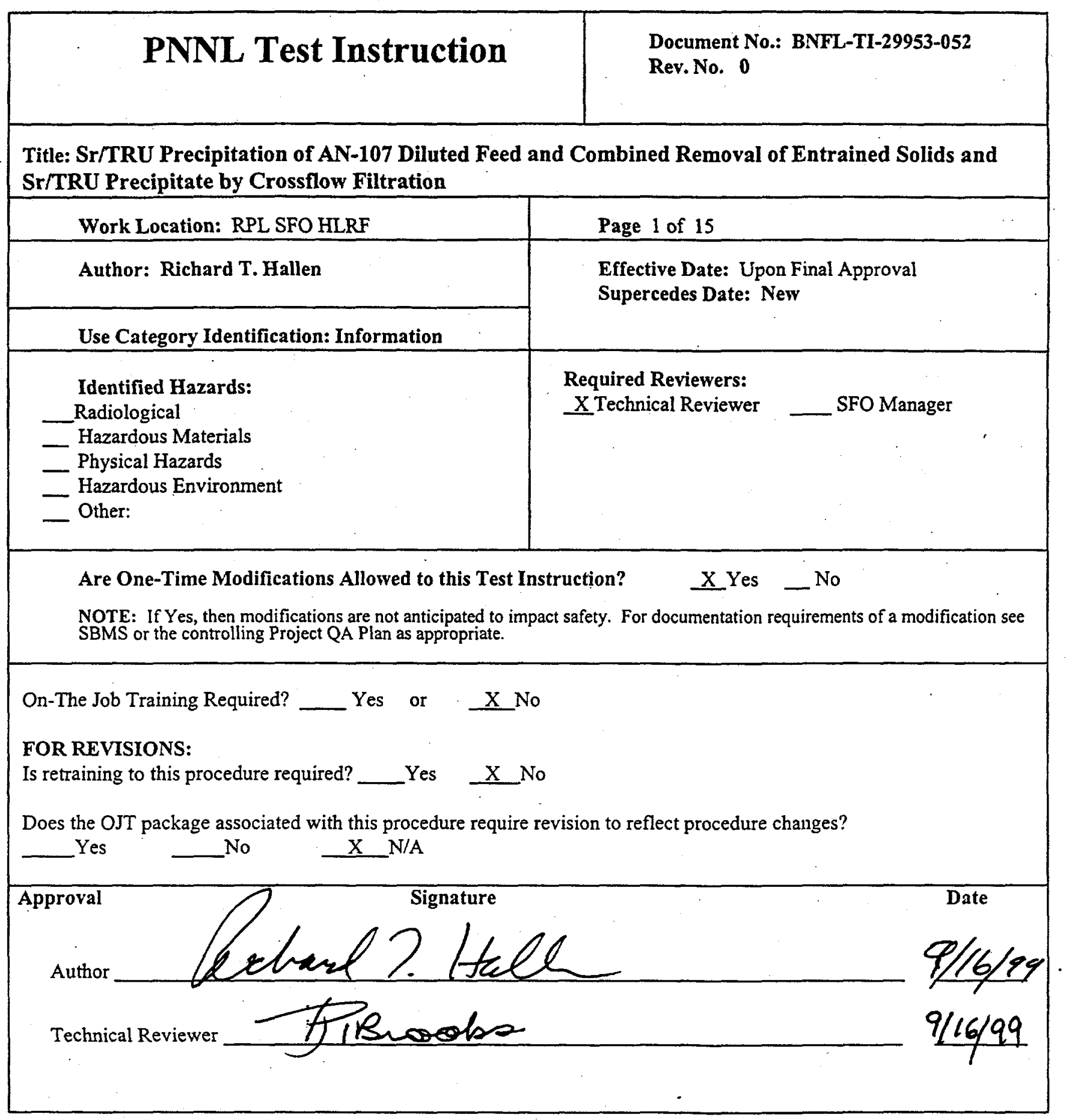

UnControlled Document 


\subsection{Applicability}

This test instruction is to be used to perform studies on permanganate treatment for Sr/TRU removal and precipitate removal from $\mathrm{AN}-107$ diluted feed. The entrained solids will not be removed prior to Sr/TRU precipitation. The combined entrained solids and Sr/TRU precipitate will be removed using the Cell Unit Filter (CUF) in the HLRF A-cell from approximately 1.4-L of AN-107 diluted feed.

\subsection{Supporting Documents}

This test instruction is not a stand-alone document. It will be used in conjunction with PNNL Operating Procedure BNFL-TP-29953-020 which contains the necessary procedural information for the safe operation of the CUF. It is also linked to PNNL Test Plan BNFL-TP-29953-013 Rev. 1 which contains an overall description of the goal of this effort, ES\&H compliance, emergency response, and the hazards assessment and mitigation.

\subsection{Responsible Staff}

The staff responsible for executing this test plan are as follows.

- Task Managers - Rich Hallen

- SFO Manager - Randy Thornhill

- Test Scientists/Engineers - Kriston Brooks, Lynette Jagoda, and Rich Hallen

- Hot Cell Technician -Don Rinehart, and Ralph Lettau

- Radiological Control Technician

\subsection{Materials, Equipment, Supplies and Reagents Needed}

\subsection{Materials Required}

1. Twenty $20 \mathrm{~mL}$ glass scintillation vials for filtrate and slurry samples, pre-labeled on top and side as follows: DF-01 through DF-20.

2. Four 1 liter polyethylene bottles. They should be labeled as follows: "AN-107 DF CUF Filtrate," "AN-107 DF Filtrate (filter unit receiver)," "CUF Dewatered Slurry," and "CUF AN-107 DF First Rinse."

3. Four $100 \mathrm{~mL}$ bottles for each wash solution labeled wash 1 through 4 . These can be filter unit bottles if small ones are available.

4. Two 10 liter containers, one labeled for the alkaline rinses and the other labeled for the acidic rinses.

5. Containers for draining from the bottom of the pump and from the sample valve.

6. 12 liters of 0.2 micron filtered DI water for determining clean water flux and for rinsing the CUF

\subsection{Equipment}

1. 4000 gram balance

2. $\mathrm{pH}$ paper

3. Hand held camera. To be used to read filtrate flowmeter. 

4. Stopwatch
5. Calculator
6. CUF Ultrafiltration system with $100 \mathrm{~mL}$ plug in place using 0.1 micron Mott-L filter and new pump rotor
7. $1000 \mathrm{~W}$ Chiller
8. 4-L flask (large funnel for waste addition)
9. hot-stir plate
10. big stir bar
11. syringe/tube for sampling 4-L flask
12. 1-L deadend filtration unit and four $150 \mathrm{~mL}$ units
13. 5 -mL pipette ( 4 needed)
14. $10 \mathrm{~mL}$ volumetric flask for density determination (ball flask)

\subsection{Reagents Needed}

1. 1 liters of $1 \mathrm{M} \mathrm{HNO}_{3}+\sim 0.1 \mathrm{M}$ Citric Acid

2. 1 liter of $5 \mathrm{ppm}$ hypochlorite solution $(\mathrm{pH}>7)$

3. $264.6 \mathrm{~mL}$ of $3.5185 \mathrm{M} \mathrm{NaOH}$

4. $96.6 \mathrm{~mL}$ of $1.0 \mathrm{M} \mathrm{NaMnO} 4$

5. $142.8 \mathrm{~mL}$ of $1.0 \mathrm{M} \mathrm{Sr}(\mathrm{NO} 3) 2$

6. $250 \mathrm{~mL}$ of $0.01 \mathrm{M} \mathrm{NaOH}$ (wash solution)

\subsection{Other Supplies}

1. Workplace Copy of Operating Procedure BNFL-TP-29953-020

2. Extra Copies of Data Sheets 1, 2, and 3

3. Laboratory Record Book

4. DAS disk for recording data

\subsection{Test Instructions for CUF Operation and Permanganate Treatment}

The laboratory record book (LRB) shall be used to record other testing information as required by this procedure and all test conditions not stated by this procedure.

Cross-contamination between samples and contamination of samples from outside sources must be minimized at each step. Use new tools and bottles for each sample as much as possible. Those tools that are reused should be washed and rinsed prior to reuse.

Keep all test materials in sealed containers as much as possible to prevent them from drying.

\subsection{Pre-start for Sr/TRU Precipitation and CUF Operation}

5.1.1 Inventory materials, equipment, supplies, and reagents to ensure all required items are available. Assure that all materials have been modified for remote handling.

5.1.2 Do the following and initial and date when each item is completed. 
Review PNNL Operating Procedure BNFL-TP-29953-020.

(D) Re

Review the work instructions in BNFL-TI-29953-052.

5.1.3 Conduct the "0.0 Pre-Start" operations in BNFL-TP-29953-020. Drain the system overflow container.

5.1.4 Perform "1.0 Start-Up" operations in BNFL-TP-29953-020 with 1 liter of filtered DI water with one variation: V4 the filtrate control valve should be closed. Run CUF for 5 minutes at between 4-6 gpm. In-line pressure should be varied from using V1 from 10 to $70 \mathrm{psig}$. Ensure 6:OSAM that there are no leaks in the system. If leaks are detected, shut down system immediately.

5.1.5 Conduct the "10.0 Draining the system" operation in BNFL-TP-29953-020.

5.1.6 Perform "1.0 Start-Up" operations in BNFL-TP-29953-020 with 1.0 liter of filtered, distilled water with one variation: V4 the filtrate control valve should be closed. Run CUF for 5 minutes at between 4-6 gpm. In-line pressure should be varied from using V1 from 10 to 70 psig.

5.1.7 Conduct the "10.0 Draining the system" operation in BNFL-TP-29953-020.

5.1.8 Perform "1.0 Start-Up" operations in BNFL-TP-29953-020 with 1.0 liter of filtered, distilled water

5.1.9 Perform "6.0 Back pulsing” operations in BNFL-TP-29953-020.

5.1.10 Shut off the system and conduct the "10.0 Draining the system" operation in BNFL-TP29953-020.

5.1.11 Perform "1.0 Start-Up" operations in BNFL-TP-29953-020 with 1.0 liter of filtered, distilled water.

5.1.12 Determine clean water flux. Conduct the "3.0 Operation during Ultrafilter Recycle Mode" operations in BNFL-TP-29953-020 using the conditions below. Filtrate flow rate should be monitored and data collected in the operating procedure. Each test should be performed for only 20 minutes and the system should be back pulsed. After each condition, the test engineer should initial and date the table below.

\begin{tabular}{|c|c|c|c|}
\hline Condition & Flowrate (gpm) & $\begin{array}{c}\text { Transmembrane } \\
\text { Pressure (psig) }\end{array}$ & $\begin{array}{c}\text { Initial and date } \\
\text { when complete }\end{array}$ \\
\hline 1 & 4.20 & 10 & \\
\hline 2 & 4.20 & 20 & \\
\hline 3 & 4.20 & 30 & \\
\hline
\end{tabular}


5.1.13 Shut off the system and conduct the "10.0 Draining the system" operation in BNFL-TP29953-020. Drain as much as possible water out of the system. Be sure to drain the pump also.

\subsection{Waste for $\mathrm{Sr} / \mathrm{TRU}$ Removal Treatment}

NOTE: The CUF clean water flux can be completed after Step 5.2 or while the waste is digesting (4 hours of heating)

5.2.1 Check balance calibration and record information below.

\section{M\&TE List:}

Qifor Balance 1:

$$
\text { metter PM } 400
$$

Calib ID $362-06-0(-061$ Calib Exp Date $8 / 2000$

RTt

Calib ID 362-06-01-054 Calib Exp Date_ 8/2000

Location Acellworth

Thermocouple:

Calib ID

$$
\text { TC325-427 }
$$

Location

Digital Thermometer:

Calib ID

$$
\text { Flake }
$$

Location

$$
\text { sin } 2275
$$$$
4 \text { cellsouth }
$$

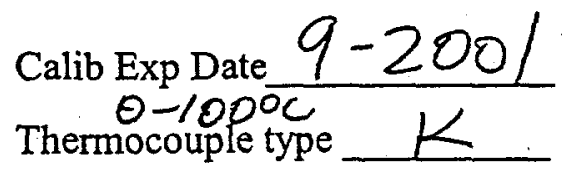

Calib Exp Date 2/2000

5.2.2 Setup the ppt reaction equipment as specified. Record the tare weight of the reaction flask and the stir bar. This may be done outside the hot cell. The precipitation is to be conducted in a 4-L flask. Secondary containment should be used to allow recovery from a possible breach of the 4-L flask. Place stir bar in flask.

Tare weight of reaction flask Hat cell temp 29.6 Tare weight of stir bar $3 8 . 4 \longdiv { 1 4 4 }$

Not all of the AN-107 Diluted Feed is to be used for this test. Approximately $400 \mathrm{~mL}$ should be saved for future Sr/TRU optimization studies. Record the weights of waste/jar(s) below. Swirl/mix the jar(s) of waste thoroughly. Transfer 1.4-L or 1848 grams of waste to the reaction flask. (The supernate density is reported as $1.32 \mathrm{~g} / \mathrm{mL}$.) There should be some solids that may 
have settled. Jar UFE is reported to have some $1 / 4$ inch chucks of solids. If solids are observed, record observation (record observations in the LRB).

$\begin{array}{cccccc}\text { Jar } & \text { Tare, g } & \text { Total, g } & \text { Sludge, g } & \text { volume, } \mathrm{mL} & \text { Identify Jars Used } \\ \text { AN-107 UFA } & 356.65 & 738.27 & 381.62 & 289.10 & \text { ue } \\ \text { AN-107 UFB } & 351.27 & 915.85 & 564.58 & 427.71 & \text { uee } \\ \text { AN-107 UFC } & 357.33 & 919.98 & 562.65 & 426.25 & \text { Save } \\ \text { AN-107 UFD } & 356.68 & 922.60 & 565.92 & 428.73 & \text { use } \\ \text { AN-107 UFE } & 358.14 & 706.10 & 347.96 & 263.61 & \text { use } \\ & & \text { Sum Total } & 2423 \mathrm{~g} & 1835 \mathrm{~mL} & \end{array}$

5.2.3 Record the weights of the jars with lid in the spaces provided below. Pour waste into reaction flask. I large funnel may be necessary to prevent spill any waste since the jars are near full. Also, if large chucks of solids are present, use a piece of plastic screen in the funned to remove the solids. Calculate the amount of material transferred to the reaction flask.

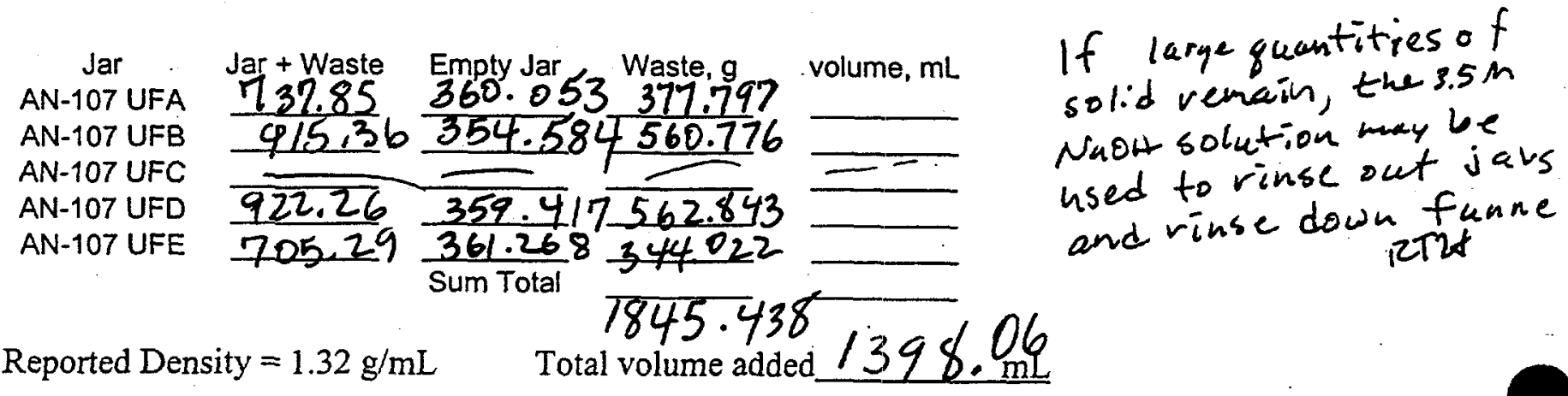

\subsection{Permanganate Treatment of AN-107 Diluted Feed}

5.3.1 Turn on stirrer. Turn on the temperature recording devise. Record temperatures of cell and waste. Flask TC reads $3 / .9$ be fore waste added

5.3.2 While continuously stirring the waste sample, personnel are to slowly (over a 2 minute period) add $264.6 \mathrm{~mL}$ of $3.5185 \mathrm{M} \mathrm{NaOH}$. This is the entire content of the bottle labeled $3.5 \mathrm{M}$ $\mathrm{NaOH}$.

Tare bottle of 3.5M NaOH 648.31
Tare Empty bottle $\frac{351.762 \mathrm{~g}}{296.548 \mathrm{~g}}$
Weight Added $\frac{264.16 \mathrm{~mL}}{2=}$

5.3.3 While continuously stirring the waste sample, personnel are to slowly (over a 10 minute period) add $142.8 \mathrm{~mL}$ of $1.0 \mathrm{M} \mathrm{Sr}\left(\mathrm{NO}_{3}\right)_{2}$. This is the entire content of the bottle labeled $1 \mathrm{M} \mathrm{Sr}$.

Tare bottle of $1 \mathrm{MSr} \frac{397.19}{231.823}$ se pros sheet

Tare Empty bottle $\frac{317.823}{231.82}$
Weight Added 165.3679<smiles>CCCCCCCCCC</smiles> 
Test Instruction 29953-052, Rev. 0

Page 7 of 15

5.3.4 While stirring, slowly (over a 10 minute period) add $96.6 \mathrm{~mL}$ of $1 \mathrm{M} \mathrm{NaMnO}_{4}$. This is the entire content of the bottle labeled $1 \mathrm{M} \mathrm{NaMnO} 4$

Tare bottle of $1 \mathrm{M} \mathrm{NaMnO} 334.88$ see prey the ed

$96.46 m<$ added Tare Empty bottle 225.3229 Weight Added $105.558 \mathrm{~g}$

5.3.5 Allow the waste to thoroughly mix after addition of all of the reagents, ie. stir for 30 minutes. After 30 minutes collect $40 \mathrm{~mL}$ of slurry in a bottle. (Put this aside and turn heater on.) then while heating, use a $10-\mathrm{mL}$ volumetric flask (ball flask) to determine the slurry density for duplicate samples: Pour contents back into the bottle. Filter two, $20 \mathrm{~mL}$ samples in vials DF-01 and DF-02 for chemical analyses. Record the weight and sample number in Data Sheet 3 ; tevet Tare flask $9.177 \mathrm{~g} \cdot 22.147 \mathrm{~g}$ Weight of $10 \mathrm{~mL}$ slurry $2.970 \mathrm{~g}$

PF r.

DE $-02-N O T$ PI

Tare flask $\frac{9.372}{\text { Flask plus } 10 \mathrm{~mL} \text { of slurry } 22.354 \mathrm{~g}}$

Weight of $10 \mathrm{~mL}$ slurry $12.982 \mathrm{~g}$

density of slurry $1.298 \mathrm{~g} / \mathrm{mL}$

5.3.6 Heat the waste mixture at $50 \pm 5^{\circ} \mathrm{C}$ with stirring for 4 hours. Thermoco epee reads $47.5^{\circ} \mathrm{C}$ at $50^{\circ} \mathrm{C}$ Q DWT

5.3.6 Turn off the stirrer and allow the waste to cool to $25 \pm 5^{\circ} \mathrm{C}$. If possible, use a video recorder to document the settling behavior of the waste mixture. Record the volume of settled solids if possible. $\mathrm{mL}$

5.3.7 Collect and filter two $20 \mathrm{~mL}$ samples for transfer to SAL for chemical analyses in vials DF-03 and DF-04. Record the weight and sample number in Data Sheet 3. These samples need to be filtered with 0.45 um syringe filter, and density of the filtrate determined. Then submitted for chemical analyses.

Tare flask

Flask plus $10 \mathrm{~mL}$ of rate

Weight of $10 \mathrm{~mL}$ filtrate

Samples could not
fir tee in Hot cal

easily

Tare flask

Flask plus $10 \mathrm{~mL}$ of filtrate

Weight of $10 \mathrm{~mL}$ filtrate

density of filtrate $\mathrm{g} / \mathrm{mL}$

5.4 Completion of Permanganate Treatment/Precipitation and Startup of CUF Testing (The CUF testing is to occur as soon after precipitation as possible. If for some reason, a delay is required contact the task manager for further instruction, work 375-6919 or home 943-5846.)

7 
5.4.1 Verify that the M\&TE List has been completed (and are working).

$$
\begin{aligned}
& \text { Page } 8 \text { of } 15 \\
& \text { Check value } 6 \text { on } \\
& \text { cuf to make save if }
\end{aligned}
$$

5.4.2 Conduct the "1.0 Start-Up" operations in BNFL-TP-29953-020 treated AN-107. Remove the stir bar. Record the weight of the reaction vessel and ppt. Slurry to Swirl/mix the waste slurry thoroughly before transferring to the CUF slurry reservior. There will be some solids left in the flask but try to minimize these by swirling the flask during the transfer of the final small volumes of wastes. If excessive solids remain, consult with the cognizant scientist/engineer or task leader on recovering these solids. A small amount of supernate could be pipetted from the slurry reservoir to wash these solids out of the flask. Record the method of recovery on this test instruction or in the LRB.

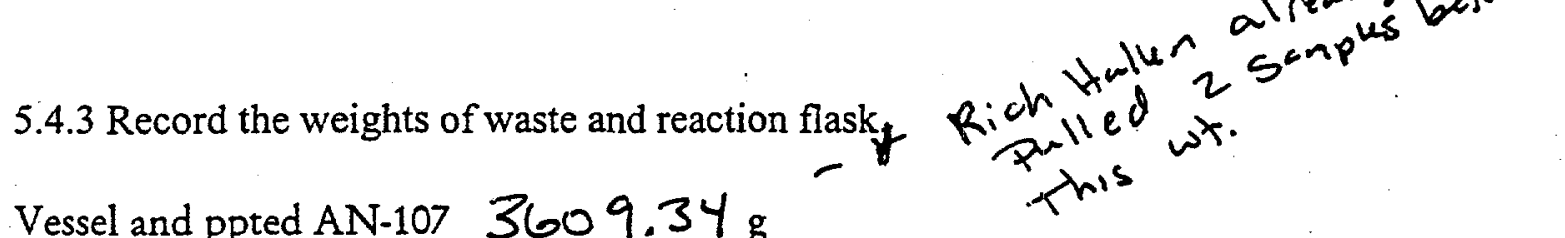
Vessel and ppted AN-107 $3609.34 \mathrm{~g}$ Empty vessel $1320.32 \mathrm{~g}$ Weight transferred to CUF $2289.02 \mathrm{~g}$

5.4.4 Record the level in the slurry reservoir sight glass.

Height Net taken inches

\subsection{CUF Operation: Sr/TRU Precipitate Removal Test with AN-107 Diluted Feed}

* This heeds to be completed a fter 8:00 5.5.1 Obtain slurry samples following "7.0 Slurry Sampling" in BNFL-TP-29953-020. The
samples should be taken before any filtration tests. The first two slurry samples should not be ise $\theta \omega$ saved, but dumped back into the slurry reservoir. Allow the waste to recirculate in the CUF for 5 minutes with no filtration, i.e. the CUF pump in operation, and the throttle valve completely low rateopen (no pressure or filtrate flux). While the waste is recirculating, use the slurry sampling value

$$
\begin{aligned}
& \text { che } \\
& \text { rescuoir }
\end{aligned}
$$
$1-2 \mathrm{~g} \rho \mathrm{m}$ to collect two $40-\mathrm{mL}$ slurry samples and conduct rheological measurements. Transfer the waste Am So back to the slurry reservoir. Collect two 20-mL slurry samples in vials DF-05 and DF-06. Use one for physical property measurements and store the other. Record the weight and sample $\checkmark$ number in Datasheet 3 Log Bbok

5.5.2 Conduct the "3.0 Operation during Ultrafilter Recycle Mode" operations in BNFL-TP29953-020 using the conditions below. Filtrate flow rate should be monitored and data collected as specified in the operating procedure. After each condition, the test engineer should initial and date the table below. If no filtrate flow occurs or the filtrate flow is less than $10 \mathrm{~mL} / \mathrm{min}$, discontinue testing, back pulse, and move to the next condition. - I suggest ve collect a single fil trate sample during each condition
NOTE: Test conditions below are suggested and conditions do not need to be run for the full 1 Rin hour if filtrate flux drops to low values. Collect data at 10 minute intervals on data sheet. 
Test Instruction 29953-052, Rev. 0

Page 9 of 15

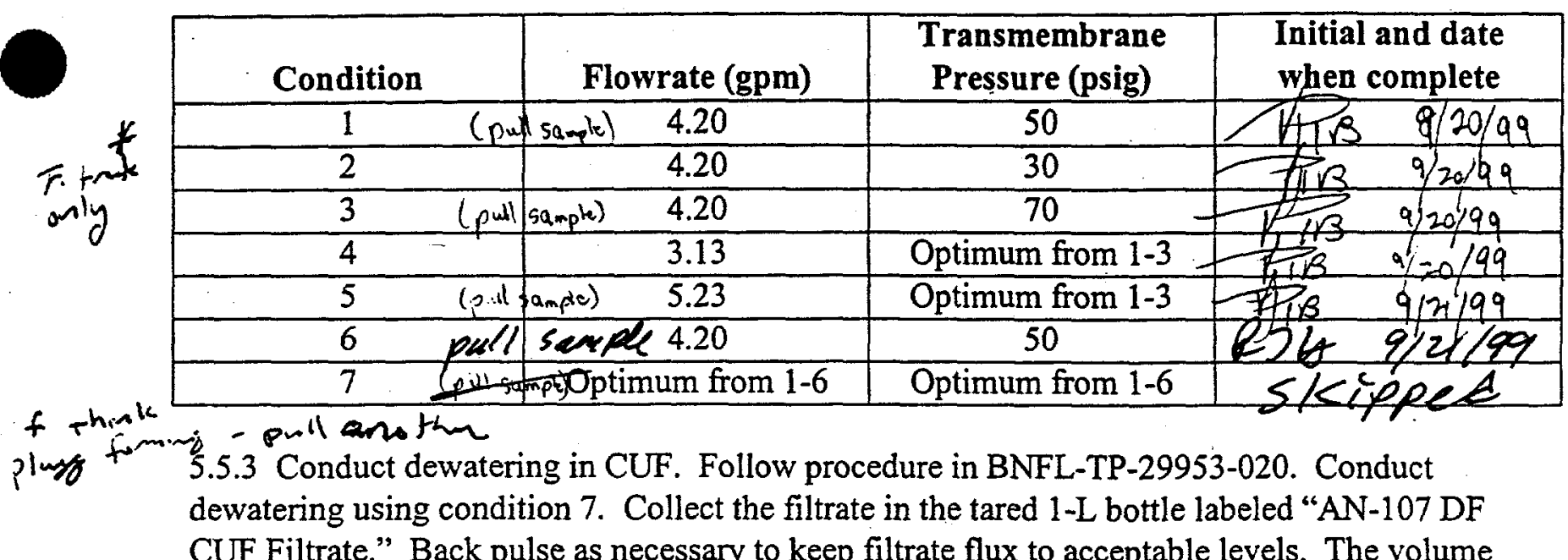
CUF Filtrate." Back pulse as necessary to keep filtrate flux to acceptable levels. The volume will only be reduced to $\sim 800 \mathrm{~mL}$ in the CUF. Additional dewatering will be done using deaden . filtration.

obtain density of CuP Filtrate Tare weight of AN-107 DF fUT Filtrate Bottle 104.50 using $10 \mathrm{~mL}$ Bottle and filtrate 1297.76 Weight of CUF Filtrate 1193.26 volumetric fleas

5.5.4 Obtain two 20-mL filtrate samples following "8.0 Filtrate Sampling" in BNFL-TP-29953020 and using the pre-labeled sample vials after approximately half of the dewatering in the CUF has been completed. Record the weight and sample number in Data Sheet 3. One will be used for chemical and radiochemical analyses and one stored.

5.5.5 Conduct the "11.0 Shutting down" operation in BNFL-TP-29953-020.

5.6 Draining the Dewatered Slurry from the CUF

5.6.1 Tare the 1 liter bottle labeled, "AN-107 DF CUF Dewatered Slurry."

Weight of bottle and lid 105.10 g

5.6.2 Conduct the "10.0 Draining the system" operation in BNFL-TP-29953-020. Collect slurry in 1 liter bottle. Make sure as much materials as possible has been collected. This material will be further dewatered using a deadens filter unit. Weigh bottle after all slurry has been removed from the CUF.

Weight of slurry, bottle and lid Weight of material collected

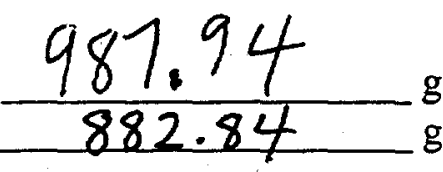

cell temp.

$310 \mathrm{C}$

NOTE: Proceed with rinsing the CUF and conduct 5.7 Dewatering using a Deaden Filtration

$10 \mathrm{~mL}$ Unit when time allows. This can start as soon as the initial rinse of the CUF is completed.

tare flask $9.444 \mathrm{~g}$

flask +filtrate $22.296 \mathrm{~g}$

density 1.285
9 flaskifiltuote $23.308 \mathrm{~g}$

density $1.286 \mathrm{~g}$ 
Test Instruction 29953-052, Rev. 0

Page 11 of 15

\begin{tabular}{|l|l|l|l|}
\hline 3 & 4.20 & 30 & \\
\hline
\end{tabular}

5.6.12 Shut off the system and conduct the " 10.0 Draining the system" operation in BNFL-TP29953-020.

5.7 Dewatering with the Deadens Filter Unit $\rightarrow$ filtrate flux low 50

5.7 Dewatering with the Deaden Filter Unit $\rightarrow$ filtrate flux
reconebike Fottrote and 5 lav ry

Tare of receiver bottle and lid 198.669

Tare of the filter assembly and lid $104.78 \mathrm{~g}$

CUF ratio

5.7.2 Assemble 1-L filtration unit and filter all of slurry in bottle labeled "CUF Dewatered

Slurry." Solids should have settled on setting. Decant most of the supernate from the bottle and filter. The supernate should filter quite fast. When approximately half the material has been filtered, swirl the bottle to suspend the solids. Continue filtering the slurry. If excessive solids remain in the bottom of the bottle, small amounts of filtrate can be used to rinse the solids from the bottle. Record weight of empty bottle. Filter the solids until compacted on filter and no free liquid remains. Disassemble filter unit and weigh

Tare of receiver bottle/lid and filtrate Weight of filtrate Tare of the filter assembly/lid and wet solids Weight of wet solids

5.7.3 The two 1-L bottles of filtrate, CUF filtrate and the deaden filtrate, should be transfer to $\mathrm{SAL}$ and combined to make a composite filtrate. Take duplicate samples of the filtrate composite. Record weight of each filtrate and vial used on Data Sheet 3.

5.8 Sr/TRU Solids Washing

Note: Additional filter units should be available because the filters may plug during washing.

5.8.1 The Sr/TRU solids are to be washed with four equal volumes of stabilized water $(0.01 \mathrm{M} 9 / 24 / 79$ $\mathrm{NaOH})$. Place the filter assembly containing wet solids on a tared receiver flask labeled wash 1. Estimate the volume of compacted solids on the filter. Use times the solids volume of wash solution Tare a $100 \mathrm{~mL}$ graduated cylinder. Add the volume of water. $3.56 \mathrm{Pm}$ Record the weight. With the vacuum turned off, pour the wash water on to the wet solids, record weight of empty graduated cylinder. Allow the solids to revet before turning the vacuum on. Then filter the solids until compacted on the filter and no free liquid remains. Disassemble and weigh receiver flask and filter assembly/solids.

Tare graduated cylinder $+\ldots \mathrm{mL}$ of wash weight of wash Tare of receiver bottle and lid

So we vil head more wash solution and a

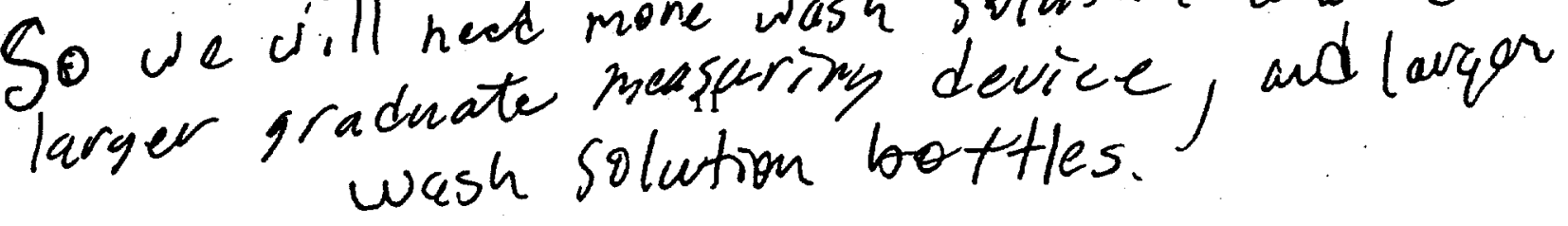


Tare of receiver bottle/lid and wash

Tare of the filter assembly/lid and washed wet solids

Weight of wash 1

\subsubsection{Repeat 5.8.1 for second wash and record weights. (Wash 2)}

Tare graduated cylinder $+\ldots \mathrm{mL}$ of wash weight of wash

Tare of receiver bottle and lid

Tare of receiver bottle/lid and wash

Tare of the filter assembly/lid and washed wet solids

Weight of wash 2

5.8.4 Repeat 5.8.1 for third wash and record weights. (Wash 3)

Tare graduated cylinder $+\ldots \mathrm{mL}$ of wash weight of wash

Tare of receiver bottle and lid

Tare of receiver bottle/lid and wash

Tare of the filter assembly/lid and washed wet solids

Weight of wash 3

\subsubsection{Repeat 5.8.1 for fourth wash and record weights. (Wash 4)}

Tare graduated cylinder $+\ldots \mathrm{mL}$ of wash weight of wash

Tare of receiver bottle and lid

Tare of receiver bottle/lid and wash

Tare of the filter assembly/lid and washed wet solids

Weight of wash 4

5.8.6 Using a pipette, transfer $5 \mathrm{~mL}$ from each of the 4 wash samples to separate vials (this volume does not have to be accurate) and transfer $5 \mathrm{~mL}$ of each wash solution into a single vial for a composite wash sample. Record the weight and sample number in Data Sheet 3 for each individual sample and for the composite sample. The individual wash samples will be analyzed by ICP only. The composite will be used for chemical and radiochemical analyses.

5.8.7 Tare a jar and transfer the wet solids out of the filter assembly. Record the weight of wet solids in the jar and the weight of the filter assembly after the solids have been removed. Dry the solids for at least 24 hours at $105^{\circ} \mathrm{C}$ and record the weight of dry solids. Transfer 1 gram of solids to a $20 \mathrm{~mL}$ vial for chemical analyses. Record vial number and weight on Data Sheet 3.

Tare Jar Jar plus wet solids

Jar and dry solids weight Amount of dry solids Weight of wet solids

5.8.8 Retain all filtrate, wash solution, and solids for future testing.

\subsection{Experimental Clean Up and Sample Disposition.}

Clean up all of the equipment used. 
Do not discard any samples without written instructions from the task manager. Duplicate samples were collected at all sampling points, but only primary samples submitted for analyses. The duplicates are to be retained until review of the analytical data is completed and notification is writing is received to dispose of these samples. The alkaline and acid CUF wash solutions should be disposed of properly.

\subsection{Sample Analysis}

The point of contact for the sample analysis of the filtrate, slurry, wash, and washed solids samples is Mike Urie and Rick Steele. Table 1 listed the analyses to be performed on the samples.

The first two slurry samples need to have slurry density determined. This can be during the tests or before analytical sample prep. Once the density is determined the samples should be filtered with a 0.45 micron disposable syringe filter as soon as possible (can be filtered in Acell when taken if density determined). The digested ppt samples should also be filtered as soon as possible.

Only one sample of each wash and one wash composite will be collected and analyzed until the data can be reviewed. If any inconsistencies are seen, the original wash solutions will be resampled and analyzed again. The wash solutions will not be combined so they may be sampled individually or a composite sample remade.

Table 1. Samples Taken during Testing and Their Required Analyses

\begin{tabular}{|c|c|c|c|c|c|}
\hline Process Step & $\begin{array}{c}\text { Number of } \\
\text { Samples }\end{array}$ & $\begin{array}{c}\text { Sample } \\
\text { Type }\end{array}$ & Step & Analysis & $\begin{array}{c}\text { Analysis } \\
\text { Description }\end{array}$ \\
\hline $\begin{array}{l}\text { Precipitated Feed } \\
\text { (.45 micron filtrate) }\end{array}$ & 2 & $\begin{array}{l}\text { Slurry } \\
\text { Filtrate }\end{array}$ & $\begin{array}{l}\text { After Precipitation } \\
\text { (Before Digestion) }\end{array}$ & $\begin{array}{l}\text { Physical Properties } \\
\text { Chemical Analyses }\end{array}$ & $\begin{array}{c}\text { slurry density } \\
\text { Sr-90, ICP, AEA }\end{array}$ \\
\hline Digested PPT (0.45um) & 2 (store 1) & Filtrate & After Digestion & $\begin{array}{l}\text { Physical Properties } \\
\text { Chemical Analyses }\end{array}$ & $\begin{array}{l}\text { filtrate density } \\
\text { Sr-90, ICP, AEA }\end{array}$ \\
\hline Recycled slurry & $\begin{array}{l}2(40 \mathrm{~mL}) \\
2 \text { (store } 1)\end{array}$ & $\begin{array}{l}\text { Slurry } \\
\text { Slurry }\end{array}$ & $\begin{array}{l}\text { CUF sampled } \\
\text { CUF sampled }\end{array}$ & $\begin{array}{c}\text { Rheology } \\
\text { Physical Properties }\end{array}$ & $\begin{array}{c}\text { viscosity } \\
\text { Table } 4\end{array}$ \\
\hline Middle De-water Step & 2 (store 1 ) & Filtrate & During Condition 2.8 & Chemical Analyses & Table 2 \\
\hline Filtrate Composite & 1 & Filtrate & CUF + deadend & Chemical Analyses & Table 2 \\
\hline Four Washes & 1 each & Filtrate & After Each Wash & Chemical Analyses & ICP Only (Na) \\
\hline Wash Composite & 1 & Filtrate & After All Washes & Chemical Analyses & Table 2 \\
\hline Washed Solids & 2 & Dry Solids & Final Solids & Chemical Analyses & Table 2 \\
\hline
\end{tabular}


Table 2. Analytical Requirements for Washed Solids, Filtrate, and Wash Solutions

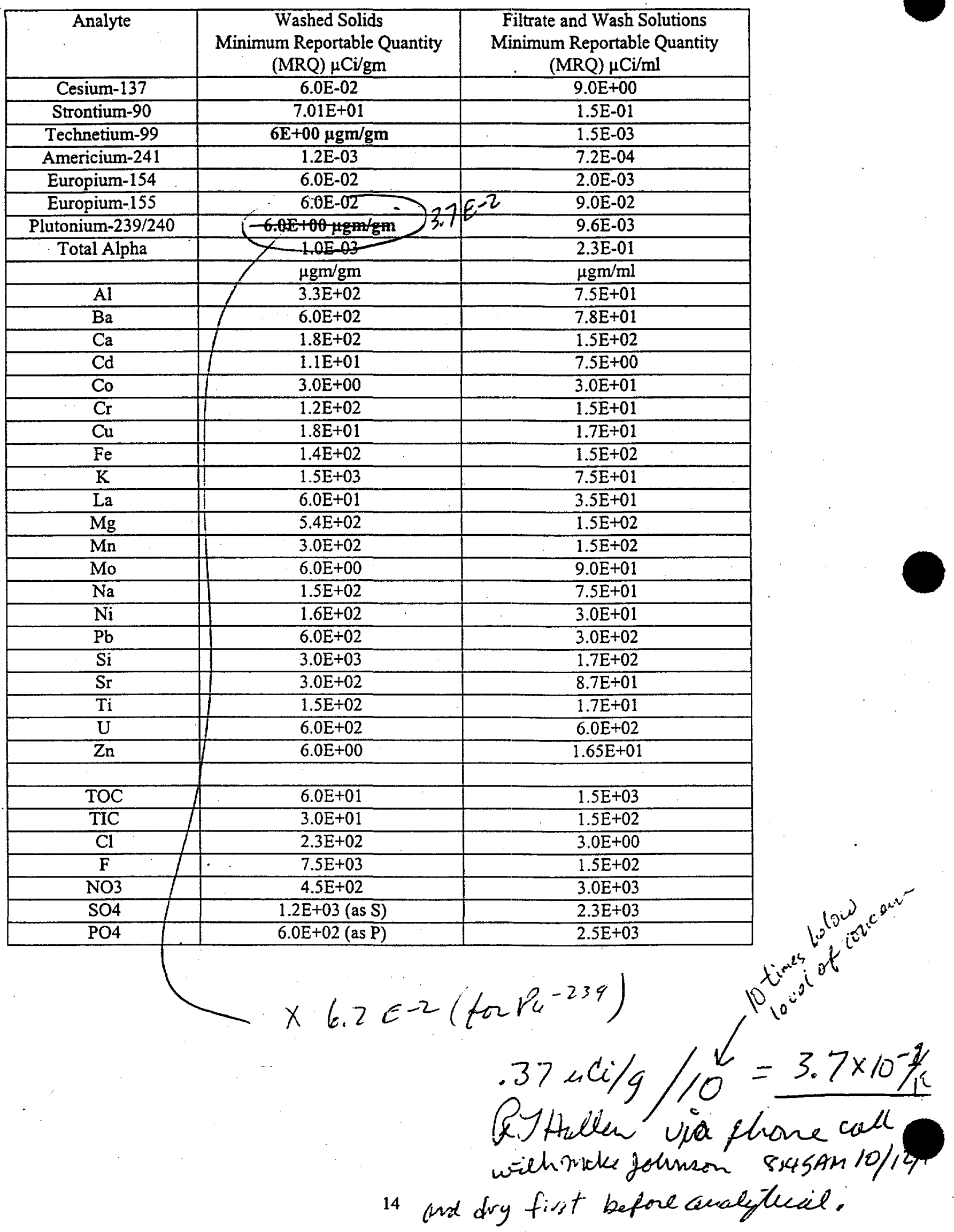


Table 3. Description of Analyses

\begin{tabular}{|l|l|l|}
\hline \multicolumn{1}{|c|}{ Constituent } & \multicolumn{1}{|c|}{ Analysis Method } & \multicolumn{1}{c|}{ PNNL Procedure No. } \\
\hline Cs-137(Eu-154, Eu-155) & GEA & PNL-ALO-450 \\
\hline Strontium-90 (Yttrium-90) & Separations and Beta Counting & PNL-ALO-476/431 \\
\hline Tc-99 & ICP/MS & PNL-ALO-281 \\
\hline $\begin{array}{l}\text { Am-241 (Cm-244, Pu-238, Pu- } \\
239 / 240)\end{array}$ & Separation and AEA & PNL-ALO-417/496 \\
\hline Metal Ions (see Table 2 list) & ICP-AES & PNL-ALO-211/280 \\
\hline TOC/TIC & Hot Persulfate & PNL-ALO-381 \\
\hline Anions & IC & PNL-ALO-212 \\
\hline Hydroxide & $\begin{array}{l}\text { Autotitration - EPA SW-846 } \\
\text { Modified Method, 310(3) }\end{array}$ & PNL-ALO-228 \\
\hline
\end{tabular}

Table 4. Physical Properties Measurements

\begin{tabular}{|l|}
\hline \multicolumn{1}{|c|}{ Analysis } \\
\hline Bulk Density \\
\hline Supernatant Density \\
\hline Particle Size Distribution \\
\hline Viscosity \\
\hline Suspended Solids Loading: \\
\hline - Weight \% Insoluble Solids in Slurry \\
\hline
\end{tabular}




\section{Test Instruction Supplement: Additional CUF Testing at 25\% Dilution of Sr/TRU Precipitated Slurry}

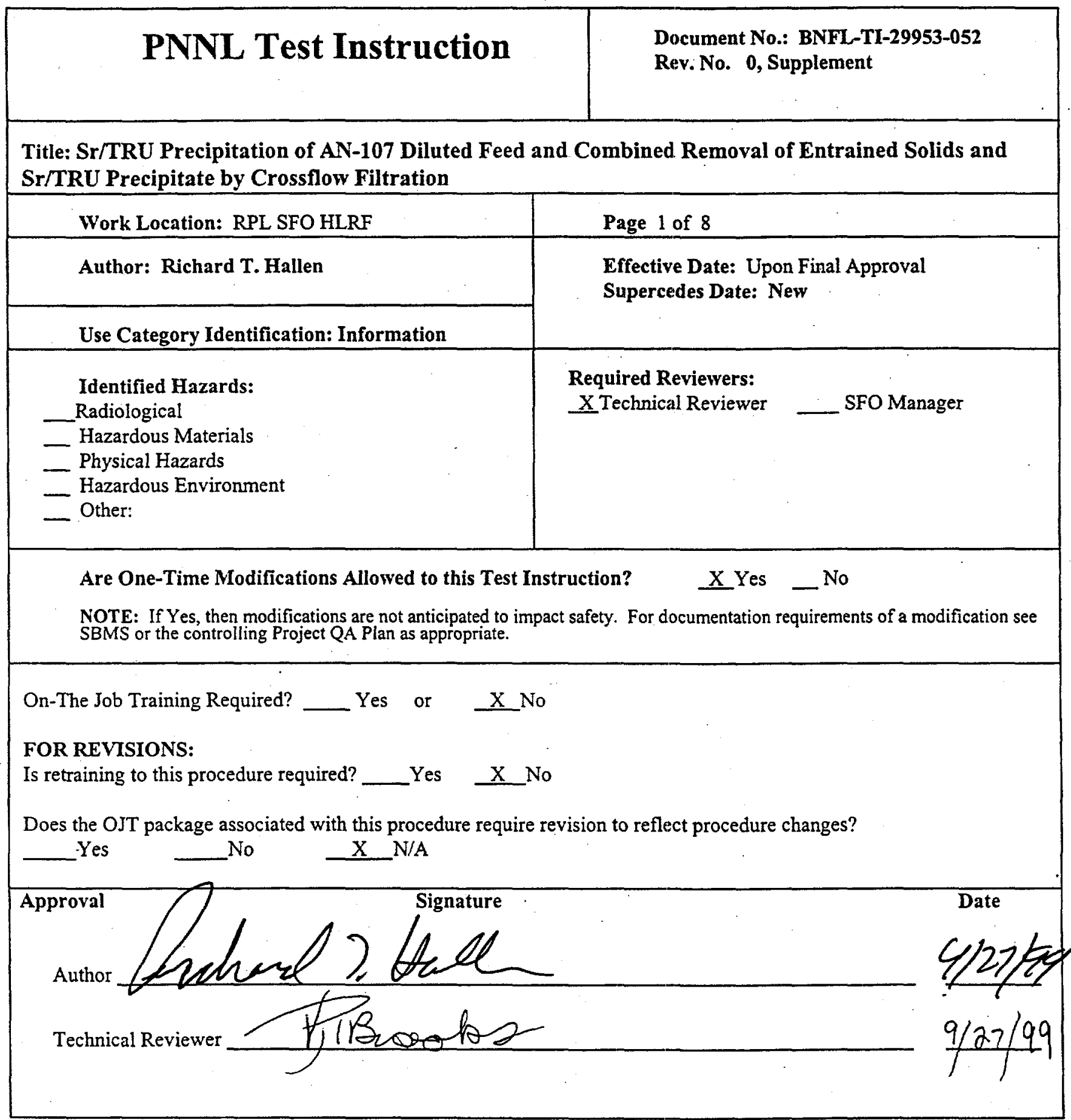




\subsection{Materials, Equipment, Supplies and Reagents Needed}

\subsection{Materials Required}

1. Four 1 liter polyethylene bottles. They should be labeled as follows: "AN-107 DF CUF Filtrate," "AN-107 DF Filtrate (filter unit receiver)," "CUF Dewatered Slurry," and "CUF AN-107 DF First Rinse."

2. Four $100 \mathrm{~mL}$ bottles for each wash solution labeled wash 1 through 4 . These can be filter unit bottles if small ones are available.

3. Two 10 liter containers, one labeled for the alkaline rinses and the other labeled for the acidic rinses.

4. Containers for draining from the bottom of the pump and from the sample valve.

5. 12 liters of 0.2 micron filtered DI water for determining clean water flux and for rinsing the CUF

\subsection{Equipment}

1. 1-L deadend filtration unit and four $150 \mathrm{~mL}$ units

2. 5-mL pipette ( 4 needed)

3. Four, $10 \mathrm{~mL}$ volumetric flask for density determination (ball flask)

\subsection{Reagents Needed}

1. 1 liters of $1 \mathrm{M} \mathrm{HNO}_{3}+\sim 0.1 \mathrm{M}$ Citric Acid

2. 1 liter of $5 \mathrm{ppm}$ hypochlorite solution $(\mathrm{pH}>7)$

3. $250 \mathrm{~mL}$ of $0.01 \mathrm{M} \mathrm{NaOH}$ (wash solution)

\subsection{Other Supplies}

1. Workplace Copy of Operating Procedure BNFL-TP-29953-020

2. Extra Copies of Data Sheets 1,2, and 3

3. Laboratory Record Book

4. DAS disk for recording data

\subsection{Pre-start for Sr/TRU Precipitation and CUF Operation}

5.1.1 Inventory materials, equipment, supplies, and reagents to ensure all required items are available. Assure that all materials have been modified for remote handling.

5.1.2 Do the following and initial and date when each item is completed.

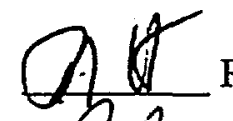
Review PNNL Operating Procedure BNFL-TP-29953-020.

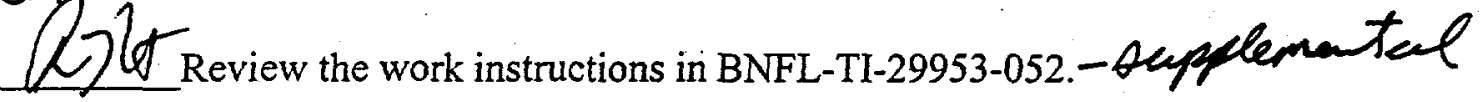

5.1.3 Conduct the "0.0 Pre-Start" operations in BNFL-TP-29953-020. Drain the system overflow container.

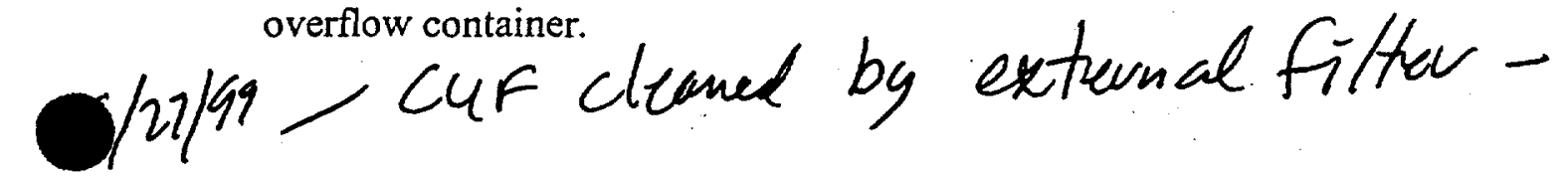


5.1.4 Perform "1.0 Start-Up" operations in BNFL-TP-29953-020 with 1 liter of filtered DI water with one variation: V4 the filtrate control valve should be closed. Run CUF for 5 minutes at between 4-6 gpm. In-line pressure should be varied from using V1 from 10 to $70 \mathrm{psig}$. Ensure that there are no leaks in the system. If leaks are detected, shut down system immediately.

\subsubsection{Conduct the "10.0 Draining the system" operation in BNFL-TP-29953-020.}

5.1.6 Perform "1.0 Start-Up". operations in BNFL-TP-29953-020 with 1.0 liter of filtered, distilled water with one variation: V4 the filtrate control valve should be closed. Run CUF for 5 minutes at between 4-6 gpm. In-line pressure should be varied from using V1 from 10 to 70 psig.

5.1.7 Conduct the "10.0 Draining the system" operation in BNFL-TP-29953-020.

5.1.8 Perform "1.0 Start-Up" operations in BNFL-TP-29953-020 with 1.0 liter of filtered, distilled water

5.1.9 Perform "6.0 Back pulsing" operations in BNFL-TP-29953-020.

5.1.10 Shut off the system and conduct the "10.0 Draining the system" operation in BNFL-TP29953-020.

5.1.11 Perform "1.0 Start-Up" operations in BNFL-TP-29953-020 with 1.0 liter of filtered, distilled water.

5.1.12 Determine clean water flux. Conduct the "3.0 Operation during Ultrafilter Recycle Mode" operations in BNFL-TP-29953-020 using the conditions below. Filtrate flow rate should be monitored and data collected in the operating procedure. Each test should be performed for only 20 minutes and the system should be back pulsed. After each condition, the test engineer should initial and date the table below.

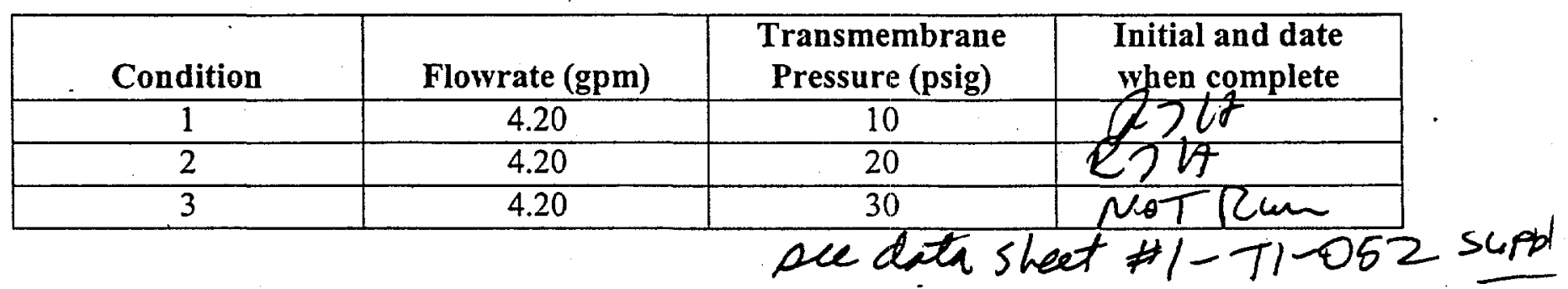

5.1.13 Shut off the system and conduct the "10.0 Draining the system" operation in BNFL-TP29953-020. Drain as much as possible water out of the system. Be sure to drain the pump also. 


\section{M\&TE List:}

Balance 1:

Calib ID

Location

Balance 2:

Calib ID

Location

Thermocouple:

Calib ID

Location

Digital Thermometer:

Calib ID

Location
Calib Exp Date

Calib Exp Date
Calib Exp Date

Thermocouple type

Calib Exp Date

\subsubsection{Verify that the M\&TE List has been completed (and are working).}

5.4.2 Conduct the "1.0 Start-Up" operations in BNFL-TP-29953-020. Transfer waste from bottles marked CUF Slurry and CUF Filtrate to slurry reservoir. Transfer the CUF Slurry first. There will likely be some solids left in the CUF Slurry bottle, try to minimize these by swirling the bottle during the transfer of the final small volumes of wastes. If significant solids remain, use the CUF Filtrate to wash the solids from the bottle. Record the weights of the bottles before and after transfer.

5.4.3 Record the weights of waste and bottles.

CUTF Slurry and bottle $944.23 \mathrm{~g}$

Empty bottle $106.65 \mathrm{~g}$

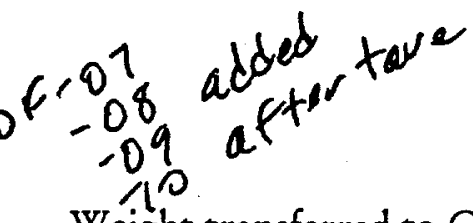

Weight transferred to CUF $g$

CUF Filtrate and bottle $1296.53 \mathrm{~g}$

Empty bottle $106.64 \quad g$

5.4.4 Record the level in the slurry reservoir sight glass.

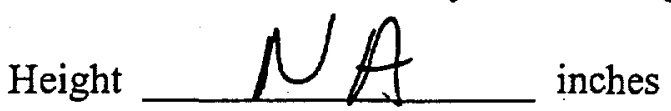




\subsection{CUF Operation: Sr/TRU Precipitate Removal Test with AN-107 Diluted Feed}

5.5.2 Conduct the "3.0 Operation during Ultrafilter Recycle Mode" operations in BNFL-TP29953-020 using the conditions of 50 psid and $4.2 \mathrm{gpm}$. Filtrate flow rate should be monitored and data collected on a data sheet every 10 minutes over a period of 1 hour. Then back pulse twice and repeat the conditions and record data for 20 minutes. Then back pulse twice, open valve 1 to drop the pressure and turn off the pump.

5.5.2 Dilute the waste in the CUF by $25 \%$. Use the $1^{\text {st }}$ CUF Rinse solution. Shake well before transferring to the slurry reservoir. Approximately 450 grams should be used to dilute the slurry. Record weights below

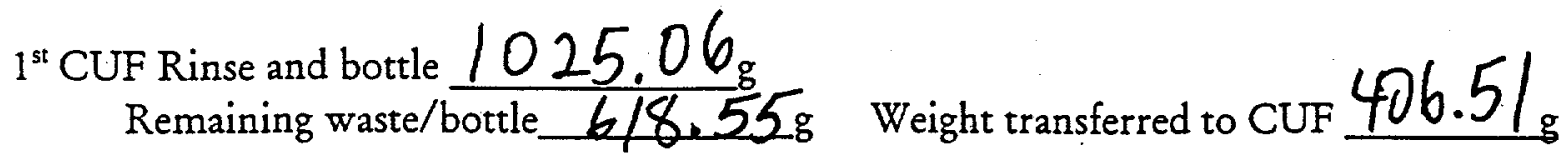

Record the level in the slurry reservoir sight glass.

Height inches

5.5.1 Obtain slurry samples following "7.0 Slurry Sampling" in BNFL-TP-29953-020. The samples should be taken before any filtration tests. The first two slurry samples should not be saved, but dumped back into the slurry reservoir. Allow the waste to recirculate in the CUF for 5 minutes with no filtration, i.e. the CUF pump in operation, and the throttle valve completely open (no pressure or filtrate flux). While the waste is recirculating collect enough sample in a bottle to determine the slurry density.

Tare flask

Flask plus $10 \mathrm{~mA}$ of filtrate

Weight of $10 \mathrm{~mL}$ trate

Tare flask

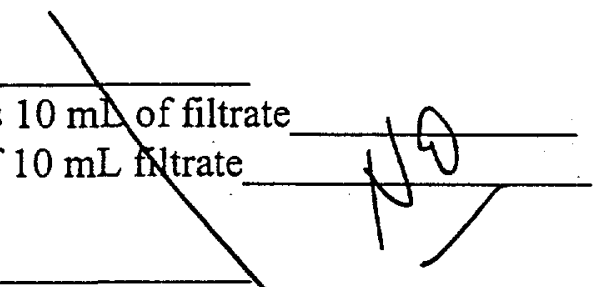

density of filtrate $\mathrm{g} / \mathrm{mL}$

Flask plus $10 \mathrm{~mL}$ of filtratg

Weight of $10 \mathrm{~mL}$ filtrate density of filtrate pev Mike

Then use the-stury sampling value to collect two 20 -mL slurry samples in vials DF-12 and DF13 fo chemical analyses and two samples in DF-14 and DF-15 for physical property measurements. Use one for physical property measurements and store the other. Record the weight and sample number in Data Sheet 3.

5.5.2 Conduct the "3.0 Operation during Ultrafilter Recycle Mode" operations in BNFL-TP29953-020 using the conditions below. Filtrate flow rate should be monitored and data collected as specified in the operating procedure. After each condition, the test engineer should initial and date the table below. If no filtrate flow occurs or the filtrate flow is less than $10 \mathrm{~mL} / \mathrm{min}$, discontinue testing, back pulse, and move to the next condition. 
NOTE: Test conditions below are suggested and conditions do not need to be run for the full 1 hour if filtrate flux drops to low values. Conditions 4 and 5 should only be run if time allows. Skip and move on to condition 7 . Condition 7 must be ran. Collect data at 10 minute intervals on data sheet. could outy reach $4.159 \mathrm{~m}$

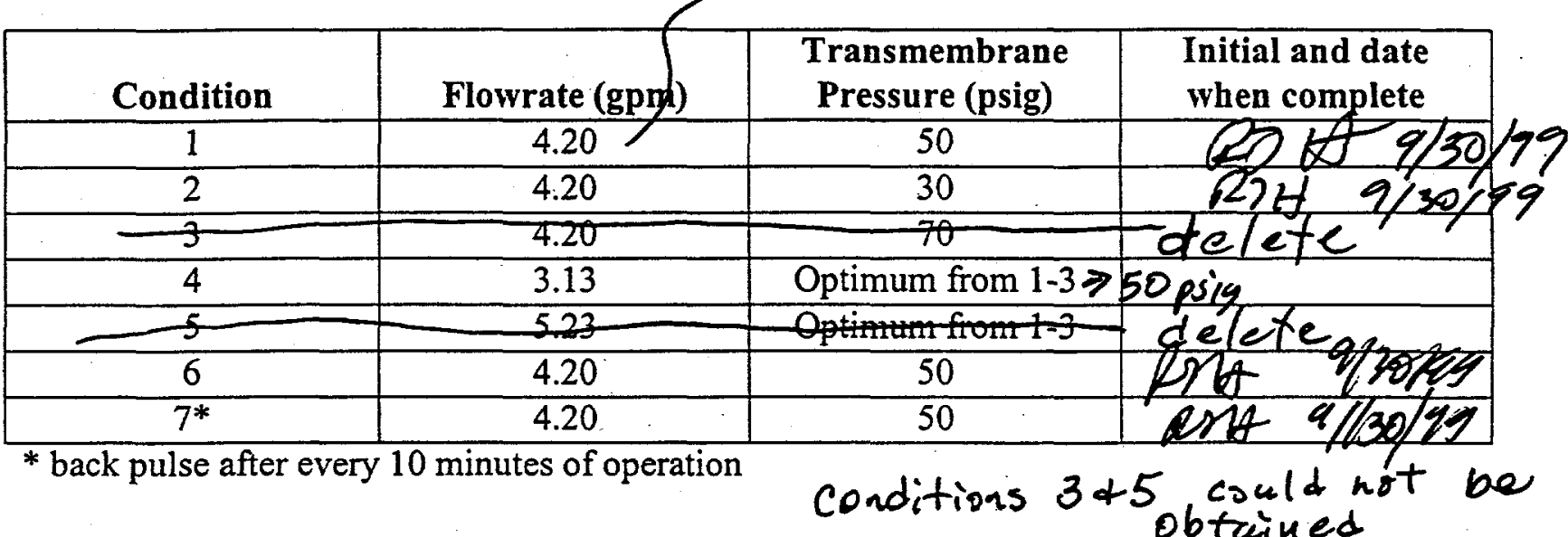

5.5.3 Conduct dewatering in CUF. Follow procedure in BNFL-TP-29953-020. Conduct dewatering using condition 7. Collect the filtrate in the tared 1-L bottle labeled "AN-107 DF CUF Filtrate." Back pulse as necessary to keep filtrate flux to acceptable levels. The volume will only be reduced to $\sim 800 \mathrm{~mL}$ in the CUF. Additional dewatering will be done using deadend filtration.

Tare weight of AN-107 DF CUF Filtrate Bottle 106.64

Bottle and filtrate

Weight of CUF Filtrate

Determine the density of the CUF filtrate.

Tare flask

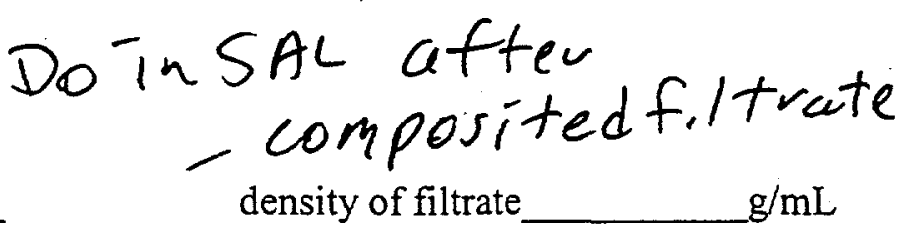

Tare flask

Flask plus $10 \mathrm{~mL}$ of filtrate

Weight of $10 \mathrm{~mL}$ filtrate

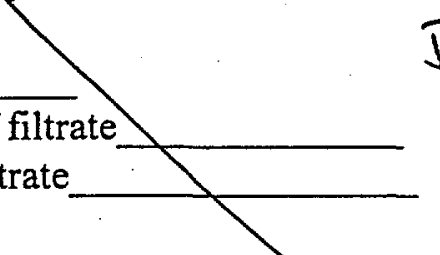

sity of filtrate $\mathrm{g} / \mathrm{mL}$

Weight of $10 \mathrm{~mL}$ filtrate

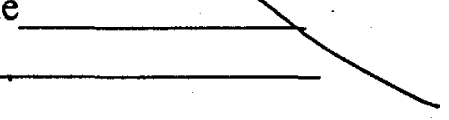

density of filtrate $\mathrm{g} / \mathrm{mL}$

5.5.4 Obtain two 20-mL filtrate samples following "8.0 Filtrate Sampling" in BNFL-TP-29953020 and using the pre-labeled sample vials after approximately half of the dewatering in the CUF has been completed. Record the weight and sample number in Data Sheet 3. One will be used for chemical and radiochemical analyses and one stored.

- Sample composited 5.5.5 Conduct the "11.0 Shutting down" operation in BNFL-TP-29953-020. filtrate in SAL 
5.6.1 Tare the 1 liter bottle labeled, "AN-107 DF CUF Dewatered Slurry."

Weight of bottle and lid g

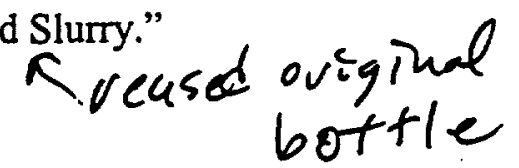

5.6.2 Conduct the "10.0 Draining the system" operation in BNFL-TP-29953-020. Collect slurry in 1 liter bottle. Make sure as much materials as possible has been collected. This material will be further dewatered using a deadend filter unit. Weigh bottle after all slurry has been removed from the CUF.

Weight of slurry, bottle and lid Weight of material collected g g

NOTE: Proceed with rinsing the CUF and conduct 5.7 Dewatering using a Deadend Filtration Unit when time allows. This can start as soon as the initial rinse of the CUF is completed.

5.6.3 Conduct the "9.0 Rinsing the system" operation in BNFL-TP-29953-020. The first rinse should be done with 1 liter of distilled water. This liquid should be collected and saved in the container labeled "AN-107 DF CUF First Rinse." The second rinse should be done with 2 liters of filtered, distilled water, and the final rinse with 1 liter filtered, distilled water. The second and third rinses should be collected separately from the first in the alkaline rinse storage container.

NOTE: Once the CUF has been rinsed you may proceed to Section 5.7 and come back and complete the CUF cleanup later.

5.6.4 Perform "1.0 Start-Up" operations in BNFL-TP-29953-020 with 1.0 liter of filtered, distilled water.

\subsubsection{Perform "6.0 Back pulsing" operations in BNFL-TP-29953-020.}

5.6.6 Determine the clean water flux at 20 psid transmembrane pressure and flow rate of 4.2 GPM following "3.0 Operation during Ultrafilter Recycle Mode" operations in BNFL-TP-29953020. Filtrate flow rate should be monitored and data collected in the operating procedure. Data should be collected for at least 20 minutes and the system should be back pulsed.

5.6.7 Shut off the system and conduct the "10.0 Draining the system" operation in BNFL-TP29953-020.

5.6.8 Conduct the acid wash of the CUF unit with $1 \mathrm{M}$ HNO3/0.1-0.2M Citric Acid as described in the CUF operating procedure if needed to regain clean water flux. The acidic solution should be allowed to sit in the CUF overnight. When drained, the acidic solution should be placed in a separate container.

5.6.9 The CUF should be drained according to "10.0 Draining the system" operation in BNFLTP-29953-020 and rinsed at least 3 times with filtered, distilled water to bring the $\mathrm{pH}$ back up to neutral. The acidic solutions should be placed in a separate container from the alkaline ones. 
5.6.10 Perform "1.0 Start-Up" operations in BNFL-TP-29953-020 with 1.0 liter of filtered, distilled water.

5.6.11 Conduct the "3.0 Operation during Ultrafilter Recycle Mode" operations in BNFL-TP29953-020 using the conditions below. Filtrate flow rate should be monitored and data collected in the operating procedure. Each test should be performed for only 20 minutes and the system should be back pulsed. After each condition, the test engineer should initial and date the table below.

\begin{tabular}{|c|c|c|c|}
\hline Condition & Flowrate (gpm) & $\begin{array}{c}\text { Transmembrane } \\
\text { Pressure (psig) }\end{array}$ & $\begin{array}{c}\text { Initial and date } \\
\text { when complete }\end{array}$ \\
\hline 1 & 4.20 & 10 & \\
\hline 2 & 4.20 & 20 & \\
\hline 3 & 4.20 & 30 & \\
\hline
\end{tabular}

5.6.12 Shut off the system and conduct the "10.0 Draining the system" operation in BNFL-TP29953-020.

\subsection{Dewatering with the Deadend Filter Unit}

5.7.1 Tare the 1-L receiver bottle/lid and filter assembly/lid of the filtration unit.

Tare of receiver bottle tid $131.05 \mathrm{~g}$

Tare of the filter assembly and lid $104.30 \mathrm{~g}$

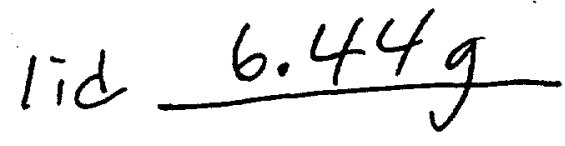

5.7.2 Assemble 1-L filtration unit and filter all of slurry in bottle labeled "CUF Dewatered Slurry." Solids should have settled on setting. Decant most of the supernate from the bottle and filter. The supernate should filter quite fast. When approximately half the material has been filtered, swirl the bottle to suspend the solids. Continue filtering the slurry. If excessive solids remain in the bottom of the bottle, small amounts of filtrate can be used to rinse the solids from the bottle. Record weight of empty bottle. Filter the solids until compacted on filter and no free liquid remains. Disassemble filter unit and weigh

Tare of receiver bottle/lid and filtrate

Tare of the filter assembly/lid and wet solids
Weight of filtrate Weight of wet solids

5.7.3 The two 1-L bottles of filtrate, CUF filtrate and the deadend filtrate, should be transfer to $\mathrm{SAL}$ and combined to make a composite filtrate. Take duplicate samples of the filtrate composite. Record weight of each filtrate and vial used on Data Sheet 3. 
1

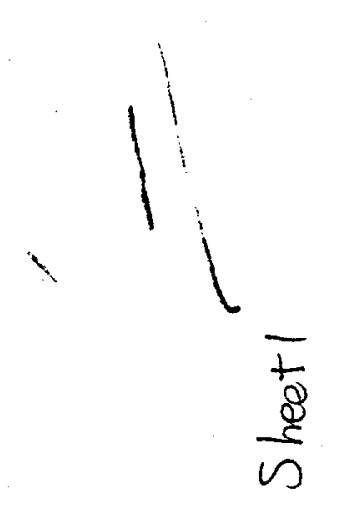

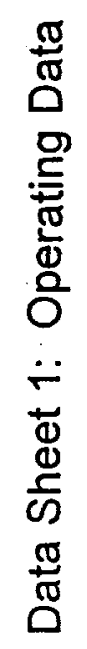

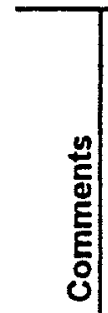

善
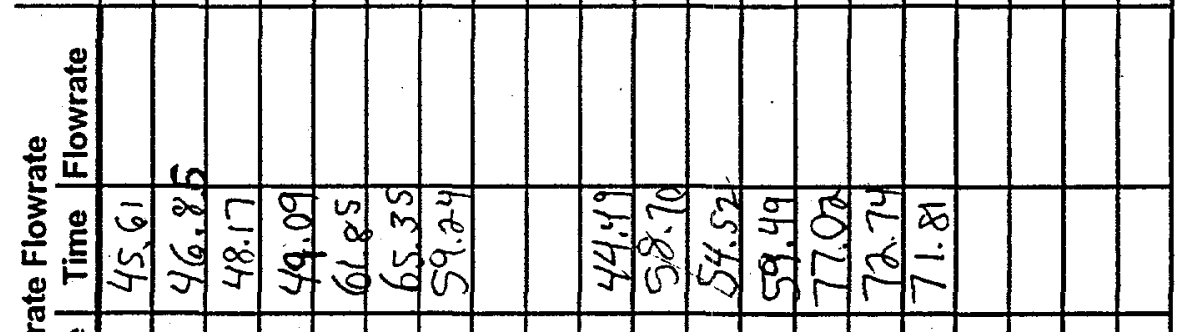

政

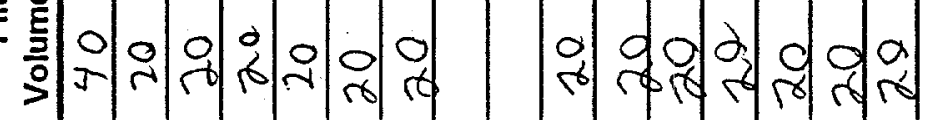

.0

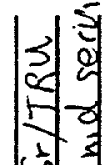

为妻

17

岁

$\sigma$ - 5 ath 0 o

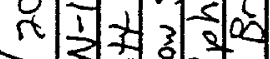

$\sigma=0$

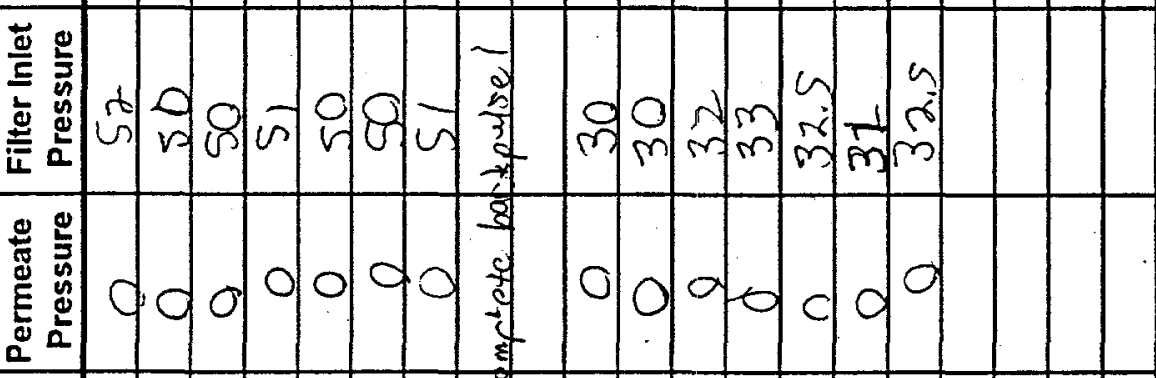

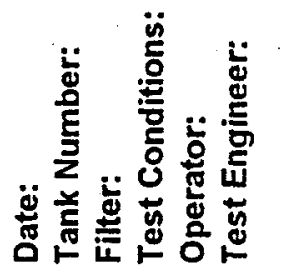

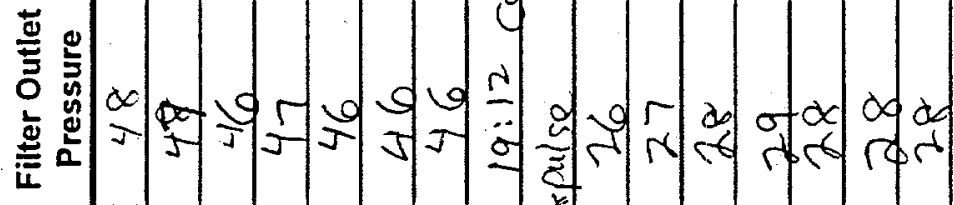
क एँ क

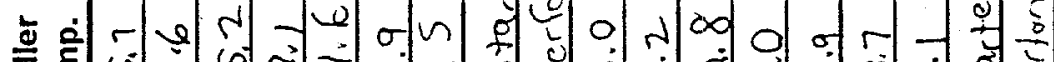

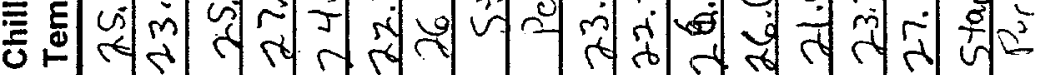
हैगे लm

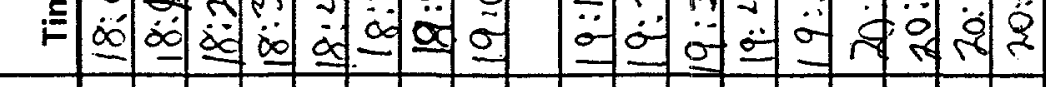

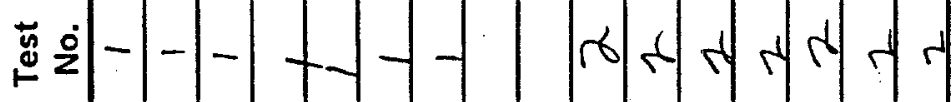


Data Sheet 1: Operating Data

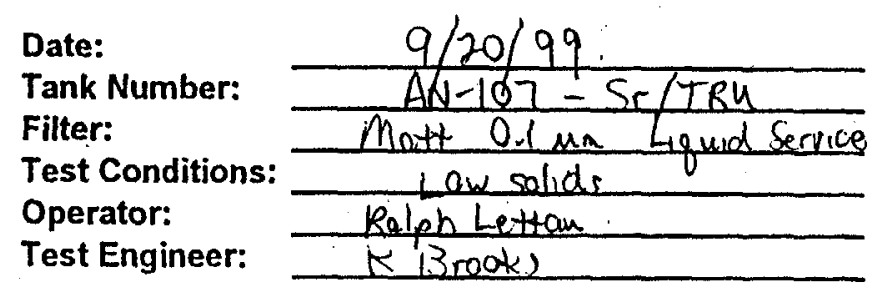

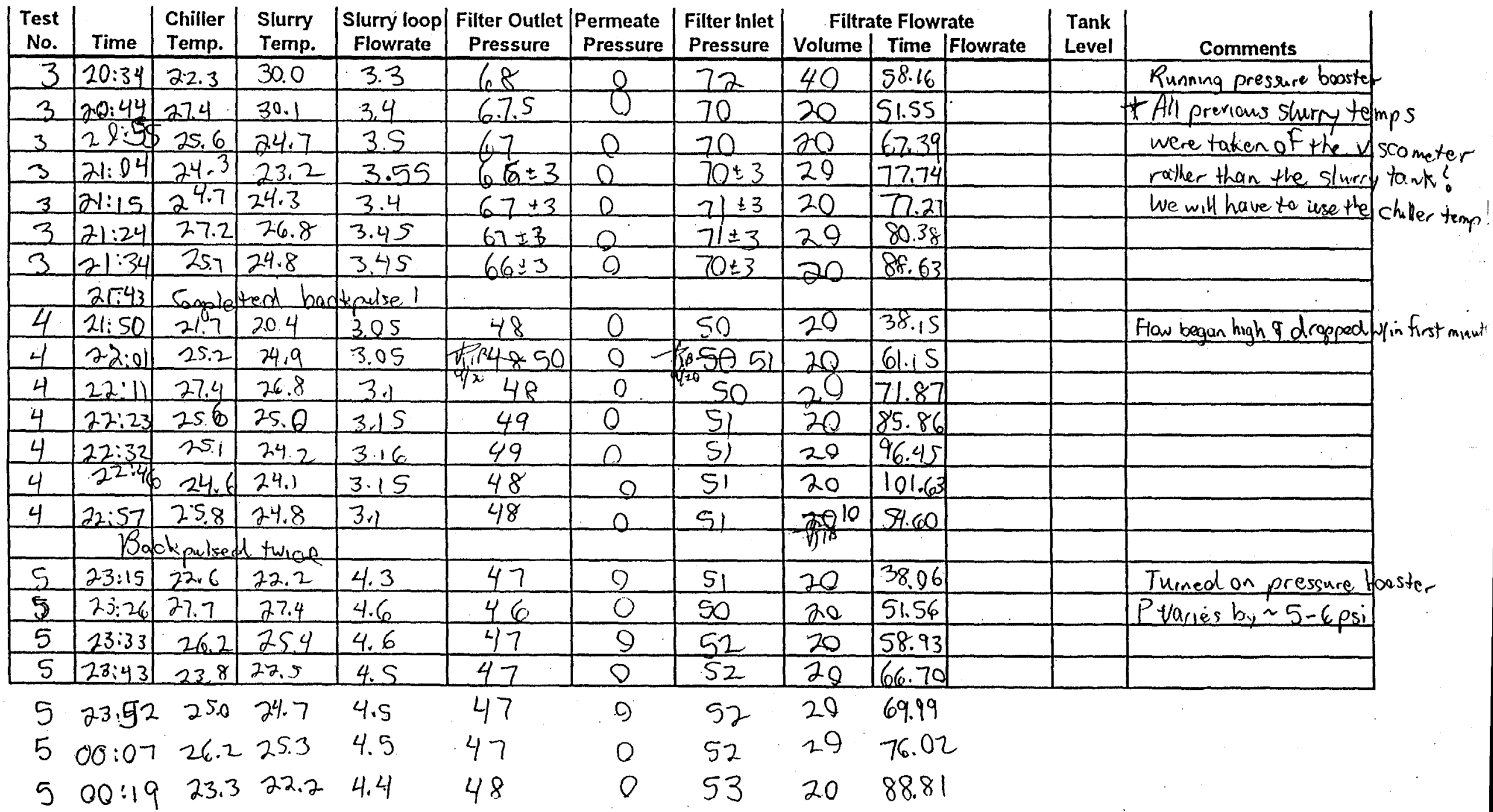

- Back palsed twize - 


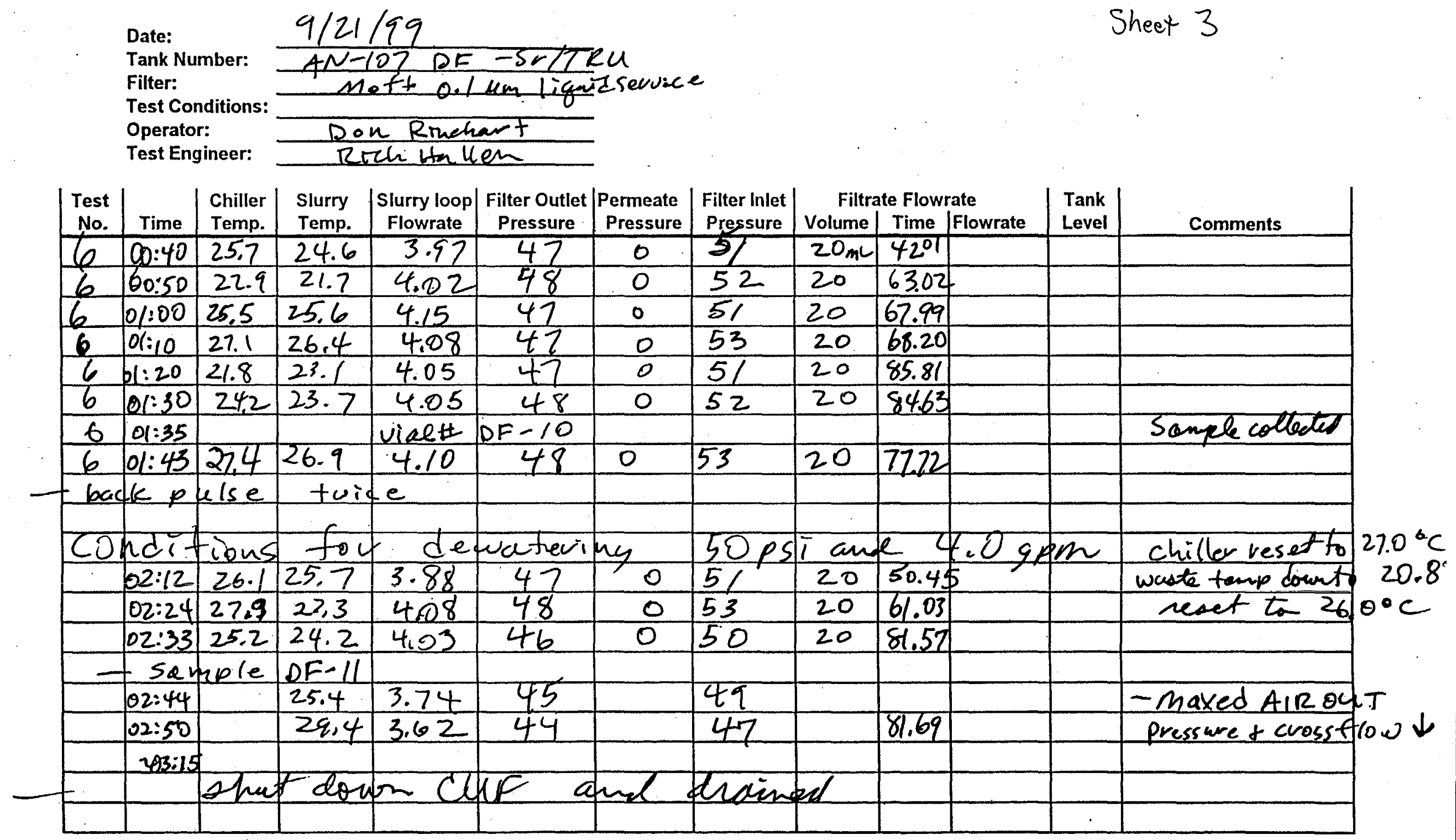




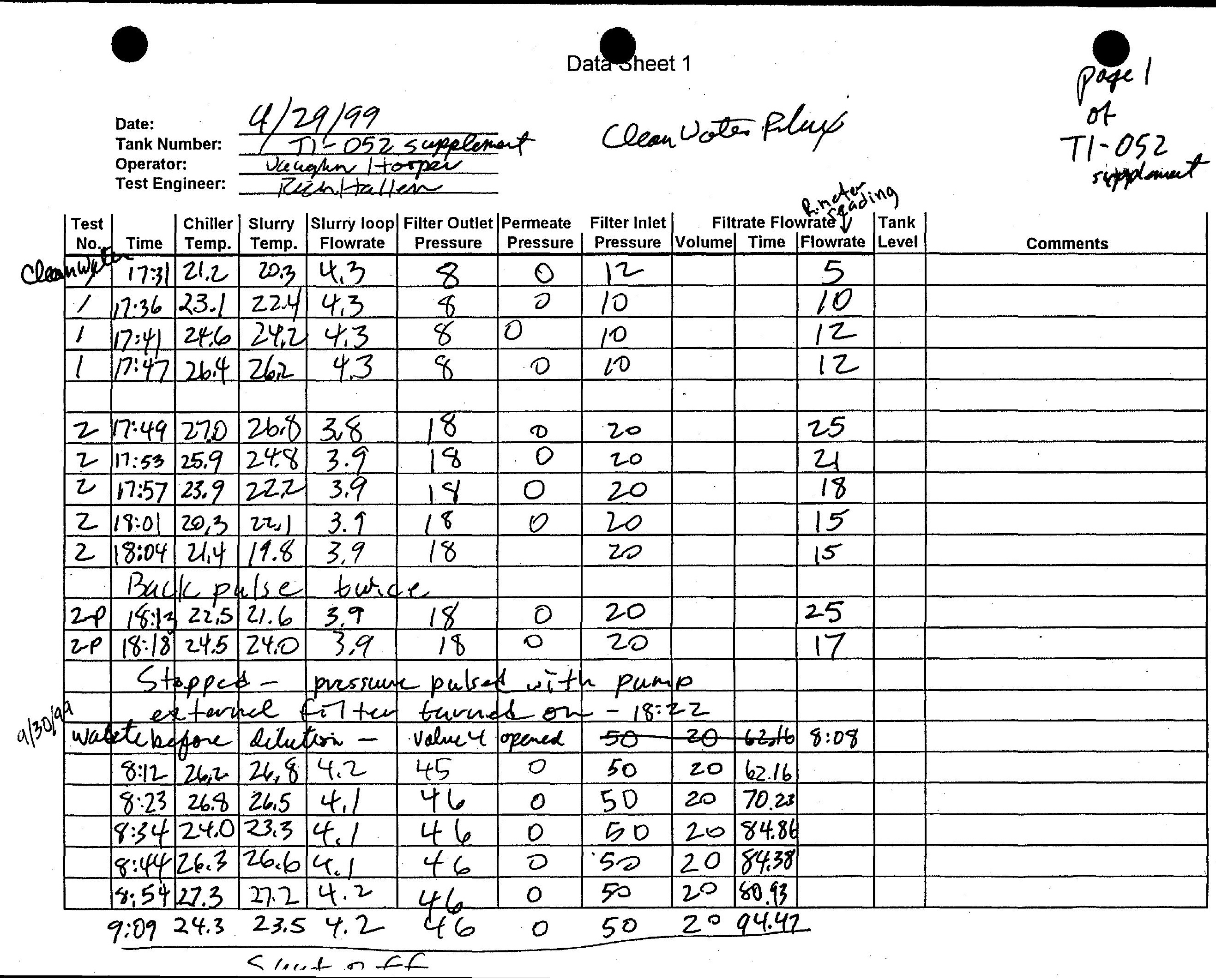




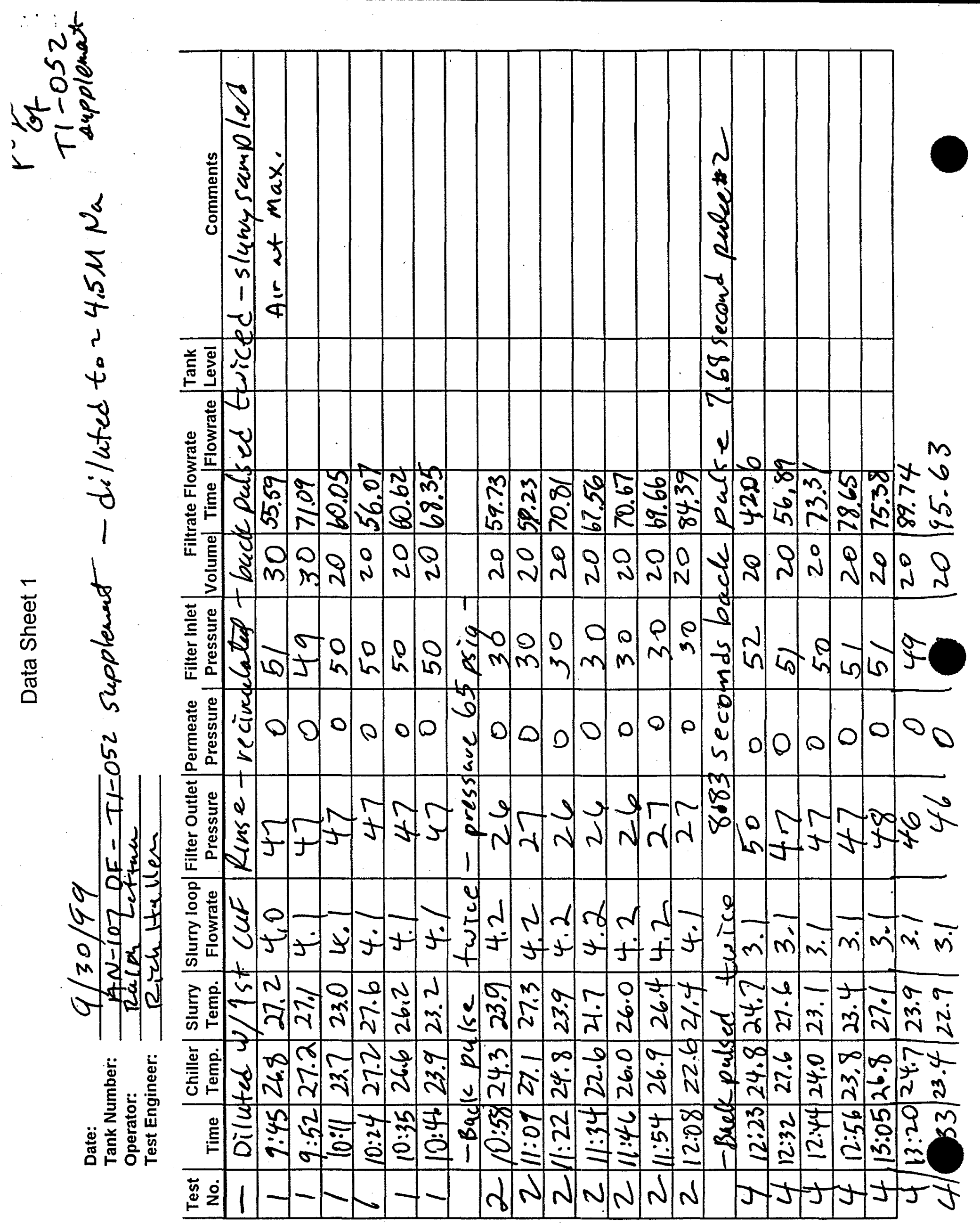




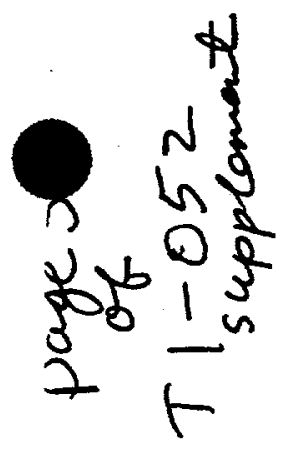

हू

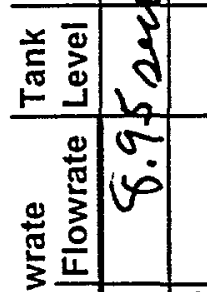

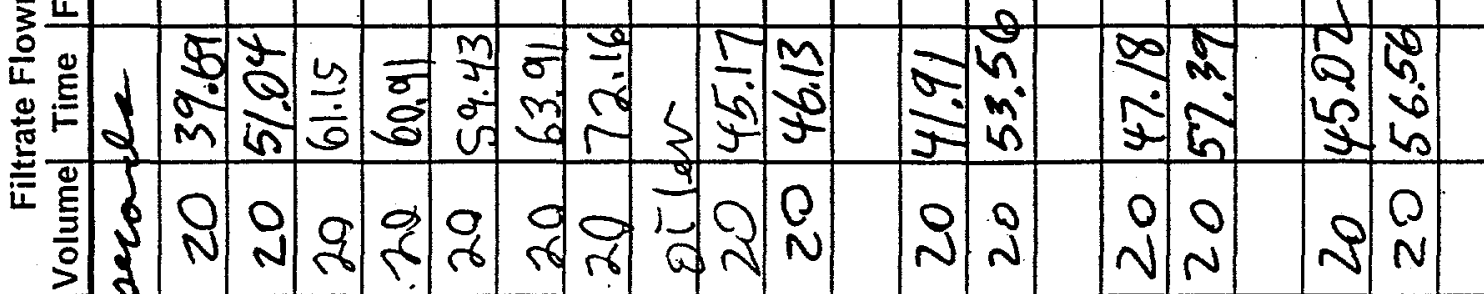

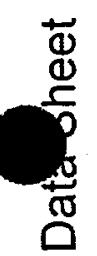

है

흘 일

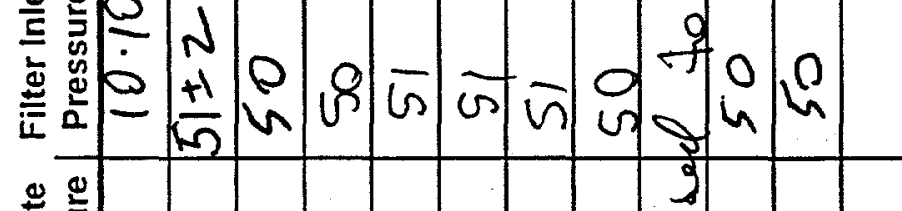

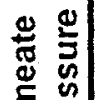

है

$\infty$

$\circ$

00000 .

iी

s。

Non e

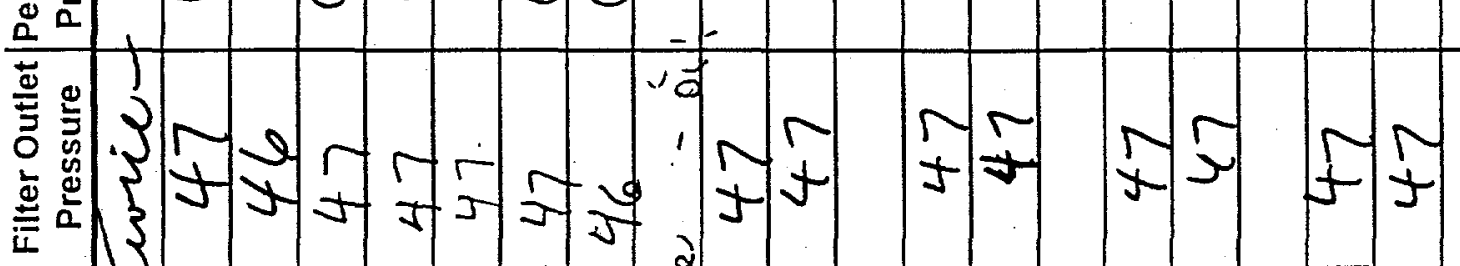

o

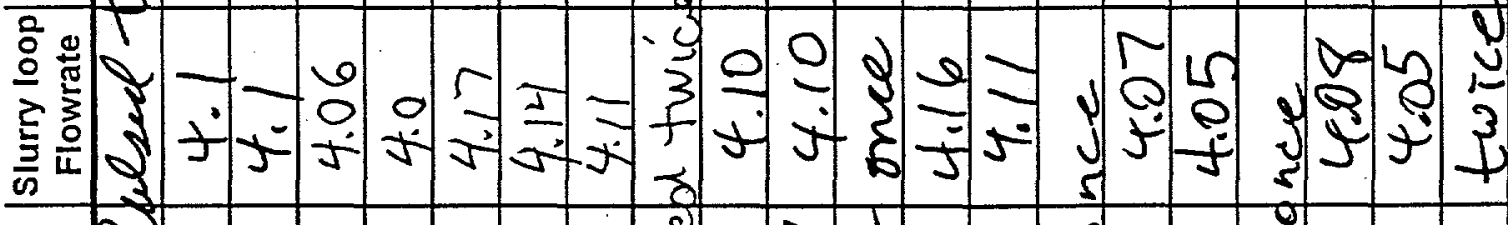

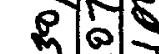

$\sigma \sum_{4}^{T}\left\{\begin{array}{l}0 \\ 0\end{array}\right.$

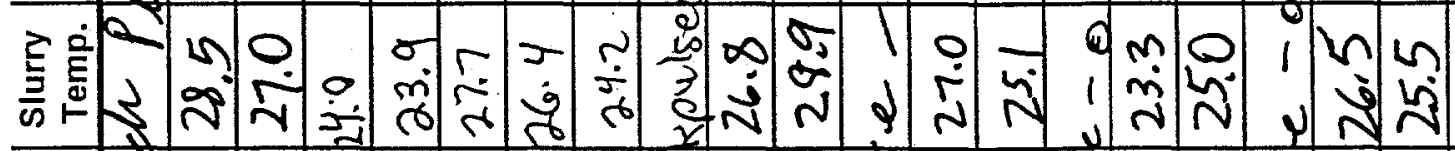

离

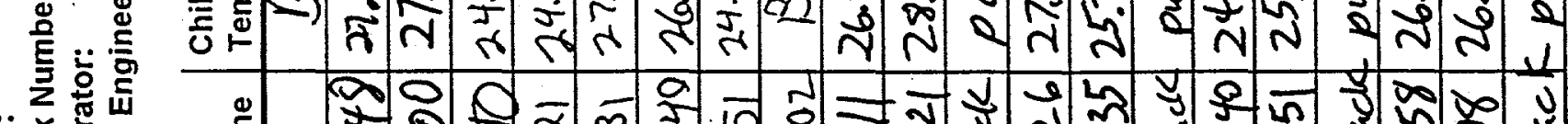

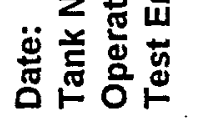

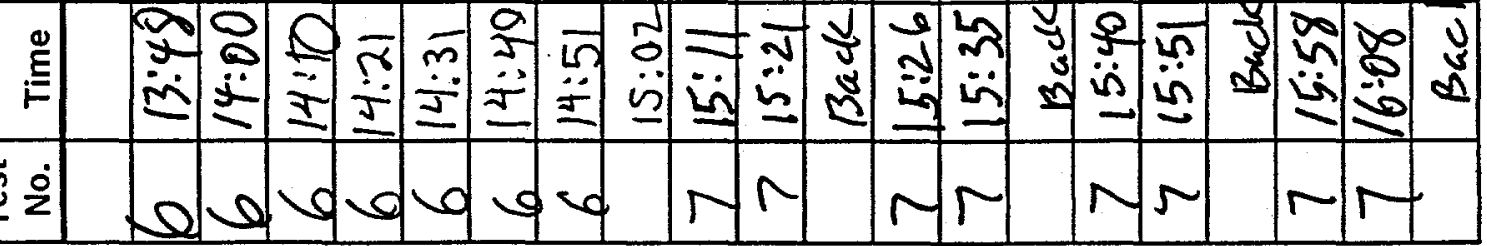




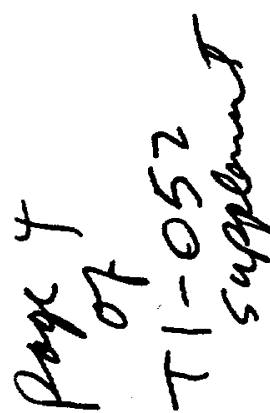

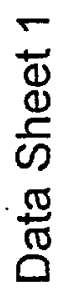

善㨍

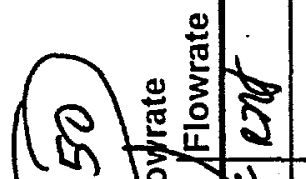

0 ह

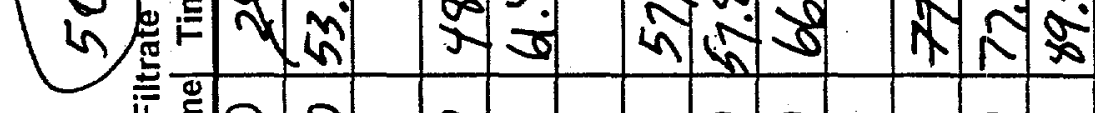

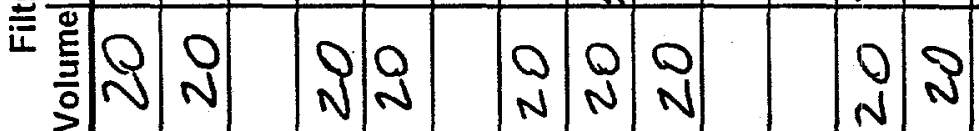

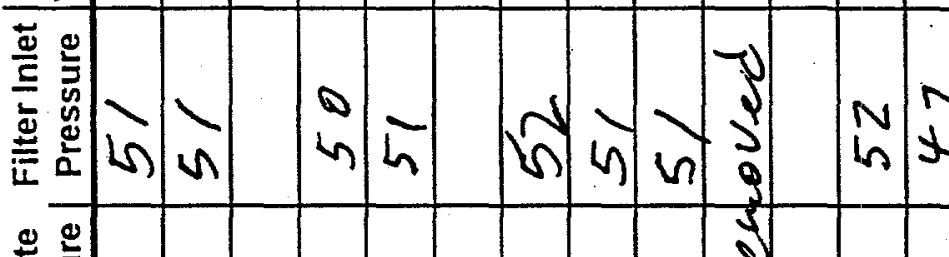

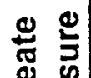

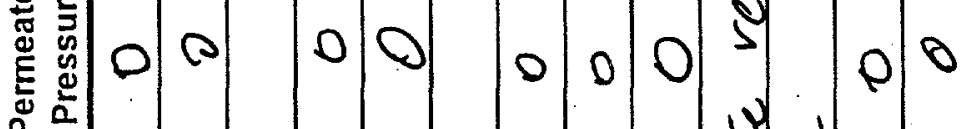

(5)

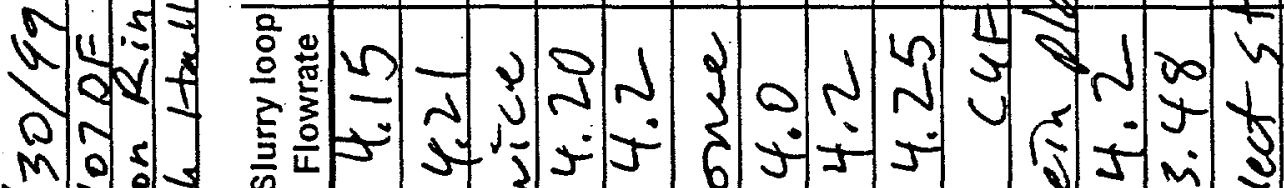

M

W $A$ हa

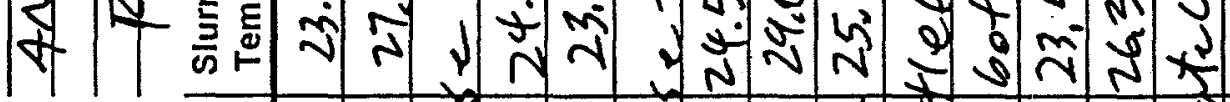

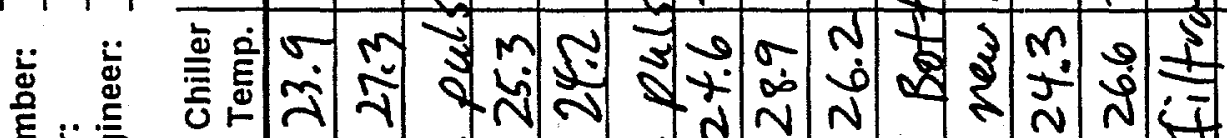

E.

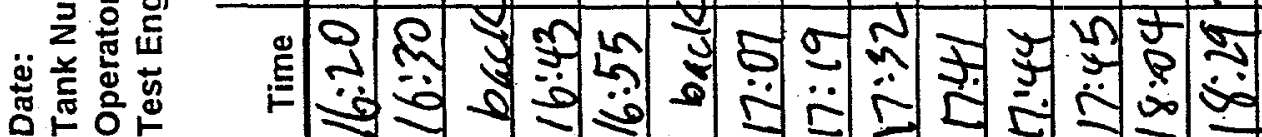

gina 
Data Sheet 1: Operating Data

$T 1-02$

Date:

Tank Number:

Filter:

Test Conditions: Clean Water FluX Operator:

Test Engineer:
Clean Water Flux after

AN-107 DF solids Removal

and Clean up

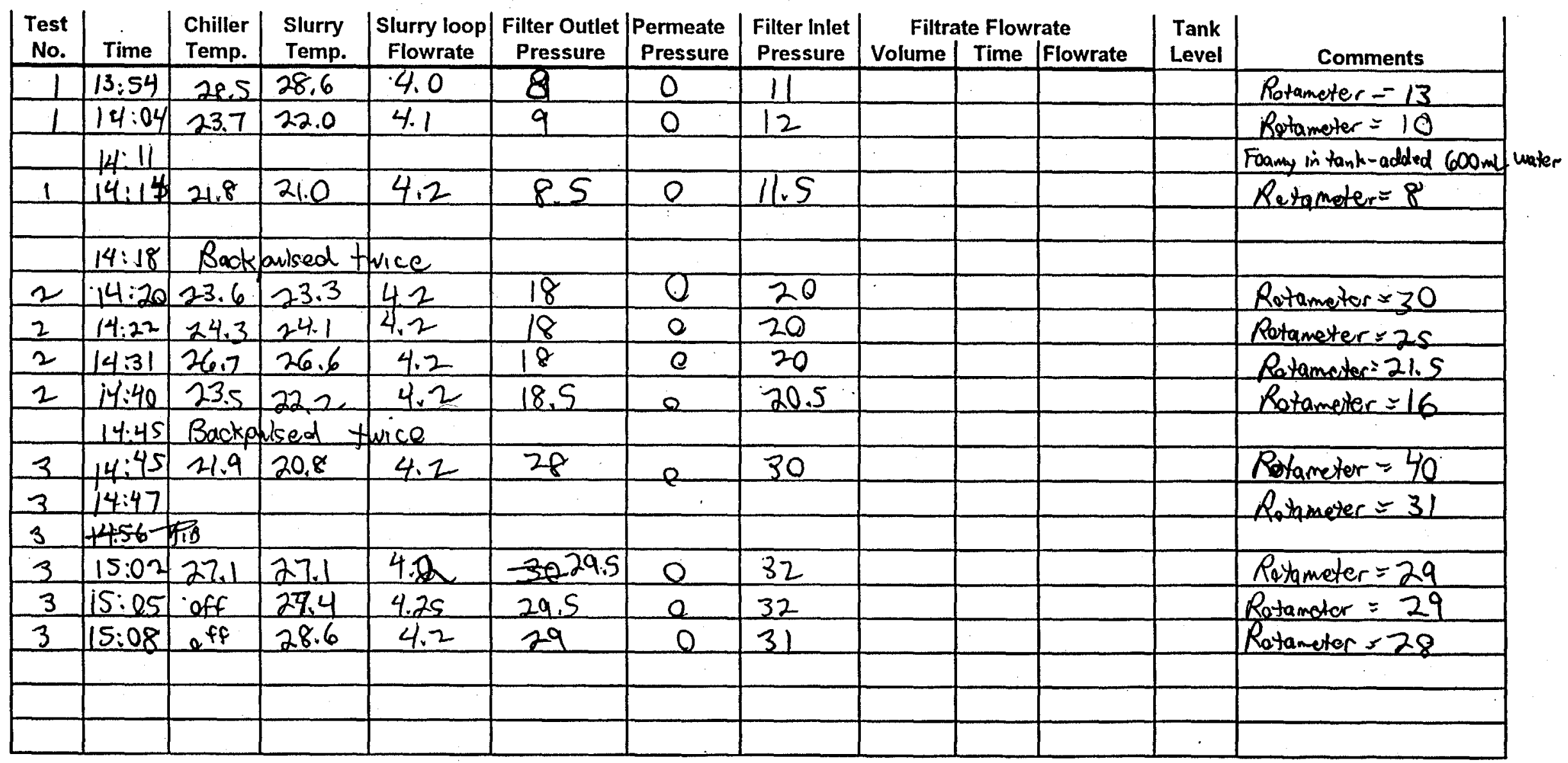


44 Prup of Dolution for ANDOT Bifuterl feed

- TP-OB-vevil - T1-052 -

heed I $m$ si, I M NamaOy, and 3.5185 M NaOH and IM HNO 3 with $0.1-0.2 M$ Ciniz Arid for cleoming up caf

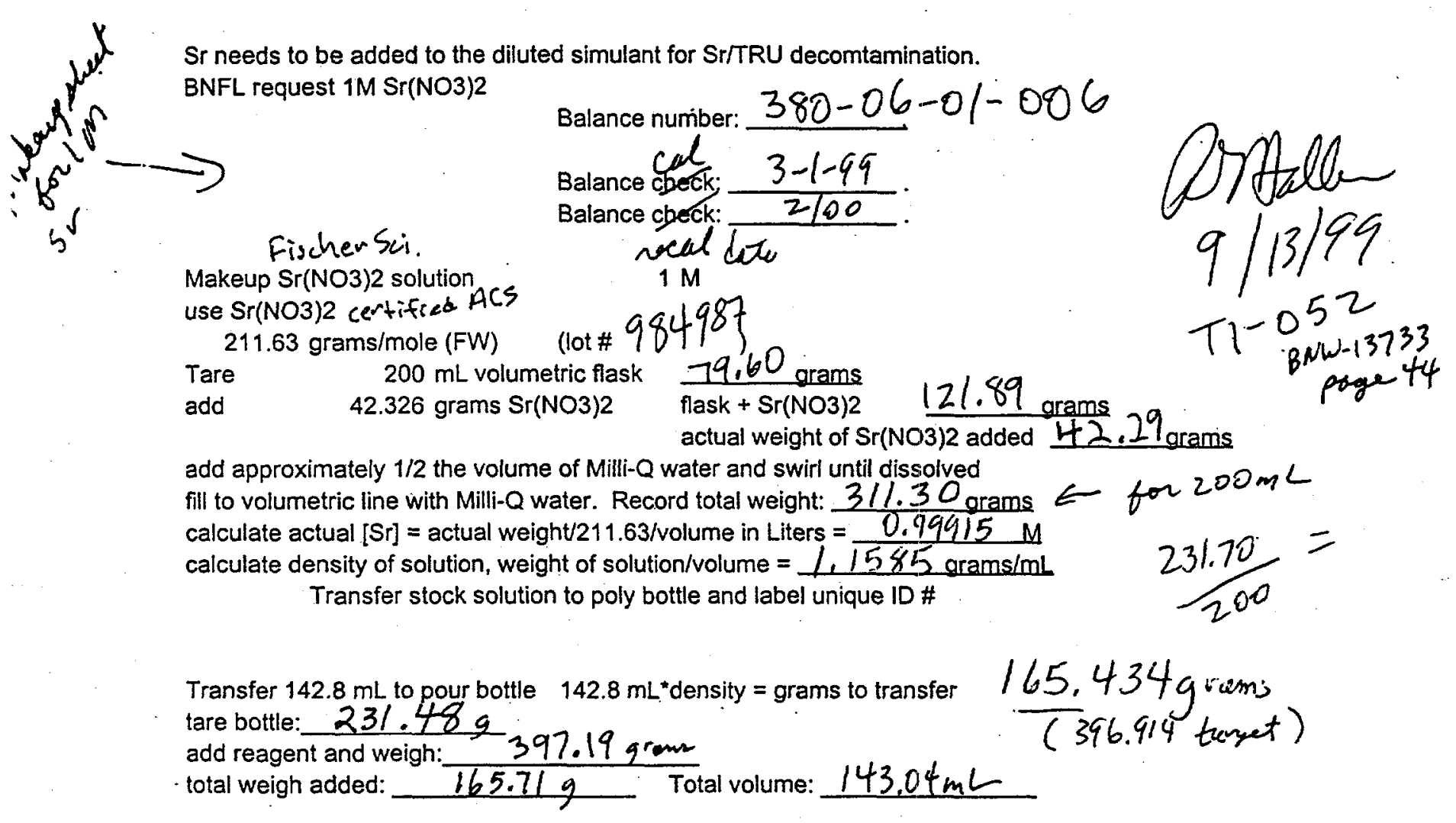

Dirertion from Mike Tohuson to lase $0.01 \mathrm{M}$ $\mathrm{NuOH}$ for Wash solatein not of water.

Prober no 2 Give - So/TRu ppt 29953.

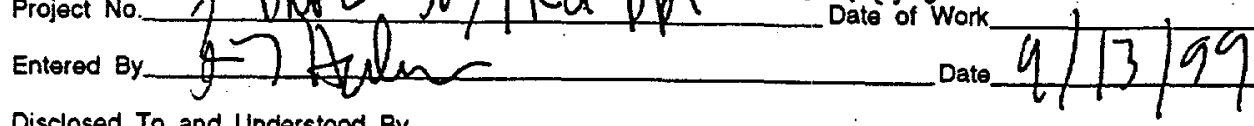
Disclosed To and Understood By Date 
45

Caustic needs to be added to diluted the waste before Sr/TRU decontamination

need 3,5185M Sift o3)2 $9 \mathrm{MK}$

$$
\text { it res Nay l }
$$

Balance number: $\frac{380-06-01-006}{3-1-99}$

cal Ponsaler

Balance check: $\frac{3-1-99}{2 / 00}$.

recall dote i conductor grade

Makeup $\mathrm{NaOH}$ solution $99.99 \%$

use $\mathrm{NaO}$

Tare

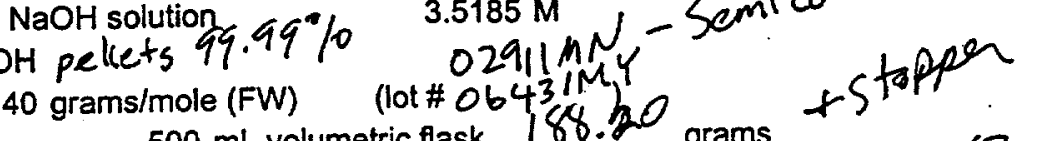

add

$500 \mathrm{~mL}$ volumetric flask

188.20 grams

258.47 grams

actual weight of $\mathrm{NaOH}$ added

add approximately $1 / 2$ the volume of Milli-Q water and swirl until dissolved

villi-Q water. Record total weight: $\frac{749.5 / \text { grams }}{3.5135 \mathrm{M}} \quad 561.31 / 500$ calculate density of solution, weight of solution/volume $=1.12262 \mathrm{grams} / \mathrm{mL}$

Transfer stock solution to poly bottle and label unique ID \#

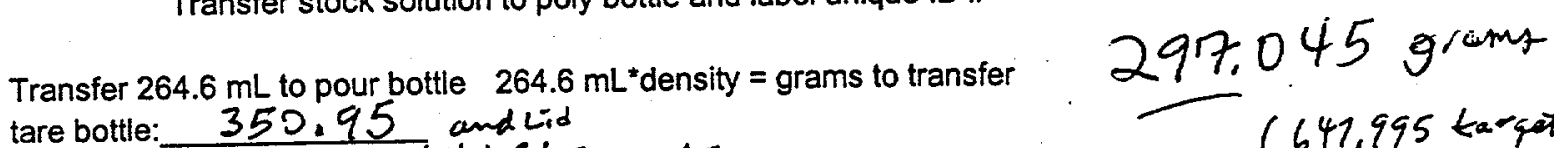

(647.995 target) add reagent and weigh: $\quad 648.31 \mathrm{grams}$

Date prepared:

Prepared by:

$$
d=1.12262 \mathrm{~g} / \mathrm{mL}
$$

Work Package Number:

264.6

$$
\times \mathrm{mL}^{2}(3.5135 \mathrm{M})=250 \mathrm{~mL}(0.01 \mathrm{M})=0.71154 \mathrm{~mL}
$$

$.71154 \mathrm{mc} \times 1.12262=0.799 \mathrm{gram}$ $250 \mathrm{ml}$ flask

tums for bot the

tore flash $=107.00 \mathrm{~g}$

$+3.5 \mathrm{MNkOH}=107.80 \mathrm{~g}$

Tore Bottle $350.62 \mathrm{~g}$

+ water $\quad 355.98 \mathrm{~g}$

$+\mathrm{NaOH} 598.99$ gram

$$
d=0.9959 \mathrm{~g} / \mathrm{m}^{2}
$$

Date of Work

Entered By

Disclosed

Date $9 / 3 / 94$

2.

Date

Dato 
46

Sodium permanganate needs to be added to the diluted simulant for Sr/TRU decontamination. BNFL request $1 \mathrm{M}$ NaMnO4

$$
\text { Balance number: } 380-06-01-006
$$$$
\text { Balance colet 3-1- } 99
$$

Balance check: $2 / 00$

rewed ate

Makeup NaMnO4 solution

$1 \mathrm{M}$

use $\mathrm{NaMnO} 4 . \mathrm{H} 2 \mathrm{O}$

$159.94 \mathrm{grams} / \mathrm{mole}(\mathrm{FW}) \quad$ (lot \# AO1067590

Tare

$100 \mathrm{~mL}$ volumetric flask 67,62

add

15.994 grams NaMnO4

$\frac{67.62 \text { grams }}{\text { flask + NaMnO4 }}$

83.63 grams

water and swirl until dissolved

add approximately $1 / 2$ the volume of Milli-Q water and swirl until dissolved

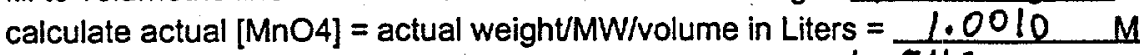

calculate density of solution, weight of solution/volume $=1.0943 \mathrm{grams} / \mathrm{mL}$

Transfer stock solution to poly bottle and label unique ID \#

Transfer $96.6 \mathrm{~mL}$ to pour bottle $\quad 96.6 \mathrm{~mL}$ density = grams to transfer tare bottle: 229.045

$105.709 \mathrm{~g}$

add reagent and weigh: $\frac{334.88 \mathrm{~g}}{105.84}$ Total volume: $96.72 \mathrm{~mL}$

$(334.749$ ) target

$-$

Need I M HNO3 with 0.1-zo-0.2M citricucie foo ¿ leaving CUF and Filter element after filtering Sr/tRh p pt.

Citrus Acid. I HoO - FW 210.14. Lot 9245600 fischer 21.00 gram citric vied 11 tho

769,23 gram $1 \mathrm{~N} \mathrm{HNO}_{3}$

apporinatels $3 / 4$ full in $1-L$ bottle

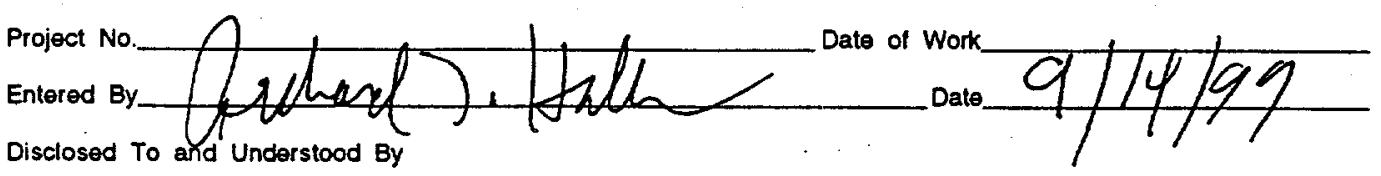

Disclosed To and Understood By

Signed 1

Date

2.

Date 
Calibration of graduated filtrate collection/ flax mcassreat rent glass piece of CuP - with valve 6 in open position - ire. Side arm also fills with filfucte. Use auto pipettes 237RA1-10-01-43/92 pipette check

$$
10.00 \mathrm{mc}=10.0447 \mathrm{~g}=10.0272 \mathrm{~g}=10.0390 \mathrm{~g}
$$

bottom outlet plugged - Valve 6 opened - filled to $10 \mathrm{ml}$ mark on graduated cylinder - some doers remain on sides of cylinder. add record volume reading

$10 m L$

$10 \mathrm{~mL}$

$10 \mathrm{~mL}$

LO ML
$18.6 \mathrm{~mL}$

$27.0 \mathrm{~mL}$

$35.7 \mathrm{~mL}$

$44.2 \mathrm{~mL}$
Coly srabuoted to $m L$ estimate the tenth of $m L$ )

$$
\begin{aligned}
& 10 \mathrm{~mL}=8.6 \mathrm{~mL} \quad 10 \mathrm{~mL}=8.4 \mathrm{~mL} 10 \mathrm{~mL}=8.7 \mathrm{~mL} \\
& 10 \mathrm{~mL}=8.5 \mathrm{~mL}
\end{aligned}
$$

Signed 1

Date

2

Date 
$12: 000^{\mathrm{m}} 9 / 20 / 99$ AN-107 DF Sr/TRA PPT and CUF

Stav Bar 38.4144grame Balme 384-06-01-0040

$$
\begin{aligned}
& \frac{\text { Vialt }}{D F-01} \frac{\text { Tare }}{16.91279} \\
& 8 / 2000 \\
& \text { DF } 02 \quad 16869 \mathrm{~g} 17.0230 \mathrm{~g} \\
& \text { DF-02 } 16.8683 \mathrm{~g} \\
& \text { DF } 03 \quad 16.9718 \mathrm{~g} \\
& D F-04 \quad 16.9215 \mathrm{~g} \\
& \text { DF-05 } 16.8945 \mathrm{~g} \\
& \text { DF }-8616.9470 \mathrm{~g} \\
& \text { Jideon Jars were Stuck } \\
& D F-07 / 6.924 \mathrm{~g} \\
& \text { DF-08 } 16.8017 \mathrm{~g}
\end{aligned}
$$

Botfle UFA had $21 / 2$ inch seflled solid that were not easily transfurred. Woste from $U F B$ was ad to UFA and well mized. All other bottles were stille Skecken well betore transter.

UAB had a very small amount of solid that didn't twauster.

Boftle UFCD lid stuck - 2:12:40 - use lid removen Brttle UFE-had eome chunky soliots - $21750 \mathrm{~mL}$

Cacicic Added Stat 2:32 temp 32.2 strined until

IM Sr afled 3:29 3:40 atetion completed at 3:35 scan started $32.9^{\circ} \mathrm{C}$

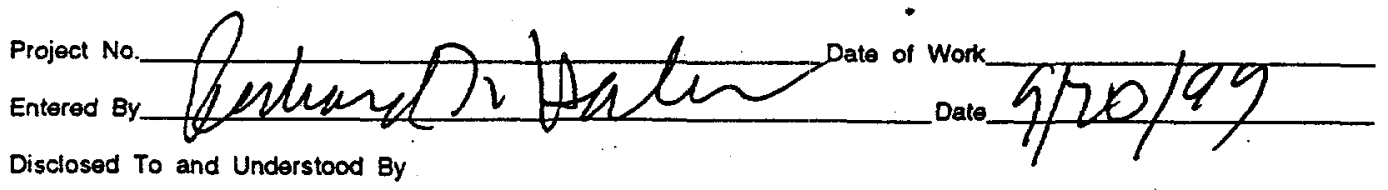

Signed 1.

Dato

Date. 
1 MiNk MaO od bed $3: 46$ temp $32.8^{\circ} \mathrm{C}$ finished at 3:57 about $2000 \mathrm{~m}$ -

49

$4: 38 \sim 50 \mathrm{~mL}$ removed for samples + Density measuremat 4:45 hasten turned on

reached $45^{\circ} \mathrm{C}$ at $5: 00$

used $20 \mathrm{mac}$ syringe DF-01-27.743g filtrate niter filter one y a raged again 2-3mc 2-3 me filter then plugged $D F-02-40.4859$ wed the filter - plages sample DF-02 not filtered! $6: 0^{\circ}$ temp $49.4^{\circ} \mathrm{C}$

$6=40 \tan 49.0^{\circ} \mathrm{C}$

$7: 20$

$48.7^{\circ} \mathrm{C} 8: 3048.4$

$8: 5548.3^{\circ} \mathrm{C}$

9:10 48.0 $0^{\circ} \mathrm{C}$ hast tamed off

* CUF had last of DI rinse $H_{2} 0$ hs lay-up Solution..

Turned on the CUF to recheck $\mathrm{H}_{2} \mathrm{O}$ flux: Tank was forms white. Whin V4 was opened Rotometer reading went to 210 . Then quickly drooped of $f$. Went down to $R=0$ with -in 5 min. Backpulsed twice- (second back pulse the chamber filled much move quickly) then drained.completely.

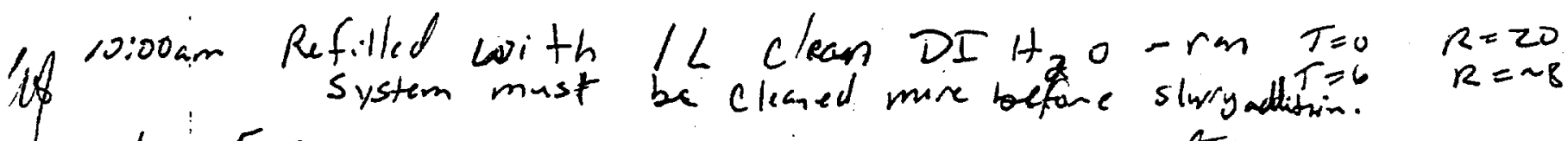
10:50 sampler of digested slewing taker

7. DF-03 $42.068 \mathrm{~g}$

DP $-04 \quad 41.622 y$ Enteject Disclosed To and Understood By $-0.0 / 20199$ Signed

Date Date 
50 apples

12:47 pm $0.05 \mu$ Cartridge filter hooked up and

$\alpha(4)$ running.

Back pulsed in 2 chambers of clean DI from top of system. Added the remainder of a $\leq H_{2} \mathrm{O}$ to the tank before by-pass to cartridge filter was opened.

$1: 22 \vee v 10$ closed (filter bypass value)

$V_{4}$ open $P=\sim 20 \quad F=-3.8 \mathrm{gpm}$

$$
\begin{array}{ll}
T=0 & R=135 \\
T=8 & R=3836019 \quad \% / 2 / 19 \\
T=20 & R=33
\end{array}
$$

System clean enough to run.

1:s5' emoting system

* dropped Flow to r $1.2 \mathrm{gpm}$ lopsig before dumping.

2:54 * Note T of slain is Still reading 3\%?. So took the thermocouple out to see what it is reading in air is Still 34.4.C - (Some jumping in the roth's of a degree)

: Therms couple may not be reading correctly.

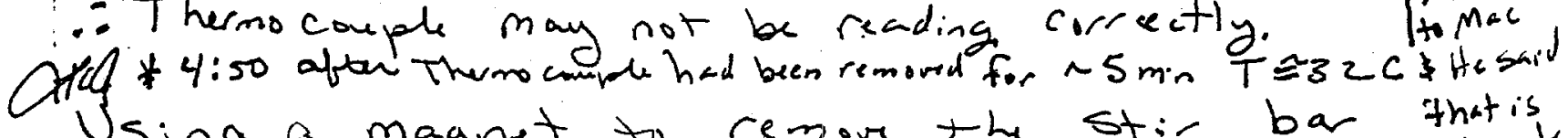
Using a magnet to remorse the stir bar that is Visual before disrupting the settling The slwry has settled into two visible layers. The bottom layer is a greenish brown and the to $p$ is a dur k Novel blue/ purple almost black.
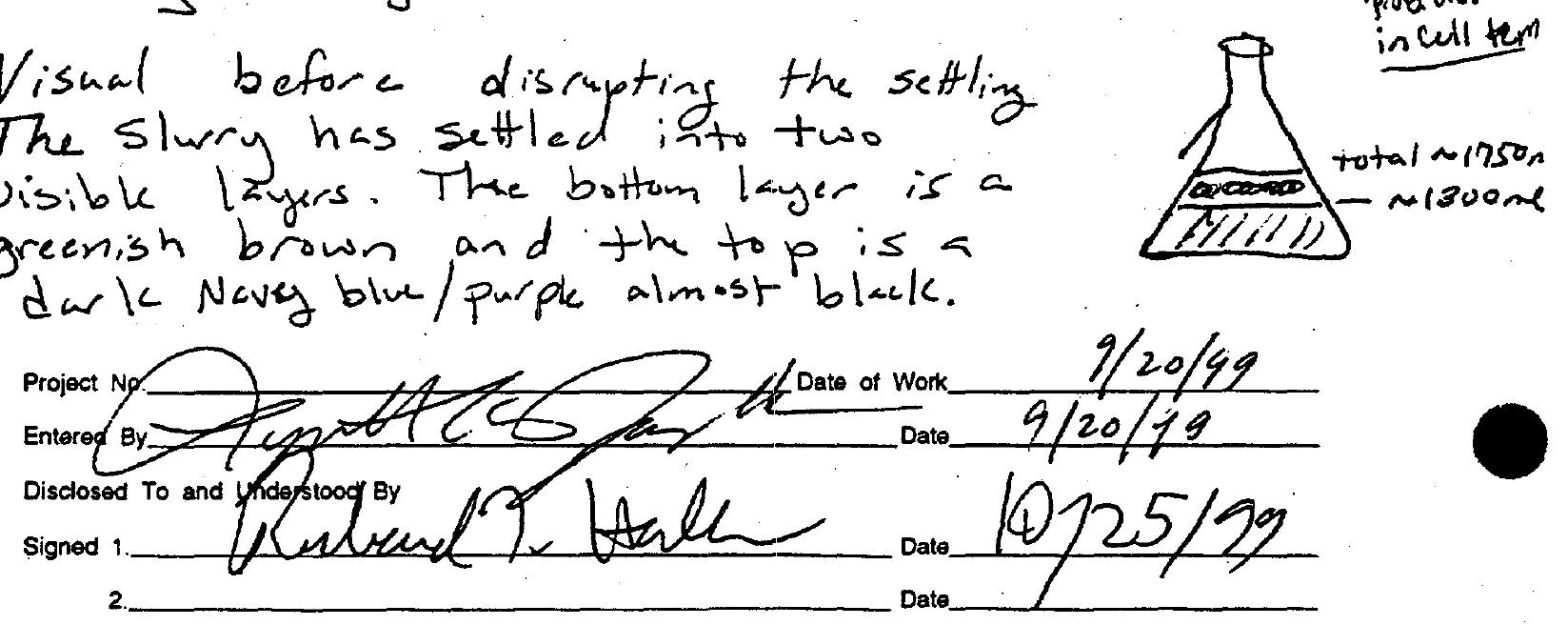
51

3:11 Stir bar removed.

3:40 wt of vessel with story $3609.34 \mathrm{~g}$

3:59 AN-107 in and CUF on -

$F \cong 1.0 \mathrm{gPm}$ Rage $(92-1.1)$

$P=0$ psid

-UUTIG) (VI open completely)

4:08: Visual check shows slurry not mixing cell. Increased flow rate to $1.8 \mathrm{gpm}$ mixing slow but well.

4:13. Taking 1' Rheology sample.

4:50 * At about 4:00 Themocupple lead that was in the slwry was unplugged and used to monitor the Rheology water bath.

17:45 Completed $z^{\text {nd }}$ rheology sample

17.51 DF-05 taken as slurry sample wt: $41.677 \mathrm{~g}$

17:53 DF.96 taken as. slurry sample U4: $41.697 \mathrm{~g}$

18:03. Started test al Conation *1 required air booster on $65 \mathrm{psi}$

18:21: Pulled filtrate sample DF-07 Wt $=38.033 \mathrm{~g}$

Heat Exchanger is leaking slightly.

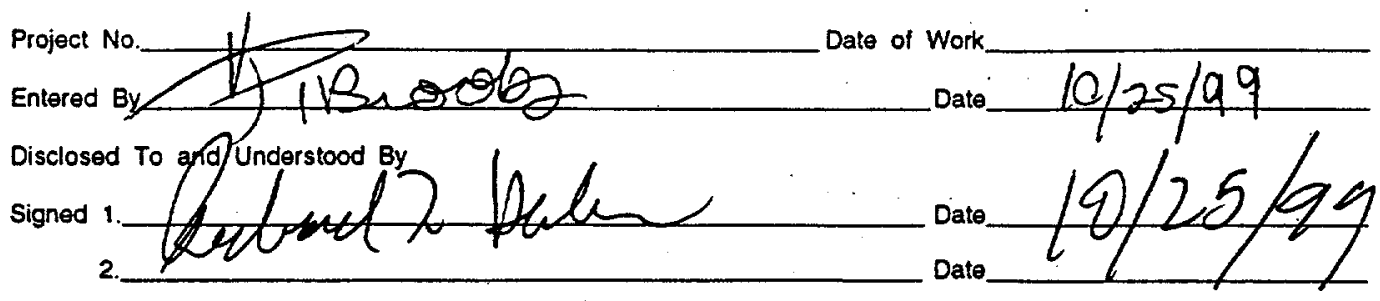


52

Tare wt Sample 4

$\begin{array}{ll}16.9849 & D F-09 \\ 16.9114 & D F-10 \\ 16.9553 & D F-11 \\ 16.9620 & D F-12 \\ 16.8648 & D F-13 \\ 16.9016 & D F-14 \\ 16.9472 & D F-15\end{array}$

20:50 Discovered that TC was still plugged into viscometer! Chan 21:01 Took sample of filtrate during condition ty.

$$
\text { DF-O8 } \quad 35.385 \mathrm{~g}
$$

$22: 19$ Checked chiller liquid level. Found to be 21 " from the top.

$0: 04$ Filled DF-09 during test $\# 5$ mass $=35.638 \mathrm{~g}$

AN -107 Deaden Filtrate Bottle (w/ lid) $136.45 \mathrm{~g}$

AN-107 DF Filter + Lid. $104.78 \mathrm{~g}$

$\rightarrow$ Botllewas banded-tave weight $198.66 \mathrm{~g} \mathrm{~W}$ at the end of condition 6 fithatasanple Collected - DF-10 - 35.537 gram $Y / 2$ way through $B$ dewatering $2400 \mathrm{~mL}$ collected - DF-11 - 34.211 grams CUF drained - small amour of slavey spilled

At 04:56 the doodenk end fitter vacuum was turned on.

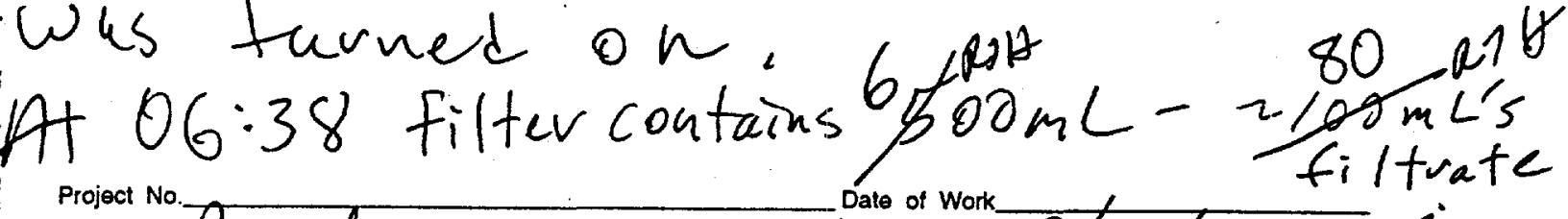
Entered By Date of Work Disclosed To and Understood By Date $9 / 2 / 197$ Signed 1. Date

2 
Cuf rinsed $w / 1$ citer of woter

53 1st sinse collectod in 1 lete bottle 2nd inse water added $=1$ Liter $\}$ colleted in 3 ad rense water olded $=1$ liter $\} 2$ eiter bottle

litar of water added to CUF test conltion $20 \mathrm{psi}+4.2 \mathrm{gpm}$

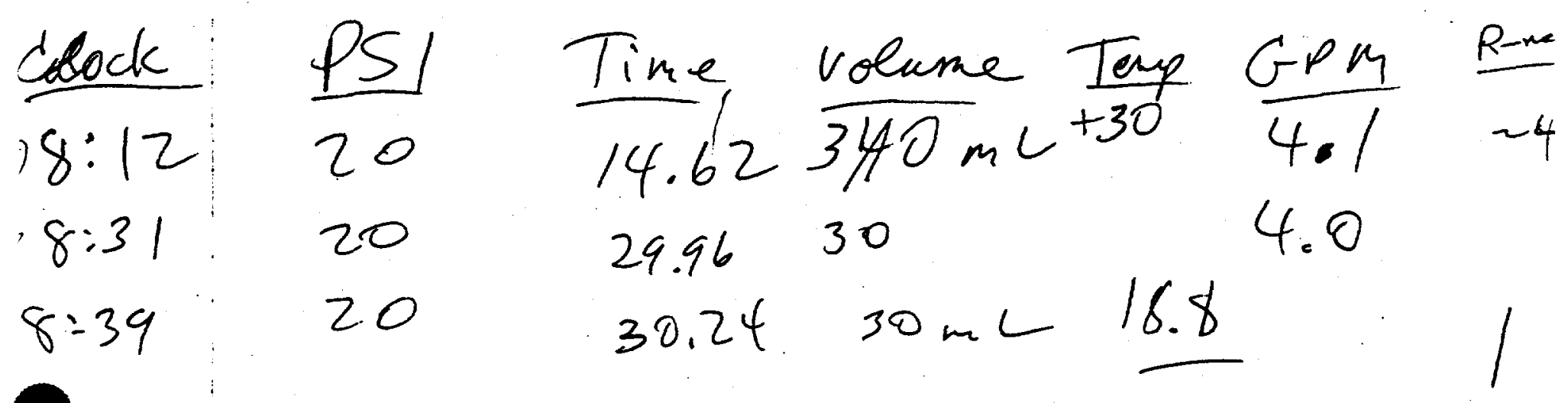

CUF not cleaned up with water alone.

Prein and wash with acid

At 10:06 Deadend filter of 500ml

Acid solution recivenlated in CUF $2 k 8 \%$.

flow of 20 psi $=20 \quad$ Flow $\approx 4.2 \quad R \cong 10$

10:27-oftio bock pulse w/ acid 23 (20psi)

10:5i - Decasunted filter e 475me

10:55-Backpulsed 2 times $R=25$

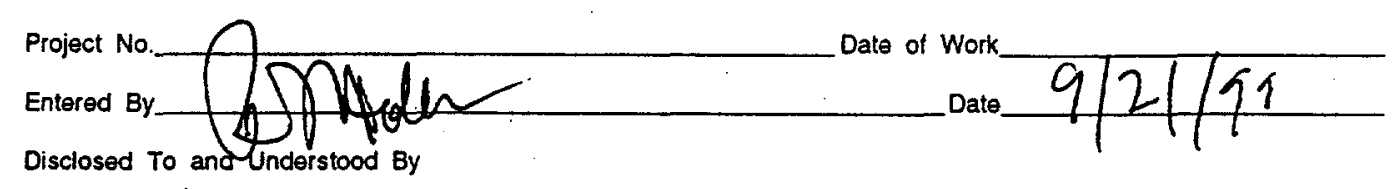

Signed 1

Date 
54

$9 / 2199$

$11: 09$ R=22 (Still 20 ps.g $\simeq 4.2 \mathrm{gpm}$ )

$11: 15 R=22.5$ - Doing 10 back pulses

11:24 after back pulses $R \cong 28$

Shutting down for soak $\sim 1$ hr.

$N / 15$ - Back on runing $R=40$ psig $24.0 \mathrm{gpm}$

1: 55 . Deconting liquid leve $-420 \mathrm{me}$ - deadund filtar

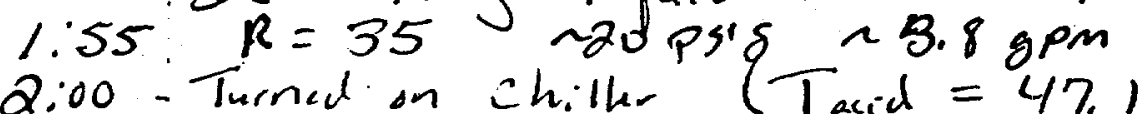

2:00 - Turnad on Chiller (Tacid $=47.1 \mathrm{C}$ )

Back pulsing 10 times

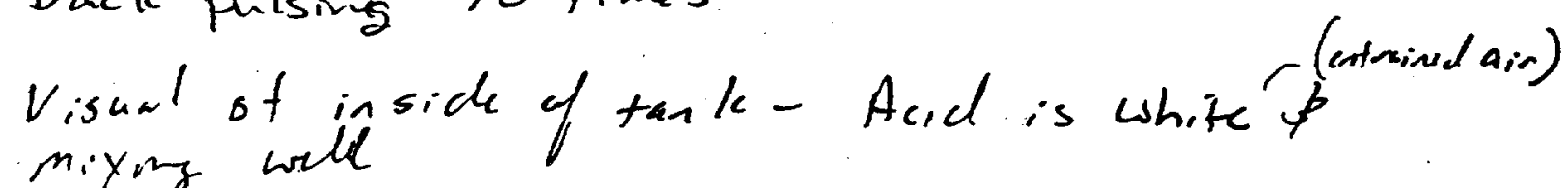

$2: 35 . \quad R=32 \quad 20$ psiz

2:40 Draining Acid (Complete drasn)

3:11. $1^{\text {st }}$ ringe in and rumar $R=40$

10 inse was 1.5 L $D I H_{2} 0$. Backpulsed

entive amountionthrough top to wash filter.

3:33 Dcconting liquid level $\left(A_{n}-100\right)$ - 375 me-deadeal

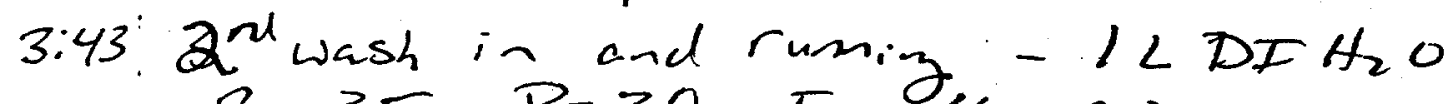

$R=35 \quad P=20 \quad F=\alpha_{4} .0 \mathrm{sgm}$

$3.49 \quad R=30$

4 i4o Draining and Rinse.

$4.553^{\text {rd }}$ rinse in and running (z Bambers entered from top)

5:08. Drainig 3rd ringe

5:35. 4tr Rinse in and running-(most entered palse though the No)

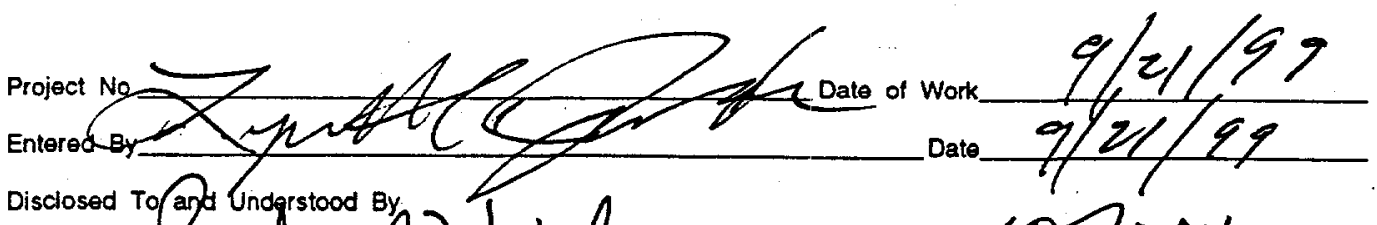

Disclosed To and Undgrstood By

Das $10725 / 99$ 
55

6.00 Turned off vacume on Decanting / filtration system. 6:41 $\mathrm{PH}$ of $4 \mathrm{th}^{\mathrm{h}}$ rinse is $-4,0$ on $\mathrm{PH}$ paper. Adding mother $3 / 4<$ of $H_{2} \mathrm{O}$

Starting a water test

$$
\begin{array}{ll}
T=0 & R=22.5 \\
T=5 & R=18.5
\end{array}
$$

1/24/99 Not clean yet. -

filter Top tare with Lid $104.78 \mathrm{~g}$ BNFL hes instructed us to recombine solids and filtrate for additional cup testing

the filter assoniny had a $350 \mathrm{~nL}$ in it - $100 \mathrm{mc}$ of settled solids and $150 \mathrm{nc}$ super nate $2400 \mathrm{~mL}$ of filtrate had beer collected the filtrate wash arsed to wash solids out of filter. Solid ware very compacted. is pipette was lased to mix filtrate and solids. After 4-r100me washes, solids still remain in filter. Weight of filter bottom with band $=200.31 \mathrm{~g}$. Ch Slurry bottle o/slariy $=914.61$

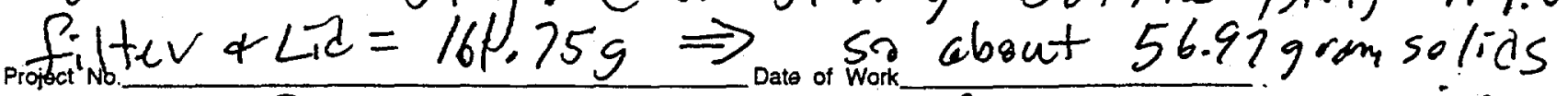
Entered By Dato $93 / 99$ remain Signed 1. Date

2 Date 


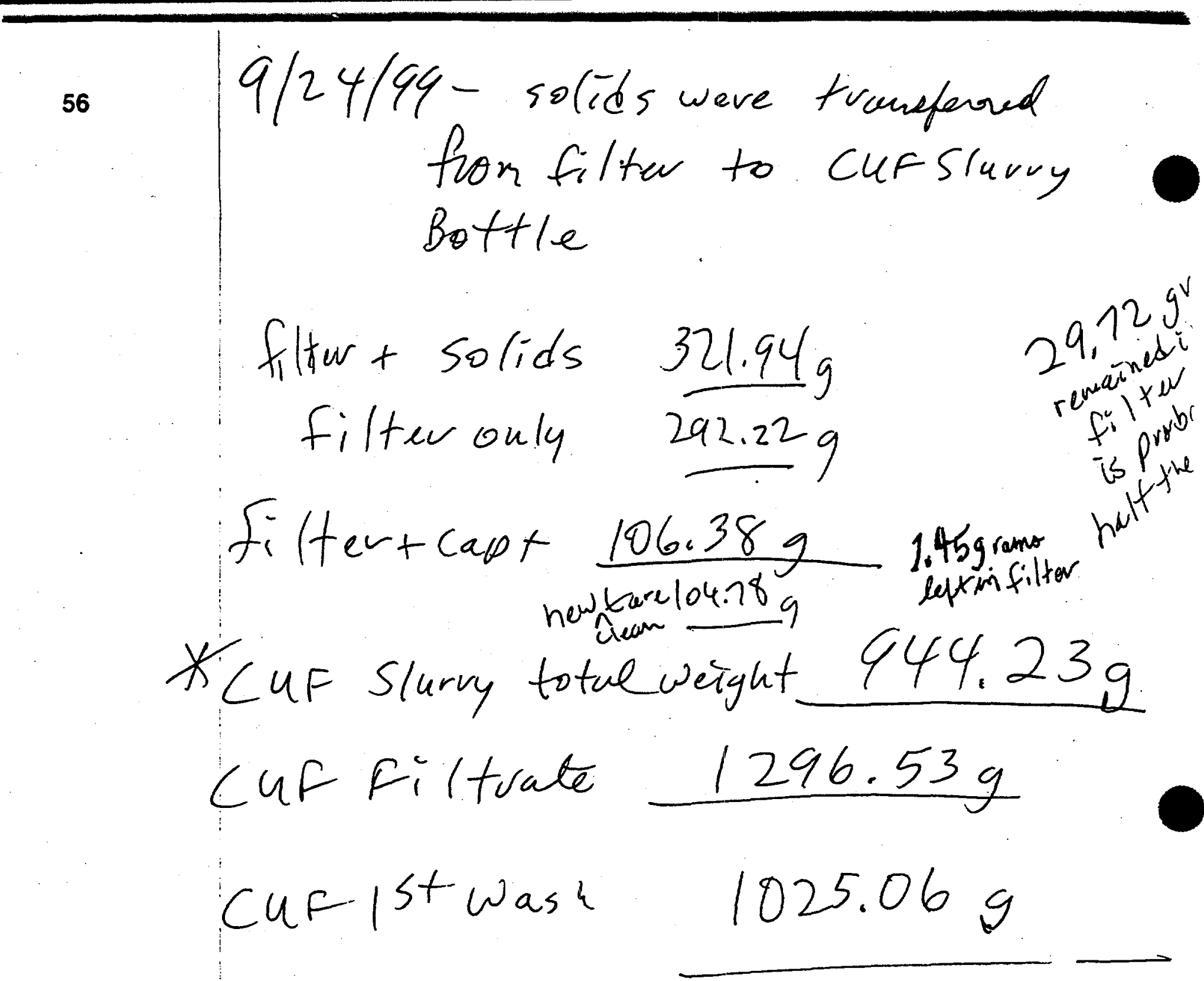

* Cantion CUF Slunvy Bottle has a disposabbre pipethe in it that will need to be re moved. 4129191 CUF moveltunto position 1:37 - extemal filter hook up to elemup CHF - 1:48 recupled woter at 15p and $1.9 \mathrm{gpm}$. Turned chiller on.

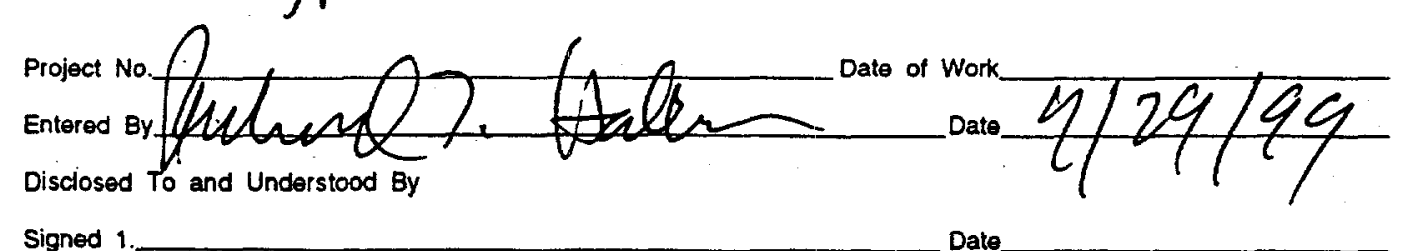


Estindtion of volume 646 of slurry

clock mywatch 2:23

$203923.65 \mathrm{mc}$ forturats

57

Sinc. donere 2:29:27

$$
1.569 .6 \mathrm{mc}-25^{\circ} \mathrm{coditution}
$$

estinate $1.96 \mathrm{~L}$ total

$2400 \mathrm{~m} L(\mathrm{~g})$ ot 1 st wash

recover filtuote fusm scupler - DF-07, DF-08, $D F-\theta 9$, ad $\theta F-10$

volvet openal

$280 \mathrm{~mL}$ move fittrate

floosete $22 c t+=0$

$\begin{array}{ll}4.2 \mathrm{gpm} & 20 \mathrm{psi} \text { inlet } \\ 4.3 \mathrm{spm} & 20 \mathrm{psi}\end{array}$

$R=18$ ot $t=5 \mathrm{~min}$

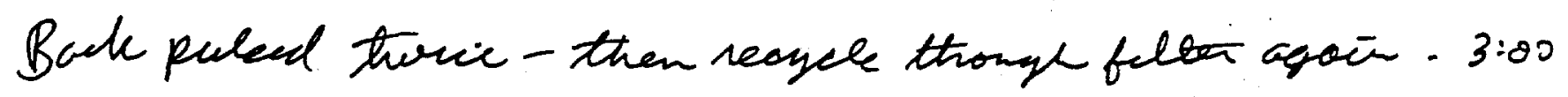
chillen - temp control seneor come unplugged.

$15: 52-R=26$ at 20 psi and $4.2 \mathrm{cpm}$

backpulsed torice 15:54 $R=26$

$$
\begin{aligned}
& t=19.6^{\circ} \mathrm{C} \\
& t=23.3^{\circ} \mathrm{C} \\
& t=25.0^{\circ} \mathrm{C} \\
& t=25.00^{\circ} \mathrm{C}
\end{aligned}
$$$$
16: 09 \quad R=21
$$$$
16: 14 \quad R=21
$$

$16: 24 \quad R=19$

16:44 clean water pack pulse in systan twice and external filter tarned back on.

18122 turned on recycle to extrunal filter

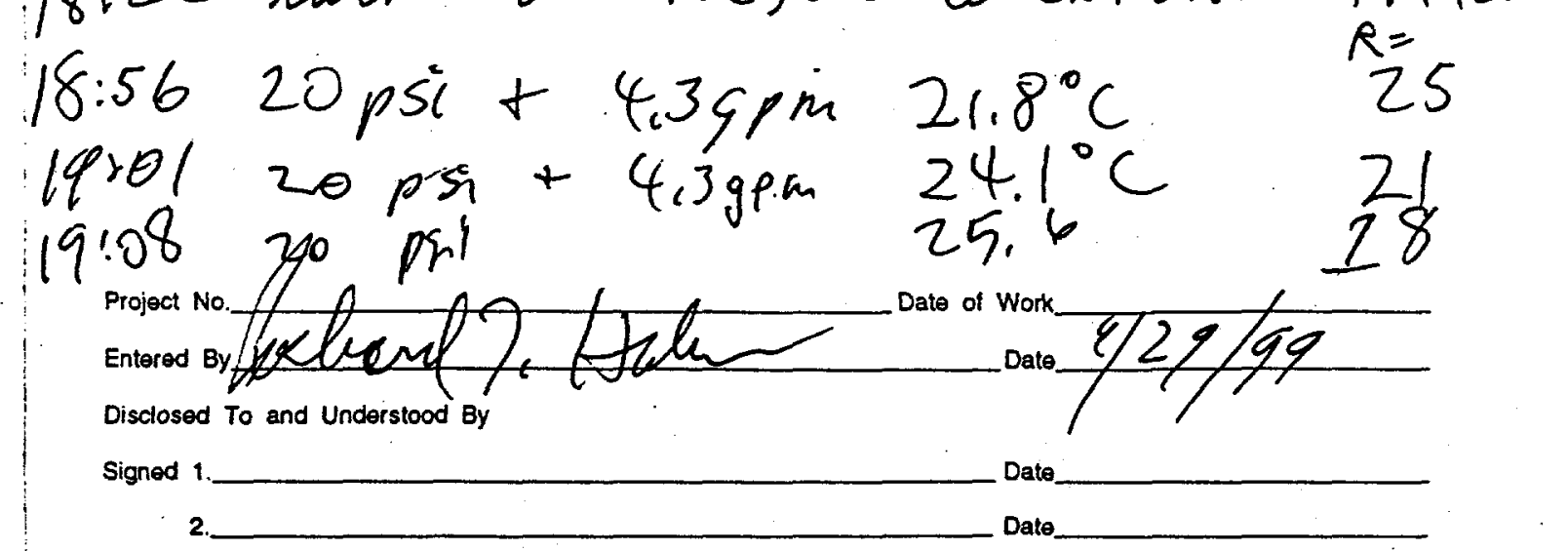

Date 
- Back valbed twice -

58

$$
\begin{array}{ll}
19: 15 & 20 \text { psi }+40 \mathrm{gpm} 23.9^{\circ} \mathrm{C} \text { R metor } \\
19: 18 \text { 20psi }+40 \mathrm{spm} 22.5^{\circ} \mathrm{C} 20
\end{array}
$$

1.15 9/30/99 Drim vater out of cuF Ceatamp 29.70 add CUF Slurry - Slarey bottle riused out with filt. wad cuF fitrate -

volve I fully opan recirculate waste at 22 gpm for 10 minutes 7:49

$$
7: 59 \text { - torget } 50 \mathrm{psi}+4.2 \mathrm{gpm}
$$

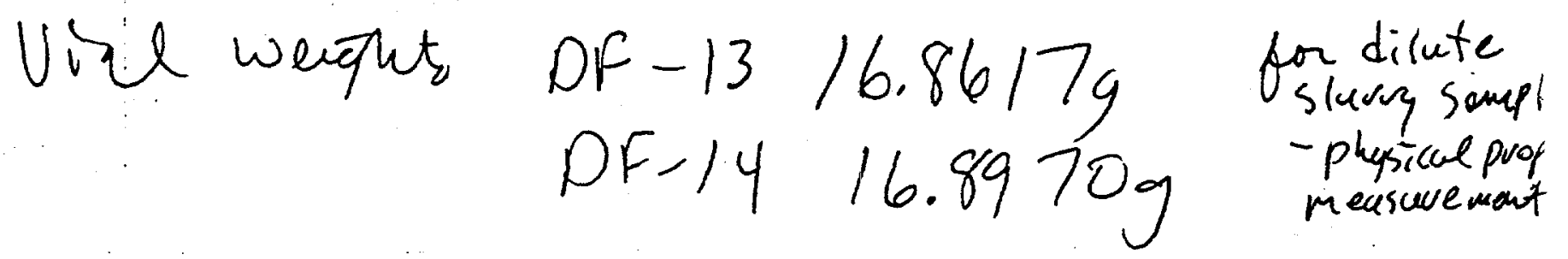

tarkeveight AN-107 CUF Filterte \#2 104.42 - Ist vash solution added apponinatey 1/2 of bottle $9 ! 23$ back pulse twocie

$9: 32$ - start slarry sampling

15t somple DF-13 $\frac{1}{D F-13-39.97 i}$ filled to $20 \mathrm{mc}-2$ value sequences DF-13-39.977g-

$2^{\text {ud }}$ somple DF $-14=40.473 y-$

9:43 stated conchtion 1

CuF Filtuate Botfle empty $=106.64 \mathrm{~g}$

CUF Dewatered Slurry empty $=106.65 \mathrm{~g}$

CuF ist Rinse $1 / 2$ full $11=618.55 \mathrm{~g}$

Entered By Dato $9 / 30 / 97$

Signed

Dale

2

Dale 
TCUF pamper Max and only get 4.1 gp meat 50 psi

59 So ve-evaluath matrix - correction $3+5$ mot rum CUF Filtrate $\$ 2$

$$
831.23 \mathrm{~g}
$$

CUF Filtrate $(4)$

936.62

CufDevatered Slurry $941.31 \mathrm{~g}$

band added to filter bottom - cur Deaden fits reweighed with Tops cap $296.79 \mathrm{~g}$

$19: 13$ filter Vacuum turned on volume $-625 \mathrm{~mL}$ empty Cur Dewatered Slurry $110.44 \mathrm{~g}$

$500 \mathrm{~m}$ of water added to cur for 1 st Rinsecollected in bottle labeled ICUF 15t Rinse 20:02 fitter volume at $575 \mathrm{~mL} 21 \mathrm{~mL} / \mathrm{min}$ 20:15 Rinse $\$ 2$ complete - 1 Liter 20:30 Rinse \#3 complete -1 Liter $20: 37$ foltervolume at $550 \mathrm{~mL}$

$20: 42$ the wash $R=20$ 20 psi $4.2 \mathrm{spm}$ lean $20.43 \quad 30 \mathrm{~mL}$ in 19.95 seconds $\quad 22.3^{\circ} \mathrm{C}$ flux $20: 4820 \mathrm{~mL}$ in 32.73 second e $22.80 \mathrm{C}$ Cup 5 hut down 8:59 valor turned off Project No Entered By Date of Wo Disclosed To and Understood By Signed

Date

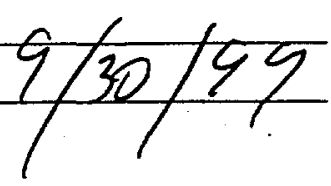

Date Date 
${ }_{60} 10 / 1 / 998: 00$ - Vacuam turned back on

$11: 25$ - 425mc in filter

$3: 13 \quad 350 \mathrm{~mL}$ in filter

$75 \mathrm{~mL}$ in 4 hown - have conother $250 \mathrm{nl}$ to va - So 2 anotten 12 poues -

$10 / 4199$ - vacaum off over weekend and sompled filter $-11: 36$ acid plued in CUF

- AN-107DFBead and fitturto - Botflew/cang and cap-with filtuet

907.44 gnams

filter assembly + new bottle + thoul solids 395.92 grams

ostematie $80 \mathrm{~mL}$ of solede

0,01M NaOH tianspered to ampty 3,5M Bottle (triple riusec tave of wash solation Bottle 583.30 grams

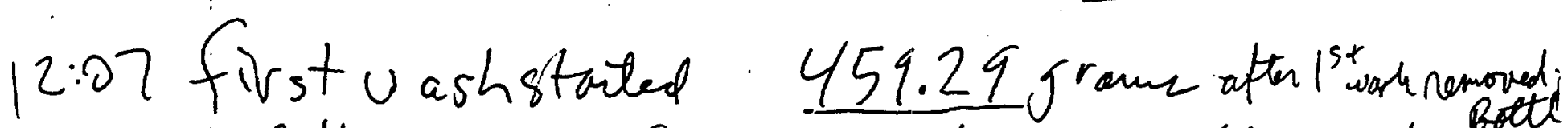
fitter viery fast- whent right \#hooagh Beth Proper No Entered By A Nobect Signed 1.

Date

2.

Date 
-HSt wash collected

61

12:19 cut valve 4 span and aid mum though the filter

13:45 bockpulad w/ arid twice then of 18 psi $R=30$

tare .706.17g mere $0.01 \mathrm{M}$ added to NCOH Bottle for solids washing

tare of washsdution bottles

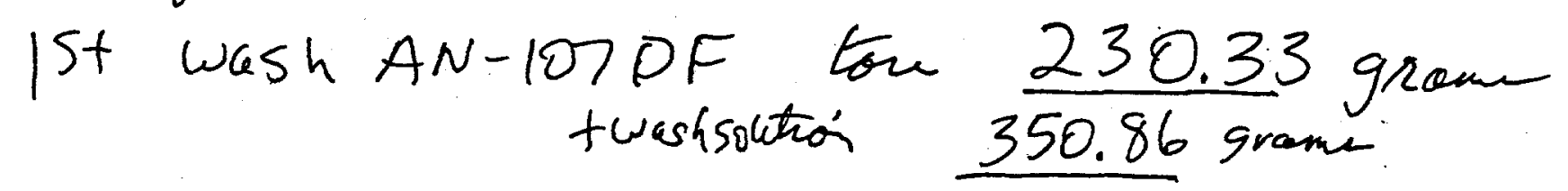

Ind wash AN-107Df tore $229.99 \mathrm{~g}$ rweshsolution $404.27 \mathrm{grom}$

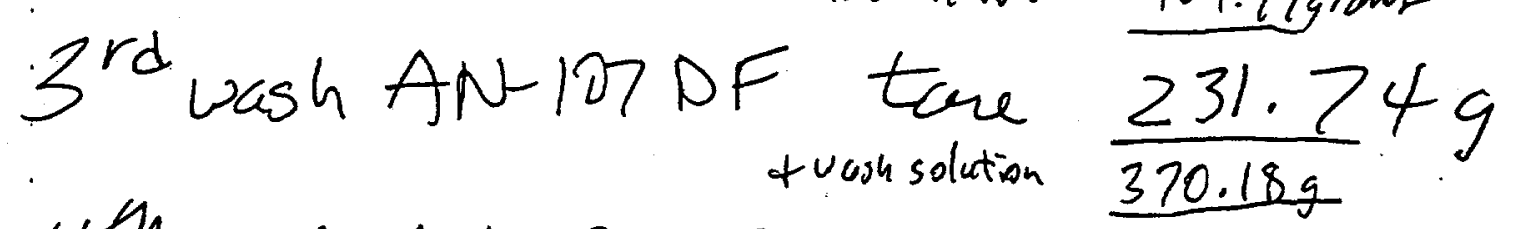

$4^{\text {th }}$ wash AN-PODDF tame $\frac{228.42 \mathrm{~g}}{\frac{415.639}{301.11}}$

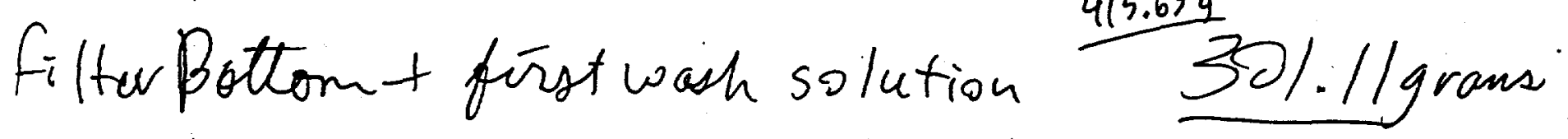

=are 180.43 gram button after 1 st wash parred sat

14:34 second wash solution coded - tore $0.01 \mathrm{~m}$ Bottle $524.07 \mathrm{gr}$

vacuum Not turned on - Solid swinled/washed

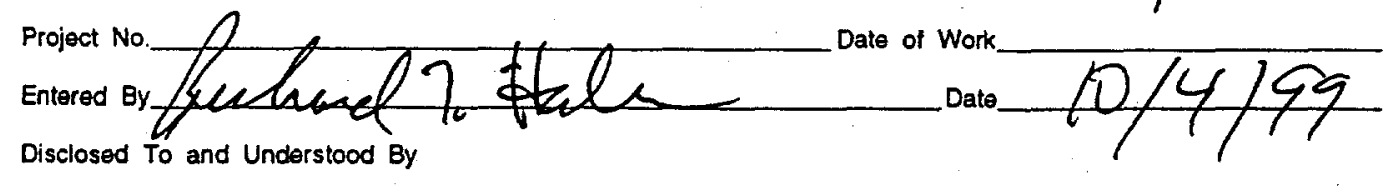

Date 
${ }_{62} 14: 47$ filter buckpalce twice with oied $t=0$ psi $R=30 \quad t=10$ min 15 psi $R=25$ 20 psi $=R=33$

15.06 boukpuled twice $t=0$ 20psi $R=35$ pressere moresed to 30 psi $R=55$ wiid drained + voter added - I Liter

wash solution filteved overnight w/o vacuum $101.05 \% 9455.59$ gram filto hottont second wash 2 ud vach soletion + botlle 404.77 grams Whash solution andleottle 528.94 grone

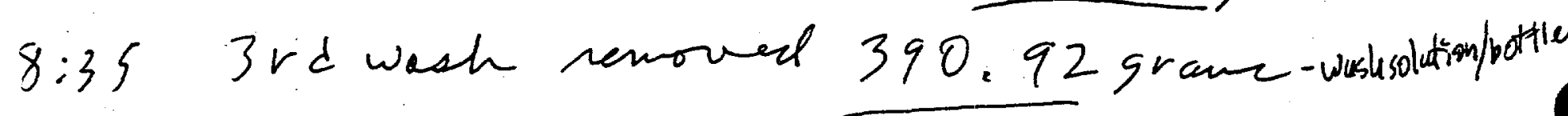
3ud worh addal vacuum not tarned on 8.45 Cuf strited with $1^{\text {st }}$ Anet cinse buck paleed 3 timo then dravied

An additional $100 \mathrm{ml}$ coashsolution oddedtobottle $525.61 \mathrm{~g}$

9125 demwatenchled-bahpulsed 3 this flux at 20 psi and $4.0 \mathrm{gpm}=32=R$ drumies

G:44 new/olean woter 20psi + 40 gpon $R=32$ bule paled 3 thine 20 p sis o o t 400 gpon $R=35$

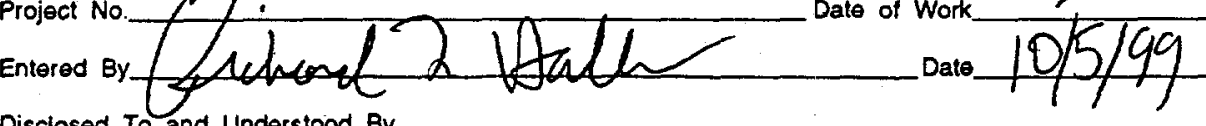
Disclosed To and Understood By

Date 


$$
\begin{aligned}
& \text { psi }=30 \text { coosstlo }=40 \quad R=55 \\
& p \text { si }=10 \text { cossflon }=4.3 \quad R=15
\end{aligned}
$$

63

pH $3,5-4.0$ - so one move since def drained t so deon with added

10:13 $\quad p_{5 i}=20 \quad 3.9 \mathrm{gpm} \quad R=32$

$10: 16$ 3rd wash completed - wo vacuum was used

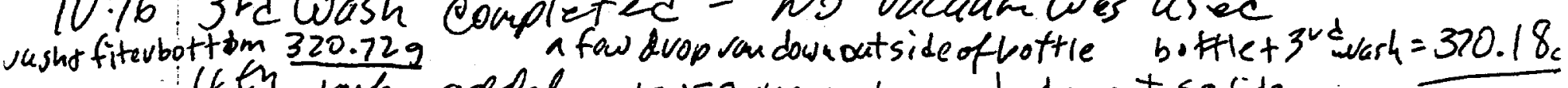
4 th wash added - 12:50 vacuum turnon to dry ont solids

wash bottle empty - $35 \% .41$ gram 4 we w wish $=274.28$ gram

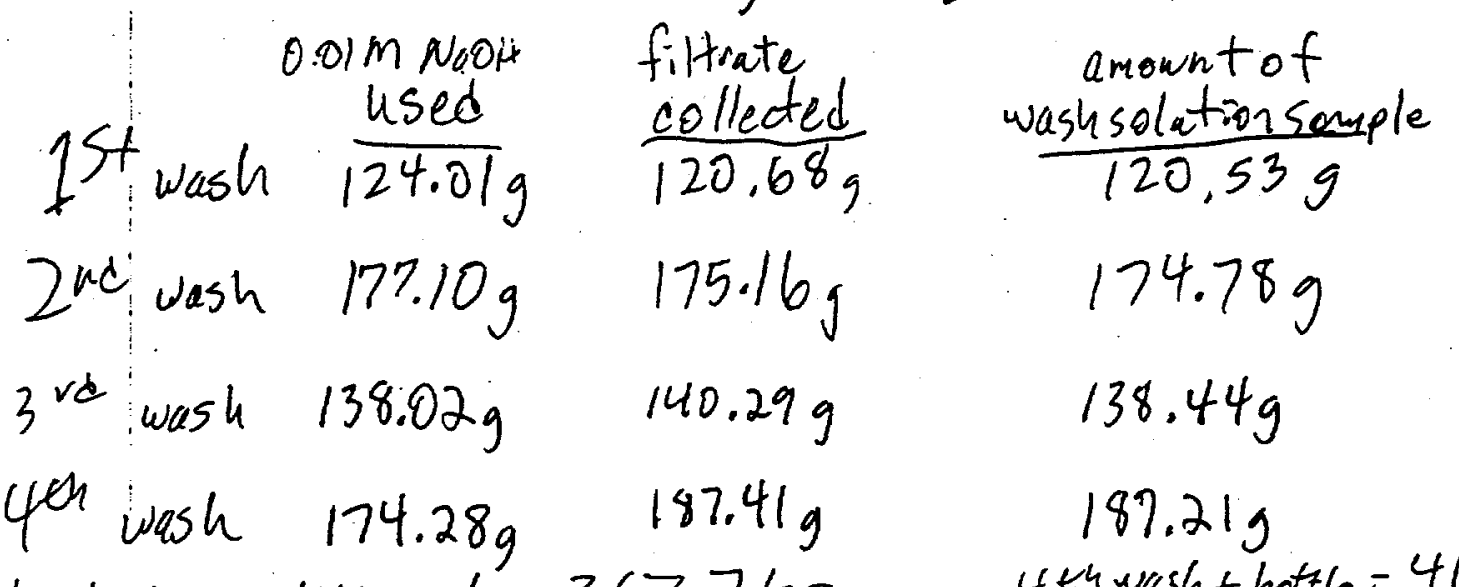

filterbottama 4 thrash $=367.76$ grams 4 th wash + bottle $=415.63$ grams filter bottom empty $=180.35$ same AN-107PF S0LIPS - fave bottle empty 258.17 grams
bottle/jart solids 349.07 grams
filter top lap t wet solids 201.85 grope

filter top/cep with solids removed. $109-68$ gram e

14:00 Performing clean water flux with CUF

10/06/99 external filter placer in line to cleon up system

8.42 git of $20 \mathrm{psi}+20 \mathrm{gmm} 11: 43$ bochpulsed 3 tans

flow $4.2 \mathrm{gpm} \quad D s i=20 \quad R=25 \quad t=3$ doped to $R=20$ Entered By Rom Disclosed To and Understood By

Signed 1

Date

Date 
64

Analyst tired Sompleutatransper to SAL Physical Meas moment Sampler for Paul Bred: $D F-05, D F-06$, and DF-13

Samples for Chemical Analyses

$D F=01, D F-02, D F-03, D F-04, D F-11, O F-14$ All ready in SAL are DF-20 and DF-21 (filtrate'
SAL $\# 4$ "tabled"

composited SAL \#4 "Labeled" samples

13:53:

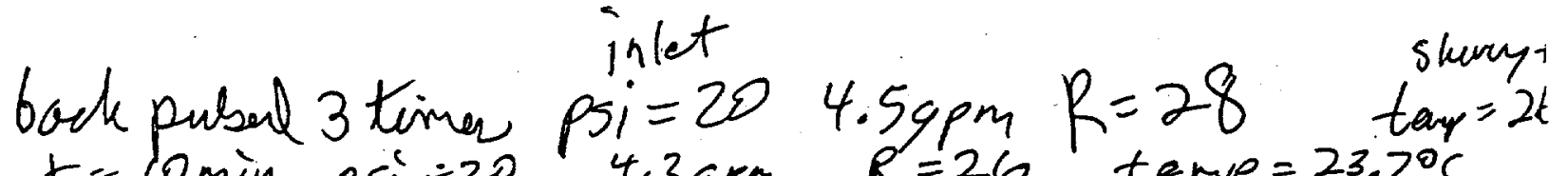

$$
\begin{aligned}
& t=10 \mathrm{~min} p \text { si }=20 \quad 4.3 \mathrm{grm} \quad R=26 \quad \text { temp }=23.7^{\circ} \mathrm{C} \\
& t=20 \mathrm{~min} p s_{i}=20 \quad 4.399^{\circ} \quad R=20 \quad \text { temp. }=19.9^{\circ} \mathrm{C} \\
& \text { obtect pressure }=18 \mathrm{ps} \text { i } \\
& t=30 \mathrm{~min} \quad p_{s i}=20 \quad 4.25 \mathrm{pm} \quad R=18 \quad \text { tans }=25.30
\end{aligned}
$$

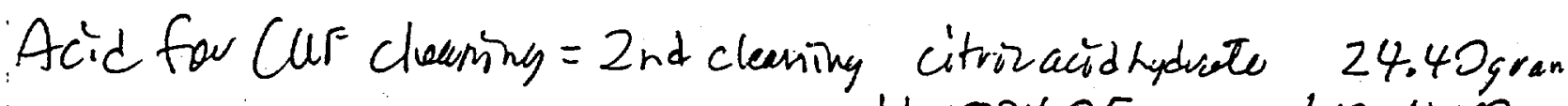
add 1024.05 prime in $\mathrm{HNO}_{3}$

$0.01 \mathrm{~m} \mathrm{NaOH}$ wash solution $1.43 \mathrm{~mL}(1.60$ grams $)$ of $3.5 \mathrm{M} \mathrm{NaOH}$ used for 2 neon washes added 499.94 greens tho.

10/137 an Sulfate Removal with Lir Resin approximately 2 grams of sulfate selective resin was provided to BNFL for AN -107 archive testing - resin propane bs Jun Lin - PNAN Entered By Signed 1 Date

2.

Date 
68 Additional Calculations for report - AN -1O? FF for Anion data we need to account for the nitrate oddedurth the $\mathrm{Sr}\left(\mathrm{NO}_{3}\right)_{2}$ - so the i is $2 \times .075 \mathrm{M}$ for the origin solution which was further diluted by $19 \%$ for the oblational Cur testing

$$
\begin{aligned}
& D F=20+D F-21 \text { Nituote } A U E=87400 \mu \mathrm{g} / \mathrm{g} \\
& \text { Clensity }=1.2414 \mathrm{~g} / \mathrm{mL} \quad \mathrm{MWNO}-\mathrm{H}=62 \mathrm{~g} / \mathrm{mole} \\
& \frac{.15 \mathrm{moles}}{L}\left(\frac{62 \mathrm{~g}}{\mathrm{~mole}}\right)\left(\frac{\mathrm{mL}}{1.241 \mathrm{~g}}\right)\left(\frac{\mathrm{L}}{1000 \mathrm{~mL}}\right)=.0075 \mathrm{~g} / \mathrm{gor} 7580 \mathrm{~ms} / \mathrm{g}
\end{aligned}
$$

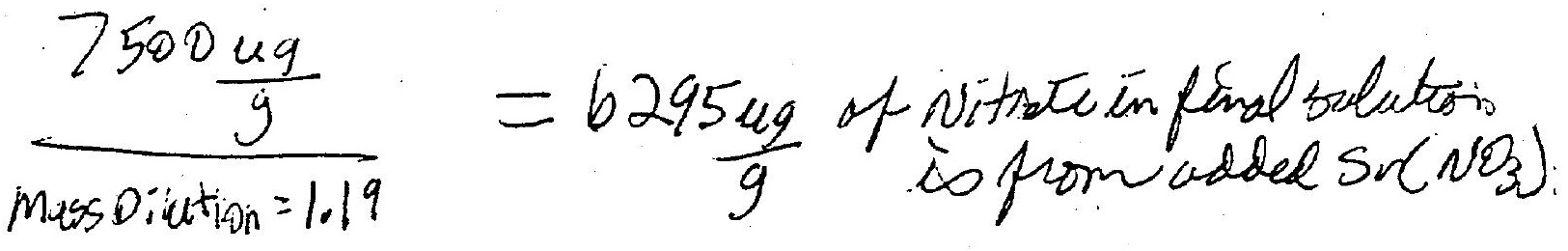

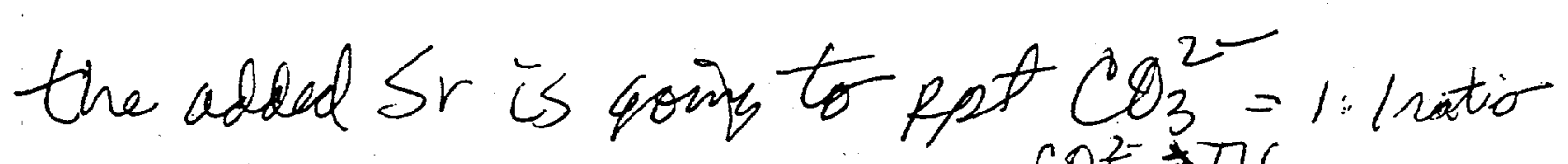

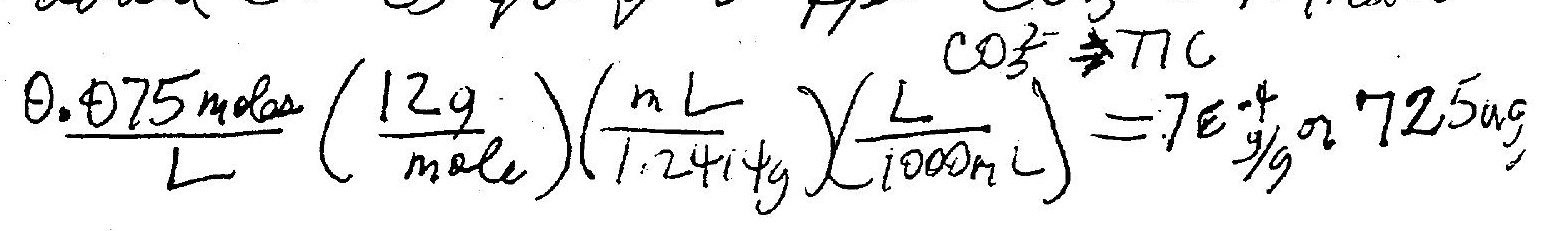

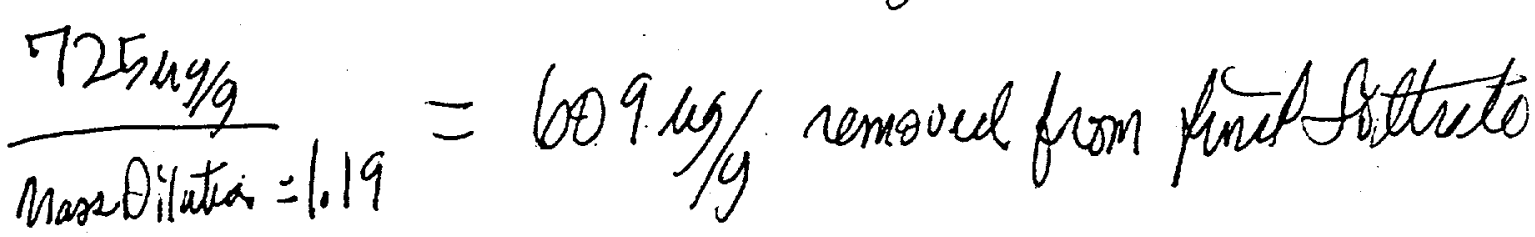

Calculate the expected yield of solids from Sr /TRU removal treatment

Project No. Entered By tefpereet

Disclosed To and Understood By

ged 1

Dato

2/11/2000 

total weight of waste treated $\rightarrow 1845.438$ grams
initial

69

We added 165.367 grams of $0.999 \mathrm{M} \operatorname{Sr}\left(\mathrm{NO}_{3}\right)_{2}$

$$
\begin{aligned}
(d=1.1585 \mathrm{~g} / \mathrm{mL}) & =0.1426 \text { moles Sr added } \\
& =12.49 \text { grams sr added }
\end{aligned}
$$

We added 105.558 grams of $1.001 \mathrm{M} \mathrm{NaMnO4}$

$$
\begin{aligned}
(d=1.0943 \mathrm{~g} / \mathrm{mL}) & =0.0966 \text { moles } \$ \mathrm{Pmn} \text { added } \\
& =
\end{aligned}
$$

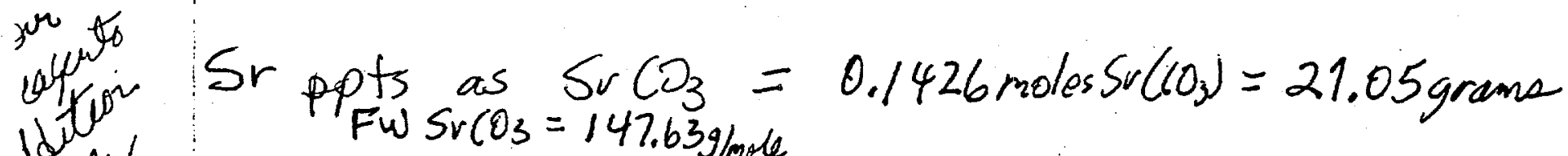
$F \omega \operatorname{src\theta _{3}}=147.63 \mathrm{~g} / \mathrm{mole}$

vv/ $M n$ rpt as $M n D_{2}=0.0966$ mole $m_{n} \theta_{2}=8.39$ grows Fo $\mathrm{MmO}_{2}=86.94$ / hole

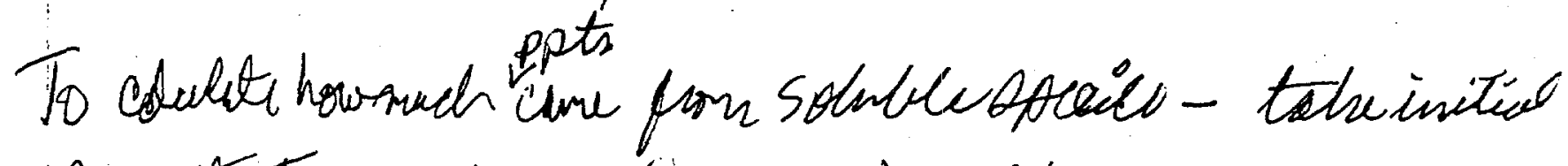
Concentration []$_{\mathrm{ug} / \mathrm{g}}(1845.438), \frac{\%}{100}$ removed $=u \mathrm{grams}$

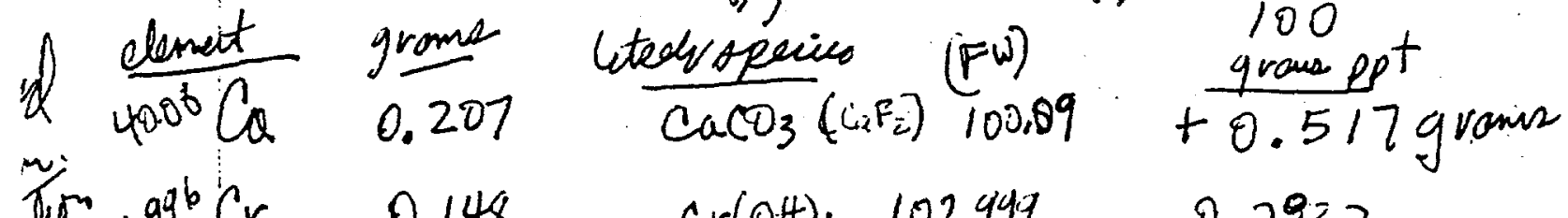

$$
\begin{aligned}
& \mathrm{Cr}(\mathrm{OH})_{3} \quad 102.499 \quad 0.2932 \text { grams }
\end{aligned}
$$

removed

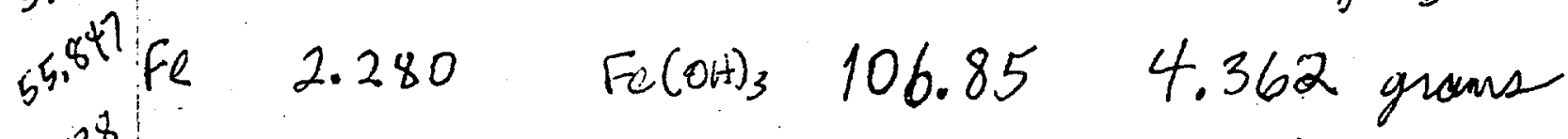

$54.43^{38} M_{n} \quad 0.600 \quad M_{n} \theta_{2} 86.94+0.950$ grams

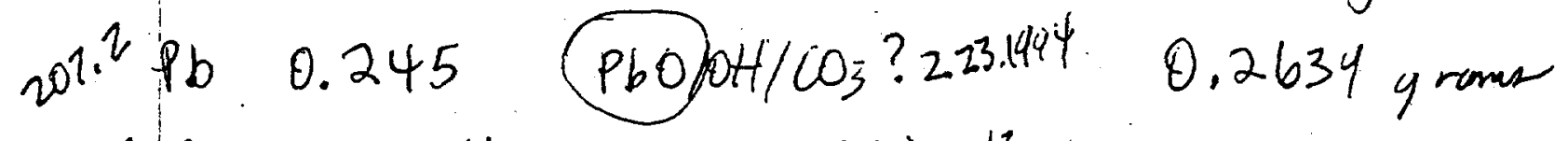

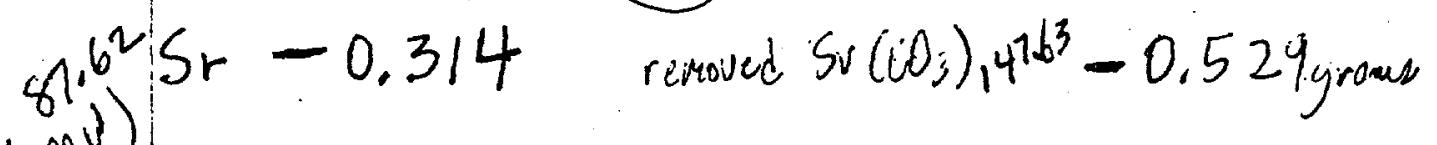

(mu)

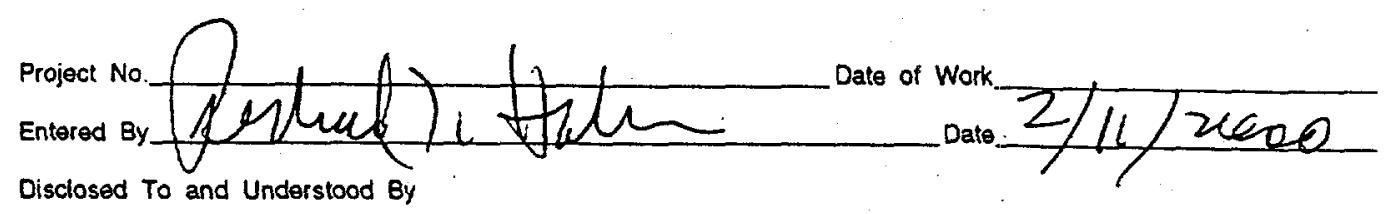

Disclosed To and Understood By

$10 / 2 / 2000$

Signed 1

Date.

Dale 
70

SrfRe a pit Solids Composettionfyied

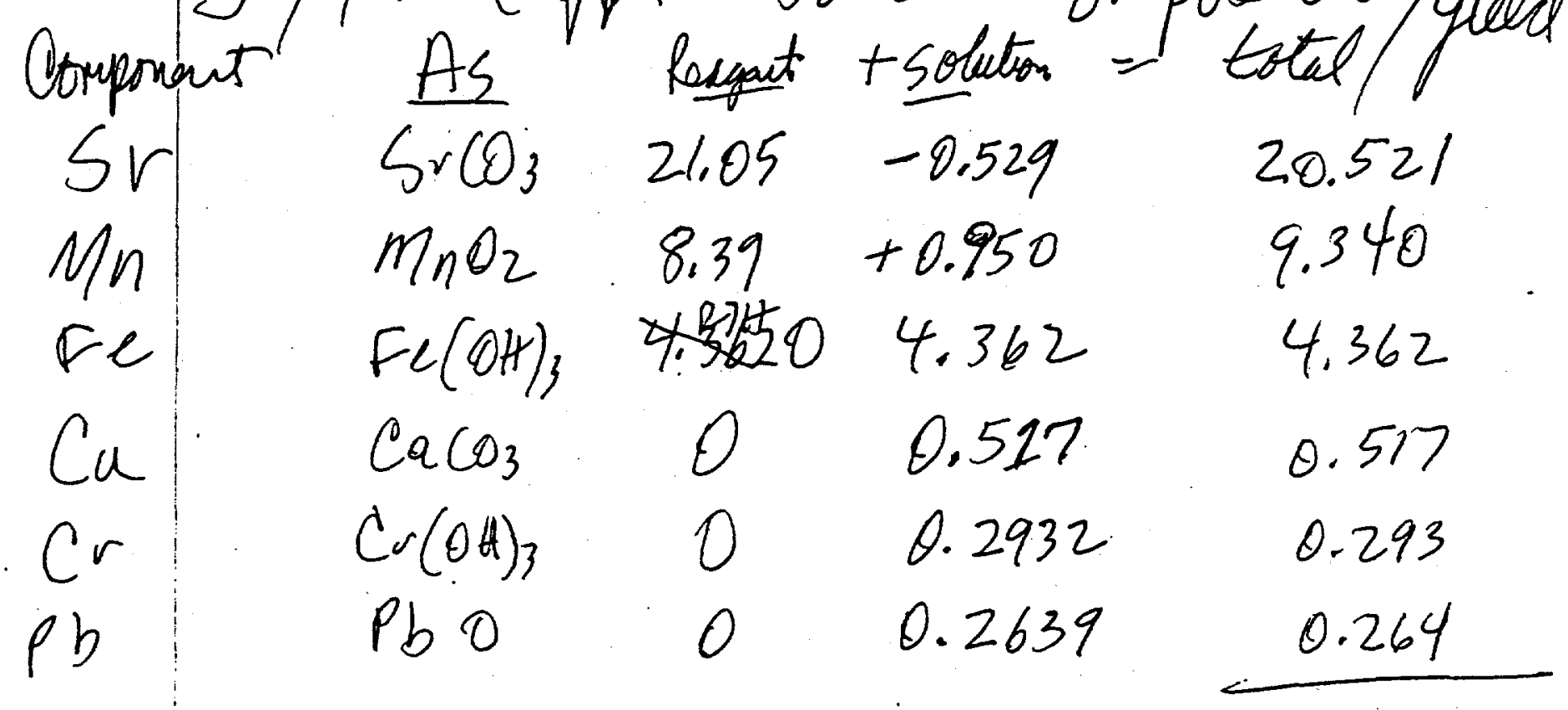

peat that the opt is 35.297 gums

Paul sport undesistued solis content of $0.62 \% \times 1845.438$ gram o $=11.44$ gran

PPI

$\begin{array}{lll}\text { gram } & & \text { As ICPelmment } \\ 20.521 & \mathrm{SrCO}_{3} & \frac{12.1794}{5.902} \\ 9.340 & \mathrm{MnO}_{2} & 2.28 \\ 4.362 & \mathrm{FeCOH}_{3} & 2.28 \\ 0.517 & \mathrm{Ca}_{3}\left(\mathrm{O}_{3}\right. & 0.207 \\ 0.293 & \mathrm{Cr}_{\mathrm{O}}\left(\mathrm{O}_{3}\right)_{3} & 0.148 \\ 0.264 & \mathrm{PbO}_{6} & 0.245\end{array}$

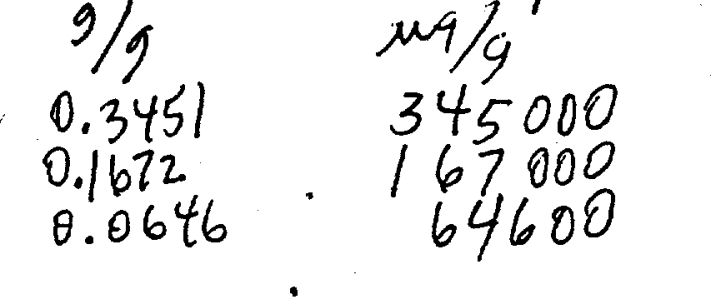

Sr predituita be 345000 bact only $272500-$ So hove $\frac{35}{x+35}=0.78973=9.3189$ gram

Project No. ant $2 / 1 / 20$ se

Disclosed

Date 
bexults suzgest 9.3189 jan of

71 sutrained edict -

major components of entraiesoboliss ore $\mathrm{Na}, \mathrm{Al}, \mathrm{Si}$, $\mathrm{Fe}$, and $\mathrm{Mn}$. Combining une get 44.616 gromefolid in utatolof $1845.438 \mathrm{~g}$ wost $296.54493,3.51 \mathrm{~m}^{2} \mathrm{raOl}$

$165.367 \mathrm{~g} 1.0 \mathrm{~m} \mathrm{sr}$ (wos)

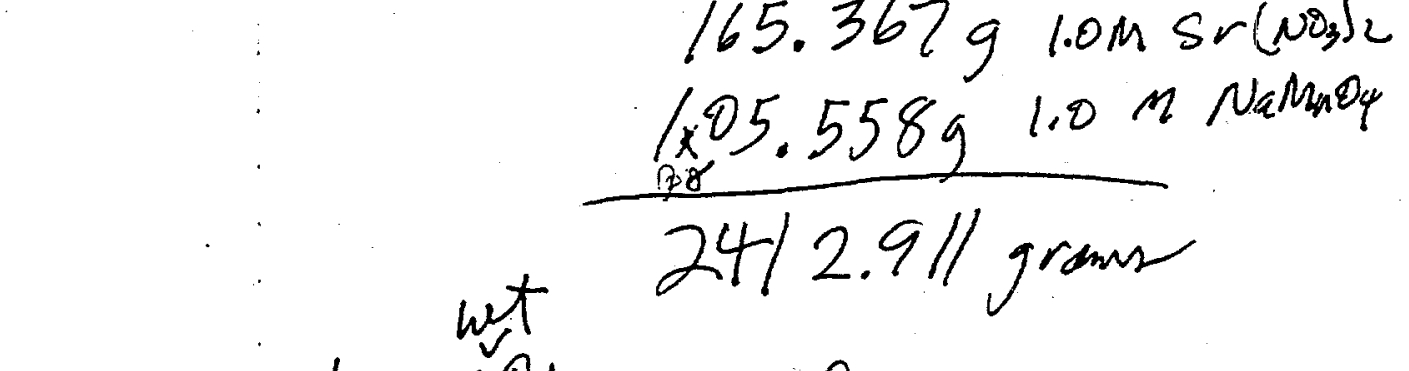

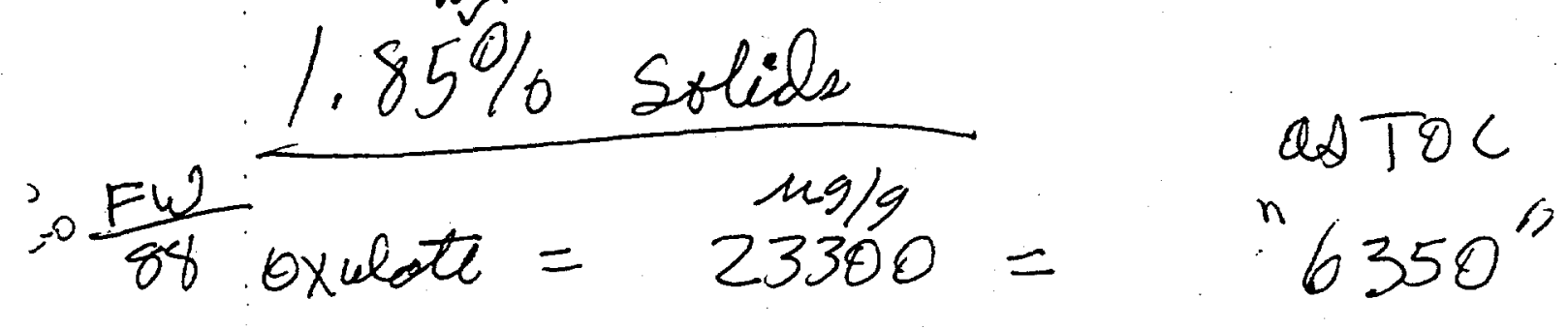

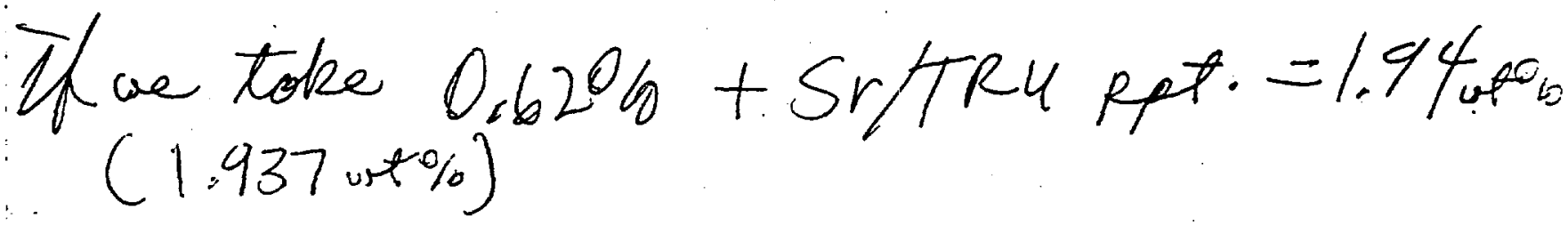

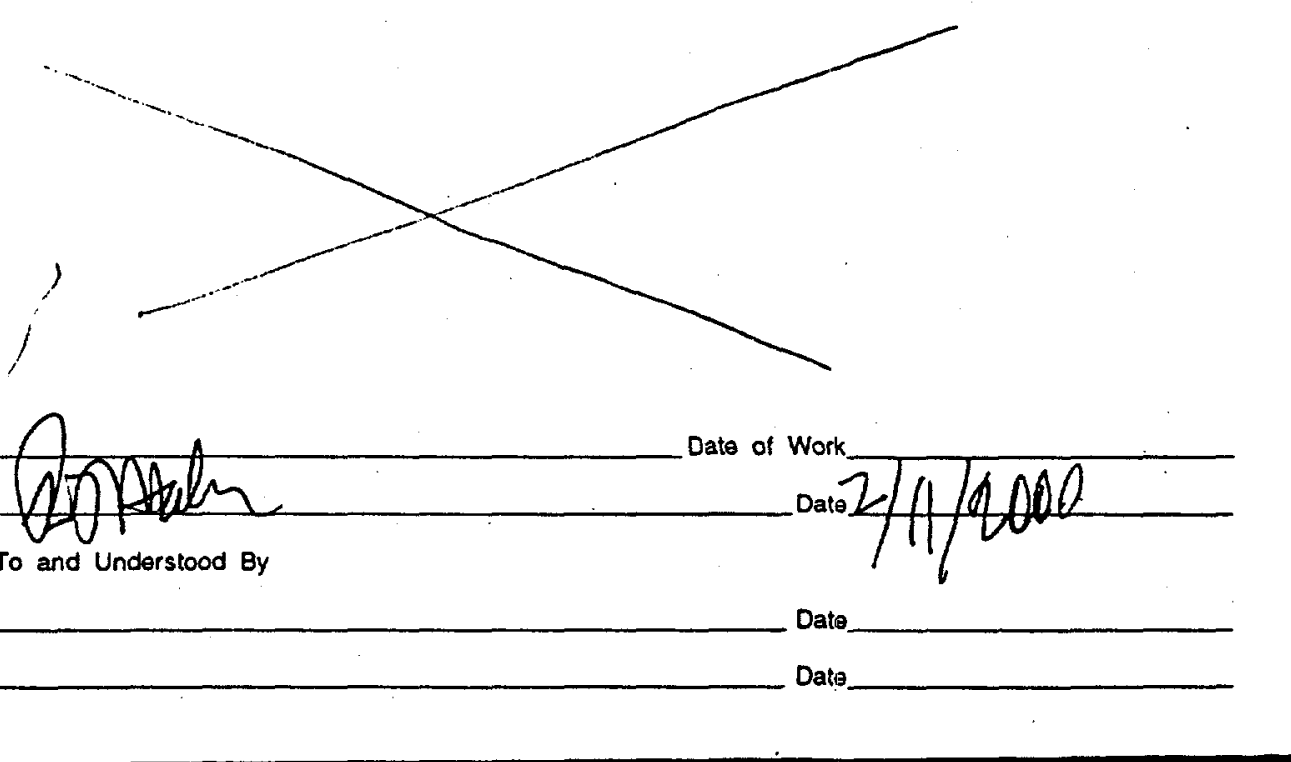


APPENDIX B: ANALYTICAL DATA

B. 1 


\section{Battelle Pacific Northwest Laboratory}

Radiochemical Processing Group-325 Building

Radioanalytical Applications Team

$11 / 15 / 1999$

Client : Hallen

Cognizant Scientist:

Concur :

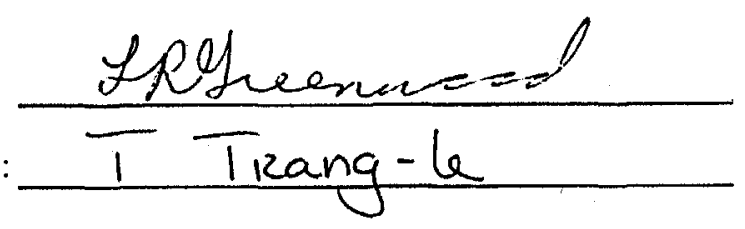

Date: $\quad \frac{11 / 15 / 99}{11 / 15 / 99}$

Procedure: PNL-ALO-450, 476, 4001, 417, 496

Measured Activities (uCi/g) with 1-sigma error

\begin{tabular}{|c|c|c|c|c|c|c|c|}
\hline $\begin{array}{l}\text { ALO ID. } \\
\text { Client ID }\end{array}$ & $\begin{array}{l}\text { Alpha } \\
\text { Error \% }\end{array}$ & $\begin{array}{c}\text { Sr-90 } \\
\text { Error \% }\end{array}$ & $\begin{array}{c}\text { Pu-239+ } \\
\text { Pu-240 } \\
\text { Error \% }\end{array}$ & $\begin{array}{l}\text { Pu-238 } \\
\text { Error \% }\end{array}$ & $\begin{array}{l}\text { Am-241 } \\
\text { Error \% }\end{array}$ & $\begin{array}{c}\mathrm{Cm}-243+ \\
\mathrm{Cm}-244 \\
\text { Error \% }\end{array}$ & $\begin{array}{l}\text { Cm-242 } \\
\text { Error \% }\end{array}$ \\
\hline $\begin{array}{l}\text { PB-0070 } \\
\text { Process Blank }\end{array}$ & $<6 . E-5$ & $\begin{array}{c}7.39 E-4 \\
11 \%\end{array}$ & $\begin{array}{c}2.20 \mathrm{E}-6 \\
14 \%\end{array}$ & $\begin{array}{c}2.72 E-6 \\
13 \%\end{array}$ & $\begin{array}{c}3.25 \mathrm{E}-6 \\
14 \%\end{array}$ & $\begin{array}{c}3.35 \mathrm{E}-6 \\
13 \%\end{array}$ & $<2 . E-7$ \\
\hline $\begin{array}{l}00-0070 \\
\text { DF-01 }\end{array}$ & & $\begin{array}{c}9.46 \mathrm{E}-1 \\
3 \%\end{array}$ & & & $\begin{array}{c}1.01 E-2 \\
4 \%\end{array}$ & $\begin{array}{c}4.24 \mathrm{E}-4 \\
6 \%\end{array}$ & $\begin{array}{c}3.86 E-5 \\
15 \%\end{array}$ \\
\hline $\begin{array}{l}\text { 00-0070 Rep } \\
\text { DF-01 }\end{array}$ & & $\begin{array}{c}1.04 E+0 \\
3 \%\end{array}$ & & & & & \\
\hline RPD & & $9 \%$ & & & & & \\
\hline $\begin{array}{l}00-0071 \\
\text { DF-11 }\end{array}$ & & $\begin{array}{c}5.85 E-1 \\
3 \%\end{array}$ & & & $\begin{array}{c}9.36 \mathrm{E}-3 \\
4 \%\end{array}$ & $\begin{array}{c}3.89 E-4 \\
5 \%\end{array}$ & $\begin{array}{c}4.17 \mathrm{E}-5 \\
10 \%\end{array}$ \\
\hline $\begin{array}{l}00-0072 \\
\text { DF-20 }\end{array}$ & $\begin{array}{c}8,10 \mathrm{E}-3 \\
3 \%\end{array}$ & $\begin{array}{c}4.69 E-1 \\
3 \%\end{array}$ & $\begin{array}{c}6.54 \mathrm{E}-4 \\
4 \%\end{array}$ & $\begin{array}{c}1.72 E-4 \\
6 \%\end{array}$ & $\begin{array}{c}5.11 \mathrm{E}-3 \\
4 \%\end{array}$ & $\begin{array}{c}2.47 E-4 \\
5 \%\end{array}$ & $\begin{array}{c}2.84 \mathrm{E}-5 \\
11 \%\end{array}$ \\
\hline $\begin{array}{l}\text { DO-0072 DUP } \\
\text { DF-20 }\end{array}$ & $\begin{array}{c}8.07 E-3 \\
3 \%\end{array}$ & $\begin{array}{c}4.78 E-1 \\
3 \%\end{array}$ & $\begin{array}{c}6.41 E-4 \\
4 \%\end{array}$ & $\begin{array}{c}1.72 E-4 \\
5 \%\end{array}$ & $\begin{array}{c}4.83 E-3 \\
4 \%\end{array}$ & $\begin{array}{c}1.82 E-4 \\
5 \%\end{array}$ & $\begin{array}{c}1.71 \mathrm{E}-5 \\
12 \%\end{array}$ \\
\hline RPD & $0 \%$ & $2 \%$ & $2 \%$ & $0 \%$ & $6 \%$ & $30 \%$ & $50 \%$ \\
\hline $\begin{array}{l}\text { 00-0072 Rep } \\
\text { DF-20 }\end{array}$ & $\begin{array}{c}8.26 \mathrm{E}-3 \\
3 \%\end{array}$ & & $\begin{array}{c}6.43 E-4 \\
4 \%\end{array}$ & $\begin{array}{c}1.61 E-4 \\
5 \%\end{array}$ & $\begin{array}{c}4.74 \mathrm{E}-3 \\
4 \%\end{array}$ & $\begin{array}{c}2.32 E-4 \\
5 \%\end{array}$ & $\begin{array}{c}2.08 E-5 \\
13 \%\end{array}$ \\
\hline $\begin{array}{l}00-0073 \\
D F-21\end{array}$ & $\begin{array}{c}7.72 \mathrm{E}-3 \\
3 \%\end{array}$ & $\begin{array}{c}4.81 E-1 \\
3 \%\end{array}$ & $\begin{array}{c}6.18 \mathrm{E}-4 \\
4 \%\end{array}$ & $\begin{array}{c}1.66 \mathrm{E}-4 \\
6 \%\end{array}$ & $\begin{array}{c}5.04 E-3 \\
4 \%\end{array}$ & $\begin{array}{c}2.43 E-4 \\
5 \%\end{array}$ & $\begin{array}{c}2.42 \mathrm{E}-5 \\
12 \%\end{array}$ \\
\hline
\end{tabular}

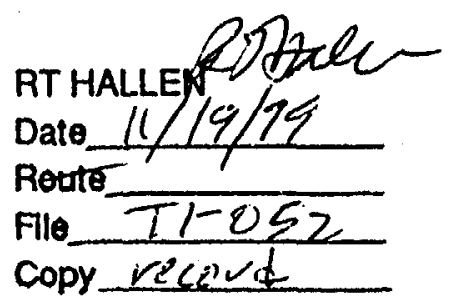


Measured Activities (uCi/g) with 1-sigma error

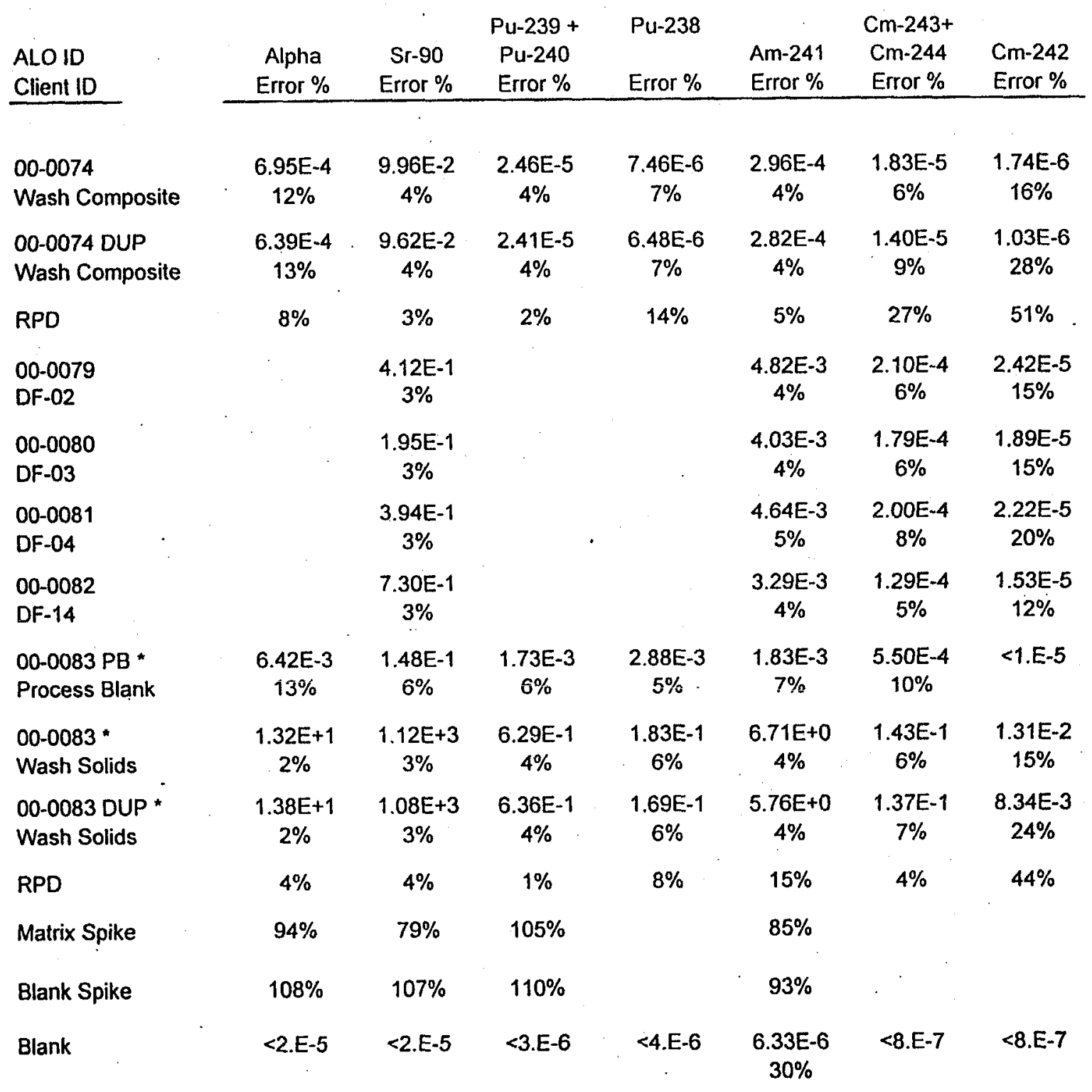

*Note: Results for the washed solids are reported per gram of dry weight. 
Battelle Pacific Northwest Laboratory

00-0070

Radiochemical Processing Group-325 Building

Radioanalytical Applications Team

$11 / 10 / 1999$

Client : Hallen

Cognizant Scientist:

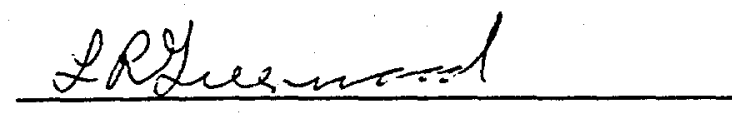

Concur :

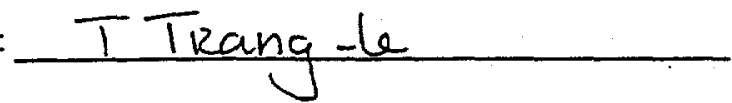

Date: $11 / 10 / 99$

Date: $11110 / 99$

Procedure: PNL-ALO-450

Gamma Energy Analyses

Measured Activities (uCi/g) with 1-sigma error

\begin{tabular}{|c|c|c|c|c|c|c|}
\hline $\begin{array}{l}\text { ALO ID } \\
\text { Client ID }\end{array}$ & $\begin{array}{l}\text { Co- } 60 \\
\text { Error \% }\end{array}$ & $\begin{array}{l}\text { Cs-134 } \\
\text { Error \% } \\
\end{array}$ & $\begin{array}{l}\text { Cs-137 } \\
\text { Error \% } \\
\end{array}$ & $\begin{array}{l}\text { Eu-154 } \\
\text { Error \% } \\
\end{array}$ & $\begin{array}{l}\text { Eu-155 } \\
\text { Error \% } \\
\end{array}$ & $\begin{array}{l}\text { Am-241 } \\
\text { Error \% } \\
\end{array}$ \\
\hline $\begin{array}{l}\text { PB-0070 } \\
\text { Process Blank }\end{array}$ & $<2 . E-5$ & $\begin{array}{c}1.88 \mathrm{E}-5 \\
43 \%\end{array}$ & $\begin{array}{c}2.55 E-4 \\
7 \%\end{array}$ & $<6 . E-5$ & $<6 . E-5$ & $<6 . E-5$ \\
\hline $\begin{array}{l}00-0072 \\
D F \cdot 20\end{array}$ & $\begin{array}{c}5.15 \mathrm{E}-2 \\
3 \%\end{array}$ & $<6 . E-3$ & $\begin{array}{c}1.24 E+2 \\
2 \%\end{array}$ & $\begin{array}{c}2.96 \mathrm{E}-2 \\
11 \%\end{array}$ & $<8 . E-2$ & $<8 . E-2$ \\
\hline $\begin{array}{l}00-0072 \text { DUP } \\
\text { DF-20 }\end{array}$ & $\begin{array}{c}5.22 \mathrm{E}-2 \\
3 \%\end{array}$ & $<6 . E-3$ & $\begin{array}{c}1.25 E+2 \\
2 \%\end{array}$ & $\begin{array}{c}2.99 E-2 \\
12 \%\end{array}$ & $<9 . E-2$ & $<8 . E-2$ \\
\hline$R P D$ & $1 \%$ & & $1 \%$ & $1 \%$ & & \\
\hline $\begin{array}{l}00-0073 \\
\text { DF-21 }\end{array}$ & $\begin{array}{c}4.80 \mathrm{E}-2 \\
3 \%\end{array}$ & $<6 . E-3$ & $\begin{array}{c}1.22 \mathrm{E}+2 \\
2 \%\end{array}$ & $\begin{array}{c}2.73 E-2 \\
12 \%\end{array}$ & $<8 . E-2$ & $<8 . E-2$ \\
\hline $\begin{array}{l}00-0074 \\
\text { Wash Composite }\end{array}$ & $\begin{array}{c}4.97 \mathrm{E}-3 \\
5 \%\end{array}$ & $<5 . E-4$ & $\begin{array}{c}1.51 E+1 \\
2 \%\end{array}$ & $\begin{array}{c}8.73 E-4 \\
46 \%\end{array}$ & $<2$.E-2 & $<2 . E-2$ \\
\hline $\begin{array}{l}\text { 00-0074 DUP } \\
\text { Wash Composite }\end{array}$ & $\begin{array}{c}5.26 \mathrm{E}-3 \\
4 \%\end{array}$ & $<6 . E-4$ & $\begin{array}{c}1.49 E+1 \\
2 \%\end{array}$ & $\begin{array}{c}1.77 \mathrm{E}-3 \\
22 \%\end{array}$ & $<2 . E-2$ & $<2 . E-2$ \\
\hline RPD & $6 \%$ & & $2 \%$ & $68 \%$ & & \\
\hline $\begin{array}{l}\text { PB-0083 } \\
\text { Process Blank }\end{array}$ & $<3 . E-3$ & $\begin{array}{c}3.58 \mathrm{E}-3 \\
21 \%\end{array}$ & $\begin{array}{c}7.48 \mathrm{E}-2 \\
3 \%\end{array}$ & $<7 . E-3$ & $<7$.E-3 & $<5 . E-3$ \\
\hline $\begin{array}{l}\text { 00-0083* } \\
\text { Wash Solids }\end{array}$ & $\begin{array}{c}4.43 E-2 \\
12 \%\end{array}$ & $<4 . E-2$ & $\begin{array}{c}6.84 \mathrm{E}+1 \\
2 \%\end{array}$ & $\begin{array}{c}1.45 E+1 \\
2 \%\end{array}$ & $\begin{array}{c}1.02 E+1 \\
2 \%\end{array}$ & $\begin{array}{c}1.35 E+1 \\
4 \%\end{array}$ \\
\hline $\begin{array}{l}\text { 00-0083 DUP * } \\
\text { Wash Solids }\end{array}$ & $\begin{array}{c}5.41 \mathrm{E}-2 \\
10 \%\end{array}$ & $<4$.E-2 & $\begin{array}{c}7.02 E+1 \\
2 \%\end{array}$ & $\begin{array}{c}1.38 \mathrm{E}+1 \\
2 \%\end{array}$ & $\begin{array}{c}9.66 \mathrm{E}+0 \\
3 \%\end{array}$ & $\begin{array}{c}1.34 E+1 \\
4 \%\end{array}$ \\
\hline RPD & $20 \%$ & & $3 \%$ & $5 \%$ & $5 \%$ & $1 \%$ \\
\hline
\end{tabular}

*Note: Results for the washed solids are reported per gram of dry weight.

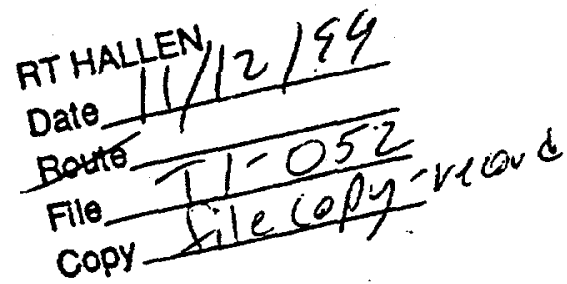


FNNL Maintenance Services Record of Calibration

RT HALLEN

TEMP.DET.

$\frac{\text { Serlat }}{325-427}$

$\frac{\text { Property" }}{N / / 7}$

Dato

Routo

File

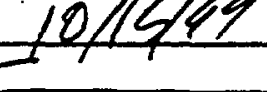

Calibration Date or Hefopy - File

Interval (Mo.) Callbration

$24 \div 09-15-99$

Callbration Due

$09-2001$

Tolerance

$\pm 3^{\circ} \mathrm{C}$ of Readidig

$\frac{\text { Buाlng }}{325 \text { BLdg }}$

COTAGH
$\frac{\mathrm{Room}}{601}$

$\frac{C A L}{27}$

Asea

300

$\frac{R \in V}{6}$

Calibration Standard

Traceable to riational Instltute of Standaids and Technology (MIST)

$0046.08-04-00$

$0097 \quad 09-15-99$

$$
0-100 \mathrm{C}
$$

Inputustandard Range

$0-100^{\circ} \mathrm{C}$
Outputrindicallon Range

$0.100 . \mathrm{C}$

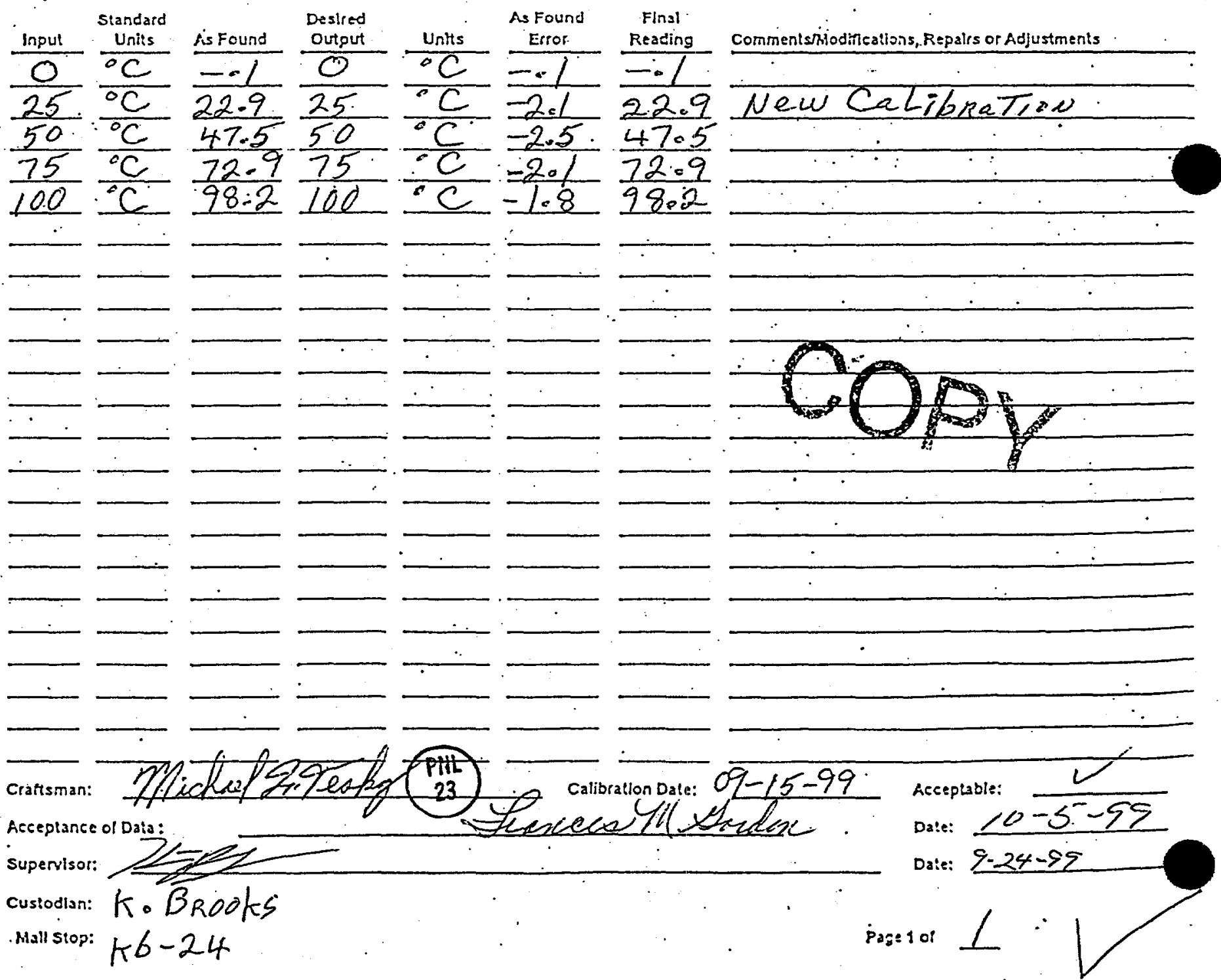




\section{Battelle PNNL/325 Bldg/RPG/Inorganic Analysis ... ICPAES Data Report}

Project:

Client:

29953

R. T. Hallen

ACL Number(s): 00-0070 through 00-0083

Client ID: "DF-01" through "WASHED SOLIDS"

ASR Number: 5536

Total Samples: 14

Procedure: PNL-ALO-211, "Determination of Elements by Inductively Coupled Argon Plasma Atomic Emission Spectrometry" (ICP-AES).

Analyst: $\quad$ D.R. Sanders

Analysis Date (Filename): 11-01-99 (A0547, ALO-128),

11-02-99 (A0548, ALO-128),

11-03-99 (A0549, ALO-128),

11-04-99 (A0550, ALO-129),

11-12-99 (A0555, ALO-115 [KOH/Ni fusion])

See Chemical Measurement Center 98620: ICP-325-405-1 File for Calibration and Maintenance Records.

M\&TE Number: $\quad$ ICPAES instrument -- WB73520

Mettler AT400 Balance -- Ser.No. 360-06-01-029

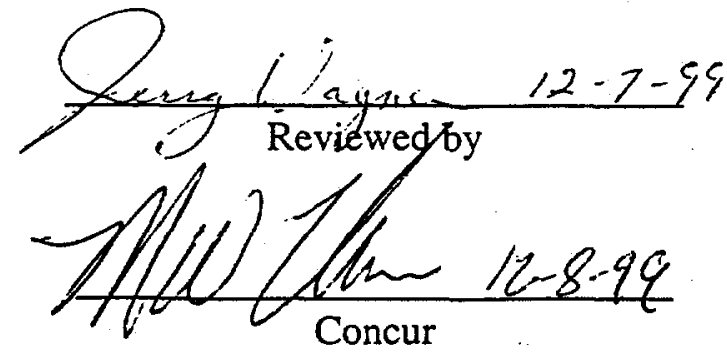

$12 / 7 / 99$ 


\section{Battelle PNNL/325 Bldg/RPG/Inorganic Analysis ... ICPAES Data Report}

Thirteen radioactive liquid samples, DF-01 through DF-14 (ACL\# 00-0070 through 00-0082), were analyzed by ICPAES after preparation by the Shielded Analytic Lab (SAL). Samples were prepared by SAL using PNL-ALO-128 acid digestion procedure. Approximately 5 to 6 grams of sample (weighed) was processed and diluted to a final volume of about $25 \mathrm{ml}$. A $1 \mathrm{ml}$ aliquot taken from each processed sample was weighed and the density estimated by dividing the aliquot weight by the weight of water using the same pipette. The final volume of each processed sample was determined using the final weight of processed sample divided by the estimated density. Concentrations reported have been corrected for process and final volumes as reflected on "Corrected" bench sheets distributed by SAL.

One radioactive solid sample was prepared in duplicate by SAL, WASHED SOLIDS (ACL\# 00-0083) using ALO-115 KOH/Ni fusion procedure. Prepared samples were analyzed by ICPAES. Approximately $0.2 \mathrm{~g}$ aliquots were used to prepare samples using fusion procedure PNL-ALO-115 (KOH/Ni). Fusion prepared samples were diluted to a final volume of $100 \mathrm{ml}$. Additional dilution up to 10-fold was necessary during ICPAES analysis because of high manganese, strontium and sodium concentration. Fusion prepared samples required additional $\mathrm{HCl}$. All solutions remained soluble after final dilution.

The one solid sample identified above, WASHED SOLIDS (ACL\# 00-0083) was also prepared in duplicate using PNL-ALO-129 acid digestion procedure for solids by SAL and analyzed by ICPAES. Sample size was about $0.4 \mathrm{~g}$ each. After digestion each sample was diluted to a final volume of approximately $20 \mathrm{ml}$ and weighed. A $1 \mathrm{ml}$ aliquot taken from each processed sample was weighed and the density estimated by dividing the aliquot weight by the weight of water using the same pipette. The final volume of each processed sample was determined using the final weight of processed sample divided by the estimated density. Relatively high analytical dilution was necessary because of very high concentration of manganese and strontium present in the sample and duplicate.

Measurement results reported have been corrected for preparation and analytical dilution. All results reported are in $\mu \mathrm{g} / \mathrm{g}$ for the solids and liquid samples. Volumes and weights have been recorded on bench sheets and included with this report.

Specific analyte of interest requested is sodium for liquid samples (ALO\# 00-0070 through 000082) prepared using PNL-ALO-128. Also requested were the following analytes in table-2 included with the ASR-5536 and special instructions. Analytes in table 2 include: $\mathrm{Al}, \mathrm{Ba}, \mathrm{Ca}$, $\mathrm{Cd}, \mathrm{Co}, \mathrm{Cr}, \mathrm{Cu}, \mathrm{Fe}, \mathrm{K}, \mathrm{La}, \mathrm{Mg}, \mathrm{Mn}, \mathrm{Mo}, \mathrm{Na}, \mathrm{Ni}, \mathrm{Pb}, \mathrm{Si}, \mathrm{Sr}, \mathrm{Ti}, \mathrm{U}$, and $\mathrm{Zn}$.

$12 / 7 / 99$ 


\section{Battelle PNNL/325 BIdg/RPG/Inorganic Analysis ... ICPAES Data Report}

The solid sample contained high concentrations ( 1 to $25 \mathrm{Wt} \%$ ) of iron, manganese, sodium, and strontium. Concentration results for the fusion prepared and acid digestion prepared samples were similar and were typically within about $20 \%$ or better for analyte concentration above EQL.

The liquid samples contained high concentrations of sodium. A few samples had moderately high concentrations of aluminum. All other analytes measured were much lower in concentration.

Quality control check-standard results met tolerance requirements for analytes of interest except as noted below. Following is a list of quality control measurement results relative to ICPAES analysis tolerance requirements under MCS-033.

Five fold serial dilution:

(Solid samples/fusion) Results were within tolerance limit of $\leq 10 \%$ after correcting for dilution.

(Solid samples/acid dig.) Analytes of interest were within tolerance limit of $\leq 10 \%$ after correcting for dilution except as follows. Iron, calcium, chromium, and sodium were about 12 to $14 \%$ low after correcting for dilution. The reason may be related to high total dissolved solids ( $\sim 0.4 \%$ TDS).

(Aqueous samples) All results for analytes of interest were within tolerance limit of $\leq 10 \%$ after correcting for dilution except sodium. Sodium concentration was slightly low (-12.9\%) after dilution correction in sample 00-0082. The difference may be due to sodium carry-over from a previous sample containing high sodium.

Duplicate RPD (Relative Percent Difference):

(Solid samples/fusion) All analytes of interest were recovered within tolerance limit of $\leq 20 \%$ relative percent difference (RPD).

\section{Duplicate RPD (Relative Percent Difference):}

(Solid samples/acid dig.) All analytes of interest were recovered within tolerance limit of $\leq 20 \%$ relative percent difference (RPD) except sodium. Sodium was $20.9 \%$ RPD which is slightly above the tolerance limit of $20 \%$. All other analyte concentrations were less than about $14 \%$ RPD, typically about $5 \% \mathrm{RPD}$ or better.

$12 / 7 / 99$ 


\section{Battelle PNNL/325 Bldg/RPG/Inorganic Analysis ... ICPAES Data Report}

(Aqueous samples) All analytes of interest were recovered within tolerance limit of $\leq 20 \%$ relative percent difference (RPD).

Post-Spiked Samples (Group A):

(Solid samples/fusion) All analytes of interest were recovered within tolerance of $75 \%$ to $125 \%$.

(Solid samples/acid dig.) All analytes of interest were recovered within tolerance of $75 \%$ to $125 \%$.

(Aqueous samples) All analytes of interest were recovered within tolerance of $75 \%$ to $125 \%$.

Post-Spiked Samples (Group B):

(Solid samples/fusion) All analytes of interest were recovered within tolerance of $75 \%$ to $125 \%$.

(Solid samples/acid dig.) All analytes of interest were recovered within tolerance of $75 \%$ to $125 \%$.

(Aqueous samples)

All analytes of interest were recovered within tolerance of $75 \%$ to $125 \%$.

Blank Spike:

(Solid samples/fusion) A blank spike is not require for fusion prepared samples.

(Solid samples/acid dig.) None prepared.

(Aqueous samples) None prepared.

Matrix Spiked Sample:

(Solid samples/fusion) A matrix spike is not require for fusion prepared samples.

(Solid samples/acid dig.) None prepared.

(Aqueous samples) None prepared.

$\underline{12 / 7 / 99}$ 


\section{Battelle PNNL/325 B/dg/RPG/Inorganic Analysis ... ICPAES Data Report}

Quality Control Check Standards (solid samples/fusion):

Concentration of all analytes of interest in the $\mathrm{KOH} / \mathrm{Ni}$ fusion prepared analytical run was within tolerance limit of $\pm 10 \%$ accuracy in standards: QC_MCVA, QC_MCVB, and QC_SSTMCV except as follows. Potassium was high (-14\%) in QC_MCVA two out of four times. Calibration Blank (ICP98.0) concentration was acceptable, less than two times IDL.

High Calibration Standard Check (solid samples/fusion):

Verification of the high-end calibration concentration for all analytes of interest is within tolerance of $\pm 5 \%$ accuracy except potassium. Potassium was slightly high (7\% \& 9\%) in QC_SST however it was within $3 \%$ when measured in a single analyte standard of the same concentration.

Quality Control Check Standards (solid samples/acid dig.):

Concentration of all analytes of interest was within tolerance limit of \pm 10\% accuracy in standards: QC_MCVA, QC_MCVB. Several analytes were slightly above (11\% to $15 \%$ ) tolerance limits in checkstandard QC_SSTMCV. The analytes of interest that were out of tolerance measured at the end of the run include iron, potassium, manganese, sodium, nickel, lead and silicon. Initially, all were within tolerance limits. Calibration Blank (ICP98.0) concentration was acceptable, less than two times IDL.

High Calibration Standard Check (solid samples/acid dig.):

Verification of the high-end calibration concentration for all analytes of interest is within tolerance of $\pm 5 \%$ accuracy except potassium, which measured $22 \%$ high at the end of the run. Potassium was not detected in the acid digested sample.

$12 / 7 / 99$ 


\section{Battelle PNNL/325 Bldg/RPG/Inorganic Analysis ... ICPAES Data Report}

\section{Quality Control Check Standards (aqueous samples):}

Concentration of all analytes of interest in the acid digested aqueous prepared analytical run was within tolerance limit of $\pm 10 \%$ accuracy in the standards: QC_MCVA, QC_MCVB, and QC_SSTMCV except as follows. Potassium was slightly high, up to $13 \%$ in two of three QC_MCVA check standard measurements. The high potassium values may be due to memory effect or carry-over from one measurement to the next. Sodium was slightly high (11\%) in QC_SSTMCV in one of two check standard measurements and may also be due to memory effect or carry-over from a sample with high sodium concentration.

High Calibration Standard Check (aqueous samples):

Verification of the high-end calibration concentration for all analytes of interest was within tolerance of $\pm 5 \%$ accuracy except potassium. Potassium concentration varied up to $11 \%$ too high in QC_SST check standard. Potassium concentration in aqueous samples usually was low when detected and then only slightly above EQL. Measurement of a single element potassium standard always came within tolerance limits.

Process Blank: (Solid samples/fusion)

All analytes of interest were within tolerance limit of $\leq \mathrm{EQL}$ or $<5 \%$ of sample concentration in PNL-ALO-115 KOH/Ni fusion prepared samples.

(Solid samples/acid dig.) All analytes of interest were within tolerance limit of $\leq \mathrm{EQL}$ or $<5 \%$ of sample concentration except silicon. Silicon concentration in the blank was equivalent to about $950 \mathrm{ug} / \mathrm{g}$, which is equivalent to about $24 \%$ of the lowest concentration found in the samples. Silicon concentrations measured in the samples are generally below EQL.

(Aqueous samples)

All analytes of interest were within tolerance limit of $\leq \mathrm{EQL}$ or $<5 \%$ of sample concentration except iron and silicon. Silicon concentration in the process-blank was about the same concentration as the samples. Iron concentration found in the blank was variable. For one set of samples it was about the same concentration as the samples. In another processed batch of samples iron in the blank was much lower than in the samples. The reason for the variability between process blanks is not known.

$\underline{12 / 7 / 99}$ 


\section{Battelle PNNL/325 BIdg/RPG/Inorganic Analysis ... ICPAES Data Report}

Laboratory Control Standard (LCS):

(Solid samples/fusion) All analytes of interest except strontium, at a concentration equal to or greater than EQL were recovered within tolerance limit of $75 \%$ to $125 \%$ in fusion prepared LCS standard. SRM-2710 Montana Soil was used for the LCS in PNL-ALO-115 fusion preparations. Strontium recovery was slightly above tolerance limit (126\% recovery measured). Strontium concentration in the WASHED SOLIDS is about one hundred times higher in concentration than the LCS.

(Solid samples/acid dig.) No LCS was prepared for PNL-ALO-129 acid digested samples.

(Aqueous samples) No LCS was prepared for PNL-ALO-128 acid digested samples.

Analytes other than those requested by the client are for information only. Please note bracketed values listed in the data report are within ten times instrument detection limit and have a potential uncertainty much greater than $15 \%$.

Comments:

1) "Final Results" have been corrected for all laboratory dilution performed on the sample during processing and analysis unless specifically noted.

2) Detection limits (DL) shown are for acidified water. Detection limits for other matrices may be determined if requested.

3) Routine precision and bias is typically $\pm 15 \%$ or better for samples in dilute, acidified water (e.g. $2 \% \mathrm{v} / \mathrm{v} \mathrm{HNO}_{3}$ or less) at analyte concentrations greater than ten times detection limit up to the upper calibration level. This also presumes that the total dissolved solids concentration in the sample is less than $5000 \mu \mathrm{g} / \mathrm{mL}$ ( 0.5 per cent by weight).

4) Absolute precision, bias and detection limits may be determined on each sample if required by the client.

5) The maximum number of significant figures for all ICP measurements is 2. 


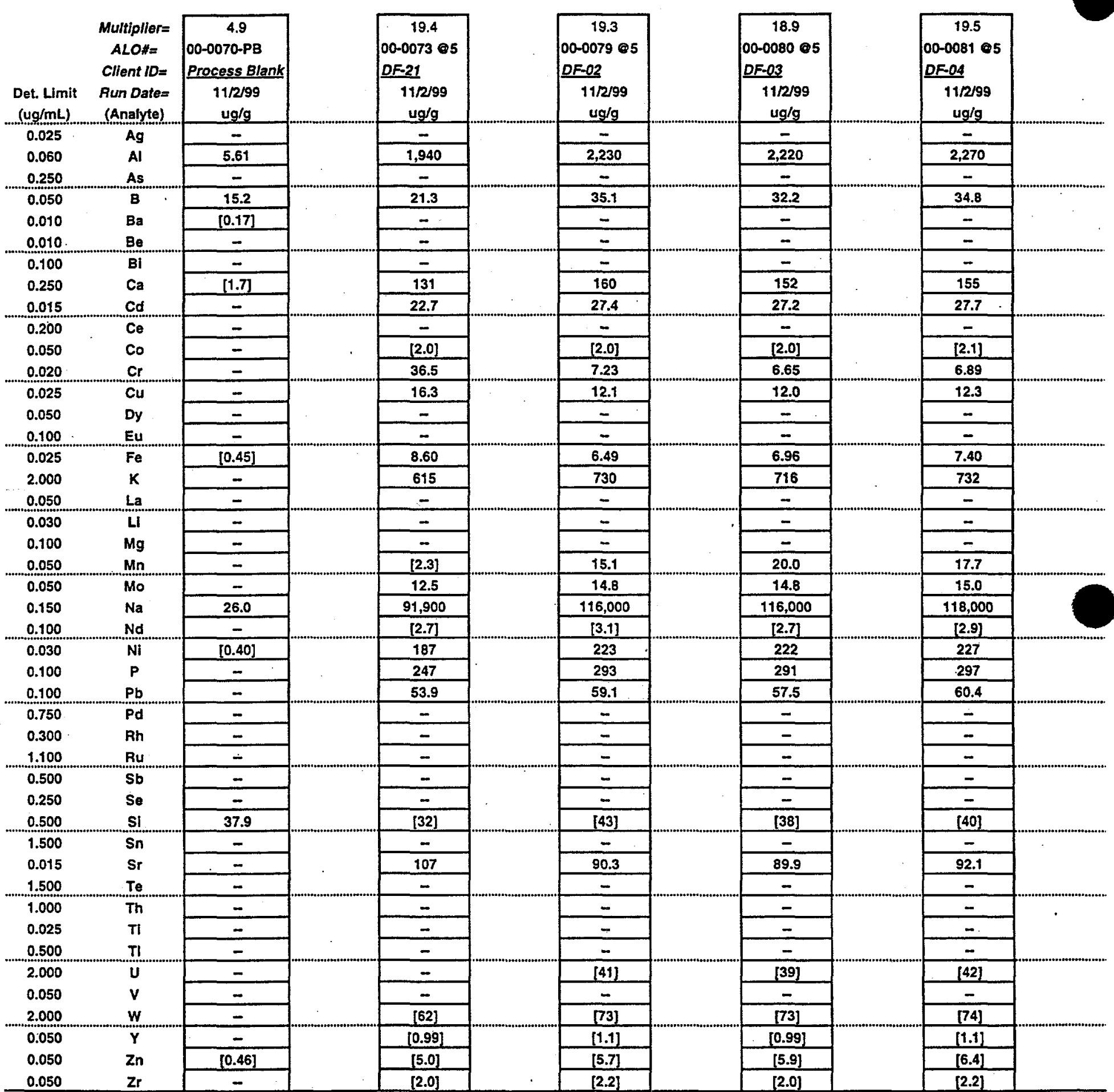

Note: 1) Overall error greater than 10-times detection limit is estimated to be within $+1-15 \%$

2) Values in brackets $\square$ are within 10-times detection limit with errors likely to exceed $15 \%$.

3) "-." indicate measurement is below detection. Sample detection limit may be found by

multiplying "det. limit" (far lett column) by "multiplier" (top of each column). 
Battelle PNNL/RPG/Inorganic Analysis ... ICPAES Data Report Page 1 of 1

\begin{tabular}{|c|c|c|c|c|c|c|c|c|c|}
\hline $\begin{array}{l}\text { Det. Limit } \\
\text { (ug/mL) }\end{array}$ & $\begin{array}{c}\text { Multiplier= } \\
\text { ALO\#= } \\
\text { Client ID= } \\
\text { Run Date= } \\
\text { (Analyte) }\end{array}$ & $\begin{array}{c}19.2 \\
00-0070 \text { \&5 } \\
\text { DF-01 } \\
11 / 1 / 99 \\
\mathrm{ug} / \mathrm{g} \\
\end{array}$ & $\begin{array}{c}18.8 \\
00-0071 @ 5 \\
\frac{D F-11}{11 / 1 / 99} \\
u g / g\end{array}$ & $\begin{array}{c}19.7 \\
00-0072 @ 5 \\
D F-20 \\
11 / 1 / 99 \\
u g / g \\
\end{array}$ & & \begin{tabular}{|c|}
19.7 \\
$00-0072$ DUP \\
$D F-20$ \\
$11 / 1 / 99$ \\
$\mathrm{ug} / \mathrm{g}$ \\
\end{tabular} & & $\begin{array}{c}19.4 \\
00-0082 \text { @5 } \\
\frac{D F-14}{11 / 1 / 99} \\
u g / g\end{array}$ & \\
\hline 0.025 & Ag & - & - & - & & - & & - & \\
\hline 0.060 & Al & 2,140 & 2,220 & 1,990 & & 2,050 & & 1,910 & \\
\hline 0.250 & As & - & - & - & & - & & - & \\
\hline 0.050 & $B$ & 39.2 & 32.5 & 19.8 & & 19.1 & & 25.5 & \\
\hline 0.010 & $\mathrm{Ba}$ & - & - & - & & - & & - & \\
\hline 0.010 & $\mathrm{Be}$ & - & - & - & & - & & - & \\
\hline 0.100 & $\mathrm{Bi}$ & - & - & - & & - & & - & \\
\hline 0.250 & $\mathrm{Ca}$ & 169 & 157 & 140 & & 144 & & 140 & \\
\hline 0.015 & $\mathrm{Cd}$ & 26.3 & 27.1 & 23.4 & & 24.0 & & 22.8 & \\
\hline 0.200 & $\mathrm{Ce}$ & - & - & - & & - & & - & \\
\hline 0.050 & Co & {$[2.0]$} & {$[2.1]$} & [2.1] & & [2.1] & & {$[1.9]$} & \\
\hline 0.020 & $\mathrm{Cr}$ & 54.5 & 51.5 & 37.0 & & 38.1 & & 13.3 & \\
\hline 0.025 & $\mathrm{Cu}$ & 11.4 & 14.8 & 16.3 & & 16.8 & & 13.4 & \\
\hline 0.050 & Dy & - & - & - & & - & & - & \\
\hline 0.100 & Eu & - & - & - & & - & & - & \\
\hline 0.025 & $\mathrm{Fe}$ & 11.8 & 15.9 & 9.29 & & 9.16 & & 5.34 & \\
\hline 2.000 & $K$ & 720 & 732 & 626 & & 634 & & 603 & \\
\hline 0.050 & $\mathrm{La}$ & [1.4] & [1.1] & - & & - & & - & \\
\hline 0.030 & Li & - & - & - & & - & & - & \\
\hline 0.100 & $\mathrm{Mg}$ & - & - & [2.4] & & [3.3] & & {$[2.4]$} & \\
\hline 0.050 & $\mathrm{Mn}$ & [1.9] & {$[1.8]$} & [2.3] & & {$[2.4]$} & & [3.9] & \\
\hline 0.050 & Mo & 14.2 & 14.7 & 12.8 & & 13.1 & & 12.4 & \\
\hline 0.150 & $\mathrm{Na}$ & 112,000 & 119,000 & 102,000 & & 110,000 & & 105,000 & \\
\hline 0.100 & Nd & [6.3] & [5.1] & {$[2.8]$} & & {$[2.7]$} & & [2.1] & \\
\hline 0.030 & $\mathrm{Ni}$ & 215 & 222 & 194 & & 200 & & 189 & \\
\hline 0.100 & $\mathbf{P}$ & 282 & 294 & 253 & & 259 & & 246 & \\
\hline 0.100 & $\mathrm{~Pb}$ & 57.9 & 65.9 & 54.9 & & 56.0 & & 55.1 & \\
\hline 0.750 & Pd & - & - & - &. & - & & - & \\
\hline 0.300 & Rh & - & - & - & & - & & - & $\cdots$ \\
\hline 1.100 & Ru & - & - & - & & - & & - & \\
\hline 0.500 & $\mathrm{Sb}$ & - & - & - & & - & & - & \\
\hline 0.250 & Se & - & - & - & & - & & - & \\
\hline 0.500 & Si & 102 & [46] & {$[28]$} & & [25] & & {$[29]$} & \\
\hline 1.500 & Sn & - & - & - & & - & & - & \\
\hline 0.015 & Sr & 161 & 153 & 113 & & 118 & & 94.4 & \\
\hline 1.500 & Te & - & - & - & & - & & - & \\
\hline 1.000 & Th & - & - & - & & - & & - & \\
\hline 0.025 & $T i$ & - & - & - & & - & & - & \\
\hline 0.500 & $\pi$ & - & - & - & & - & & - & \\
\hline 2.000 & $u$ & [50] & [44] & [39] & & - & & [39] & \\
\hline 0.050 & $v$ & - & - & - & & - & & - & \\
\hline 2.000 & $w$ & [69] & [73] & [63] & & [65] & & [62] & \\
\hline 0.050 & $Y$ & [2.0] & [1.6] & {$[1.0]$} & & [1.0] & & - & \\
\hline 0.050 & $\mathrm{Zn}$ & {$[5.7]$} & {$[6.0]$} & {$[5.7]$} & & {$[6.0]$} & & - $[5.5]$ & \\
\hline 0.050 & $\mathbf{Z r}$ & [3.8] & [3.4] & [2.1] & & {$[2.1]$} & & [1.5] & \\
\hline
\end{tabular}

Note: 1) Overall error greater than 10-times detection limit is estimated to be within $+1 \cdot 15 \%$.

2) Values in brackets $]$ are within 10-times detection limit with errors likely to exceed $15 \%$.

3) "..* indicate measurement is below detection. Sample detection limit may be found by

multiplying "det. limit" (far left column) by "multiplier" (top of each column). 
Battelle PNNL/RPG/Inorganic Analysis ... ICPAES Data Report Page 1 of 2

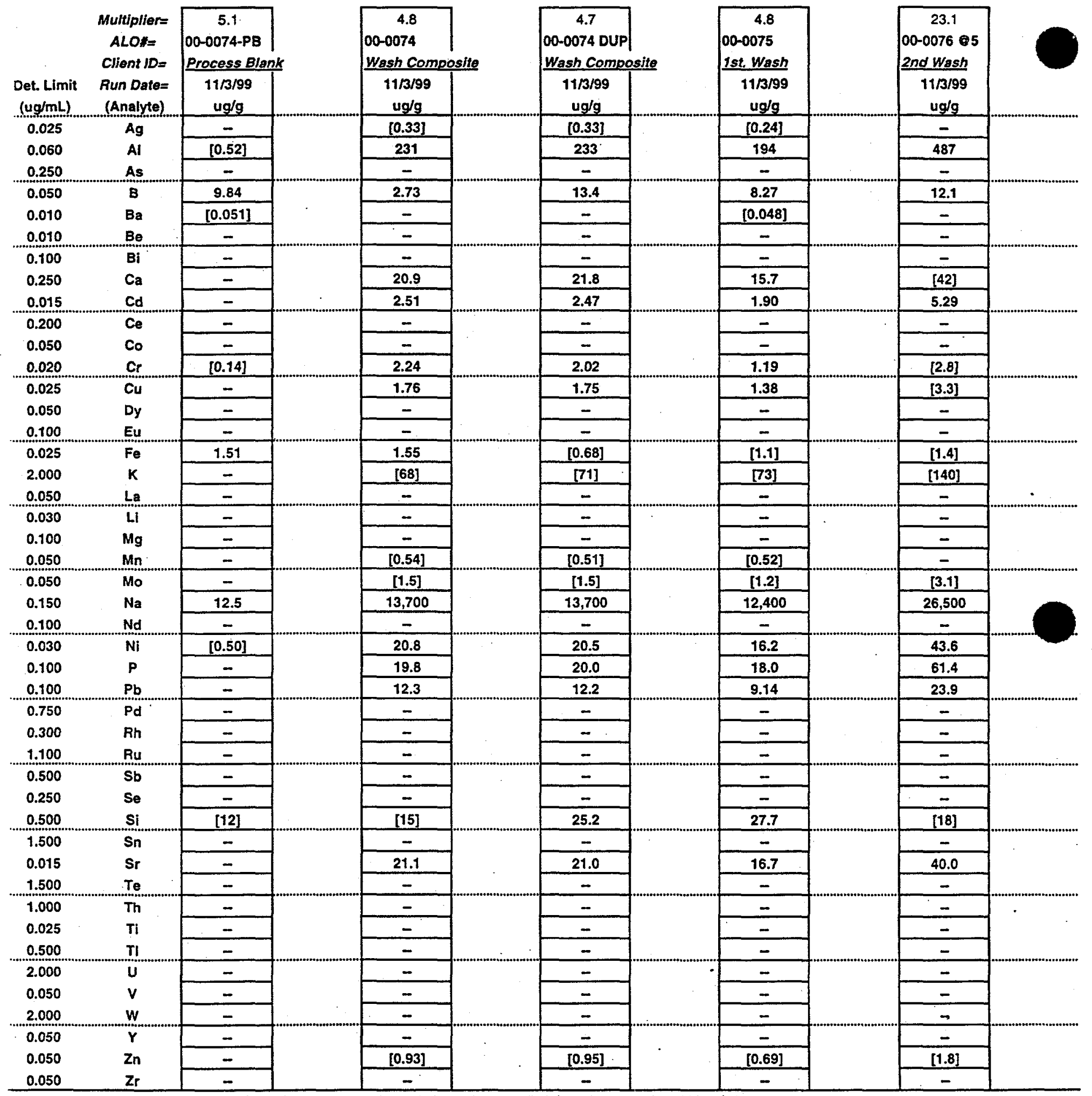

Note: 1) Overall error greater than 10-times detection limit is estimated to be within $+1-15 \%$.

2) Values in brackets [] are within 10-times detection limit with errors likely to exceed $15 \%$.

3) "..- indicate measurement is below detection. Sample detection limit may be found by

multiplying "det. limit" (far left column) by "multiplier" (top of each column). 


\section{Battelle PNNL/RPG/Inorganic Analysis ... ICPAES Data Report Page 2 of 2}

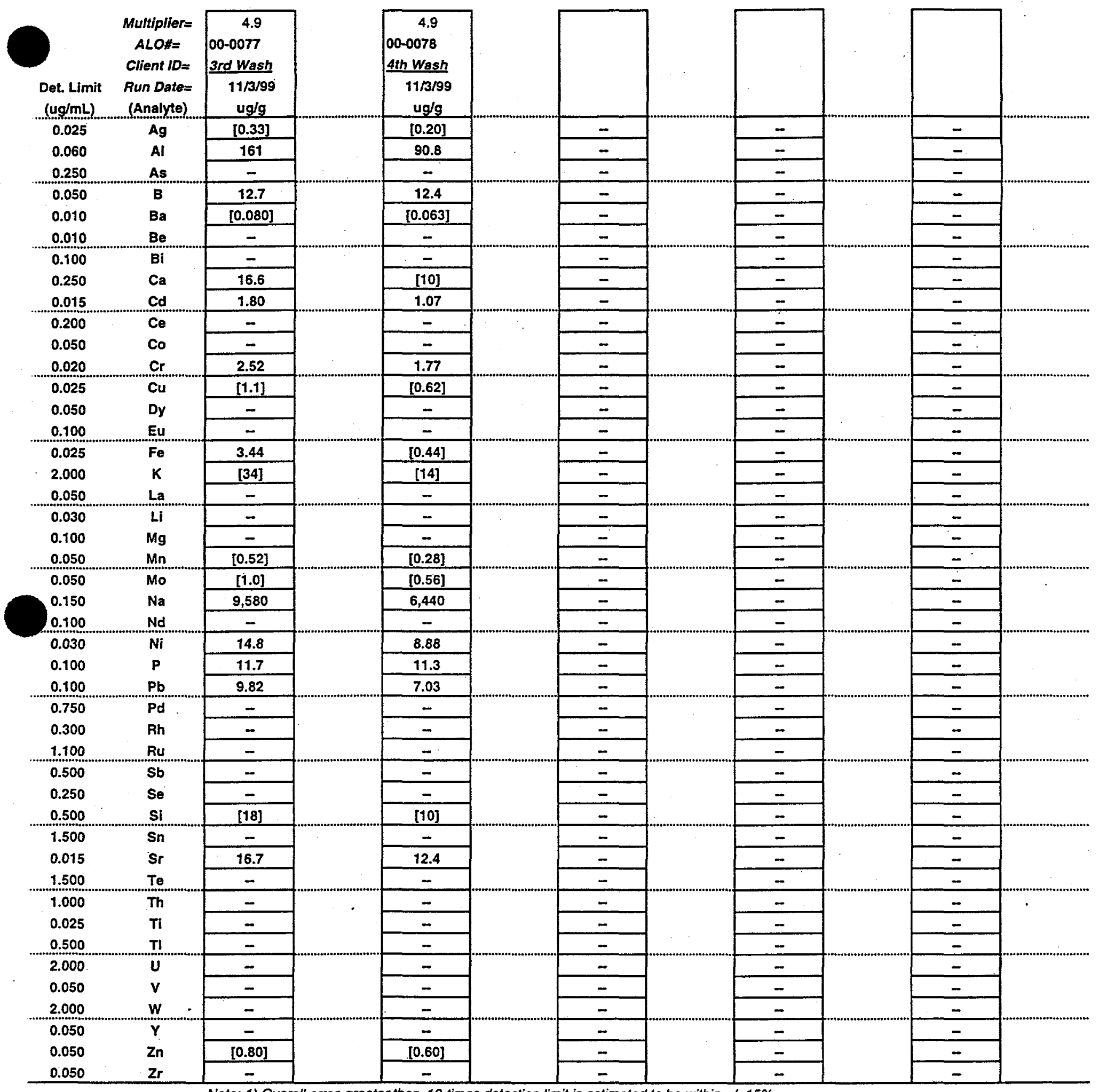

Note: 1) Overall error greater than 10-times detection limit is estimated to be within $+1-15 \%$.

2) Values in brackets $\square$ are within 10-times detection limit with errors likely to exceed $15 \%$.

3) "-." indicate measurement is below detection. Sample detection limit may be found by multiplying "det. limit" (far left column) by "multiplier" (top of each column). 
Battelle PNNL/RPG/Inorganic Analysis ... ICPAES Data Report Page 1 of 1

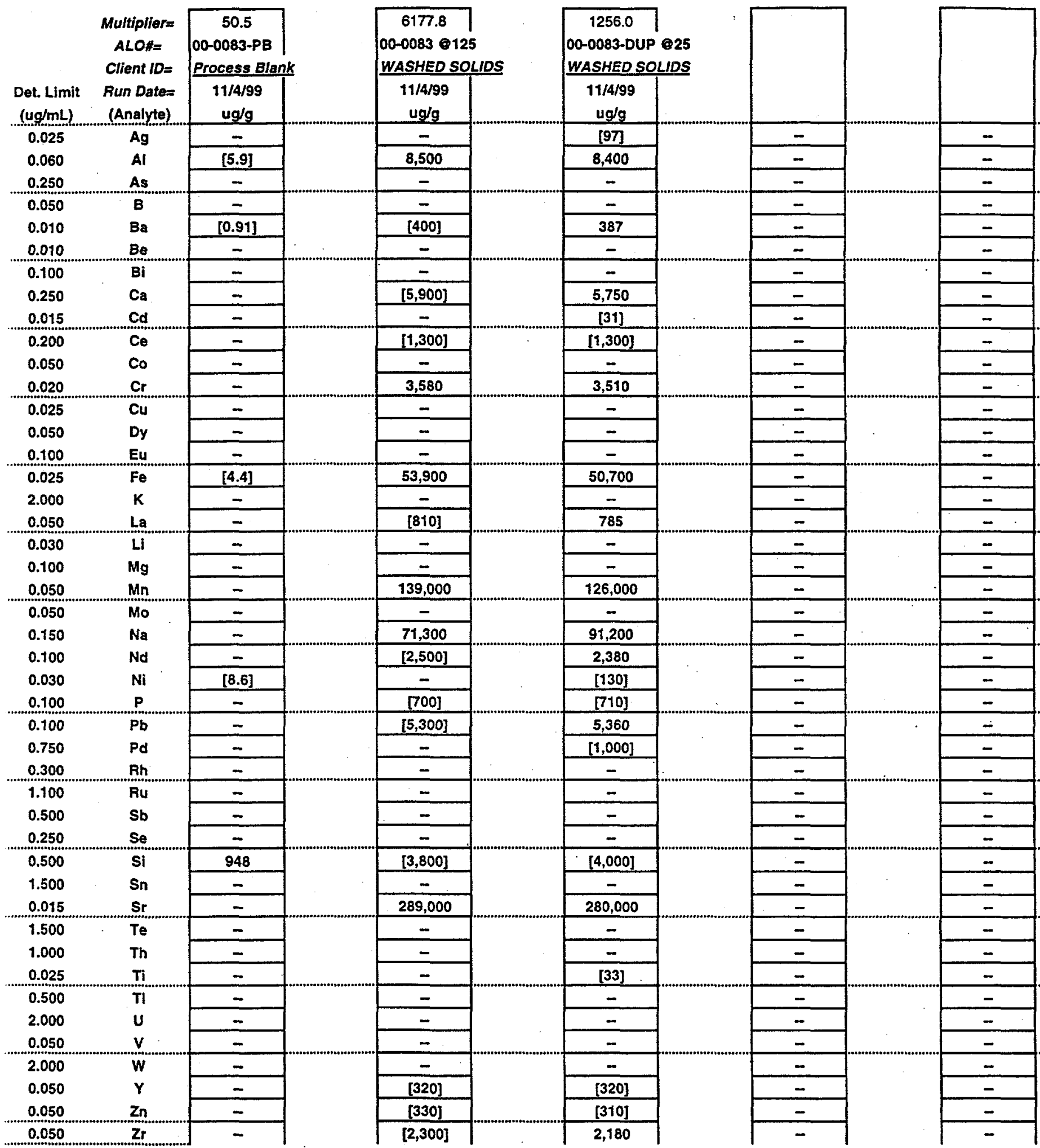

Note: 1) Overall error greater than 10 -times detection limit is estimated to be within $+1.15 \%$.

2) Values in brackets $\square$ are within 10-times detection limit with errors likely to exceed $15 \%$.

3) ".." indicate measurement is below delection. Sample delection limit may be found by

multiplying "det. limit" (far left column) by "multiplier" (top of each column). 
Battelle PNNL/RPG/Inorganic Analysis ... ICPAES Data Repore 1 of 1

\begin{tabular}{|c|c|c|c|c|c|c|c|c|c|}
\hline & Multiplier = & 1044.9 & & 995.0 & & 1100.1 & & & \\
\hline & $A L O \#=$ & 00-0083-PB- & $\mathrm{Ni} \odot 2$ & OO-0083-NI & & $00-0083-0 U$ & $-N 1 \odot 2$ & & \\
\hline & Client $10=$ & Process Bla & & WASHED S & LIDS & WASHED S & LIDS & & \\
\hline $\begin{array}{c}\text { Det. Limit } \\
(\mathrm{ug} / \mathrm{mL})\end{array}$ & $\begin{array}{c}\text { Run Date= } \\
\text { (Analyte) }\end{array}$ & $\begin{array}{c}11 / 12 / 99 \\
u g / g\end{array}$ & & $\begin{array}{c}11 / 12 / 99 \\
u g / g\end{array}$ & & $\begin{array}{c}11 / 12 / 99 \\
u g / g\end{array}$ & & . & \\
\hline 0.025 & $\mathrm{Ag}$ & - & & {$[100]$} & & {$[120]$} & & - & \\
\hline 0.060 & Al & {$[110]$} & & 7,770 & & 7,260 & & - & \\
\hline 0.250 & As & - & & - & & - & & - & \\
\hline 0.050 & $\mathbf{B}$ & - & & [61] & & {$[57]$} & & - & . \\
\hline 0.010 & $\mathrm{Ba}$ & [11] & & 321 & & 314 & & - & \\
\hline 0.010 & $\mathrm{Be}$ & - & & - & . & - & & - & \\
\hline 0.100 & $\mathbf{B i}$ & - & & - & & $=$ & & - & \\
\hline 0.250 & $\mathrm{Ca}$ & - & & 5,300 & & 5,220 & & $\ldots$ & \\
\hline 0.015 & $\mathrm{Cd}$ & - & & [34] & & [36] & & $\cdots$ & \\
\hline 0.200 & $\mathrm{Ce}$ & - & & [560] & 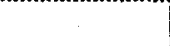 & [490] & & - & \\
\hline 0.050 & Co & - & & - & & - & & $=$ & \\
\hline 0.020 & $\mathbf{C r}$ & - & & 3,100 & & 3,170 & & - & \\
\hline 0.025 & $\mathrm{Cu}$ & - & & {$[63]$} & & [71] & & - & \\
\hline 0.050 & Dy & - & . & - & & - & & - & \\
\hline 0.100 & Eu & - & & $=$ & & - & & - & \\
\hline 0.025 & $\mathrm{Fe}$ & {$[180]$} & & 44,300 & & 43,400 & & - & \\
\hline 0.050 & La & - & & 644 & & 633 & & - & \\
\hline 0.030 & $\mathrm{LI}$ & - & & - & & [34] & & - & : \\
\hline 0.100 & $\mathbf{M g}$ & - & & [190] & & {$[200]$} & & - & \\
\hline 0.050 & $\mathrm{Mn}$ & {$[100]$} & & 125,000 & & 118,000 & & - & \\
\hline 0.050 & Mo & - & & {$[67]$} & & - & & - & \\
\hline 0.150 & $\mathrm{Na}$ & {$[1,100]$} & & 71,900 & & 72,700 & & - & \\
\hline 0.100 & Nd & - & & 1,820 & & 1,670 & & - & \\
\hline 0.100 & $\mathbf{P}$ & - & & [840] & & {$[790]$} & & - & \\
\hline 0.100 & $\mathrm{~Pb}$ & - & & 3,790 & & 4,600 & & - & \\
\hline 0.750 & $P d$ & - & & - & & - & & - & \\
\hline 0.300 & Rh & - & & - & & - & & - & \\
\hline 1.100 & Ru & - & & $=$ & & - & & - & ..................... \\
\hline 0.500 & Sb & - & & - & & - & & - & \\
\hline 0.250 & $\mathrm{Se}$ & - & . & - & & - & & - & \\
\hline 0.500 & Si & - & & 5,740 & & {$[5,100]$} & & - & \\
\hline 1.500 & Sn & - & & $=$ & & - & & - & \\
\hline 0.015 & Sr & - & & 255,000 & & 242,000 & & - & \\
\hline 1.500 & Te & - & & - & & - & (............. & - & \\
\hline 1.000 & Th & - & & - & . & - & & - & \\
\hline 0.025 & $T i$ & - & & [57] & & {$[50]$} & : & $=$ & \\
\hline 0.500 & $T !$ & - & & - & & - & & - & \\
\hline 2.000 & $\mathbf{U}$ & - & & {$[2,300]$} & & {$[3,000]$} & & - & . \\
\hline 0.050 & $V$ & - & & - & & - & & - & \\
\hline 2.000 & $W$ & - & & - & & - & & - & \\
\hline 0.050 & $\mathbf{Y}$ & - & . & [260] & & [260] & & - & \\
\hline 0.050 & $\mathrm{Zn}$ & - & & [310] & & {$[300]$} & & - & \\
\hline 0.050 & $\mathrm{Zr}$ & - & & 1,550 & & 1,620 & & - & \\
\hline
\end{tabular}

Note: 1) Overall error greater than 10-times detection limit is estimated to be within. $+1.15 \%$.

2) Values in brackets [] are within 10-times detection limit with errors likely to exceed $15 \%$.

3) ".." indicate measurement is below detection. Sample detection limit may be found by

multiplying "det. limit" (far left column) by "multiplier" (top of each column). 
Pacific Northwest National Laboratory Radiochemical Processing Laboratory

Shielded Facility Operation Team

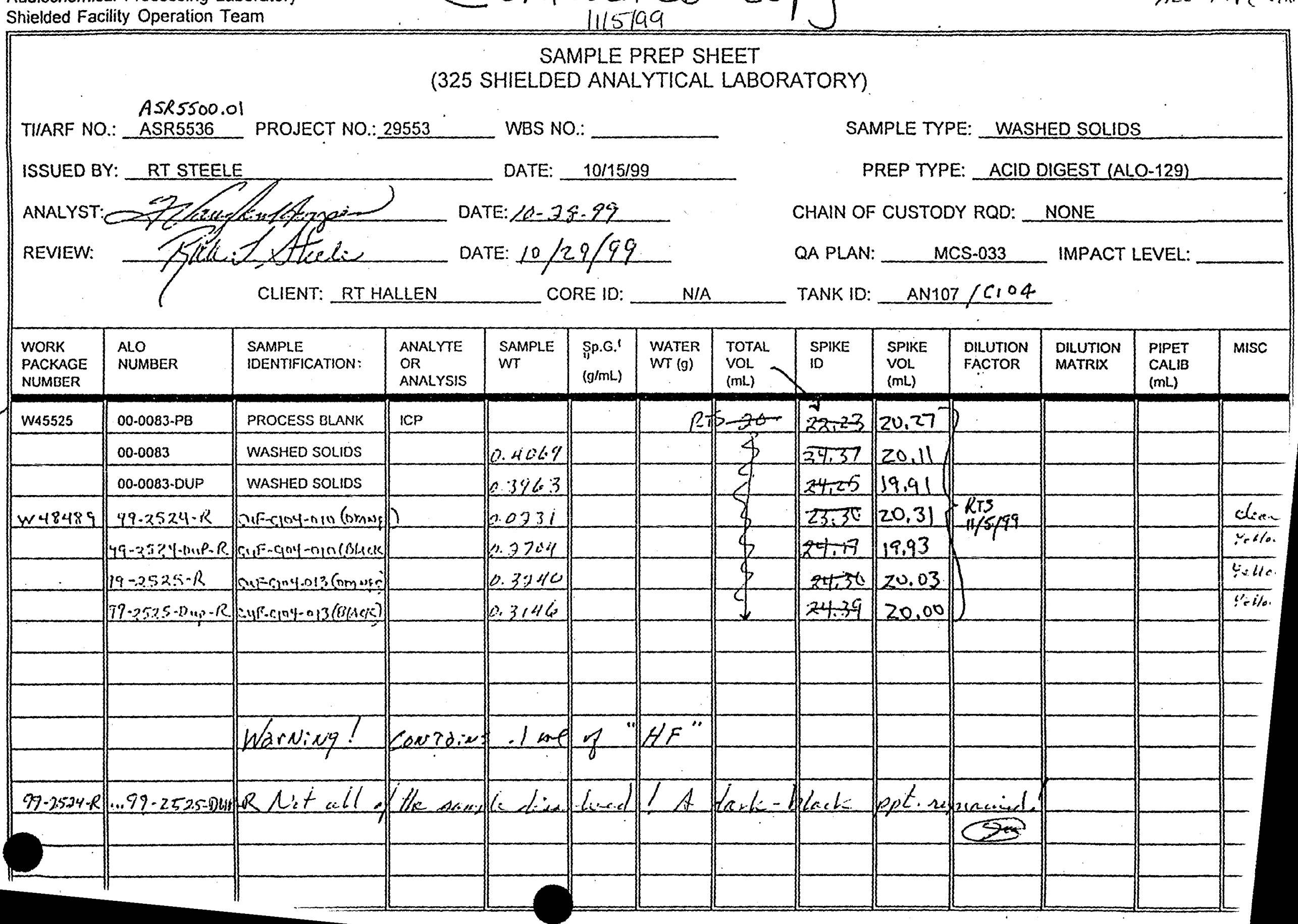


Battelle l'acific Northwest Liboratorics

Arialytical Clsemistry Laboralory

Shiclucu Analytical Laboraton/Sample Recciving Laboratory

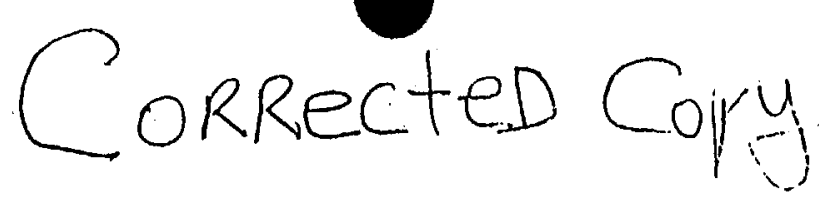

EXIIIBIT I

PAGE I of I

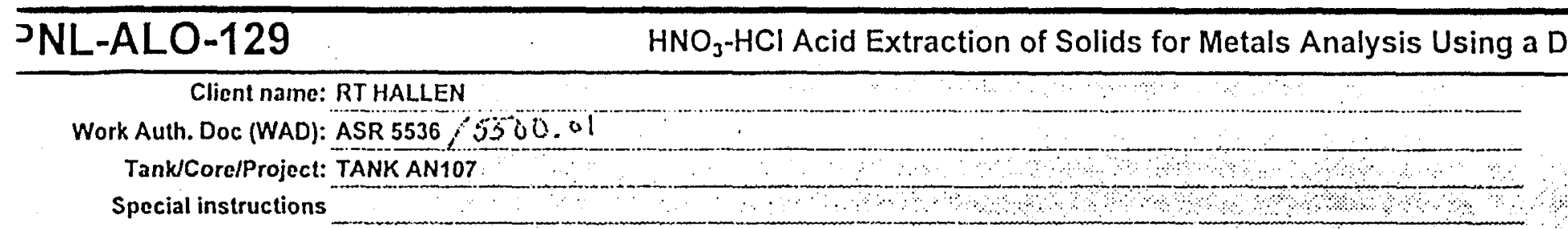

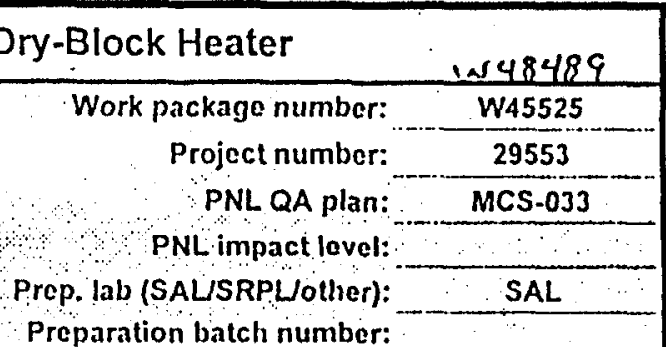

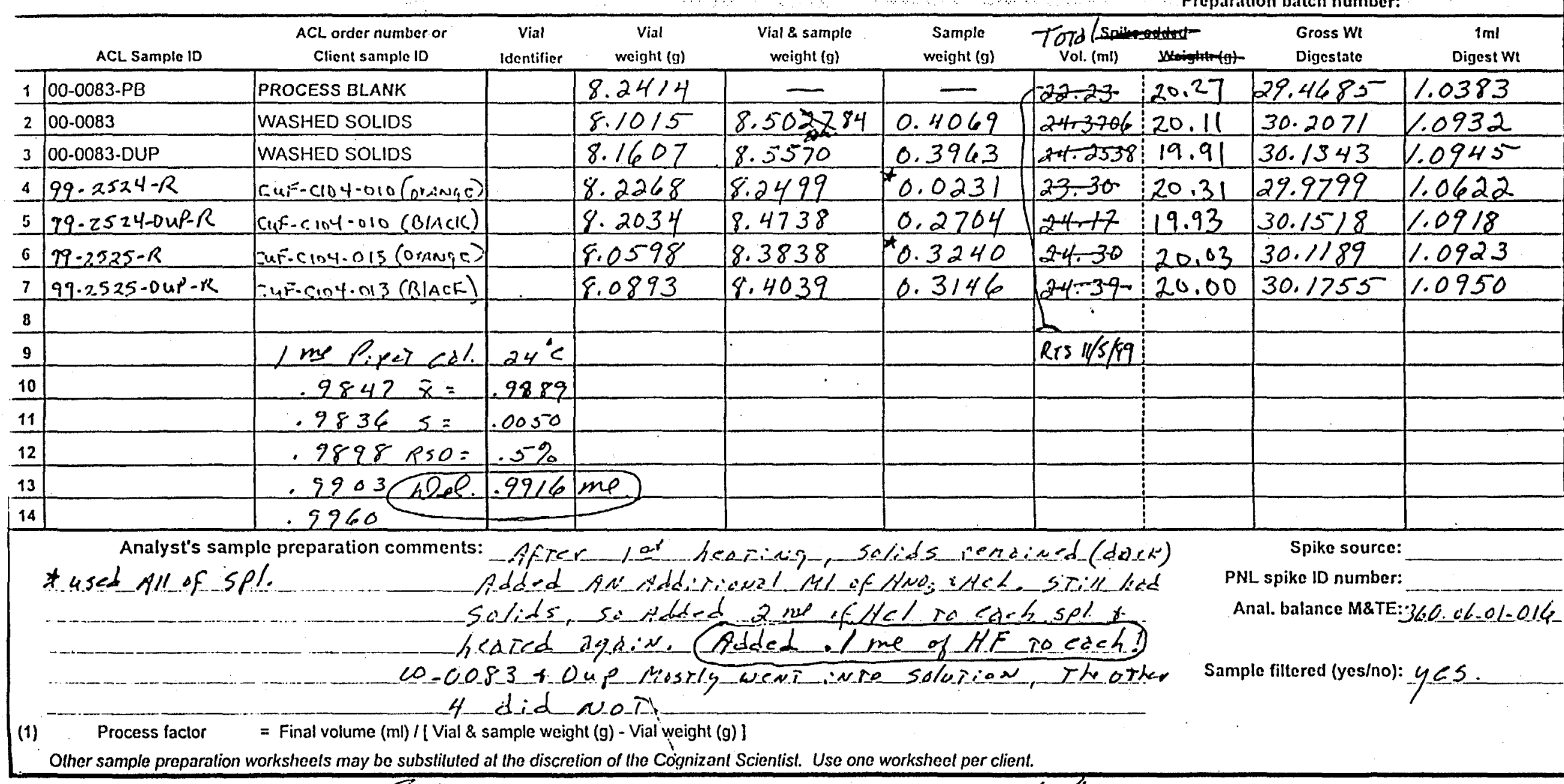

Analysudate:

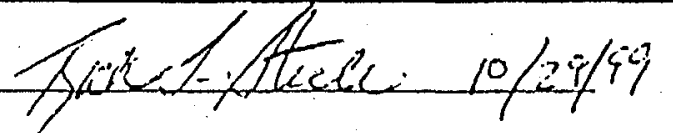

Rev. $2.07-2.3-95$, AIIK 


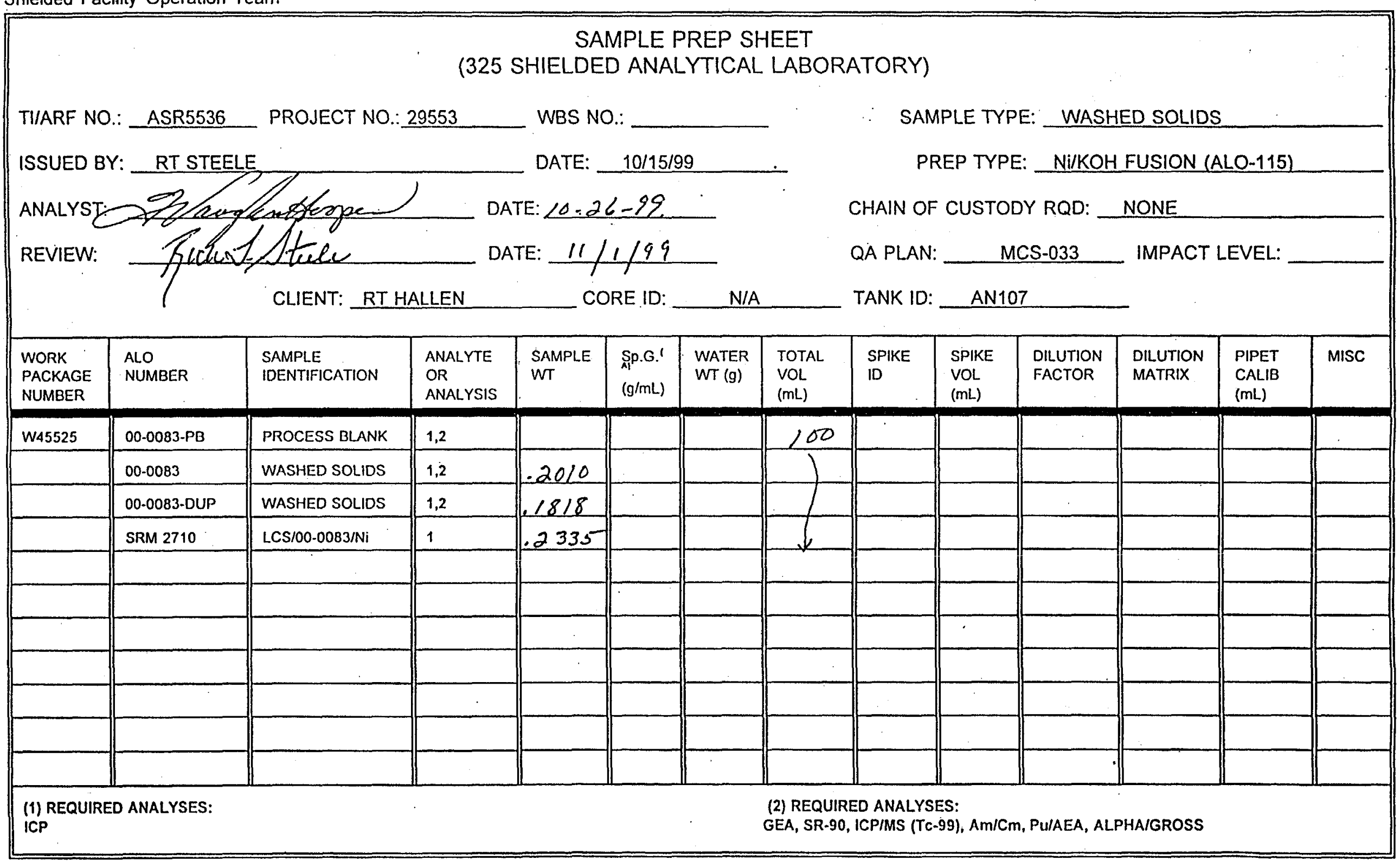

(A) Specific Gravity of ORIGINAL material. SEE ASR5536 SPECIAL INSTRUCTIONS \& TABLE 2 FOR ANALYTE LIST AND MRQs PAGE 1 OF 1

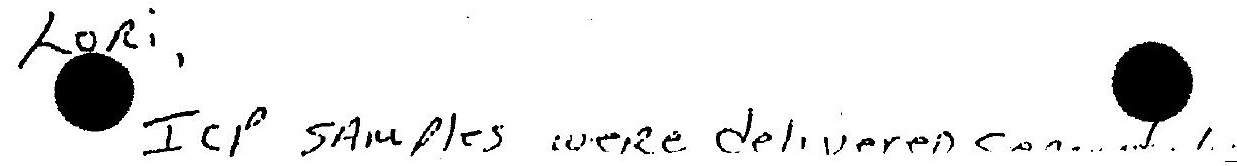


Battelle Pacific Northwest Laboratories

Analytical Chemistry Laboratory

Shielded Analytical Laboralory

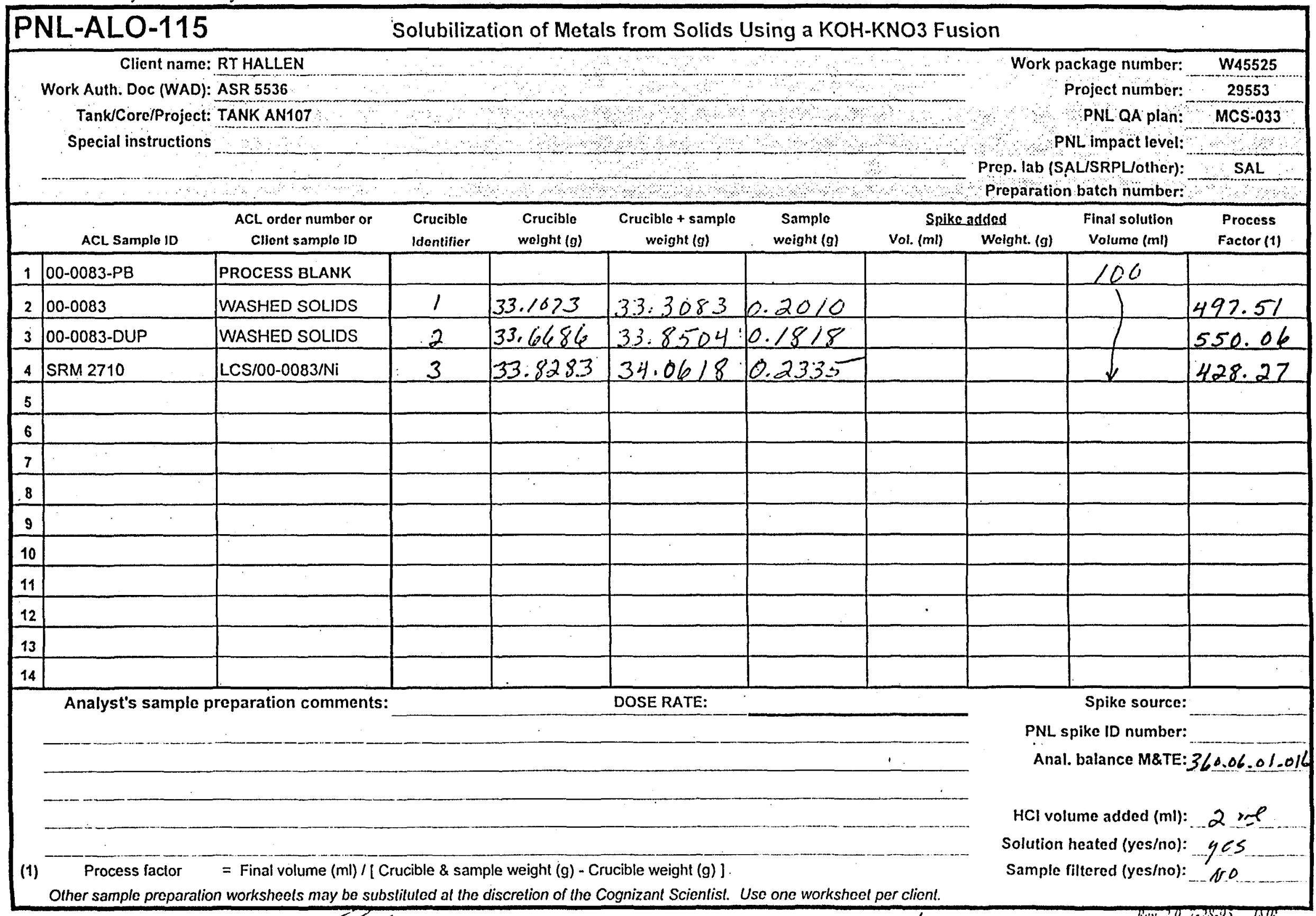

Other sample preparation worksheels may be substituled at the discretion of the Cognizant Scientist. Use one worksheet per client. 
(325 SHIELDED ANALYTICAL LABORATORY)

TIIARF NO.: ASR5536 PROJECT NO.: 29553

ISSUED BY: RT STEELE

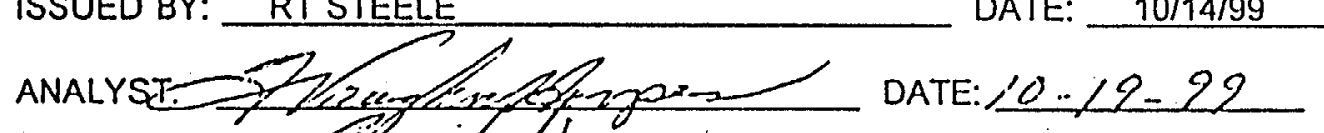

REVIEW:

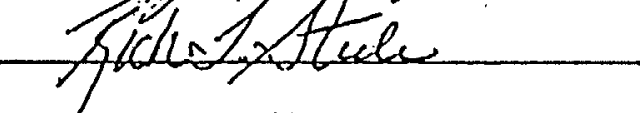

CLIENT: RT HALLEN
DATE: $10-19-99$ CORE ID:

\begin{tabular}{|c|c|c|c|c|c|}
\hline $\begin{array}{l}\text { WORK } \\
\text { PACKAGE } \\
\text { NUMBER }\end{array}$ & $\begin{array}{l}\text { ALO } \\
\text { NUMBER }\end{array}$ & $\begin{array}{l}\text { SAMPLE } \\
\text { IDENTIFICATION }\end{array}$ & $\begin{array}{l}\text { ANALYTE } \\
\text { OR } \\
\text { ANALYYSIS }\end{array}$ & $\begin{array}{l}\text { SAMPLE } \\
\text { WT }\end{array}$ & $\begin{array}{l}\text { Spp.G.' } \\
(\mathrm{g} / \mathrm{mL})\end{array}$ \\
\hline \multirow[t]{12}{*}{ WA5525 } & 00-0070:PB & PROCESS BLANK & 2 & $11.57 / 3$ & \\
\hline & $00-0070$ & DF -01 & 1 & $6.3285^{\circ}$ & \\
\hline & $00-0071$ & $D F-11$ & 1 & 6.4475 & \\
\hline & $00-0072$ & $D F-20$ & 2 & 6.0216 .2 & \\
\hline & $00-0073$ & $D F-2 i$ & 2 & 6.342 .3 & \\
\hline & $00-0079$ & DF -02 & 1 & 6.447 .3 & \\
\hline & $00-0080$ & DF -03 & 1 & $6.5-701$ & \\
\hline & $00-0081$ & DF-04 & 1 & $6.3 \div 195-$ & \\
\hline & $00-0082$ & DF -14 & 1 & $1 ., 2437$ & \\
\hline & $00-0072$-DUP & DF -20 & 2 & 6.2764 & \\
\hline & $00-0071$ & WASH & 2 (ICP & $5: 11141$ & \\
\hline & $00.074 .04 f$ & COMPOSITE & DONE) & $5195 \%$ & \\
\hline
\end{tabular}

(1) REQUIRED ANALYSES:

Sr.90, Am/Cm, ICP Na (INCLUDE ALL ICP)

SAMPLE TYPE: AQUEOUS

PREP TYPE: ACID DIGEST (ALO-128)

CHAIN OF CUSTODY RQD: NONE

QA PLAN: MCS-033 IMPACT LEVEL:

TANK ID:

\begin{tabular}{|c|c|c|c|c|c|c|c|}
\hline $\begin{array}{l}\text { WATER } \\
\text { WT (g) }\end{array}$ & $\begin{array}{l}\text { TOTAL } \\
\text { VOL } \\
(\mathrm{mL})\end{array}$ & $\begin{array}{l}\text { SPIKE } \\
\text { ID }\end{array}$ & $\begin{array}{l}\text { SPIKE } \\
\text { VOL } \\
(\mathrm{mL})\end{array}$ & $\begin{array}{l}\text { DILUTION } \\
\text { FACTOR }\end{array}$ & $\begin{array}{l}\text { DILUTION } \\
\text { MATRIX }\end{array}$ & $\begin{array}{l}\text { PIPET } \\
\text { CAL.JB } \\
\text { (mL) }\end{array}$ & Misc \\
\hline & $2 x=1-5$ & 23.75 & 2 & & & & \\
\hline & $39 \cdot 47^{2}$ & 24.36 & & & & & \\
\hline & 20.43 & 24.16 & & & & & \\
\hline & $x+7 d$ & 24.58 & & & & & \\
\hline & $27.10^{-}$ & 24.62 & & & & & \\
\hline & $24-6-8$ & 24.91 & $11 / 5119$ & & & & \\
\hline & $20 \% .75^{-}$ & 24.78 & & & & & \\
\hline & 19. 44 & 24.81 & & & & . & \\
\hline & $2 \pi, 78$ & 24.22 & & & & & \\
\hline & $a_{2}-5=-6-7$ & 24.75 & & & & & \\
\hline & $26,3+3$ & 24.65 & & & & & \\
\hline & $26,2=$ & 24.53 & $\checkmark$ & & & & \\
\hline
\end{tabular}

(2) REQUIRED ANALYSES:

GEA, SR-90, ICPIMS (TC-99), Am/Cm, PU/AEA, ALPHA/GROSS, ICP

(A) Specific Gravity of ORIGINAL material. SEE ASR5536 SPECIAL INSTRUCTIONS \& TABLE 2 FOR ANALYTE LIST AND MRQS

PAGE 1. OF 1
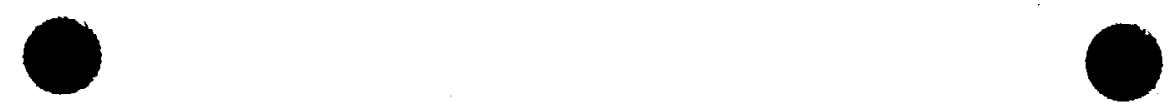
Battelle Pacific Northwest laboratories Analytical Chemistry Laboratory

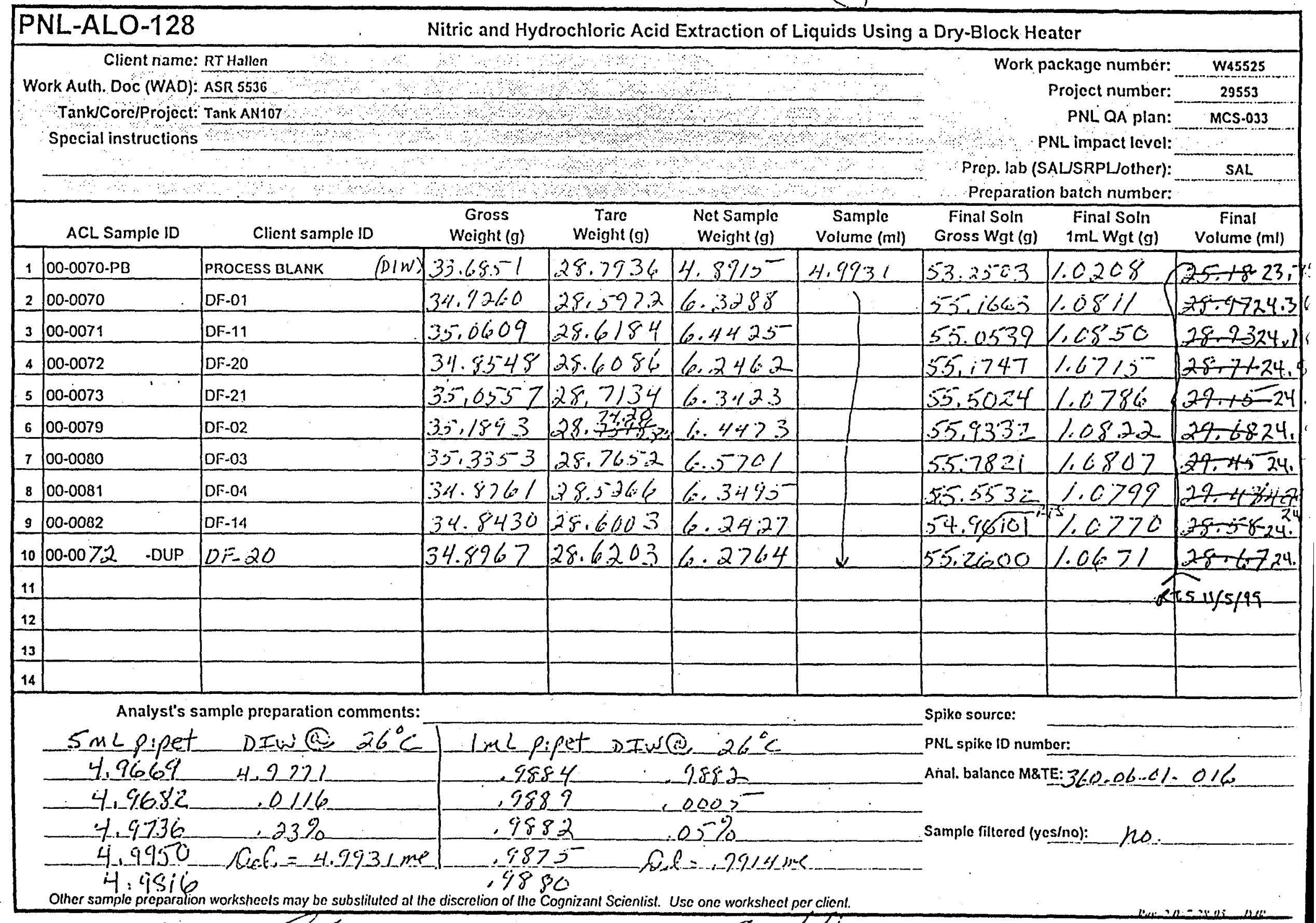




\section{Corrected Copy}

\section{SAMPLE PREP SHEET}

(325 SHIELDED ANALYTICAL LABORATORY)

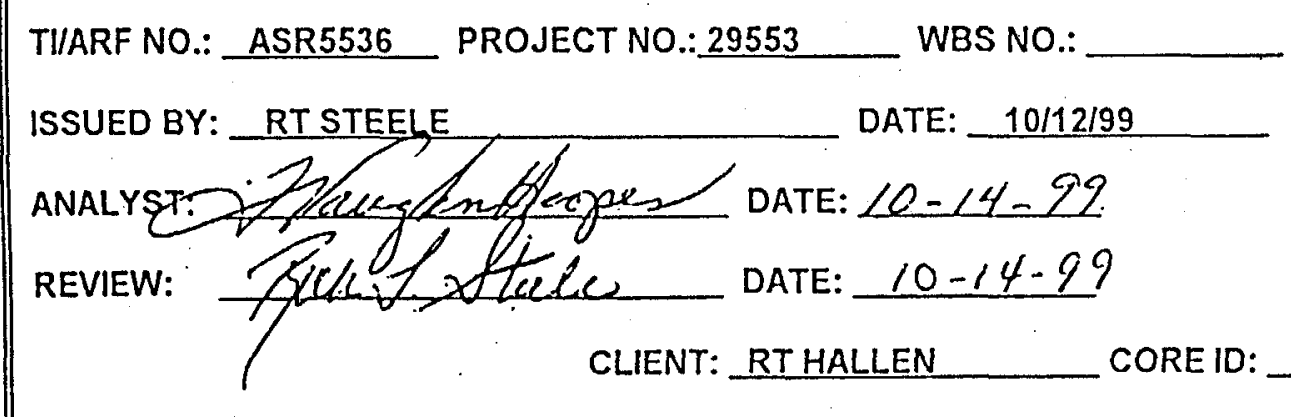

\begin{tabular}{|c|c|c|c|c|c|c|c|c|c|c|c|c|c|}
\hline $\begin{array}{l}\text { WORK } \\
\text { PACKAGE } \\
\text { NUMBER }\end{array}$ & $\begin{array}{l}\text { ALO } \\
\text { NUMBER }\end{array}$ & $\begin{array}{l}\text { SAMPLE } \\
\text { IDENTIFICATION }\end{array}$ & $\begin{array}{l}\text { ANALYTE } \\
\text { OR } \\
\text { ANALYSIS }\end{array}$ & $\begin{array}{l}\text { SAMPLE } \\
\text { WT }\end{array}$ & $\begin{array}{l}\text { Sp.G." } \\
(g / m L)\end{array}$ & $\begin{array}{l}\text { WATER } \\
\text { WT (g) }\end{array}$ & $\begin{array}{l}\text { TOTAL } \\
\text { VOL } \\
(\mathrm{mL})\end{array}$ & $\begin{array}{l}\text { SPIKE } \\
\text { ID }\end{array}$ & $\begin{array}{l}\text { SPIKE } \\
\text { VOL } \\
(\mathrm{mL})\end{array}$ & $\begin{array}{l}\text { DILUTION } \\
\text { FACTOR }\end{array}$ & $\begin{array}{l}\text { DILUTION } \\
\text { MATRIX }\end{array}$ & $\begin{array}{l}\text { PIPET } \\
\text { CALIB } \\
\text { (mL) }\end{array}$ & MISC \\
\hline \multirow[t]{7}{*}{ W45525 } & $00-0074 . \mathrm{PB}$ & PROCESS BLANK & ICP & $4.4 \% \cdot 4$ & & & $2 \div 7 \div-2-4-$ & 25.30 & & & & & \\
\hline & $00-0074$ & WASH COMPOSITE & & 5.1441 & & & $26,3 \%$ & 24.65 & & & & & \\
\hline & 00-0074-DUP & WASH COMPOSITE & & 5.1951 & & & 26.35 & 24.53 & Rs & & & & \\
\hline & $00-0075$ & 15T WASH & & $5.17,-8$ & & & 27.79 & 24.61 & $11 / 5 / 99$ & & & & \\
\hline & 00.0076 & 2ND WASH & & $\therefore 3231$ & & & 26.76 & 24.58 & & & & & \\
\hline & 00.0077 & 3RD WASH & & $5.113^{\circ} 0$ & & & 26,96 & 25.23 & & & & & \\
\hline & 00.0078 & 4TH WASH & & 5.0790 & & & $26-6-4$ & 24.94 & & & & & \\
\hline & & & & & & & & & & & & & \\
\hline & & & & & & & & & & & & & \\
\hline & & & & & & & & & & & & & \\
\hline & & & & & & & & & & & & & \\
\hline & & & & & & & & & & & & & \\
\hline & & & & & & & & & & & & & \\
\hline & & & & & & & & & & & & & \\
\hline
\end{tabular}

(1) Specific Gravity of ORIGINAL material. SEE ASR5536 SPECIAL INSTRUCTIONS \& TABLE 2 FOR METALS LIST AND MRQS

PAGE 1 OF 1 


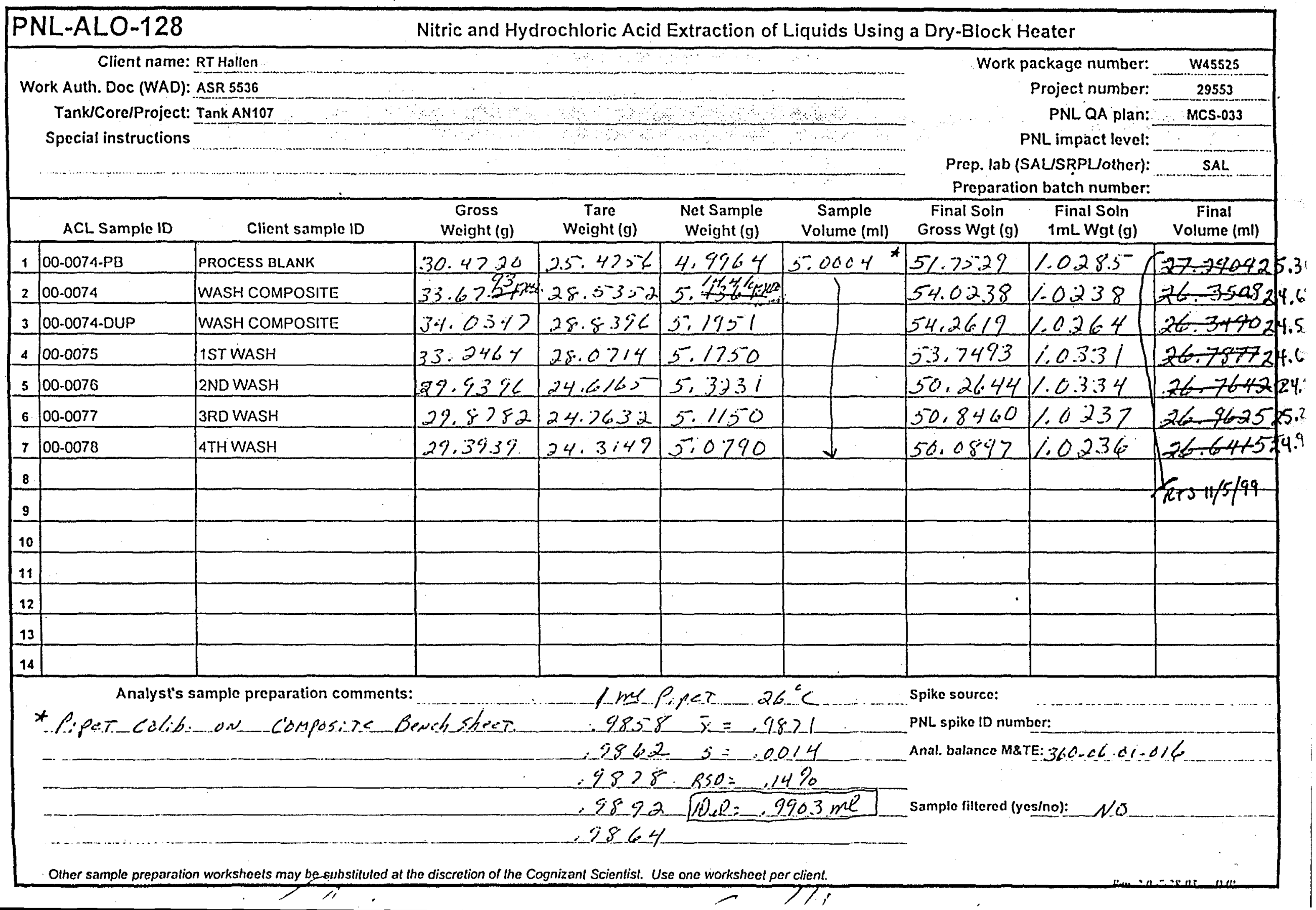




\section{Battelle PNNL/325 Bldg/RPG/Inorganic Analysis ... ICPAES Data Report}

Project:

29953

Client:

R.T. Hallen \& K.P. Brooks

ACL Number(s): 99-2524-R through 99-2525-DUP-R

[re-runs]

Client ID: "CUF-C104-010(Orange)" through "CUF-C104-013(Black)"

ASR Number: 5500.01

Total Samples: 4

Procedure: PNL-ALO-211, "Determination of Elements by Inductively Coupled Argon Plasma Atomic Emission Spectrometry" (ICP-AES).

Analyst: $\quad$ D.R. Sanders

Analysis Date (Filename): $\quad$ 11-04-99 (A0550)

See Chemical Measurement Center 98620: ICP-325-405-1 File for Calibration and Maintenance Records.

M\&TE Number: ICPAES instrument -- WB73520

Mettler AT400 Balance -- Ser.No. 360-06-01-029
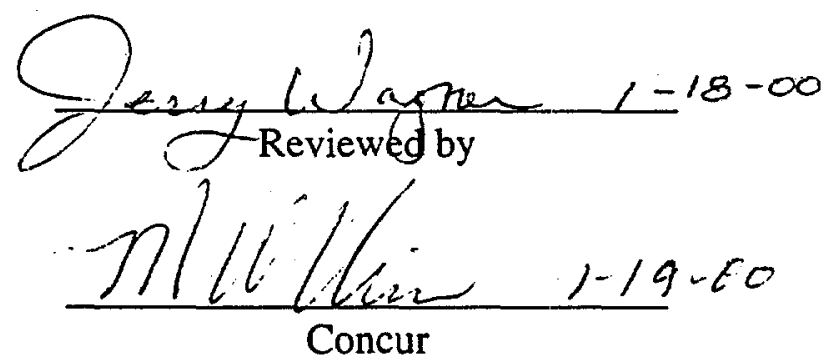

$1 / 18 / 00$

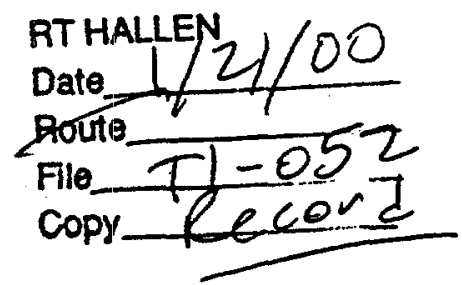




\section{Battelle PNNL/325 Bldg/RPG/Inorganic Analysis ... ICPAES Data Report}

Four radioactive solid samples CUF-C104-010(Orange) through CUF-C104-013(Black) (ACL\# 99-2524-R through 99-2525-DUP-R) were prepared by SAL using ALO-129 acid digestion of solids procedure. Prepared samples were analyzed by ICPAES. Approximately $0.02 \mathrm{~g}$ to $0.32 \mathrm{~g}$ aliquots were processed and diluted to a final volume of about $20 \mathrm{ml}$ (weighed). Some dark-black residue remained insoluble from all the samples after processing. The final volume of each processed sample was determined using the final weight of processed sample divided by an estimated density. Analytical dilution of 5 -fold to 50 -fold was required because of high concentration of aluminum, iron, manganese, sodium, thorium, uranium, and zirconium. Sample CUF-C104-010(Orange) was prepared with only about one-tenth the amount of solids . compared with the other three samples. As a result, only a 5-fold analytical dilution was required.

The concentration of palladium reported previously appears to be an artifact caused by spectral interference particularly from high concentrations of thorium and uranium. Because of this, the actual concentration of palladium is too low to determine by ICPAES without chemical separation of the interfering analytes. Sodium in sample CUF-C104-010(Orange) appeared to be about ten times higher than the other three samples. The reason for the discrepancy is not known.

Measurement results reported have been corrected for preparation and analytical dilution. All results reported are in $\mu \mathrm{g} / \mathrm{g}$ for the solids samples. Volumes and weights have been recorded on bench sheets and included with this report.

Quality control check-standard results met tolerance requirements for analytes of interest except as noted below. Following is a list of quality control measurement results relative to ICPAES analysis tolerance requirements under MCS-033.

Five fold serial dilution:

(Solid samples/acid dig.) Analytes of interest were within tolerance limit of $\leq 10 \%$ after correcting for dilution except silver, magnesium and uranium. Because of the very high concentration of thorium, interference correction to silver, magnesium and uranium were incorrect leading to inaccurate concentration values in the 5 -fold diluted sample. At 25 -fold and 50 -fold dilution all analytes of interest were within $\leq 10 \%$ after correcting for dilution. 


\section{Battelle PNNL/325 BIdg/RPG/Inorganic Analysis ... ICPAES Data Report}

Duplicate RPD (Relative Percent Difference):

(Solid samples/acid dig.) All analytes of interest were recovered within tolerance limit of $\leq 20 \%$ relative percent difference (RPD) except silicon in ACL\# 99-2524-R and its duplicate analyzed at 5-fold dilution. As noted earlier the reason for the large (150\% RPD) for silicon is not known.

Post-Spiked Samples (Group A):

(Solid samples/acid dig.) All analytes of interest were recovered within tolerance of $75 \%$ to $125 \%$.

Post-Spiked Samples (Group B):

(Solid samples/acid dig.) All analytes of interest were recovered within tolerance of $75 \%$ to $125 \%$.

Blank Spike:

(Solid samples/acid dig.) None prepared.

Matrix Spiked Sample:

(Solid samples/acid dig.) None prepared.

Quality Control Check Standards (solid samples/acid dig.):

Concentration of all analytes of interest was within tolerance limit of $\pm 10 \%$ accuracy in standards: QC_MCVA.

Tin and thorium were low ( $-15 \%$ and $-61 \%$ respectively) in

QC_MCVB. Single element standards of $2 \mathrm{ppm}$ tin and $10 \mathrm{ppm}$ thorium were measured separately and were within the tolerance limits.

Several analytes: iron, potassium, manganese, sodium, nickel, lead, silicon and zirconium were a little high (11\% to $15 \%)$ and out of tolerance limits in check-standard QC_SSTMCV.

Calibration Blank (ICP98.0) concentration was acceptable, less than two times IDL.

High Calibration Standard Check (solid samples/acid dig.):

Verification of the high-end calibration concentration for all analytes of interest is within tolerance of $\pm 5 \%$ accuracy except potassium, which measured $22 \%$ high at the end of the run. Potassium was not detected in any of the samples.

$1 / 18 / 00$ 


\section{Battelle PNNL/325 Bldg/RPG/Inorganic Analysis ... ICPAES Data Report}

\section{Process Blank:}

(Solid samples/acid dig.) All analytes of interest were within tolerance limit of $\leq \mathrm{EQL}$ or $<5 \%$ of sample concentration except silicon. Silicon concentration in the blank was equivalent to about $1300 \mathrm{ug} / \mathrm{g}$. Silicon at about $25,000 \mu \mathrm{g} / \mathrm{g}$ was only found in sample CUF-C104-010 (Orange)

(ACL\# 99-2524-R).

\section{Laboratory Control Standard (LCS):}

(Solid samples/acid dig.) No LCS was prepared for PNL-ALO-129 acid digested samples.

Analytes other than those requested by the client are for information only. Please note bracketed values listed in the data report are within ten times instrument detection limit and have a potential uncertainty much greater than $15 \%$.

Comments:

1) . "Final Results" have been corrected for all laboratory dilution performed on the sample during processing and analysis unless specifically noted.

2) Detection limits (DL) shown are for acidified water. Detection limits for other matrices may be determined if requested.

3) Routine precision and bias is typically $\pm 15 \%$ or better for samples in dilute; acidified water (e.g. $2 \% \mathrm{v} / \mathrm{v} \mathrm{HNO}_{3}$ or less) at analyte concentrations greater than ten times detection limit up to the upper calibration level. This also presumes that the total dissolved solids concentration in the sample is less than $5000 \mu \mathrm{g} / \mathrm{mL}(0.5$ per cent by weight).

4) Absolute precision, bias and detection limits may be determined on each sample if required by the client.

5) The maximum number of significant figures for all ICP measurements is 2. 
Battelle PNNL/RPG/Inorganic Analysis ... ICPAES Data Report Page 1 of 1

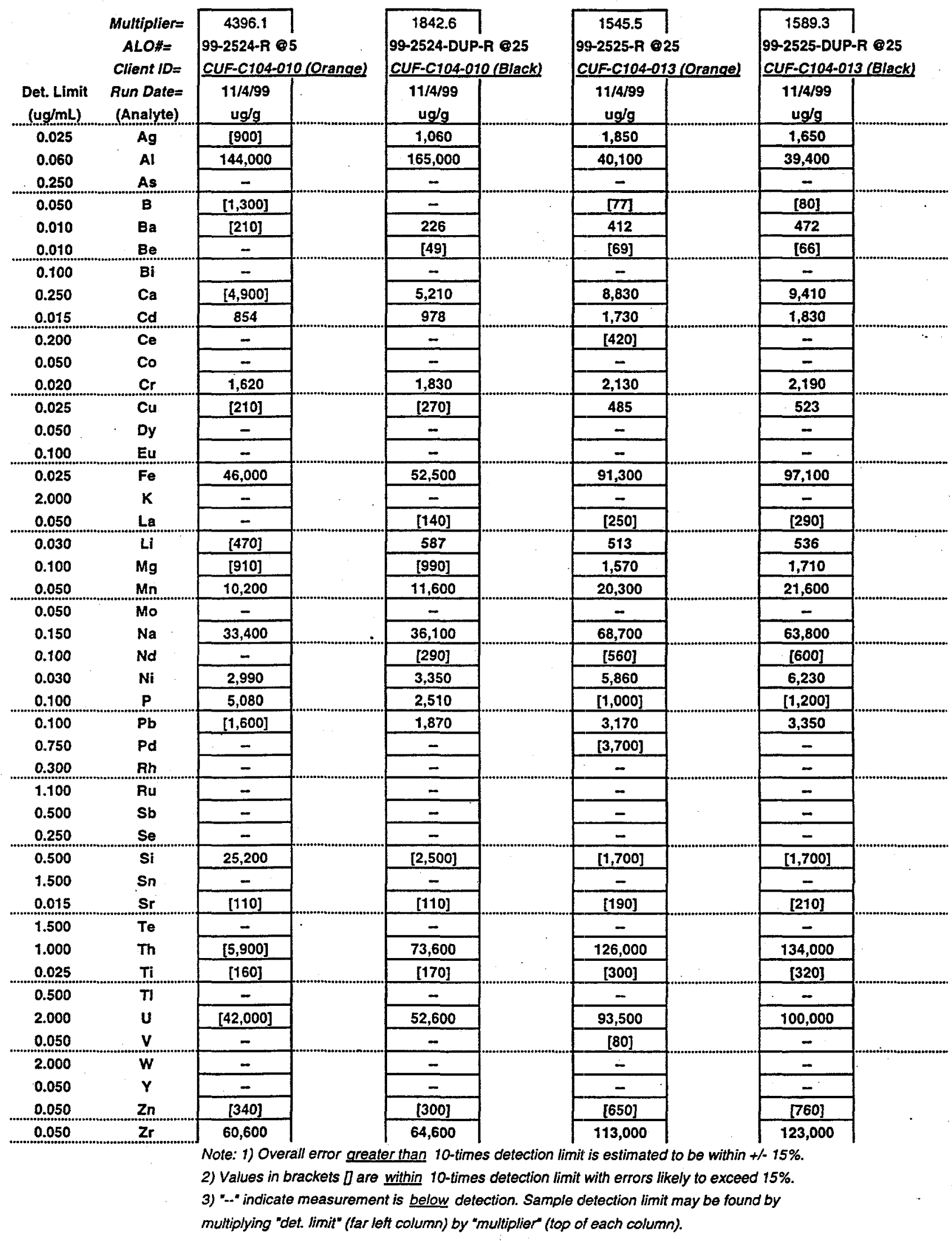


Battelle PNNL/RPG/Inorganic Analysis ... ICPAES Data Report Page 1 of 1

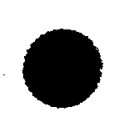

Det. Limit

$(\mathrm{ug} / \mathrm{mL})$

0.025

0.060

0.250

0.050

0.010

0.010

0.100

0.250

0.015

0.200

0.050

0.020

0.025

0.050

0.100

0.025

2.000

0.050

0.030

0.100

0.050

0.050

0.150

0.100

0.030

0.100

0.100

0.750

0.300

1.100

0.500

0.250

0.500

1.500

0.015

1.500

1.000

0.025

0.500

2.000

0.050

2.000

0.050

0.050

0.050
Multiplier $=$
ALO\# $=$

Client $I D=$

Run Date=

(Analyte).

Ag

Al

As

Ba

$\mathrm{Be}$

Bi

$\mathrm{Ca}$

$\mathrm{cd}$

$\mathrm{Ce}$

co

Cr

$\mathrm{Cu}$

Dy

Ey

$\mathrm{Fe}$

La

Li

$\mathrm{Mg}$

Mn

Mo

Nd

$\mathrm{Ni}$

$P$

$\mathrm{Pb}$

Pd

Rh

Ru

Sb

Se

si

sn

Sr

Te

Th

TI

TI

v

Y

Zn
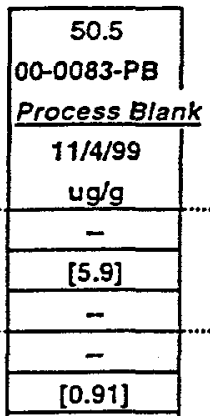

\begin{tabular}{|c|}
\hline$[0.91]$ \\
\hline- \\
\hline- \\
\hline- \\
\hline
\end{tabular}

$-$

\begin{tabular}{|c|}
\hline- \\
\hline- \\
\hline- \\
\hline- \\
\hline- \\
\hline
\end{tabular}

\begin{tabular}{|c|}
\hline- \\
\hline- \\
\hline- \\
\hline 44$]$
\end{tabular}

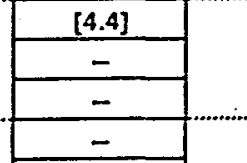

\begin{tabular}{|c|}
\hline- \\
\hline- \\
\hline- \\
\hline- \\
\hline-
\end{tabular}

\begin{tabular}{|c|}
\hline$[8.6]$ \\
\hline- \\
\hline
\end{tabular}

\begin{tabular}{|c|}
\hline- \\
\hline- \\
\hline- \\
\hline-
\end{tabular}

\begin{tabular}{|c|}
\hline 6177.8 \\
$00-0083$ Q125 \\
WASHEO SOLIDS \\
\hline $\begin{array}{c}11 / 4 / 99 \\
u g / g\end{array}$ \\
\hline- \\
\hline 8.500 \\
\hline
\end{tabular}

\begin{tabular}{|c|}
\hline 8,500 \\
\hline- \\
\hline- \\
\hline$[400]$ \\
\hline
\end{tabular}

\begin{tabular}{|c|}
\hline- \\
\hline- \\
\hline 53,900 \\
\hline- \\
\hline$[810]$ \\
\hline- \\
\hline
\end{tabular}

\begin{tabular}{|c|}
\hline- \\
\hline 139,000 \\
\hline- \\
\hline
\end{tabular}

\begin{tabular}{|c|}
\hline 71,300 \\
\hline$[2,500]$ \\
\hline- \\
\hline
\end{tabular}

\begin{tabular}{|c|}
\hline$[700]$ \\
\hline$[5,300]$ \\
\hline- \\
\hline- \\
\hline
\end{tabular}

$[2,300]$

\begin{tabular}{|c|}
\hline$[400]$ \\
\hline- \\
\hline- \\
\hline$[5,900]$ \\
\hline- \\
\hline$[1,300]$ \\
\hline- \\
\hline 3,580 \\
\hline- \\
\hline
\end{tabular}

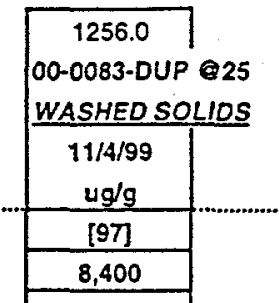

\begin{tabular}{|c|}
\hline 8,400 \\
\hline- \\
\hline- \\
\hline 387 \\
\hline
\end{tabular}

\begin{tabular}{|c|}
\hline- \\
\hline- \\
\hline 5,750 \\
\hline$[31]$ \\
\hline
\end{tabular}

$[1,300]$

3,510

$-$

$-$

$-$

$-$

785

$-$

-

\begin{tabular}{c|}
\hline- \\
\hline 126,000 \\
\hline-
\end{tabular}

\begin{tabular}{|c|}
\hline 91,200 \\
\hline 2,380 \\
\hline$[130]$ \\
\hline
\end{tabular}

[710]

5,360

$[1,000]$

\begin{tabular}{|c|c|}
\hline- & - \\
\hline - & - \\
\hline- & - \\
\hline - & - \\
\hline$[3,800]$ & {$[4,000]$} \\
\hline- & - \\
\hline 289,000 & 280,000 \\
\hline - & - \\
\hline - & - \\
\hline$=$ & [33] \\
\hline- & - \\
\hline - & - \\
\hline - & - \\
\hline- & - \\
\hline [320] & [320] \\
\hline [330] & [310] \\
\hline$[2,300]$ & 2,180 \\
\hline
\end{tabular}

Note: 1) Overall error greater than 10-times detection limit is estimated to be within $+1.15 \%$.

2) Values in brackets $D$ are within 10-times detection limit with errors likely to exceed $15 \%$.

3) ".-" indicate measurement is below detection. Sample detection limit may be found by

multiplying "det. limit" (far left column) by "multiplier" (lop of each column).

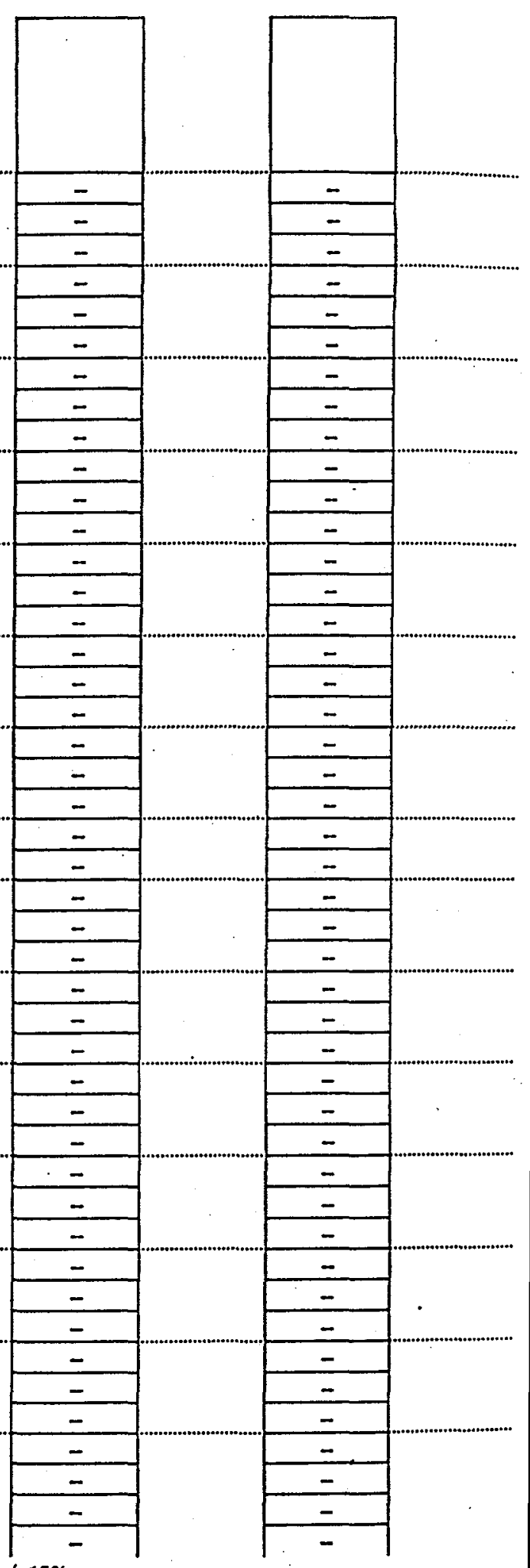




\title{
Battelle PNNL/RPG/Inorganic Analysis --- IC Report
}

\author{
REVISION 01 - Addition of 00-0083 Process Blank Results \\ Client: $\quad$ R. Hallen \\ Charge Code/Project: W45525/29953 \\ ACL Numbers: $00-0072$ to $-0074,-0083$ \\ Analyst: $\quad$ MJ Steele \\ ASR Number: $\quad 5536$ \\ Analysis Date: November 01-03,11, 1999
}

Procedure: PNL-ALO-212, "Determination of Inorganic Anions by Ion Chromatography" M\&TE: IC system (WD25214); Balance (360-06-01-031) --- See Chemical Measurement Center 98620 RIDS IC File for Calibration, Standards Preparations, and Maintenance Records.

\section{Final Results:}

\begin{tabular}{|c|c|c|c|c|c|c|c|c|c|c|}
\hline & & Hot Cell & $1 \mathbf{F}$ & $\mathrm{Cl}$ & $\mathrm{NO}_{2}$ & 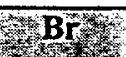 & No 3 & $\mathbf{P O}$ & SOg & $\mathrm{CP}_{2} \mathrm{O}$ \\
\hline Lab ID & Sample ID & Dil Fetr & $\mu \mathrm{g} g$ & $1 \mathrm{Hg} / \mathrm{g}$ & $\mathrm{Hg}$ & $\mu \mathrm{g} g$ & $\mathrm{hg} / \mathrm{g}$ & wghg & Hg/g: & $\lg g$ \\
\hline $00-0072$ & DF-20 & 8.02 & $<2000$ & $<2000$ & 21,800 & $<2000$ & 86,700 & $<4000$ & $<4000$ & $<4000$ \\
\hline & 00-0072 MS Rec & & $113 \%$ & $101 \%$ & $109 \%$ & $109 \%$ & $115 \%$ & $111 \%$ & $114 \%$ & $111 \%$ \\
\hline $00-0073$ & DF-21 & 8.02 & $<2000$ & $<2000$ & 21,600 & $<2000$ & 88,100 & $<4000$ & $<4000$ & $<4000$ \\
\hline $00-0074$ & Wash Comp & 4.95 & $<125$ & $<125$ & 2,900 & $<125$ & 11,600 & $<250$ & 480 & 3,600 \\
\hline 00-0074 Dup & Wash Comp Dup & 4.91 & $<125$ & $<125$ & 2,700 & $<125$ & 10,700 & $<250$ & 460 & 3,300 \\
\hline & RPD & & $n / a$ & $\mathbf{n} / \mathbf{a}$ & $8 \%$ & $n / a$ & $7 \%$ & n/a & $6 \%$ & $8 \%$ \\
\hline $00-0083 \mathrm{~PB}$ & Process Blank & $102.0^{*}$ & $<25$ & $<25$ & $<50$ & $<25$ & $<50$ & $<50$ & $<50$ & $<50$ \\
\hline $00-0083$ & Washed Solids & 114.0 & $<300$ & $<300$ & 1,800 & $<300$ & 8,000 & $<600$ & 1,200 & 25,500 \\
\hline 00-0083 Dup & Washed Solids Dup & 89.91 & $<250$ & 400 & 1,700 & $<250$ & 8,700 & $<500$ & 1,200 & 21,100 \\
\hline & $\mathrm{RPD}$ & & n/a & $n / a$ & $8 \%$ & n/a & $9 \%$ & $\mathrm{n} / \mathrm{a}$ & $1 \%$ & $19 \%$ \\
\hline & 00-0083 MS Rec & & $102 \%$ & $99 \%$ & $102 \%$ & $105 \%$ & $98 \%$ & $104 \%$ & $105 \%$ & $99 \%$ \\
\hline
\end{tabular}

RPD $=$ Relative Percent Difference (between sample and duplicate/replicate)

MS Rec $=$ Matrix Spike Standard \% recovery

* = average $00-0083$ hot cell dilution factor to provide process blank results in $\mu \mathrm{g} / \mathrm{g}$.

The samples were analyzed by ion chromatography (IC) for inorganic anions as specified in the governing ASR. The liquid samples were diluted at the IC workstation from 100 -fold to 1,000 -fold to ensure that all anions were within the calibration range. The liquid samples are reported in $\mu \mathrm{g} / \mathrm{g}$ of liquid and the solids samples are reported in $\mu \mathrm{g} / \mathrm{g}$ of dried solids.

\section{Q.C. Comments:}

Duplicates: Duplicate preparations from the hot cells were provided to the IC laboratory for both the liquid and solids matrices; i.e., samples "Wash Comp" and "Washed Solids", respectively. The relative percent differences (RPD) between replicates are within the acceptance criteria of $20 \%$ for all anions measured above the EQL.

Matrix Spike: Matrix spikes were prepared and measured for samples "DF-20" and "Washed Solids". The spike recoveries for all anions are within the $75 \%$ to $125 \%$ recovery acceptance criteria.

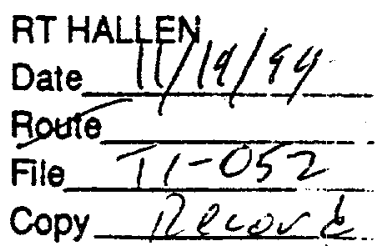




\section{Battelle PNNL/RPG/Inorganic Analysis --- IC Report}

Blank Spike: Although no blank spike, which is used as the laboratory control sample, was analyzed directly with these samples, three blank spike samples were analyzed with each of the daily runs. All anions for the blank spikes recovered within the acceptance criteria of $80 \%$ to $120 \%$.

System Blank/Processing Blanks: Approximately ten system blanks were process during the analysis of the samples. With the exception of only single nitrate value, no anions were detected above reportable concentrations in the system blanks. Since the nitrate results are high, this single QC failure does not affect the reported nitrate results.

Quality Control Calibration Verification Check Standards: Approximately ten mid-range verification standards were analyzed throughout the analysis runs. Except for a single phosphate value, the reported results for all analytes of interest were recovered within the acceptance criteria of $\pm 10 \%$ for the verification standard. The one phosphate result recovered at $+11 \%$ above the true value. No phosphate was detected in any of the samples, thus the single phosphate failure has no impact on the reported results.

\section{General Comments:}

- The reported "Final Results" have been corrected for all dilution performed on the sample during processing or analysis.

- The low calibration standards are defined as the estimated quantitation limit (EQL) for the reported results and assume non-complex aqueous matrices. Actual detection limits or quantitation limits for specific sample matrices may be determined, if requested.

- Routine precision and bias are typically $\pm 15 \%$ or better for non-complex aqueous samples that are free of interference and have similar concentrations as the measured anions.
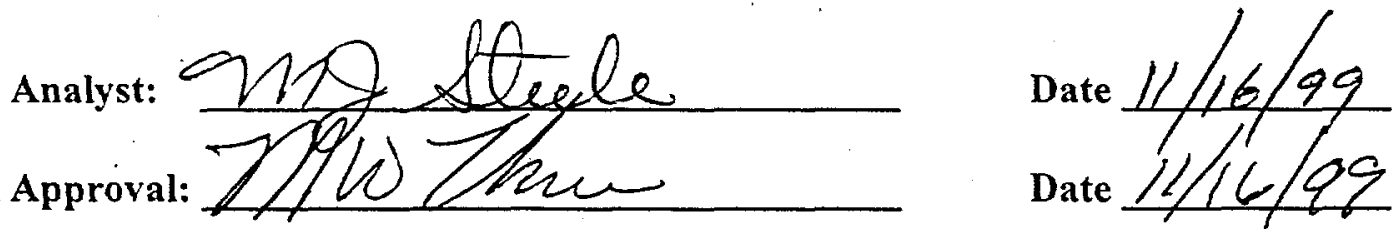

Archive Information:

Files: ASR 5533 Lumetta.doc

ASR $54635533-36-68-71 . x l s$ 
Date November 5, 1999

To Richard Hallen

From Tom Farmer

Subject ICP/MS Analysis of Submitted Samples

(ALO\#00-0070,0072-0074 and 00-0083)

The previously reported sample results were incorrect due to an error in the dilution volumes received from Rick Steele. Here are the corrected results using the correct dilution volumes.

James

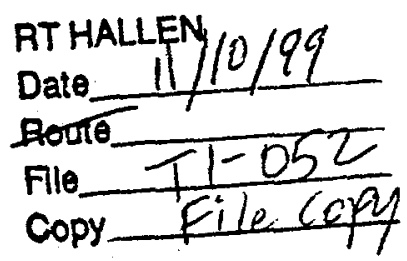




\section{Hallen Tc-99 Analysis}

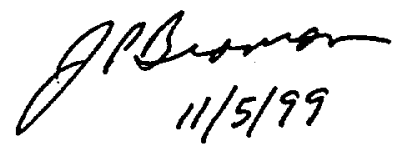

November 4, 1999(Revised 11/5/99)

Results are reported in $\mu \mathrm{g}$ analyte/g (ppm) of original sample.

The uncertainty of the results is estimated at $\pm 10 \%$.

\begin{tabular}{|c|c|c|c|c|}
\hline $\begin{array}{l}\text { Sample } \\
\text { ID }\end{array}$ & & $\begin{array}{l}\text { ICP/MS } \\
\text { Number }\end{array}$ & $\begin{array}{l}\text { Tc-99 } \\
\mu \mathrm{g} / \mathrm{g}\end{array}$ & $\begin{array}{c}\text { *Ru-101 } \\
\mu g / g\end{array}$ \\
\hline $\begin{array}{l}1 \% \mathrm{HNO} 3 \\
1 \% \mathrm{HNO} 3 \\
1 \% \mathrm{HNO} 3 \\
\end{array}$ & & $\begin{array}{r}9 b 03 a 1 \\
9 b 03 a 6 \\
9 b 03 a 18 \\
\end{array}$ & $\begin{array}{l}<0.0002 \\
<0.0002 \\
<0.0002\end{array}$ & \\
\hline $00-0070-\mathrm{PB}$ & Process Blank & $9 b 03 a 8$ & $<0.01$ & 0.001 \\
\hline $\begin{array}{l}00-0072 \\
00-0072-D U P\end{array}$ & $\begin{array}{l}\text { DF-20 } \\
\text { DF-20 }\end{array}$ & $\begin{array}{l}9 b 03 a 14 \\
9 b 03 a 15\end{array}$ & $\begin{array}{l}2.59 \\
2.56\end{array}$ & $\begin{array}{l}4 \\
4\end{array}$ \\
\hline $\begin{array}{l}00-0073 \\
00-0073+\text { spike } \\
\text { Spike Recovery }\end{array}$ & $\begin{array}{l}\text { DF-21 } \\
\text { DF-21 }\end{array}$ & $\begin{array}{l}9 b 03 a 16 \\
9 b 03 a 17\end{array}$ & $\begin{array}{r}2.86 \\
3.33 \\
103 \%\end{array}$ & 5 \\
\hline $00-0074$ & Wash Composite & $9 \mathrm{~b} 03 \mathrm{a} 12$ & 0.293 & 0.5 \\
\hline 00-0074-DUP & Wash Composite & $9 b 03 a 13$ & 0.287 & 0.5 \\
\hline 00-0083-PB & Process Blank & $9 \mathrm{~b} 03 \mathrm{a} 7$ & $<0.5$ & 0.01 \\
\hline $00-0083$ & Washed Solids & $9 b 03 a 10$ & 6.73 & 5 \\
\hline 00-0083-DUP & Washed Solids & $9 b 03 a 11$ & 10.5 & 7 \\
\hline SRM 2710 & LCS/00-0083/Ni & $9 \mathrm{~b} 03 \mathrm{ag}$ & $<0.5$ & 0.03 \\
\hline $\begin{array}{l}\text { CCV results are re } \\
2 \mathrm{ppb} T c-99 \mathrm{CCV} \\
2 \mathrm{ppb} T c-99 \mathrm{CCV}\end{array}$ & rted in $\mathrm{ng} / \mathrm{ml}(\mathrm{ppb})$ & $\begin{array}{r}9 b 03 a 3 \\
9 b 03 a 19\end{array}$ & $\begin{array}{l}2.19 \\
2.14\end{array}$ & \\
\hline $100 \mathrm{ppb} \mathrm{Co}$ & & $9 b 03 a 20$ & $<0.0002$ & \\
\hline
\end{tabular}

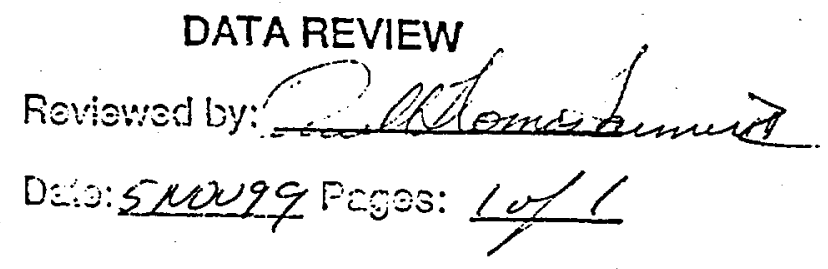




\title{
Battelle PNNL/RPG/Inorganic Analysis --- TOC/TIC Report
}

\author{
Client: \\ R. Hallen \\ Charge Code/Project: W45525/29953
}

ACL Numbers: $00-0072$ to $00-0074,00-0083$

Analyst: $\quad$ MJ Steele

ASR Number:

5536

Analysis Date: December 9-10, 1999

Procedure: PNL-ALO-381, "Direct Determination of TC, TOC, and TIC in Radioactive Sludges and Liquids by Hot Persulfate Method"

M\&TE: Carbon System (WA92040); Balance (360-06-01-023).

Final Results:

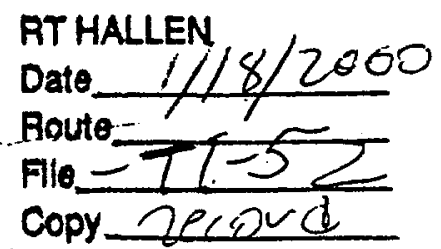

\begin{tabular}{|c|c|c|c|c|c|c|c|c|c|}
\hline \multirow{2}{*}{ Lab Number } & \multirow[b]{2}{*}{ Sample ID } & \multirow{2}{*}{$\begin{array}{l}\text { Density } \\
\text { ug/m } \text { (1) }^{11)}\end{array}$} & \multirow{2}{*}{$\begin{array}{l}\text { Hot Cell } \\
\text { Dil Fetr }\end{array}$} & \multicolumn{2}{|c|}{ TIC } & \multicolumn{2}{|c|}{ TOC } & \multicolumn{2}{|c|}{ TC } \\
\hline & & & & $u g / g$ & RPD(\%) & ug $/ \mathrm{g}$ & RPD(\%) & ug $/ \mathrm{g}$ & RPD(\%) \\
\hline Liquids & & & & & & & & & \\
\hline $00-0072 \mathrm{~PB}$ & Process Blank & & 6.47 & $<40$ & & $<120$ & & -- & \\
\hline $00-0072$ & DF-20 & 1.255 & 8.02 & 6,700 & & 14,000 & & 20,700 & \\
\hline 00-0072 Rep & DF-20 Rep & & 8.02 & 6,900 & 3 & 14,000 & 0 & 20,900 & 1 \\
\hline $00-0073$ & DF-21 & 1.255 & 8.02 & 6,800 & & 13,200 & & 20,000 & \\
\hline 00-0073 Rep & DF-21 Rep & & 8.02 & 6,900 & 1 & 13,200 & 0 & 20,100 & 0 \\
\hline $00-0074$ & Wash Composite & 1.018 & 4.95 & 1,000 & & 2,400 & & 3,400 & \\
\hline 00-0074 Rep & Wash Composite (Rep) & & 4.95 & 1,000 & 0 & 2,300 & 4 & 3,300 & 3 \\
\hline 00-0074 Dup & Wash Composite Duplicate & 1.025 & 4.91 & 1,000 & & 2,400 & & 3,400 & \\
\hline 00-0074 Dup Rep & Wash Composite Duplicate (Rep) & & 4.91 & 1,100 & 10 & 2,500 & 4 & 3,600 & 6 \\
\hline $99-2350 \mathrm{MS}$ & MS Recovery & & $n / a$ & 101 & & 97 & & 100 & \\
\hline
\end{tabular}

\begin{tabular}{|l|l|c|c|c|c|c|c|}
\hline \multirow{2}{*}{ Lab Number } & \multirow{2}{*}{ Sample ID } & \multicolumn{2}{|c|}{ TIC } & \multicolumn{2}{|c|}{ TOC } & \multicolumn{2}{|c|}{ TC } \\
\cline { 3 - 9 } & ug/g & RPD(\%) & ug/g & RPD(\%) & ug/g & RPD(\%) \\
\hline Solids & & & & & & & \\
\hline $00-0083$ & Wahsed Solids & 44,600 & & 1,100 & & 45,700 & \\
\hline $00-0083$ Dup & Washed Solids Duplicate & 57,100 & 25 & 1,800 & n/a & 58,900 & 25 \\
\hline $00-0083$ MS & Washed Solids MS Recovery & $80 \%$ & & $89 \%$ & & $85 \%$ & \\
\hline $00-0083$ Rep & Washed Solids (Rep) & 51,300 & & 1,600 & & 52,900 & \\
\hline $00-0083$ Dup Rep & Washed Solids Duplicate (Rep) & 38,000 & 30 & 2,000 & n/a & 40,000 & 28 \\
\hline
\end{tabular}

$\mathrm{RPD}=$ Relative Percent Difference (between sample and duplicate/replicate)

The analysis of the subject samples submitted under ASR 5536 was performed by the hot persulfate wet oxidation method. The hot persulfate method uses acid decomposition for TIC and acidic potassium persulfate oxidation at $92-95^{\circ} \mathrm{C}$ for TOC, all on the same sample, with TC being the sum of the TIC and TOC.

The table above shows the results, rounded to two to three significant figures. The raw data bench sheets and calculation work sheets showing all calculations are attached. All sample results are corrected for average percent recovery of system calibration standards and are also corrected for 


\section{Battelle PNNL/RPG/Inorganic Analysis --- TOC/TIC Report}

contribution from the instrument calibration blanks. Per the ASR request, all liquid samples were processed by weight and reported in $\mu \mathrm{g} / \mathrm{g}$. The liquid samples were diluted in the Shielded Analytical Laboratory hot cells to reduce the dose associated with the samples analyzed for TIC/TOC; the hot cell dilution factors are provided in the table. An estimate of the density of each liquid sample was obtained during the dilution process by weighing the volume fraction of the sample used for dilution. The density of each liquid is reported in $\mu \mathrm{g} / \mathrm{ml}$.

\section{Q.C. Comments:}

The TIC standard is calcium carbonate and TOC standard is $\alpha$-Glucose (the certificates of purity are attached). The standard materials were used in solid form for system calibration standards as well as matrix spikes. TIC and TOC percent recovery are determined using the appropriate standard (i.e., calcium carbonate for TIC or glucose for TOC).

The QC for the methods involves calibration blanks, system calibration standards, sample duplicates, and one matrix spike per matrix type.

Calibration Standards: The QC system calibration standards for the 12/09/99 and 12/10/99 analysis runs were all within acceptance criteria, with the average recoveries being $100.2 \%$ and $101.1 \%$ for TIC and $99.7 \%$ and $100.5 \%$ for TOC, respectively.

Calibration Blanks: The six calibration blanks run at the beginning and end of the analysis runs were acceptable. The standard deviation calculated from the calibration blanks is less than the estimated method detection limit for both TIC and TOC.

Duplicates: The relative percent differences (RPD) between liquid replicates and the Wash Composite duplicates (00-0074) are within the acceptance criteria of 20\%. The RPD for the Washed Solids (00-0083) TIC was above the acceptance criteria. The Washed Solids were analyzed in duplicate twice, with both sets of analyses providing a poor RPD. The TIC concentration for the Washed Solids is quite high, requiring very small sample sizes to be used. The poor reproducibility is most likely due to heterogeneity of the Washed Solids sample combined with the small sample sizes used.

Matrix Spike: The accuracy of the carbon measurements can be estimated by the recovery results from the matrix spike. No matrix spike was prepared for the liquid samples from this ASR. However, a liquid matrix spike prepared from a sample from other ASRs and run in the same batch demonstrated recoveries of $101 \%$ for TIC and $97 \%$ for TOC, well within the $75 \%$ to $125 \%$ recovery acceptance criteria. The matrix spike for the solids sample run (i.e., 00-0083, Washed Solids MS) recovered at $80.1 \%$ for TIC and $89.2 \%$ for TOC. The recoveries are within the acceptance criteria of $75 \%$ to $125 \%$. The poorer than normal spike recoveries are most likely attributed to the poor RPDs and sample heterogeneity. 


\section{Battelle PNNLRPG/Inorganic Analysis --- TOC/TIC Report}

\section{General Comments:}

- The reported "Final Results" have been corrected for all dilution performed on the sample during processing or analysis.

- Routine precision and bias are typically $\pm 15 \%$ or better for non-complex samples that are free of interferences.

- The estimated quantitation limit (EQL) is defined as 5 times the MDL. Results less than 5 times the MDL have higher uncertainties, and RPDs are not calculated for any results less than 5 times the MDL.

- Some results may be reported as less than ("<") values. These less than values represent the sample MDL (method detection limit), which is the system MDL adjusted for the volume of sample used for the analysis. The system MDL is based on the attached pooled historical blank data. The evaluation and calculation of the system MDL is included in the data package.

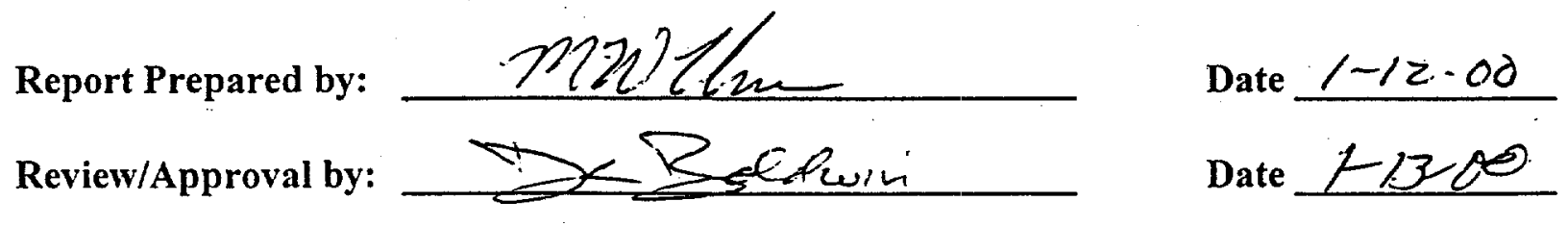
Archive Information: 
PNNL Radiochemical Processing Group: TOC/TIC/TC Calculations ${ }^{\star *}$ Review** Report - Hot Persulfate Method PNL-ALO-381

\begin{tabular}{|c|c|c|c|}
\hline $\begin{array}{l}\text { Client: } \\
\text { Project : } \\
\text { Work Pkg: }\end{array}$ & $\begin{array}{l}\text { R Hallen } \\
29953 \\
\text { W45525 }\end{array}$ & \multicolumn{2}{|c|}{ (CMC K88409) } \\
\hline \multirow{3}{*}{$\begin{array}{l}\text { Analyzed: } \\
\text { ASR: }\end{array}$} & $12 / 10 / 99$ & & \\
\hline & 5536 (Solids) & & \\
\hline & & $\begin{array}{l}\text { Raw TIC } \\
\text { (ug C) }\end{array}$ & $\begin{array}{c}\text { Raw TOC } \\
(\text { ug C) }\end{array}$ \\
\hline \multirow[t]{6}{*}{ Blanks: } & Calibration blank (start of batch) & 13.8 & 57.6 \\
\hline & Calibration blank (start of batch) & 14.0 & 52.6 \\
\hline & Calibration blank (end of batch) & 14.6 & 42.1 \\
\hline & & & \\
\hline & & & \\
\hline & & & \\
\hline
\end{tabular}

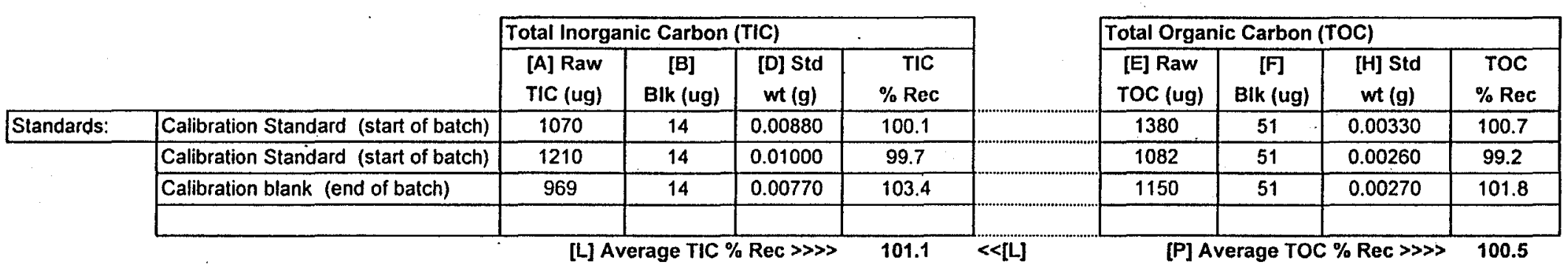

\begin{tabular}{|c|c|c|}
\hline Formulas: & Standard TIC \% Recovery $=\left((A-B) /\left((C / 100)^{*} D\right)\right)^{*} 10^{-6 *}+100$ & Matrix Spike Recoveries: \\
\hline & Standard TOC \% Recovery $=\left((E-F) /\left((G / 100)^{*} H-H\right)\right)^{*} 10^{6 *} * 100$ & TIC \% Recovery $=\left(((Q-R) /(L / 100))-S^{*} T\right) * 100 / U$ \\
\hline & $\begin{array}{l}\text { Sample TIC (ug C/g) }=(1-J) /\left(K^{*} \sqcup / 100\right) \\
\text { Sample TOC (ug } C / g=(M-N) /\left(O^{*} P / 100\right)\end{array}$ & $\begin{array}{l}\text { TOC \% Recovery }=\left(((Q-R) /(P / 100))-S^{*} T\right)^{*} 100 / U \\
\text { TC \% Recovery }=\left(\left(\left(\left(Q^{T C}-R^{T C C}\right) /(L 100)\right)-V^{T I C}\right)+\left(\left(\left(Q^{T O C}-R^{T O C}\right) /(P / 100)\right)-V^{T O C}\right)\right)^{*} 100 / U^{T C+}+T O C\end{array}$ \\
\hline
\end{tabular}

Comments: Due to the precision carried in the spreadsheet, some results may appear to be slightly off due to rounding.

The Pooled SD is the averaged SD for a recent list of 12 sample batches. MDL is based upon the Pooled SD. MDL $=3 \times$ pooled SD.

If either the Sample or Duplicate are $<5 \times$ mdl, then the RPD is not calculated and displayed as " $\mathrm{n} / \mathrm{a}$ ".

TIC and TOC are measured; TC is the sum of the TIC and TOC results. 
PNNL Radiochemical Processing Group: TOC/TIC/TC Calculations ${ }^{\star \star}$ Review* ${ }^{\star \star}$ Report - Hot Persulfate Method PNL-ALO-381

Client: R Hallen

Project : 29953

Work Pkg: W45525

Analyzed: 12/10/99

ASR: $\quad 5536$ (Solids)
Analyzer M\&TE: WA92040 -- 701

Balance M\&TE: $\quad 360-06-01-023$

TOC STD: Glucose CSM-53219 $\gg>\quad 40.00 \%$ Carbon $<<[G]$

TIC STD: CaCO3 CMS-139285»》 $11.99 \%$ Carbon $<<[C]$

\section{Sample Results.}

\begin{tabular}{|c|c|c|c|c|c|c|c|c|c|c|c|c|c|}
\hline ACL Number & \begin{tabular}{|c|c|} 
Client Sample ID \\
\end{tabular} & $\begin{array}{c}\text { [I] Raw } \\
\text { TIC (ug C) }\end{array}$ & $\begin{array}{c}\text { [J] } \\
\text { Blk (ug C) } \\
\end{array}$ & $\begin{array}{c}{[\mathrm{K}] \text { Sam }} \\
\mathrm{W}(\mathrm{g})\end{array}$ & $\begin{array}{c}\text { TIC } \\
\text { (ug C/g) }\end{array}$ & $\begin{array}{c}\text { TIC } \\
\text { RPD (\%) }\end{array}$ & $\begin{array}{c}\text { [M] Raw } \\
\text { TOC (ug C) }\end{array}$ & $\begin{array}{c}\text { [N] } \\
\text { Blk (ug C) }\end{array}$ & $\begin{array}{c}\text { [O] Sam } \\
\text { Wt(g) }\end{array}$ & $\begin{array}{c}\text { TOC } \\
\text { (ug C/g) }\end{array}$ & $\begin{array}{c}\text { TOC } \\
\text { RPD }(\%) \\
\end{array}$ & $\begin{array}{c}\text { TC } \\
\text { (ug C/g) }\end{array}$ & $\begin{array}{c}\text { TC } \\
\text { RPD }(\%) \\
\end{array}$ \\
\hline $00-0083$ & Wahsed Solids & 1280 & 14 & 0.0281 & 44,568 & & 81 & 51 & 0.0281 & 1,070 & & 45,638 & \\
\hline 00-0083 Dup & Washed Solids Duplicate & 1700 & 14 & 0.0292 & 57,119 & 25 & 104 & 51 & 0.0292 & 1,813 & $n / a$ & 58,932 & 25 \\
\hline $00-0083 \mathrm{MS}$ & Washed Solids MS & 1982 & 14 & 0.0286 & see below & & 835 & 51 & 0.0286 & see below & & see below & \\
\hline $00-0083 \operatorname{Rep}$ & Washed Solids (Rep) & 1600 & 14 & 0.0306 & 51,273 & & 100 & 51 & 0.0306 & 1,600 & & 52,873 & \\
\hline 00-0083 Dup $R$ & Washed Solids Duplicate (Rep) & 1332 & 14 & 0.0343 & 38,012 & 30 & 120 & 51 & 0.0343 & 2,008 & $\mathrm{n} / \mathrm{a}$ & 40,019 & 28 \\
\hline
\end{tabular}

\section{Matrix Spike Results}

\begin{tabular}{|c|c|c|c|c|c|c|c|c|c|c|}
\hline ACL Number & Client Sample ID & $\begin{array}{c}\text { [Q] Raw MS } \\
\text { (ug C) }\end{array}$ & $\begin{array}{c}\text { [R] MS Bik } \\
\text { (ug C) }\end{array}$ & $\begin{array}{l}\text { [S] Sam } \\
\text { (ug C/g) }\end{array}$ & $\begin{array}{c}\text { [T] MS Sam } \\
\text { Wt(g) }\end{array}$ & $\begin{array}{l}\text { [V] Sample } \\
\text { (ug C) }\end{array}$ & $\begin{array}{l}\text { Spike } \\
\text { wt (g) }\end{array}$ & \begin{tabular}{|c}
$\begin{array}{c}\text { [U] Spike } \\
\text { (ug C) }\end{array}$ \\
\end{tabular} & $\begin{array}{l}\text { MS } \\
\% \text { Recovery } \\
\end{array}$ & \\
\hline \multirow[t]{3}{*}{$00-0083$ MS } & TIC Recovery & 1982 & 14 & 44568 & 0.0286 & 1275 & 0.0070 & 839 & 80.1 & TIC \\
\hline & TOC Recovery & 835 & 51 & 1070 & 0.0286 & 31 & 0.0021 & 840 & 89.2 & TOC \\
\hline & \multicolumn{7}{|c|}{ Total Carbon Recovery (TIC + TOC) } & 1679 & 84.7 & TC \\
\hline
\end{tabular}

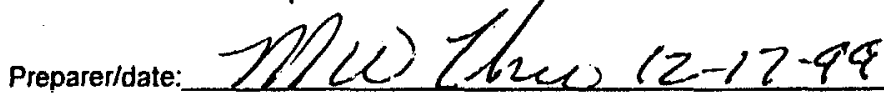

Reviewer/date:

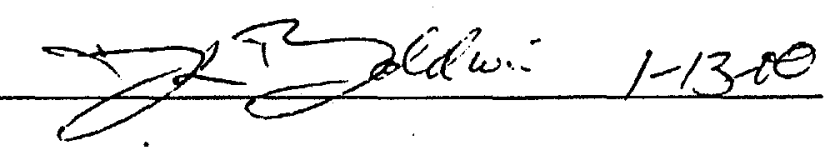




\section{WT\% SOLIDS DATA SHEET}

(325 SHIELDED ANALYTICAL LABORATORY)

CLIENT: $\quad$ RT HALLEN
QA PLAN: $\quad$ MCS-033

WORK PACKAGE

W45525

ASR/ARF/LOI/TI:

ASR5536

QA PLAN: MCS-033

IMPACT LEVEL:

PROCEDURE NUMBER:

PNL-ALO-504

\section{0-0083 WASHED SOLIDS}

SAMPLE IDENTIFICATION

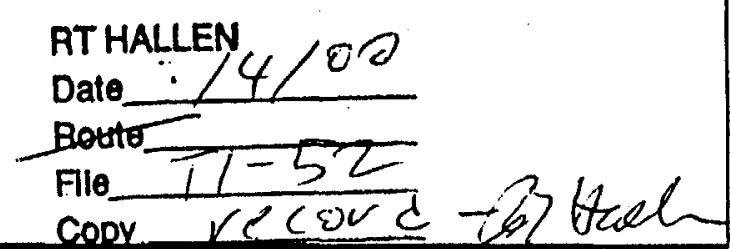

\begin{tabular}{|c|c|c|c|c|c|c|}
\hline \multirow{2}{*}{$\begin{array}{c}\text { ACL } \\
\text { NUMBER } \\
00-0083 . \\
\end{array}$} & \multirow{2}{*}{$\begin{array}{c}\text { CLIENT } \\
\text { IDENTIFICATION } \\
\text { WASHED SOLIDS }\end{array}$} & \multirow{2}{*}{$\begin{array}{l}\text { TARE WEIGHT (G) } \\
16.7572\end{array}$} & \multirow{2}{*}{$\begin{array}{c}\text { (A) } \\
\text { SAMPLE WET WEIGHT } \\
\text { PLUS TARE }\end{array}$} & \multicolumn{2}{|c|}{$\begin{array}{l}\text { (B) } \\
\text { SAMPLE DRY WEIGHT } \\
\text { PLUS TARE }\end{array}$} & \multirow{2}{*}{$\frac{\text { WEIGHT \% SOLIDS }}{36.93 \%}$} \\
\hline & & & & 18.5767 & 18.5685 & \\
\hline 00-0083-DUP & WASHED SOLIDS & 17.0414 & 2.3 .4848 & 19.3895 & 19.3819 & $36.32 \%$ \\
\hline . & & & & & 19.3840 & \\
\hline . & & & & & & \\
\hline : & & & & & & \\
\hline & & & & & & \\
\hline & & & & & & \\
\hline & & & & & & \\
\hline
\end{tabular}

$W T \%$ SOLIDS $=\frac{B-\text { TARE }}{A-\text { TARE }} \times 100$

THERMOCOUPLE: $2 / 16$
DATE/TIME IN: $10-2 /-99$

DATE/TIME OUT: 10.22 .99

1000 OVEN TEMPERATURE: $104{ }^{\circ} \mathrm{C}$ BALANCE: CELL 2 (360-06-01-016) BALANCE: CELL 5 (360-06-01-039)

Date:

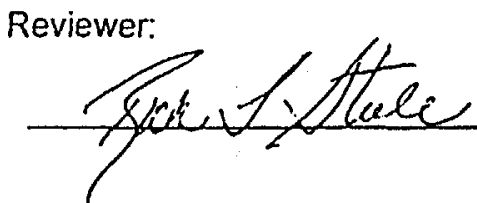


APPENDIX C: RHEOGRAMS

C. 1 
Figure 1. $50 \mathrm{cP}$ Standard, Brookfield Lot 102298, Analyzed on Bohlin CS Before AN-107 Initial Diluted Feed Samples 1/22/99

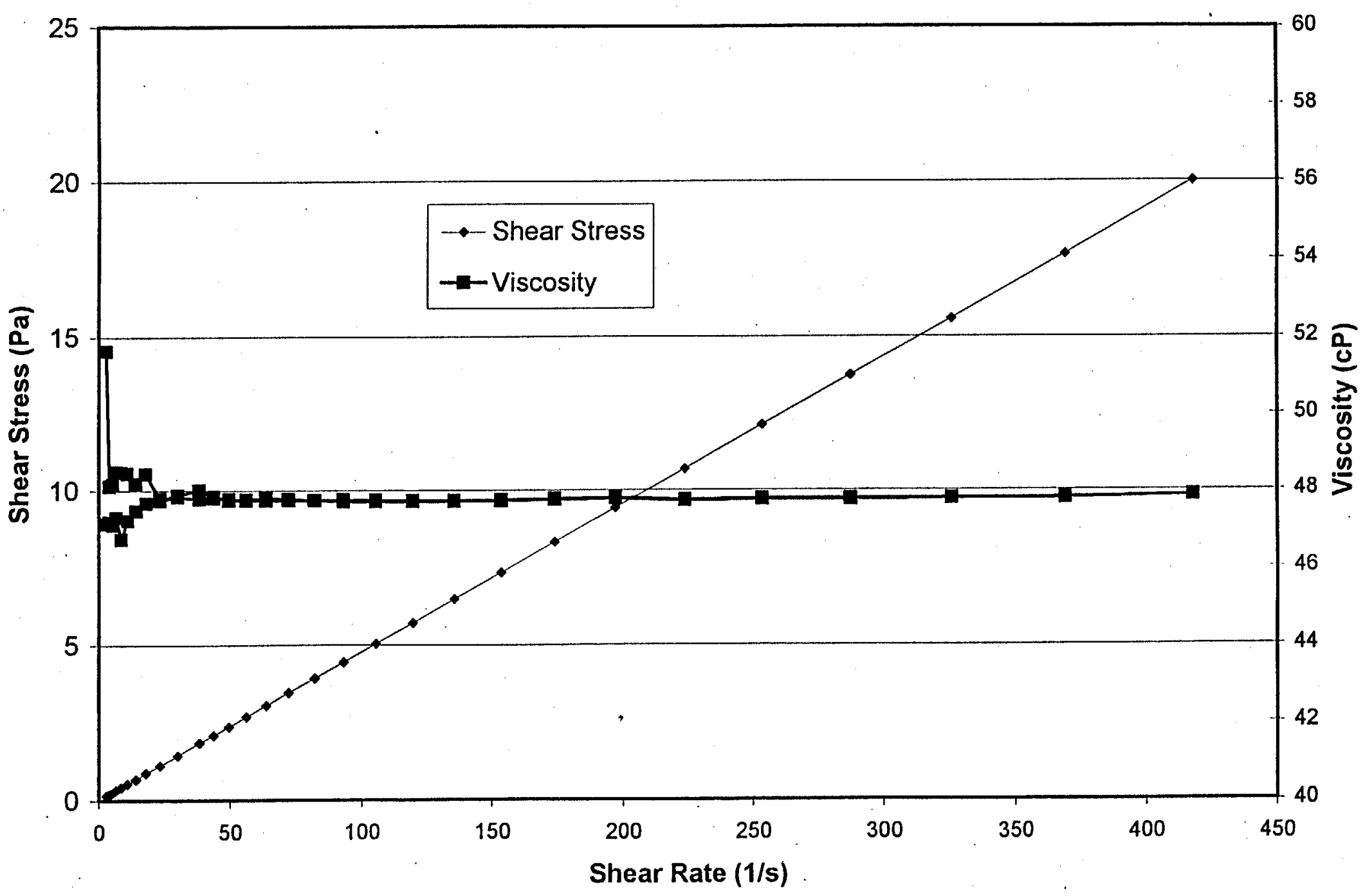




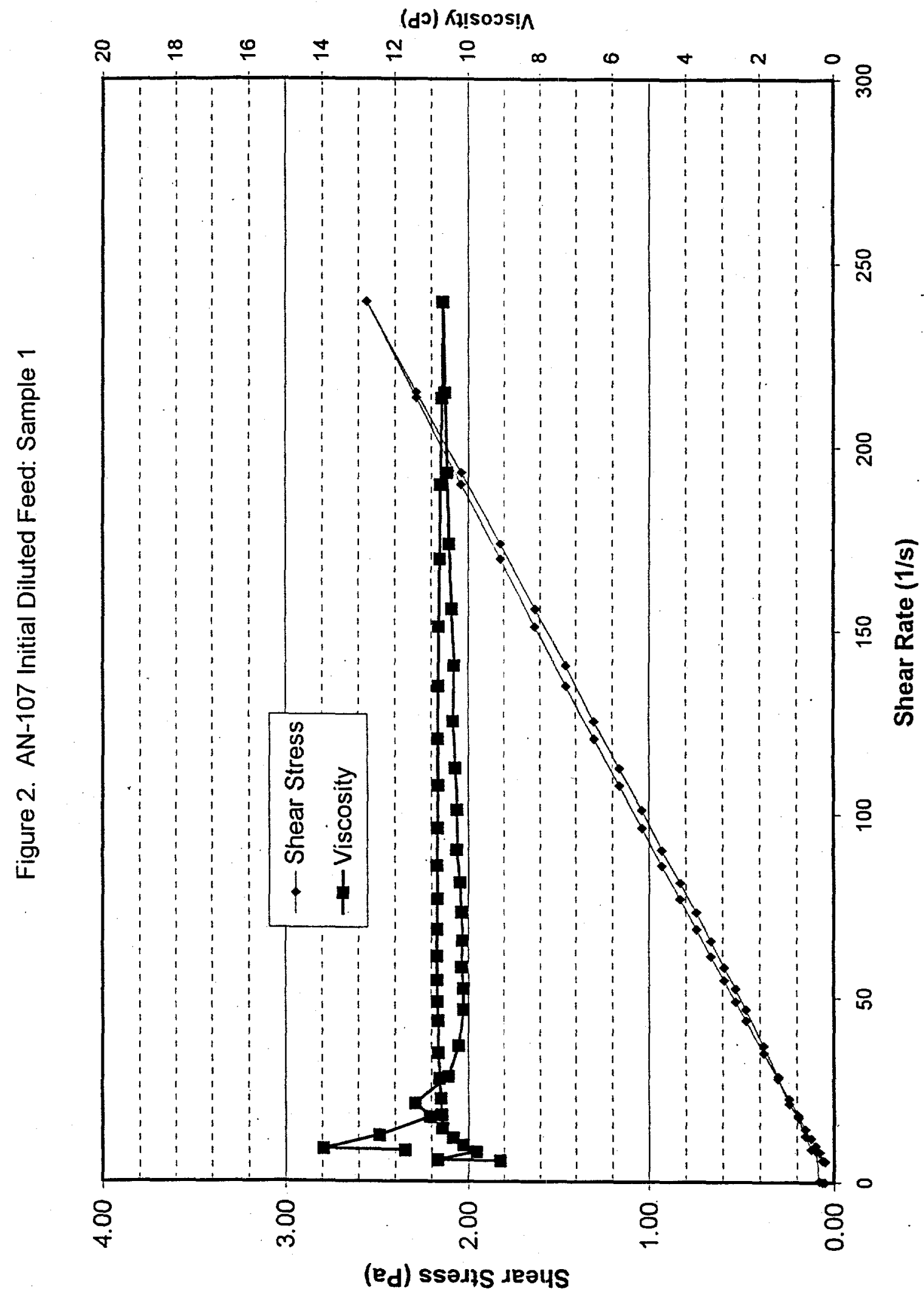




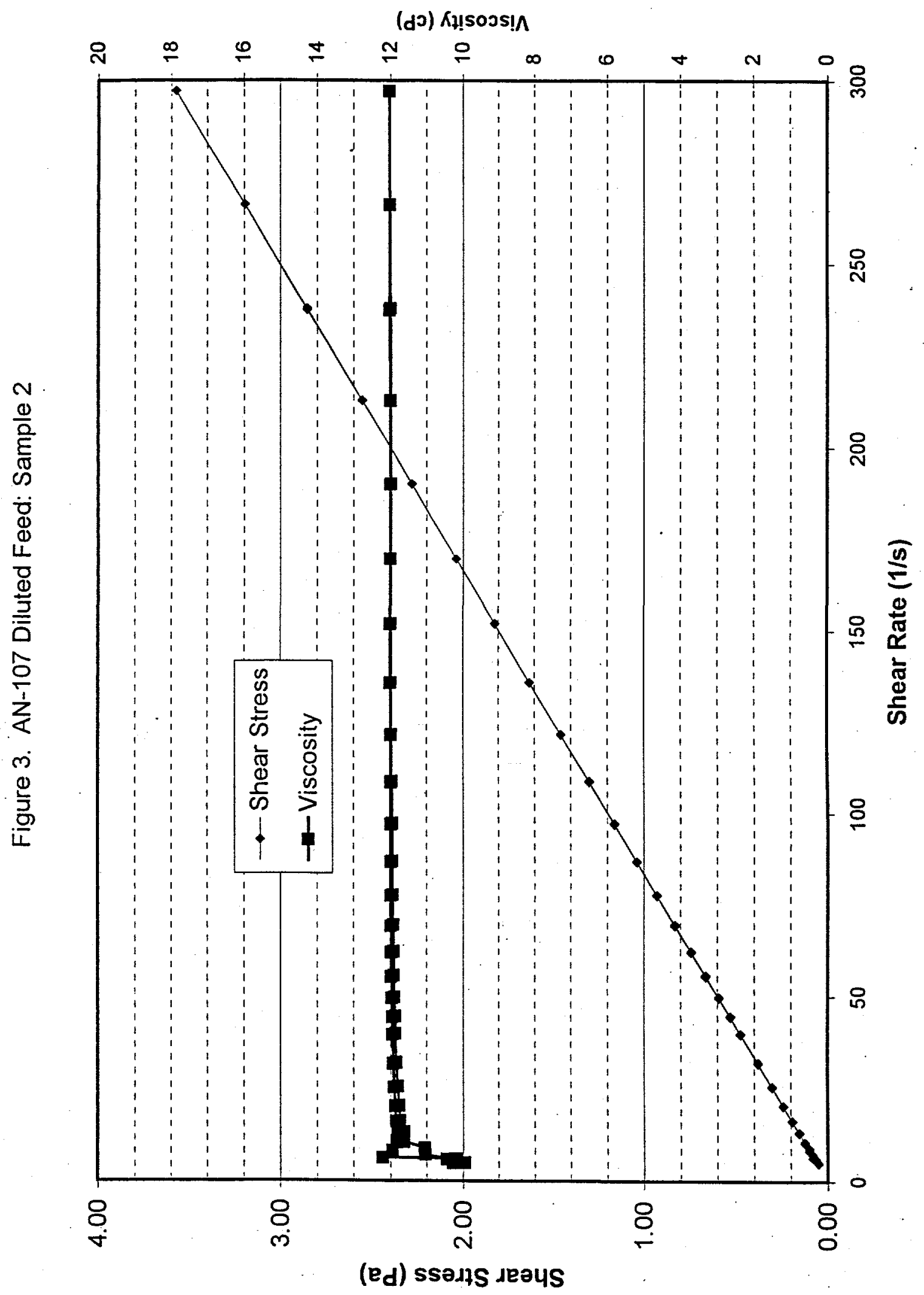


Figure 4. $50 \mathrm{cP}$ Standard, Brookfield Lot 102298, Analyzed on Haake M5 Viscometer Before AN107 SR/TRU Percipitated Samples 8/24/99

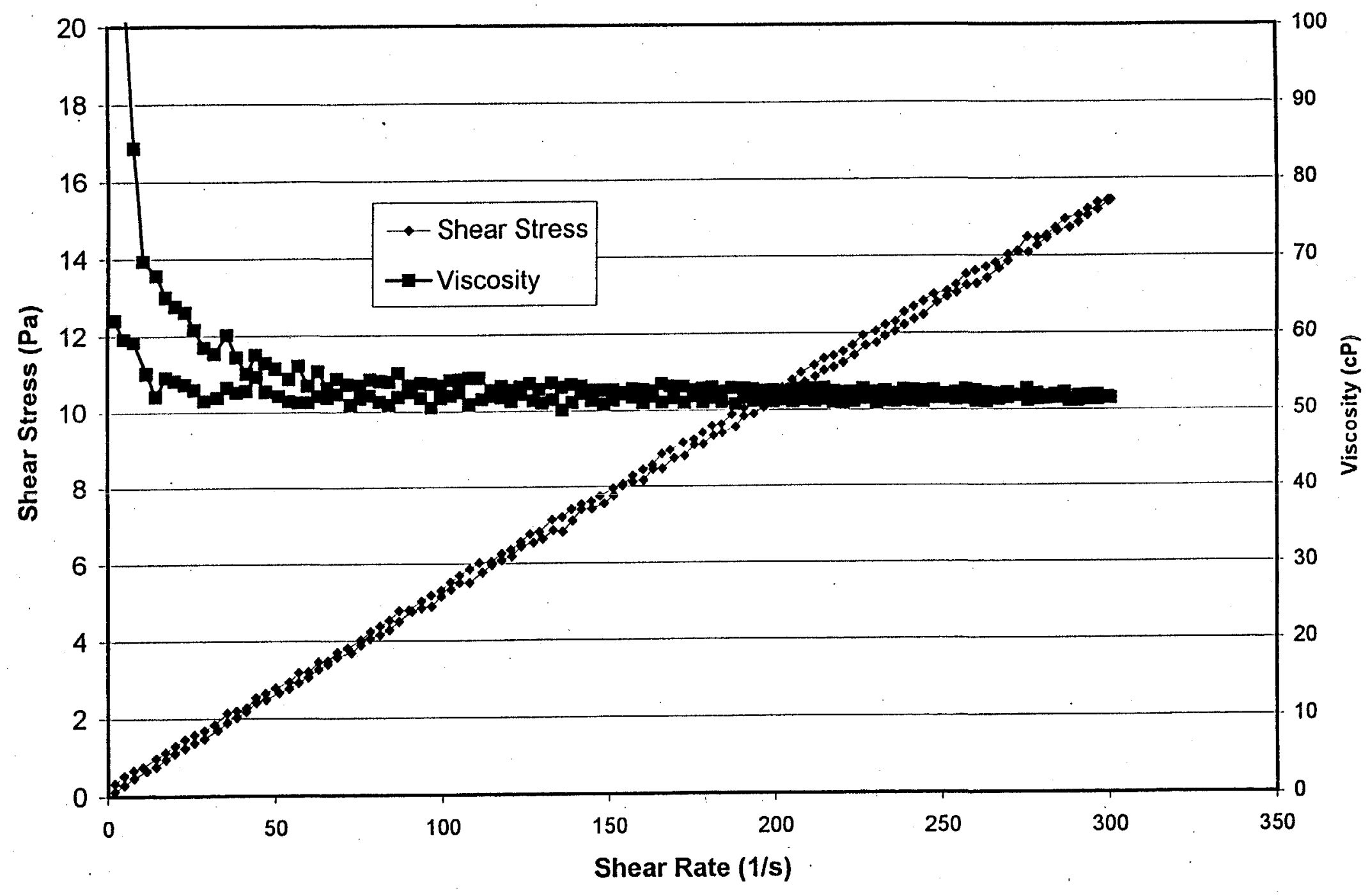




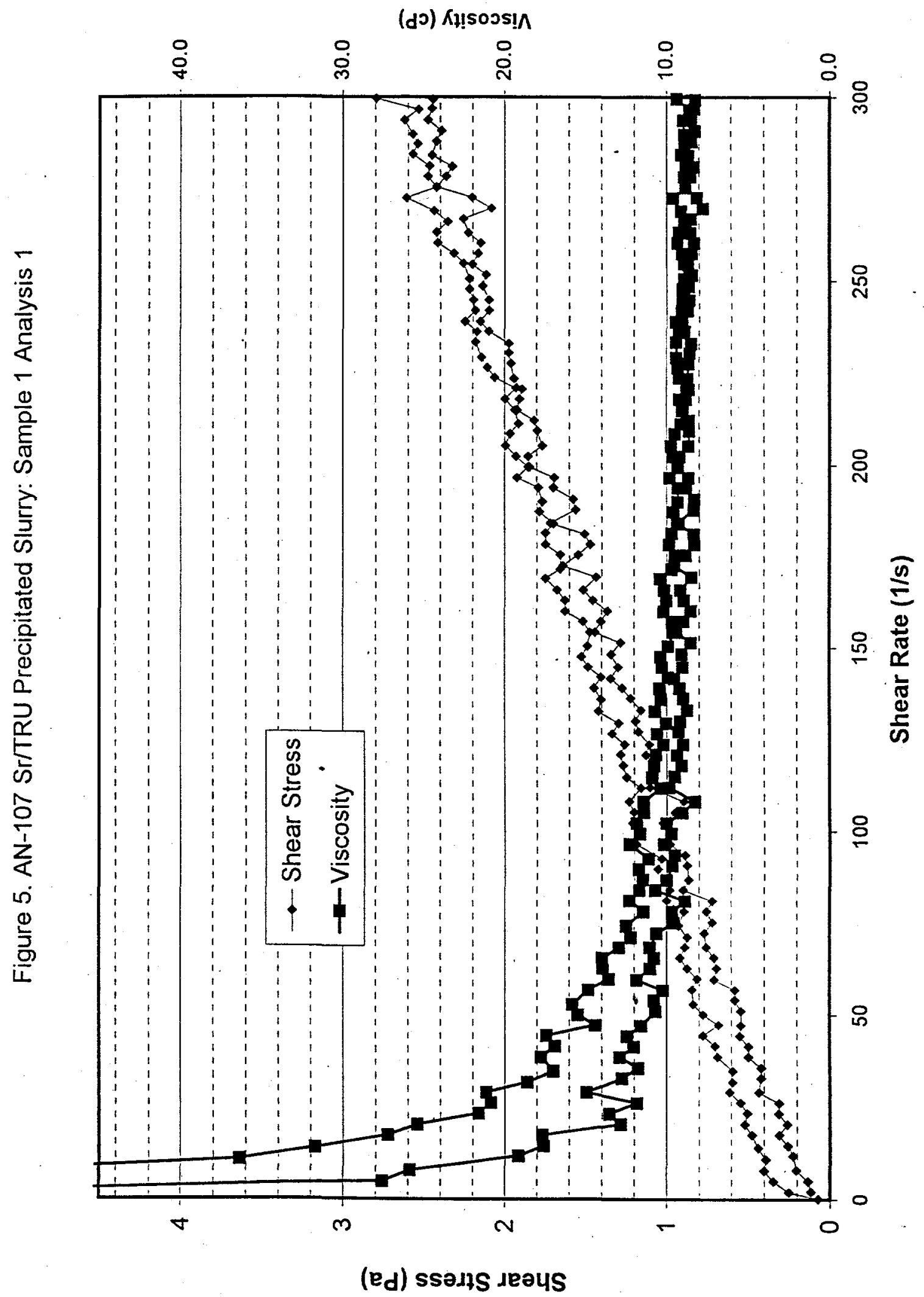




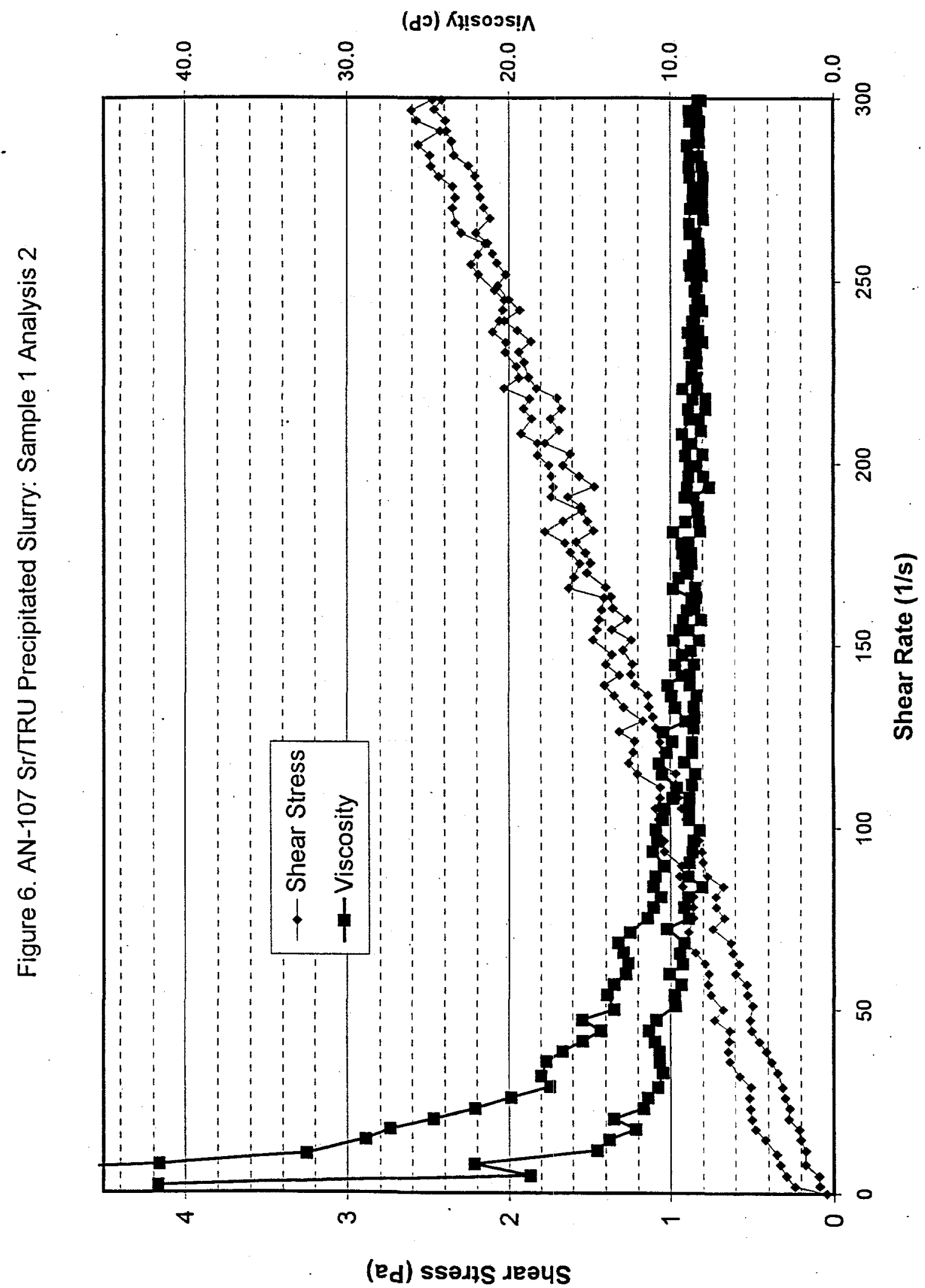




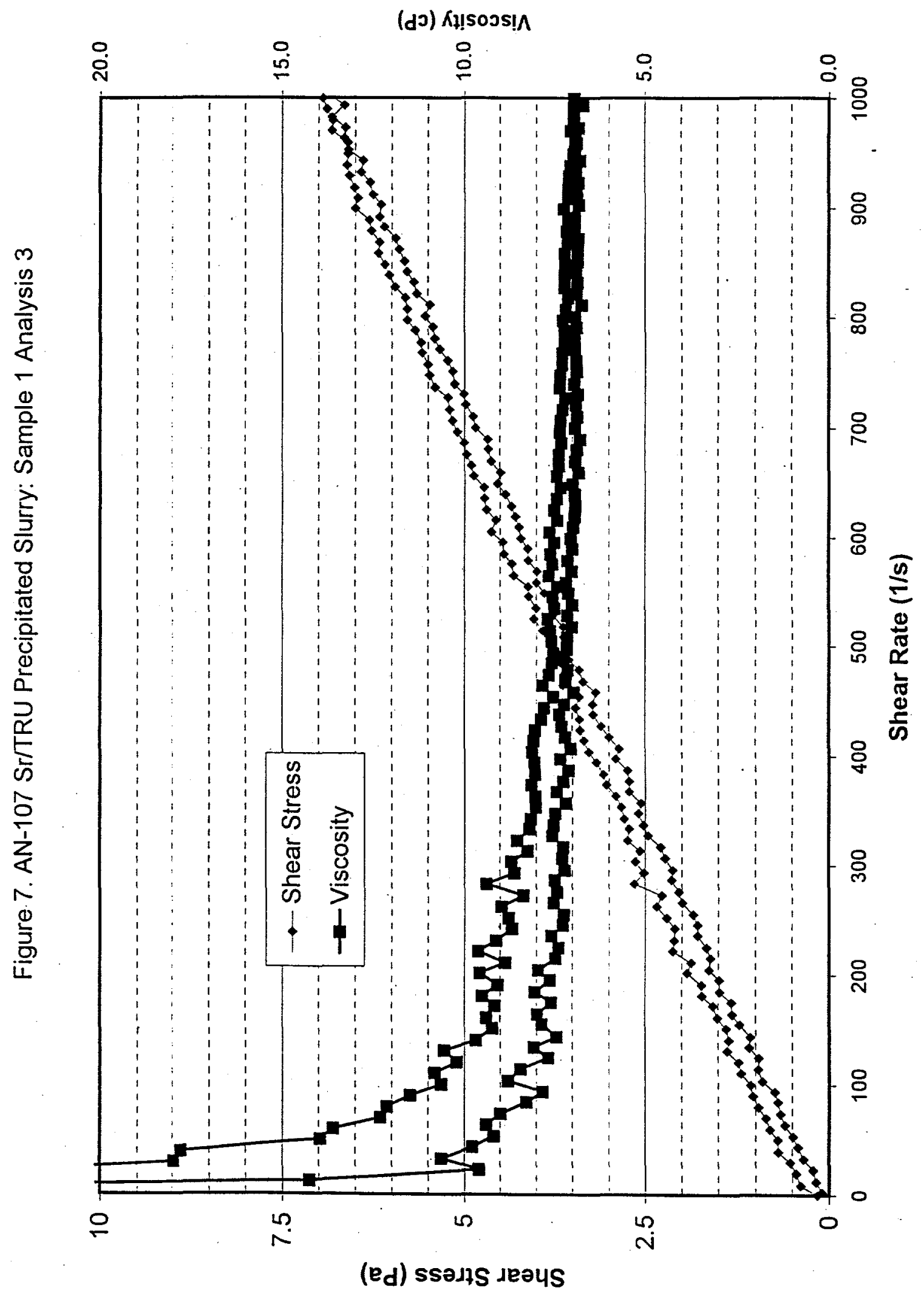




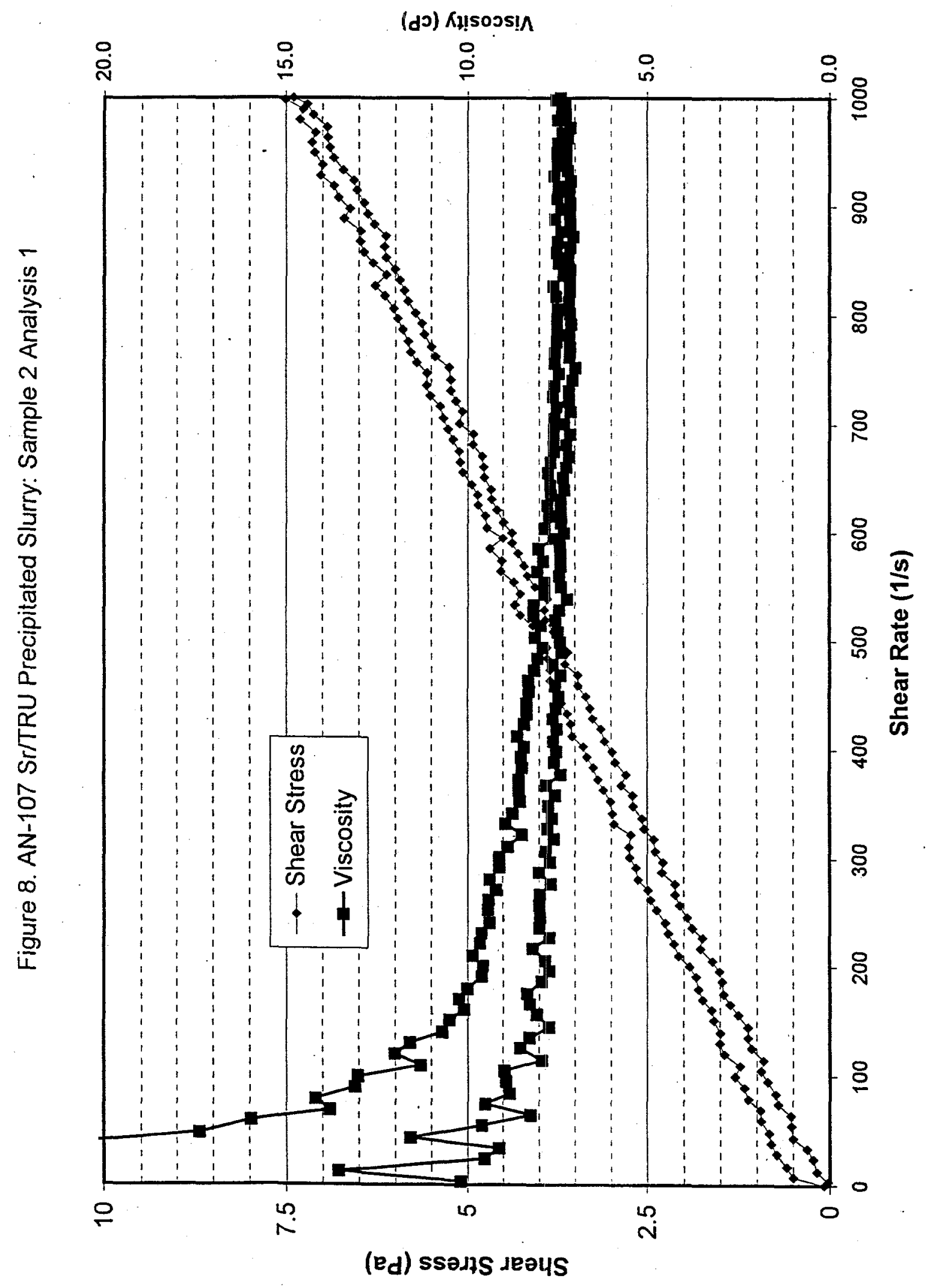




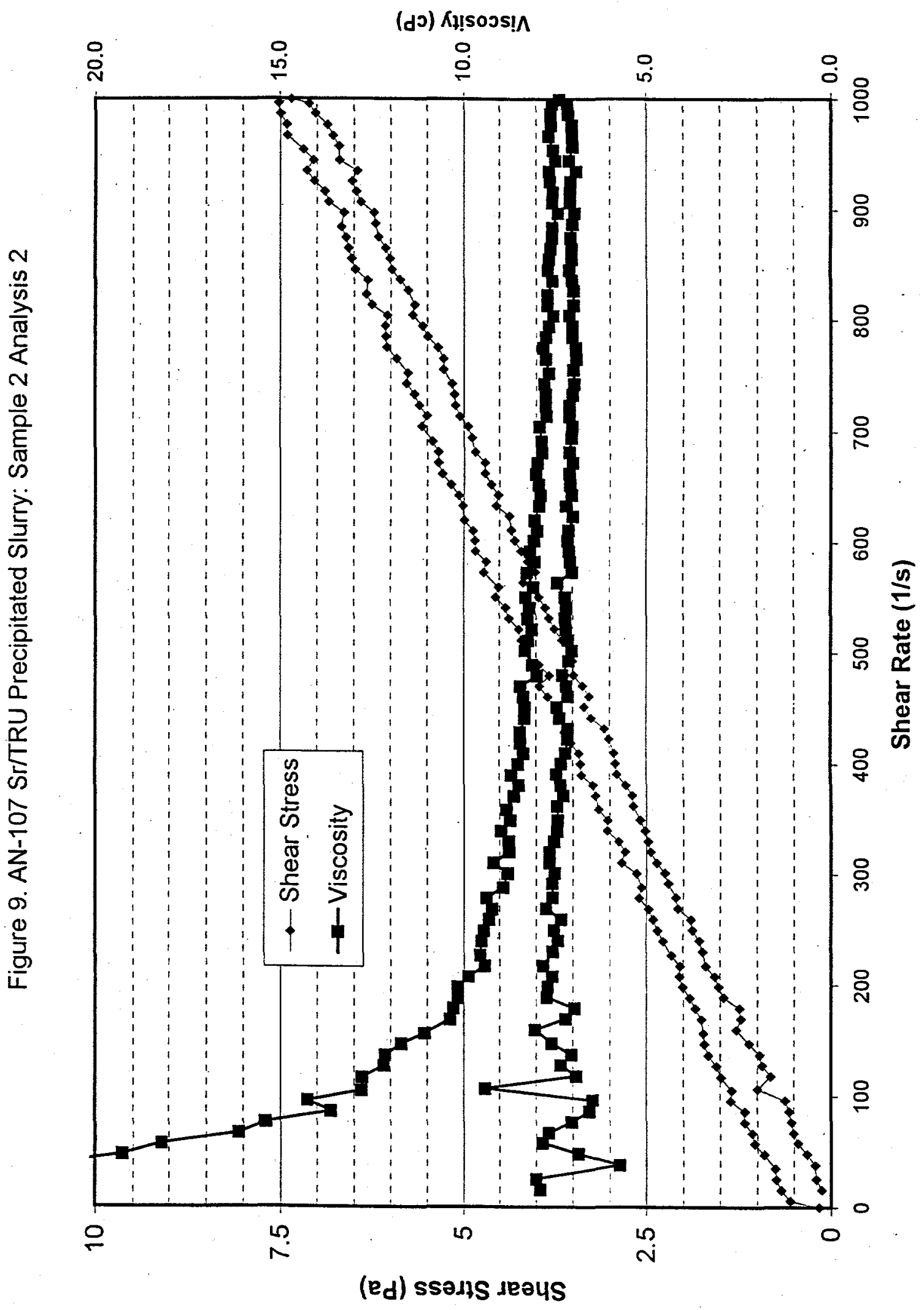




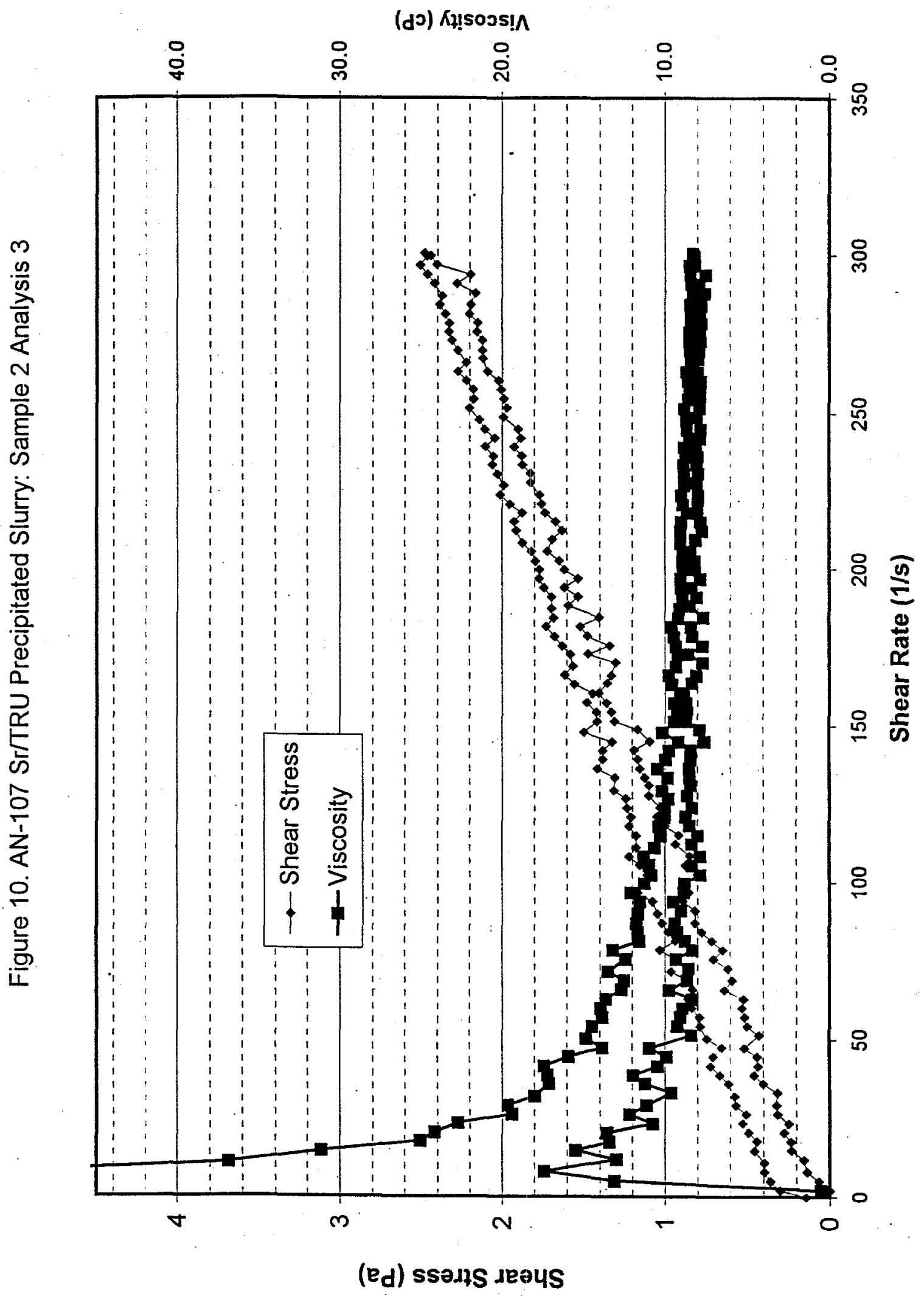


APPENDIX D: CALCULATIONS

D.1 
TI-052, actual test conditions for An-107 DF Sr/TRU removal and CUF tests

Weight of starting AN-107 DF

Density from Paul Bredt

Total volume of treated AN-107D

$3.5185 \mathrm{M} \mathrm{NaOH}$ added

Density of $\mathrm{NaOH}$

Volume of $\mathrm{NaOH}$ added

1.0M Sr added

Density of $\mathrm{Sr}$

Volume of $\mathrm{Sr}$ added

1.0M MnO4 added

Density of MnO4r

Volume of $\mathrm{MnO} 4$ added

Density of resulting slurry

Density of CUF Filtrate
1845.44 grams

$1.32 \mathrm{~g} / \mathrm{mL}$

$1398.06 \mathrm{~mL}$

296.548 grams

$1.12261 \mathrm{~g} / \mathrm{mL}$

$264.16 \mathrm{~mL}$

1.1607

165.367 grams

$1.15852 \mathrm{~g} / \mathrm{mL}$

$142.74 \mathrm{~mL}$

105.558 grams

$1.09432 \mathrm{~g} / \mathrm{mL}$

$96.46 \mathrm{~mL}$

$1.2975 \mathrm{~g} / \mathrm{mL}$

$1.2855 \mathrm{~g} / \mathrm{mL}$

\section{Calculated Mass Dilution Factor}

1.3075 samples DF-01 to 04

sample DF-11

Waste was further dilute, approximately $25 \%$ and rerun through the CUF

grams CUF slurry, grams filtrate, plus DF-07,08,09,10

diluted with
837.58 grams

1189.89 grams

85 grams

2112.47 grams

406.51 grams of first CUF was 1.1924 use value of 1.19 total mass total volume $2412.911 \quad 1859.6617$ 


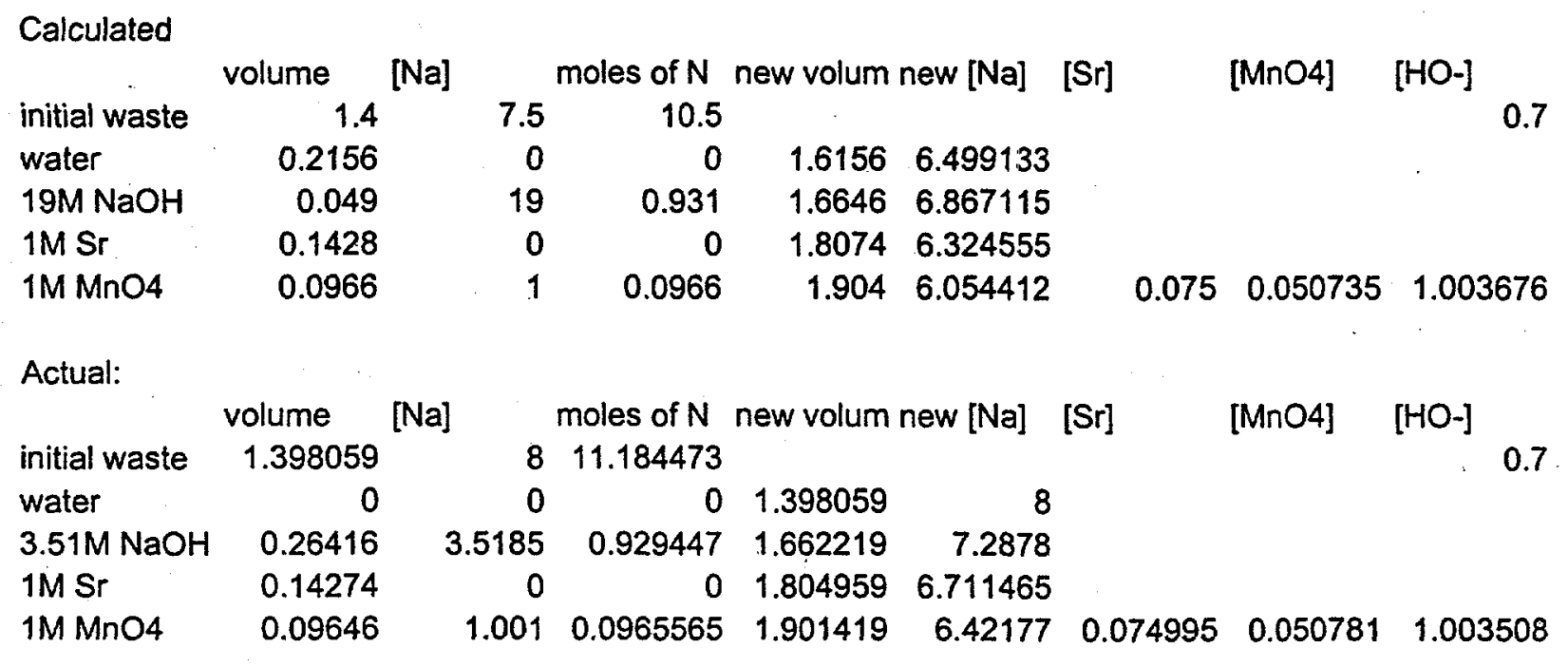

Total volume of treated AN-107DF $\quad 1398.0591 \mathrm{~mL}$

$\begin{array}{lc}\text { 3.5185M NaOH added } & 296.548 \mathrm{grams} \\ \text { Density of } \mathrm{NaOH} & 1.1226075 \mathrm{~g} / \mathrm{mL} \\ \text { Volume of } \mathrm{NaOH} \text { added } & 264.16 \mathrm{~mL} \\ & 165.367 \mathrm{grams} \\ \text { 1.0M Sr added } & 1.158519 \mathrm{~g} / \mathrm{mL} \\ \text { Density of } \mathrm{Sr} & 142.74 \mathrm{~mL} \\ \text { Volume of } \mathrm{Sr} \text { added } & 105.558 \mathrm{grams} \\ & 1.0943189 \mathrm{~g} / \mathrm{mL} \\ \text { 1.0M MnO4 added } & 96.46 \mathrm{~mL} \\ \text { Density of MnO4r } & 1.2975 \mathrm{~g} / \mathrm{mL} \\ \text { Volume of MnO4 added } & 1.2855 \mathrm{~g} / \mathrm{mL} \\ & 837.58 \text { grams } \\ \text { Density of resulting slurry } & 1189.89 \text { grams } \\ \text { Density of CUF Filtrate } & 85 \text { grams } \\ \text { Waste was further dilute, approximately } 25 \% \text { and rerun through the CUF } \\ \text { grams CUF slurry, } \\ \text { grams filtrate, } \\ \text { plus DF-07,08,09,10 }\end{array}$




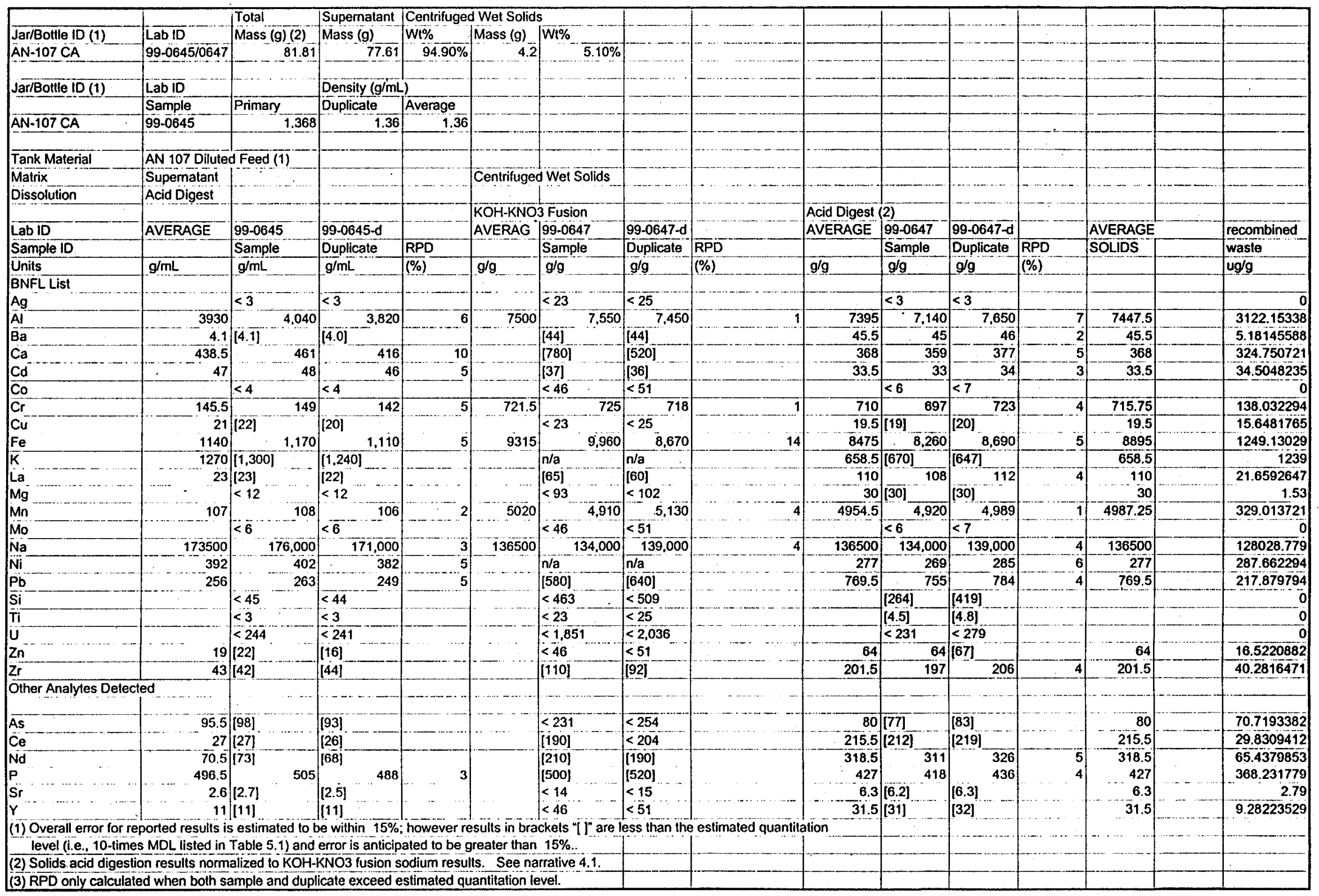




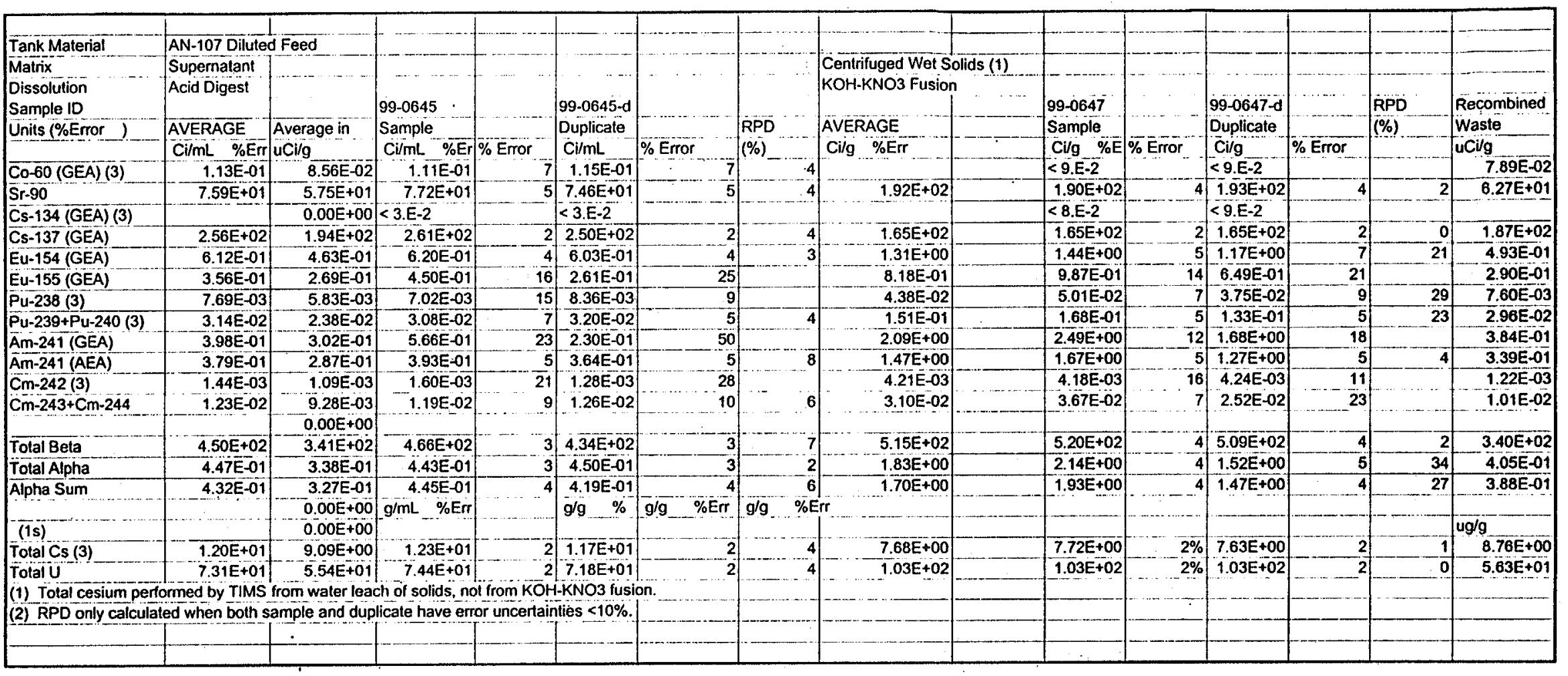




\begin{tabular}{|c|c|c|c|c|c|c|c|c|c|c|c|c|c|c|c|}
\hline Tank Material & AN-107 Dilutec & Feed & & & & & & & & & & & & & \\
\hline Matrix & Supernatant & 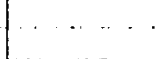 & & & & Centrifuged W & Vet Solids & & & & $\cdots-$ & & 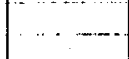 & ...... & $-\infty$ \\
\hline Lab id & ouperiadiati & & $99-0645$ & $99-0645-d$ & & & SEl solios & $99-0647$ & $99-0647-d$ & & & & & & \\
\hline Sample iD & & AVERAGE & Sample & Duplicate & RPD & & AVERAG & Sample & Duplicate & RPD & & & & & \\
\hline Units & Type of Prep & $\mathrm{g} / \mathrm{mL}(2)$ & $g / \mathrm{mL}(2)$ & $\mathrm{g}^{\prime} \mathrm{mL}(2)$ & $(\%)$ & Type of Prep & $g / g(2)$ & $g / g(2)$ & $g / g(2)$ & $(\%)$ & $\mathrm{ug} / \mathrm{g}$ & & ug/g & MW & conc. $M$ \\
\hline rc-99 (ICP/MS) & Acid Digest & 4.315 & 4.4 & 4.23 & & 4 Fusion & 3.77 & 3.62 & $\quad 3.92$ & 8 & 3) 3.203252 & TC-99 (ICP & $2.76 E+00$ & & \\
\hline$\overline{\mathrm{T} C-99}$ (ICP/MS) & Direct/Dilution & 4.035 & 4.09 & 3.98 & & $n / a$ & & $n / a$ & & & & TC-99 (ICP & $0.00 E+00$ & & \\
\hline TIC & DirectDilution & 16300 & 16.400 & 16,200 & & 1 Direct & 17850 & 18,200 & 17.500 & 4 & 12284.39 & TIC & $1.06 E+04$ & 12 & $1.16 E+00$ \\
\hline TOC & Direct/Dilution & 29900 & 30,000 & 29,800 & 0 & Direct & 32000 & 31,100 & 32.900 & 1 & 22496.04 & TOC & $1.94 E+04$ & 12 & $2.13 E+00$ \\
\hline tc (sum) & Directioilution & 46200 & 46,400 & 46,000 & & 1 Direct & 50800 & 51,200 & 50,400 & 2 & 34828.89 & TC (sum) & $3.00 E+04$ & 12 & $3.30 E+00$ \\
\hline Fluoride & Directioilution & 6350 & 6,300 & 6,400 & & 2 Water Leach & 4400 & 4,500 & 4,300 & 3 & 4655.393 & Fluoride & $4.01 E+03$ & 19 & $2.79 E-01$ \\
\hline Chloride & DirectDilution & 1400 & 1,400 & 1.400 & & 2 Water Leach & & $<1200$ & $<1200$ & & 976.9118 & Chloride & $8.42 E+02$ & & \\
\hline Nitrite (3) & DirecuDilution & 51350 & 51,100 & 51.600 & 1 & Water Leach & 31050 & 30,900 & 31,200 & 1 & 37415.28 & Nitrite (3) & $3.22 \mathrm{E}+04$ & 46 & $9.25 \mathrm{E}-01$ \\
\hline Bromide (3) & Direculoilution & HOIVIO! & $<490$ & $\angle 480$ & & Water Leach & \#DIVIoI & $<1200$ & $<1200$ & & & Bromide ( & $0.00 E+00$ & & \\
\hline Nitrate & Directoilution & 161000 & 161,000 & 161,000 & & owater Leach & 111000 & 111,000 & 111,000 & 0 & 118005.9 & Nitrate & $1.02 E+05$ & 62 & $2.16 E+00$ \\
\hline Phospha & Directuilution & 3000 & 3.000 & 3.000 & & 2 Water Leach & & $<2400$ & $<2400$ & & 2093.382 & Phosphate & $1.80 E+03$ & 31 & $7.68 \mathrm{E}-02$ \\
\hline Sulfate & Direc/Dilution & 7650 & 7.900 & 7.400 & 6 & 6 Water Leach & 7000 & 7.000 & 7,000 & 1 & 5695.125 & Sulfale & $4.91 E+03$ & & $6.75 \mathrm{E}-02$ \\
\hline \multirow[t]{2}{*}{ Oxalate (3) } & Directuilution & 1300 & 1,300 & 1,300 & 1 & 1 Water Leach & 32100 & 32,200 & 32,000 & 1 & 2544.232 & Oxalate (3 & $2.19 E+03$ & & \\
\hline & & $\mathrm{mmole}^{\prime} \mathrm{mL}-$ & $\mathrm{mmole} / \mathrm{mL}$ & mmole/mL & & & $\mathrm{mmole} / \mathrm{mL}$ & $\overline{\mathrm{mmole} / \mathrm{mL}}$ & mmole/mL & & mmole/g & & mmole/g? & & \\
\hline \multirow[t]{2}{*}{ Hydroxide } & Directuilution & \begin{tabular}{|l|}
0.717 \\
\end{tabular} & $\begin{array}{ll}\cdots & 0.722 \\
\end{array}$ & 0.712 & & $n / m$ & & & & & 0.500318 & Hydroxide & 0.8650 & & 1.14176035 \\
\hline & & $\mathrm{pH}$ & $\mathrm{pH}$ & $\mathrm{pH}$ & & & $\mathrm{pH}$ & $\mathrm{pH}$ & $\mathrm{pH}$ & & & & & & \\
\hline $\mathrm{pH}$ & Direct & $n / m$ & 13.33 & 13.31 & & $n / m$ & $\mathrm{n} / \mathrm{m}$ & $n / m$ & $n / m$ & & & & & & \\
\hline \multicolumn{16}{|c|}{ (1) RPD only calculated when sample and duplicale results above threshold for method's RPD calculation. (Calculated prior to rounding) } \\
\hline \multicolumn{16}{|c|}{ (2) Value in parentheses for Tc-99 are in units of Cl/mL for supernatants and Cilg for solids. } \\
\hline \multicolumn{7}{|c|}{ (3) Not an analyle of interest specified in Test Plan BNFL-29953-6; included for information only. } & & & & & & & & & \\
\hline \multirow[t]{3}{*}{ For the SirTRU precipit } & itation. & 1845.438 & grams of wast & te was dilute & ed with & 296.548 & grams of 3 . & $.5185 \mathrm{M} \mathrm{NaOH}$ & 264.16 & $\mathrm{~mL}$ & 0.929447 & & & $\mathrm{jH}$ added & \\
\hline & & & & & & & & & & & 21.36777 & \multirow{2}{*}{\multicolumn{2}{|c|}{$\begin{array}{l}\text { moles of sodium and } \\
\text { grams of sodium }\end{array}$}} & & \\
\hline & so all compone & ents diluted by & 0.86155465 & except sodi & ium and hy & droxide & & & & & & & & & \\
\hline
\end{tabular}




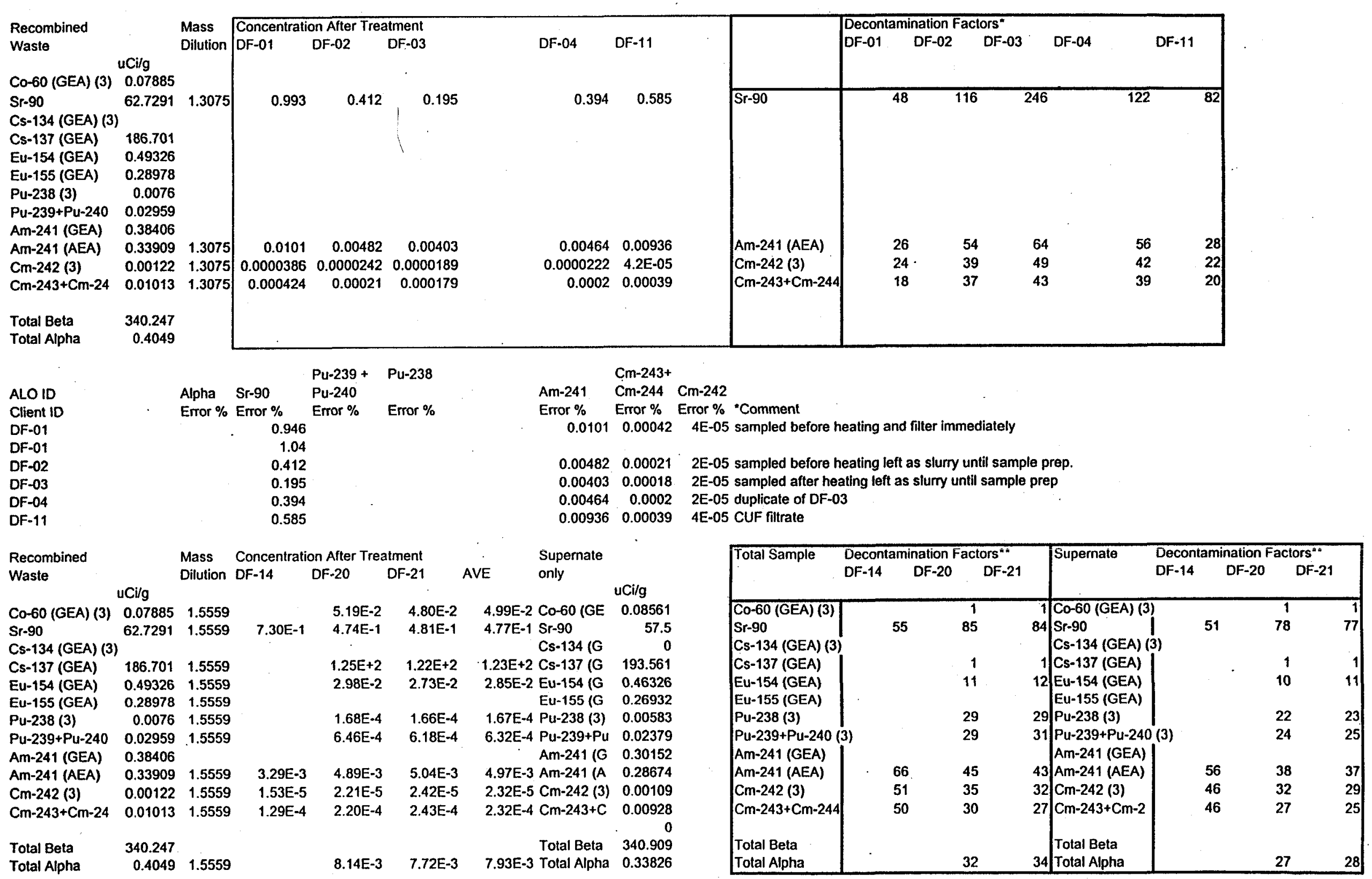


Removal of Tc by Sr/TRU ppt

\section{Supernate}

only

Tc-99

Tc-99

Average
Mass Dilution from

Sr/TRU Treatment

$\mathrm{ug} / \mathrm{g}$

3.172794118

2.966911765

3.069852941

1.555925526
Concentration After Treatment DF-20 DF-20-dup DF-21

$\mathrm{ug} / \mathrm{g} \quad \mathrm{ug} / \mathrm{g} \quad \mathrm{ug} / \mathrm{g}$

$2.59 \quad 2.56 \quad 2.86$

99-0647-d

Duplicate RPD

$\begin{array}{llll} & 99-0647 & \begin{array}{l}99-0647-d \\ \text { Duplicate }\end{array} & \text { RPD } \\ \text { AVERAGE } & \text { Sample } & & \end{array}$

Type of Prep

Fusion

3.77

3.62

3.92

8

\section{Sr/TRU Solids}

00-0083 Washed Solids 00-0083-DUP Washed Solids

AN-107 Diluted Feed analyses, Report -003

Centrifuged Wet Solids

$\begin{array}{ll} & \\ & \\ \text { 9b03a10 } & \\ 9 \mathrm{~b} 03 \mathrm{a} 11 & 6.73 \\ & 10.5\end{array}$

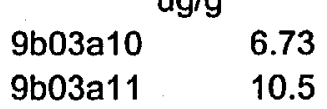

\section{Percent Removed}

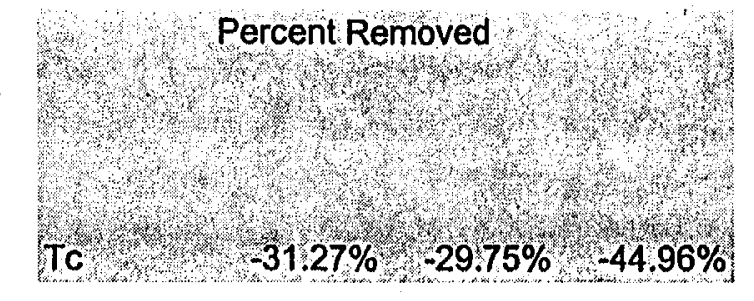

$\begin{array}{lll}0.761779 & 0.770706 & 0.689863\end{array}$

. (1)

00-0083-DUP Wash


AN-107 Diluted Feed, Sr/RU and Solids Removal, ICP metals.

\begin{tabular}{|c|c|c|c|c|c|c|c|c|c|c|c|c|}
\hline \multirow{2}{*}{$\begin{array}{l}\text { recombined } \\
\text { waste } \\
\text { ug/g }\end{array}$} & \multirow{3}{*}{$\begin{array}{l}\text { Mass } \\
\text { Ditution }\end{array}$} & \multicolumn{5}{|c|}{ Concentration After Treatment } & & \multirow{2}{*}{\multicolumn{2}{|c|}{ Percent Removed }} & \multirow{3}{*}{ DF-03 } & \multirow{3}{*}{$D F-04$} & \multirow{3}{*}{ DF-11 } \\
\hline & & DF-01 & DF-02 & DF-03 & DF-04 & $F=11$ & & & & & & \\
\hline & & & & & & & & & & & & \\
\hline $0 \mathrm{Ag}$ & & & & & & & $\mathrm{Ag}$ & & & & & \\
\hline $3122.153 \mathrm{Al}$ & 1.3075 & 2140 & 2230 & 2220 & 2270 & 2220 & $\begin{array}{l}\mathrm{Al} \\
\mathrm{Ba}\end{array}$ & 10 & 7 & 7 & 5 & 7 \\
\hline & 1.3075 & 169 & 160 & 152 & 155 & 157 & $\begin{array}{l}\mathrm{Ba} \\
\mathrm{Ca}\end{array}$ & 32 & 36 & 39 & 38 & 37 \\
\hline $34.50482 \mathrm{Cd}$ & 1.3075 & 26.3 & 27.4 & 27.2 & 27.7 & 27.1 & $\mathrm{Cd}$ & 0 & -4 & -3 & -5 & -3 \\
\hline $0 \mathrm{Co}$ & 1.3075 & 2 & 2 & 2 & 2.1 & 2.1 & Co & & & & & \\
\hline $138.0323 \mathrm{Cr}$ & 1.3075 & 54.5 & 7.23 & 6.65 & 6.89 & 51.5 & $\mathrm{Cr}$ & 48 & 93 & 94 & 93. & 51 \\
\hline $\mathrm{OCu}$ & 1.3075 & 11.4 & 12.1 & 12 & 12.3 & 14.8 & $\mathrm{Cu}$ & & & & & \\
\hline $1249.13 \mathrm{Fe}$ & 1.3075 & 11.8 & 6.49 & 6.96 & 7.4 & 15.9 & $\mathrm{Fe}$ & 99 & 99 & 99 & 99 & 98 \\
\hline $1239 \mathrm{~K}$ & 1.3075 & 720 & 730 & 716 & 732 & 732 & $K$ & 24 & 23 & 24 & 23 & 23 \\
\hline $5.61 \mathrm{La}$ & 1.3075 & 1.4 & & & & 1.1 & La & 67 & & & & 74 \\
\hline $0 \mathrm{Mg}$ & & & & & & & $\mathrm{Mg}$ & & & & & \\
\hline $329.0137 \mathrm{Mn}$ & 1.3075 & 1.9 & 15.1 & 20 & 17.7 & 1.8 & $\mathrm{Mn}$ & 99 & 94 & 92 & 93 & 99 \\
\hline $\mathrm{O}$ MO & 1.3075 & 14.2 & 14.8 & 14.8 & 15 & 14.7 & Mo & & & & & \\
\hline $128028.8 \mathrm{Na}$ & 1.3075 & 112000 & 116000 & 116000 & 118000 & 119000 & $\mathrm{Na}$ & -14 & -18 & -18 & -21 & -22 \\
\hline $287.6623 \mathrm{Ni}$ & 1.3075 & 215 & 223 & 222 & 227 & 222 & $\mathrm{Ni}$ & 2 & -1 & -1 & -3 & -1 \\
\hline $217.8798 \mathrm{~Pb}$ & 1.3075 & 57.9 & 59.1 & 57.5 & 60.4 & 65.9 & $\mathrm{~Pb}$ & 65 & 65 & 65 & 64 & 60 \\
\hline $\begin{array}{l}0 \mathrm{Si} \\
0 \mathrm{Ti}\end{array}$ & 1.3075 & 102 & 43 & 38 & 40 & 46 & $\mathrm{Si}$ & & . & & & \\
\hline $0 \mathrm{U}$ & 1.3075 & 50 & 41 & 39 & 42 & 44 & $\ddot{u}$ & & & & & \\
\hline $3.264 \mathrm{Zn}$ & 1.3075 & 5.7 & 5.7 & 5.9 & 6.4 & 6 & $\mathrm{Zn}$ & -128 & -128 & -136 & -156 & -140 \\
\hline $10.2765 \mathrm{Zr}$ & 1.3075 & 3.8 & 2.2 & 2 & 2.2 & 3.4 & $\mathrm{Zr}$ & 52 & 72 & 75 & 72 & 57 \\
\hline Othe & ytes Detecte & & & & & & Oth & lytes Dete & & & & \\
\hline 0 As & . & & & & & & As & & & & & \\
\hline $0 \mathrm{Ce}$ & & & & & & & $\mathrm{Ce}$ & & & & & \\
\hline $16.2435 \mathrm{Nd}$ & 1.3075 & 6.3 & 3.1 & 2.7 & 2.9 & 5.1 & $\mathrm{Nd}$ & 49 & 75 & 78 & 77 & 59 \\
\hline $368.2318 \mathrm{P}$ & 1.3075 & 282 & 293 & 291 & 297 & 294 & $\mathrm{P}$ & 0 & -4 & -3 & -5 & -4 \\
\hline $2.79 \mathrm{Sr}$ & 1.3075 & 161 & 90.3 & 89.9 & 92.1 & 153 & $\mathrm{Sr}$ & -7445 & -4132 & $x-4113$ & 4216 & -7070 \\
\hline$O Y$ & 1.3075 & 2 & 1.1 & 0.99 & 1.1 & 1.6 & $Y$ & & & & & \\
\hline
\end{tabular}


recombined waste Mass
Dilution

\begin{tabular}{|l}
\hline $\begin{array}{l}\text { Concentration After Treatment } \\
\text { DF-14 } \quad \text { DF-20 }\end{array}$ DF-20 dup DF-20 ave DF-21 \\
\hline
\end{tabular}

$\mathrm{ug} / \mathrm{g}$

$0 \mathrm{Ag}$

$3122.153 \mathrm{Al}$

$2.3205 \mathrm{Ba}$

$324.7507 \mathrm{Ca}$

$34.50482 \mathrm{Cd}$

0 Co

$138.0323 \mathrm{Cr}$

$$
0 \mathrm{Cu}
$$

$1249.13 \mathrm{Fe}$

$1239 \mathrm{~K}$

$5.61 \mathrm{La}$

$0 \mathrm{Mg}$
329.0137

$0 \mathrm{Mo}$

$128028.8 \mathrm{Na}$

$287.6623 \mathrm{Ni}$

$217.8798 \mathrm{~Pb}$

$$
\begin{aligned}
& 0 \mathrm{Si} \\
& 0 \mathrm{Ti}
\end{aligned}
$$

$0 \mathrm{U}$

$3.264 \mathrm{Zn}$

$10.2765 \mathrm{Zr}$

1.555926
1.555926
1.555926
1.555926
1.555926
1.555926
1.555926
1.555926
1.555926

1.555926
1.555926
1.555926
1.555926
1.555926
1.555926

1.555926
1.555926
1.555926
Des Detected

$\begin{array}{rrrrr}1913 & 1990 & 2050 & 2020 & 1940 \\ & & & & \\ 140 & 140 & 144 & 142 & 131 \\ 22.8 & 23.4 & 24 & 23.7 & 22.7 \\ 1.9 & 2.1 & 2.1 & 2.1 & 2 \\ 13.3 & 37 & 38.1 & 37.55 & 36.5 \\ 13.4 & 16.3 & 16.8 & 16.55 & 16.3 \\ 5.34 & 9.29 & 9.16 & 9.225 & 8.6 \\ 603 & 626 & .634 & 630 & 615 \\ & & & & \\ 3.9 & 2.3 & 2.4 & 2.35 & 2.3 \\ 12.4 & 12.8 & 13.1 & 12.95 & 12.5 \\ 105000 & 102000 & 110000 & 106000 & 91900 \\ 189 & 194 & 200 & 197 & 187 \\ 55.1 & 54.9 & 56 & 55.45 & 53.9 \\ 29 & 28 & 25 & 26.5 & 32 \\ & & & & \\ 39 & 39 & & 39 & \\ 5.5 & 5.7 & 6 & 5.85 & 5 \\ 1.5 & 2.1 & 2.1 & 2.1 & 2 \\ & & & & .\end{array}$

$1913 \quad 1990$

1990

2050

2020

$\begin{array}{rrrrr}1913 & 1990 & 2050 & 2020 & 1940 \\ 140 & 140 & 144 & 142 & 131 \\ 22.8 & 23.4 & 24 & 23.7 & 22.7 \\ 1.9 & 2.1 & 2.1 & 2.1 & 2 \\ 13.3 & 37 & 38.1 & 37.55 & 36.5 \\ 13.4 & 16.3 & 16.8 & 16.55 & 16.3 \\ 5.34 & 9.29 & 9.16 & 9.225 & 8.6 \\ 603 & 626 & 634 & 630 & 615 \\ & & & & \\ & & & & \\ 3.9 & 2.3 & 2.4 & 2.35 & 2.3 \\ 12.4 & 12.8 & 13.1 & 12.95 & 12.5 \\ 185000 & 102000 & 110000 & 106000 & 91900 \\ 189 & 194 & 200 & 197 & 187 \\ 55.1 & 54.9 & 56 & 55.45 & 53.9 \\ 29 & 28 & 25 & 26.5 & 32 \\ & & & & \\ 39 & 39 & & 39 & \\ 5.5 & 5.7 & 6 & 5.85 & 5 \\ 1.5 & 2.1 & 2.1 & 2.1 & 2\end{array}$

$\begin{array}{rl}0 \mathrm{As} & \\ 0 \mathrm{Ce} & \\ 16.2435 \mathrm{Nd} & 1.555926 \\ 368.2318 \mathrm{P} & 1.555926 \\ 2.79 \mathrm{Sr} & 1.555926 \\ 0 \mathrm{Y} & 1.555926\end{array}$

$\begin{array}{rrrrrr} & & & & & \\ 2.1 & 2.8 & 2.7 & 2.75 & 2.7 & \\ 246 & 253 & 259 & 256 & 247 & P \\ 94.4 & 113 & 118 & 115.5 & 107 & \\ & .1 & 1 & 1 & 0.99 & Y\end{array}$

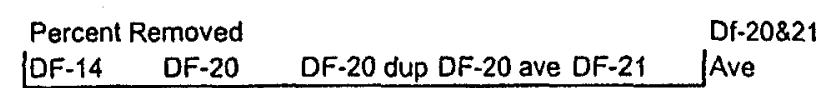

$15-1$

$\begin{array}{rrrrrr}5 & 1 & -2 & -1 & 3 & 1980 \mathrm{Al} \\ 33 & 33 & 31 & 32 & 37 & 136.5 \mathrm{Ca} \\ -3 & -6 & -8 & -7 & -2 & 23.2 \mathrm{Cd}\end{array}$

$23.2 \mathrm{Cd}$

$2.05 \mathrm{Co}$

$\begin{array}{llllll}85 & 58 & 57 & 58 & 59 & 37.025 \mathrm{Cr}\end{array}$

$\begin{array}{llllll}99 & 99 & 99 & 99 & 99 & 16.425 \mathrm{Cu}\end{array}$

$\begin{array}{llllll}99 & 99 & 99 & 99 & 99 & 8.9125 \mathrm{Fe} \\ 24 & 21 & 20 & 21 & 23 & 622.5 \mathrm{~K}\end{array}$

$24 \quad 21 \quad 20$

$98 \quad 99 \quad 99$

$-28$

$-2$

-24
-5
61

77

Other Analytes Detected

$622.5 \mathrm{~K}$

$\mathrm{La}$

$2.325 \mathrm{Mn}$

$12.725 \mathrm{Mo}$

$98950 \mathrm{Na}$

$192 \mathrm{Ni}$

$54.675 \mathrm{~Pb}$

$29.25 \mathrm{Si}$

$39 \mathrm{Ui}$

$5.425 \mathrm{Zn}$

$2.05 \mathrm{Zr}$

$\begin{array}{rr}-159 & -0.009554 \\ 69 & 0.013078\end{array}$

Other Analytes Detected

$\begin{array}{ll}\text { As } & \text { As } \\ \text { Ce } & \text { Ce }\end{array}$

$\begin{array}{lllllllll}\mathrm{Ce} & & & & & \mathrm{Ce} & & \\ \mathrm{Nd} & 80 & 73 & 74 & 74 & 74 & 2.725 \mathrm{Nd} & 74 & 0.022152\end{array}$

$\begin{array}{lccccccrr}\mathrm{P} & -4 & -7 & -9 & -8 & -4 & 251.5 \mathrm{P} & -6 & -0.042599 \\ \mathrm{Sr} & -5164 & -6202 & -6481 & -6341 & -5867 & 111.25 \mathrm{Sr} & -6104 & -0.31429\end{array}$

Y 
Remioval of TIC and TOC by Sr/TRU ppt

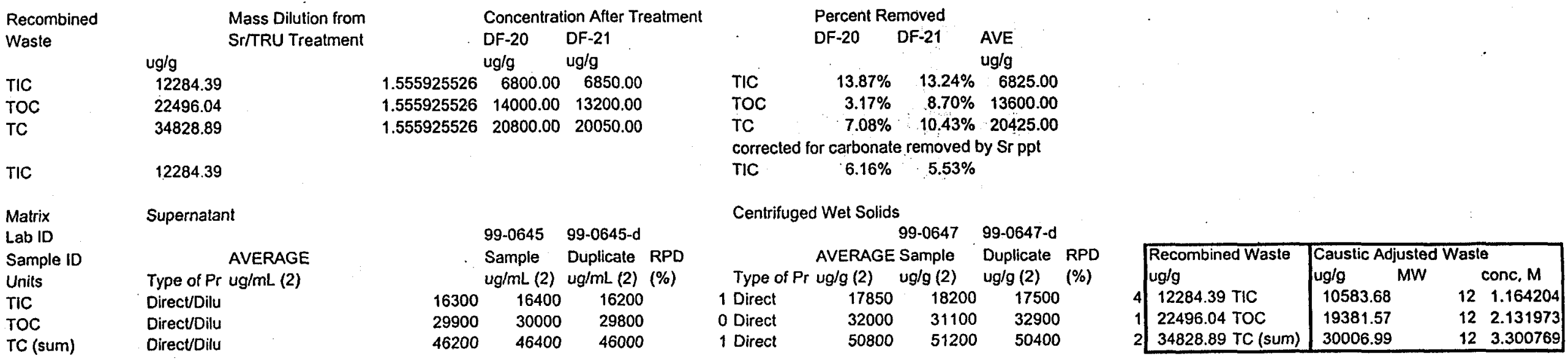

Preliminary results for carbon analyses of Sr/TRU treated AN-107 diluted feed

$\begin{array}{lllcc} & & & & \text { diluter } \\ \text { Lab Number } & \text { Matrix } & \text { Sampe ID } & \begin{array}{c}\text { Hot Cell } \\ \text { Dil Factor ml }\end{array} \\ \text { 00-0072 PB } & \text { Liquid } & \text { Process Blank } & 6.473 \\ 00-0072 & \text { Liquid } & \text { DF-20 } & 8.0167 \\ 00-0072 \text { Rep } & \text { Liquid } & \text { DF-20 Rep } & 8.0167 \\ 00-0073 & \text { Liquid } & \text { DF-21 } & 8.0192 \\ 00-0073 \text { Rep } & \text { Liquid } & \text { DF-21 Rep } & 8.0192 \\ 00-0074 & \text { Liquid } & \text { Wash Composite } & 4.9451 \\ 00-0074 \text { Rep } & \text { Liquid } & \text { Wash Composite (Rep) } & 4.9451 \\ \text { 00-0074 Dup } & \text { Liquid } & \text { Wash Composite Duplicale } & 4.9111 \\ 00-0074 \text { Dup Rep } & \text { Liquid } & \text { Wash Composite Duplicate (Rep) } & 4.9111 \\ \text { 99-2350 MS } & \text { Liquid } & \text { MS Recovery } & \mathrm{n} / \mathrm{a} & \\ 00-0083 & \text { Solid } & \text { Washed Solids } & \mathrm{n} / \mathrm{a} & \mathrm{n} / \mathrm{a} \\ 00-0083 \text { Dup } & \text { Solid } & \text { Washed Solids Duplicate } & \mathrm{n} / \mathrm{a} & \mathrm{n} / \mathrm{a} \\ 00-0083 \text { MS } & \text { Solid } & \text { Washed Solids MS Recovery } & \mathrm{n} / \mathrm{a} & \mathrm{n} / \mathrm{a} \\ 00-0083 \text { Rep } & \text { Solid } & \text { Washed Solids (Rep) } & \mathrm{n} / \mathrm{a} & \mathrm{n} / \mathrm{a} \\ 00-0083 \text { Dup Rep } & \text { Solid } & \text { Washed Solids Duplicate (Rep) } & \mathrm{n} / \mathrm{a} & \mathrm{n} / \mathrm{a}\end{array}$

diluted sample

\begin{tabular}{|c|c|c|c|c|c|c|c|c|}
\hline \multicolumn{3}{|c|}{ Total Inorganic Carbon } & \multicolumn{3}{|c|}{ Tolal Organic Carbon } & \multicolumn{3}{|c|}{ Total Carbon } \\
\hline $\begin{array}{l}\text { TIC } \\
\mathrm{ug} / \mathrm{ml}\end{array}$ & $\begin{array}{l}\text { TIC } \\
\text { ug/g }\end{array}$ & $\begin{array}{l}R P D \\
(\%)\end{array}$ & $\begin{array}{l}\text { TOC } \\
\mathrm{ug} / \mathrm{ml}\end{array}$ & $\begin{array}{l}\text { TOC } \\
\mathrm{ug} / \mathrm{g}\end{array}$ & $\begin{array}{l}\text { RPD } \\
(\%)\end{array}$ & $\begin{array}{l}\text { TC } \\
\mathrm{ug} / \mathrm{ml}\end{array}$ & \begin{tabular}{|l}
$\mathrm{TC}$ \\
ug/g
\end{tabular} & $\begin{array}{l}\text { RPD } \\
(\%)\end{array}$ \\
\hline$<6$ & $<6$ & & $<17$ & $<17$ & & & & \\
\hline 840 & 850 & & 1,800 & 1,800 & & 2,600 & 2,600 & \\
\hline 860 & 880 & 3 & 1,800 & 1,900 & 5 & 2,700 & 2,700 & 4 \\
\hline 850 & 870 & & 1,600 & 1,700 & & 2,500 & 2,500 & \\
\hline 860 & 870 & 0 & 1,600 & 1,700 & 0 & 2,500 & 2,500 & 0 \\
\hline 210 & 200 & & 480 & 470 & & 690 & 680 & \\
\hline 210 & 210 & 5 & 470 & 470 & 0 & 690 & 680 & 0 \\
\hline 210 & 210 & & 490 & 480 & & 700 & 690 & \\
\hline 220 & 220 & 5 & 510 & 510 & 6 & 720 & 720 & 4 \\
\hline $101 \%$ & & & $97 \%$ & & & $100 \%$ & & \\
\hline$n / a$ & 44,600 & & n/a & 1.100 & & $\mathrm{n} / \mathrm{a}$ & 45,700 & \\
\hline $\mathrm{n} / \mathrm{a}$ & $\begin{array}{c}57,100 \\
80 \%\end{array}$ & 25 & n/a & $\begin{array}{l}1,800 \\
89 \%\end{array}$ & $n / a$ & $n / a$ & $\begin{array}{c}58,900 \\
85 \%\end{array}$ & 25 \\
\hline$n / a$ & 51,300 & & $n / a$ & 1.600 & & $n / a$ & 52,900 & \\
\hline$n / a$ & 38,000 & 30 & $n / a$ & 2,000 & $n / a$ & $n / a$ & 40.000 & 28 \\
\hline
\end{tabular}




\begin{tabular}{|c|c|c|c|c|c|c|c|c|c|}
\hline \multirow[b]{3}{*}{ Fluoride } & \multirow{2}{*}{\multicolumn{3}{|c|}{ mass diluti DF-20 }} & \multirow[b]{2}{*}{ DF -21} & \multirow[b]{2}{*}{ average } & & \multicolumn{3}{|c|}{ Percent Removed } \\
\hline & & & & & & & DF-20 & DF-21 & average \\
\hline & 4655.393 & 1.555926 & 2000 & $<2000$ & $<2000$ & Fluoride & $>33 \%$ & $>33 \%$ & $<2000$ \\
\hline Chloride & 976.9118 & \multicolumn{2}{|c|}{$1.555926<2000$} & $<2000$ & $<2000$ & Chloride & & & $<2000$ \\
\hline Nitrite (3) & 37415.28 & 1.555926 & 21800 & 21600 & 21700 & Nitrite (3) & $9.34 \%$ & $10.18 \%$ & 21700 \\
\hline Bromide (3) & & & & & & Bromide (3) & & & \\
\hline Nitrate & 118005.9 & 1.555926 & 86700 & 88100 & 87400 & Nitrate & $-14.32 \%$ & $-16.16 \%$ & 87400 \\
\hline Phosphate & 2093.382 & 1.555926 & 1000 & $<4000$ & $<4000$ & Phosphate & & & $<4000$ \\
\hline Sulfate & 5695.125 & 1.555926 & 1000 & $<4000$ & $<4000$ & Sulfate & & & $<4000$ \\
\hline \multirow[t]{2}{*}{ Oxalate (3) } & 2544.232 & 1.555926 & 1000 & $<4000$ & $<4000$ & Oxalate (3) & & & $<4000$ \\
\hline & & & & & & & Corrected & for addition & of $\mathrm{Sr}(\mathrm{NO} 3)_{2}$ \\
\hline Nitrite (3) & 37415.28 & 1.555926 & 21800 & 21600 & 21700 & Nitrite (3) & $9.34 \%$ & $10.18 \%$ & 21700 \\
\hline Bromide (3) & & & & & & Bromide (3) & & & \\
\hline Nitrate & 118005.9 & 1.555926 & 86700 & 88100 & 87400 & Nitrate & $-6.01 \%$ & $-7.86 \%$ & 87400 \\
\hline
\end{tabular}


Tank AN-107 NOTES

Filter

Operator Raiph Lettau

Test Engineer Kriston Brooks

Backpulsed 2 times

Backpulsed 2 times

\begin{tabular}{ll} 
Date & \multicolumn{1}{c}{$\quad$ 9/20/99 Sheet \#2 } \\
Tank & AN-107 \\
Filter & Mott 0.1 micron - L \\
Test Conditions & Low Solids \\
Operator & Ralph Lettau \\
Test Engineer & Kriston Brooks
\end{tabular}

Backpulsed 2 times

Flow began high and droppe within the 1st minute.

Backpulsed 2 times
Slurry

Loop Filter Filter Filtrale Filtrate

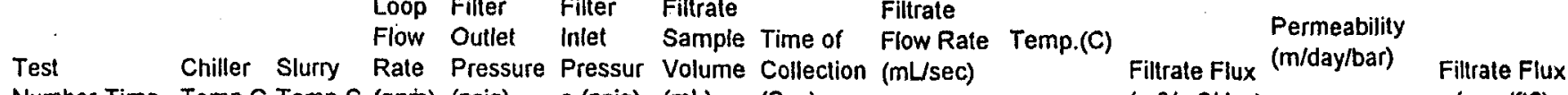
Number Time Temp C Temp C (gpm) (psig) e (psig) (mL) (Sec)

$\begin{array}{lll}1 & 18: 03 & 25.7 \text { NA } \\ 1 & 18: 14 & 23.6 \text { NA } \\ 1 & 18: 23 & 25.2 \text { NA } \\ 1 & 18: 33 & 27.1 \text { NA } \\ 1 & 18: 43 & 24.6 \text { NA } \\ 1 & 18: 53 & 22.9 \text { NA } \\ 1 & 19: 03 & 26.5 \text { NA }\end{array}$

4
4.1
4
4
4
4
4
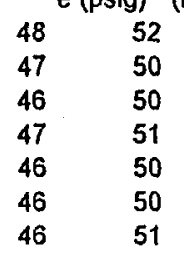

40
20
20
20
20
20
20

$45.61 \quad 0.877$ $\begin{array}{ll}45.61 & 0.877 \\ 46.85 & 0.427\end{array}$ $\begin{array}{ll}48.17 & 0.415\end{array}$ $\begin{array}{ll}49.09 & 0.407\end{array}$ $\begin{array}{ll}61.85 & 0.323\end{array}$ $\begin{array}{ll}65.35 & 0.306\end{array}$ $\begin{array}{ll}59.24 & 0.338\end{array}$

25.7
23.6
25.2
27.1
24.6
22.9
26.5
Chiller
(m3/m2/day)

$\begin{array}{lll}4.073 & 1.181 \quad \text { (gpm/ft2) } \\ 2.104 & 0.629 & 0.0359\end{array}$

$\begin{array}{lll}4.073 & 1.181 & 0.0694\end{array}$

$2.104 \quad 0.629$

$1.956 \quad 0.591$

$\begin{array}{ll}1.820 & 0.539\end{array}$

0.0359

0.0333

0.0310

0.468

0.0264

$1.538 \quad 0.465$

0.0262

$1.533 \quad 0.459$

0.0261

Chiller temperature used instead of slumy temper

$\begin{array}{rrrr}2 & 19: 17 & 23 \mathrm{NA} & 4.19 \\ 2 & 19: 27 & 22.2 \mathrm{NA} & 4.2 \\ 2 & 19: 39 & 26.8 \mathrm{NA} & 4.2 \\ 2 & 19: 47 & 26 \mathrm{NA} & 4.2 \\ 2 & 19: 57 & 21.9 \mathrm{NA} & 4.25 \\ 2 & 20: 07 & 23.7 \mathrm{NA} & 4.2 \\ 2 & 20: 17 & 27.1 \mathrm{NA} & 4.3\end{array}$

$\begin{array}{lr}26 & 30 \\ 27 & 30 \\ 28 & 32 \\ 29 & 33 \\ 28 & 32.5 \\ 28 & 31 \\ 28 & 32.5\end{array}$

$\begin{array}{lrl}20 & 44.49 & 0.450 \\ 20 & 58.7 & 0.341 \\ 20 & 54.52 & 0.367 \\ 20 & 59.49 & 0.336 \\ 20 & 77.02 & 0.260 \\ 20 & 72.74 & 0.275 \\ 20 & 71.81 & 0.279\end{array}$

23

$\begin{array}{lll}23 & 2.253 & 1.167\end{array}$

0.0384

$\begin{array}{lll}26.8 & 1.652 & 0.799\end{array}$

$\begin{array}{lll}26 & 1.548 & 0.724\end{array}$

$21.9 \quad 1.343 \quad 0.644$

$\begin{array}{lll}23.7 & 1.351 & 0.664 \\ 27.1 & 1.244 & 0.596\end{array}$

$\begin{array}{llllr}3 & 20: 34 & 22.3 & \text { NA } & \\ 3 & 20: 44 & 27.4 & 3.3 \\ 3 & 20: 55 & 25.6 & 24.7 & 3.4 \\ 3 & 21: 04 & 24.3 & 23.2 & 3.55 \\ 3 & 21: 15 & 24.7 & 24.3 & 3.4 \\ 3 & 21: 24 & 27.2 & 26.8 & 3.45 \\ 3 & 21: 34 & 25.7 & 24.8 & 3.45\end{array}$

$\begin{array}{rl}68 & 72 \\ 67.5 & 70 \\ 67 & 70 \\ 66 & 70 \\ 67 & 71 \\ 67 & 71 \\ 66 & 70\end{array}$

40
20
20
20
20
20
20

\begin{tabular}{ll}
$58.16 \quad 0.688$ \\
\hline
\end{tabular}

$\begin{array}{ll}51.55 & 0.388\end{array}$

$\begin{array}{ll}67.39 & 0.297\end{array}$

$\begin{array}{ll}77.74 & 0.257\end{array}$

$77.27 \quad 0.259$

$80.38 \quad 0.249$

$88.63 \quad 0.226$

22.

$\begin{array}{ll}22.3 & 3.517\end{array}$

0.729

lurry tempe

$\begin{array}{lllll}4 & 21.50 & 21.7 & 20.4 & 3.05\end{array}$

$\begin{array}{lllll}4 & 22: 01 & 25.2 & 24.9 & 3.05\end{array}$

$\begin{array}{llll}422: 11 & 27.4 & 26.8 & 3.1\end{array}$

$\begin{array}{lllll}4 & 22: 23 & 25.6 & 25 & 3.15\end{array}$

$\begin{array}{lllll}422: 32 & 25.1 & 24.2 & 3.16\end{array}$

$\begin{array}{lllll}4 & 22: 46 & 24.6 & 24.1 & 3.15\end{array}$

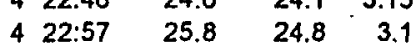

48
50
48
49
49
48
48

50
51
50
51
51
51
51

$\begin{array}{rrr}20 & 38.15 & 0.524 \\ 20 & 61.15 & 0.327 \\ 20 & 71.87 & 0.278 \\ 20 & 85.86 & 0.233 \\ 20 & 96.45 & 0.207 \\ 20 & 101.63 & 0.197 \\ 10 & 54.6 & 0.183\end{array}$

(a)

(1)

$\begin{array}{ccc}1.048 & 0.224 & 0.0179\end{array}$.

AN-107 CUF Results

$2 / 23 / 00$ 


$\begin{array}{lrrrrr}\text { Turned on pressure booster } & 5 & 23: 15 & 22.6 & 22.2 & 4.3 \\ \text { Flow \& Pressure bouncing } & 5 & 23: 26 & 27.7 & 27.4 & 4.6 \\ \text { P varies by }-5-6 \text { psig } & 5 & 23: 33 & 26.2 & 25.4 & 4.6 \\ & 5 & 23: 43 & 23.8 & 22.5 & 4.5 \\ & 5 & 23: 52 & 25 & 24.7 & 4.5 \\ & 5 & 0: 07 & 26.2 & 25.3 & 4.5 \\ & 5 & 0: 19 & 23.3 & 22.2 & 4.4 \\ 9 \text { Sheet \#3 } & & & & & \\ \text { U } & 6 & 0: 40 & 25.7 & 24.6 & 3.97 \\ & 6 & 0: 50 & 22.9 & 21.7 & 4.02 \\ & 6 & 1: 00 & 25.5 & 25.6 & 4.15 \\ & 6 & 1: 10 & 27.1 & 26.4 & 4.08 \\ 1: 35 \text { - sample collected vial } & 6 & 1: 20 & 21.8 & 23.1 & 4.05 \\ & 6 & 1: 30 & 24.2 & 23.7 & 4.05 \\ & 6 & 1: 43 & 27.4 & 26.9 & 4.1\end{array}$

$\begin{array}{rrrrr}47 & 51 & 20 & 38.06 & 0.525 \\ 46 & 50 & 20 & 51.56 & 0.388 \\ 47 & 52 & 20 & 58.93 & 0.339 \\ 47 & 52 & 20 & 66.7 & 0.300 \\ 47 & 52 & 20 & 69.99 & 0.286 \\ 47 & 52 & 20 & 76.02 & 0.263 \\ 48 & 53 & 20 & 88.81 & 0.225 \\ 47 & 51 & 20 & 42.01 & 0.476 \\ 48 & 52 & 20 & 63.02 & 0.317 \\ 47 & 51 & 20 & 67.99 & 0.294 \\ 47 & 53 & 20 & 68.2 & 0.293 \\ 47 & 51 & 20 & 85.81 & 0.233 \\ 48 & 52 & 20 & 84.63 & 0.236 \\ 48 & 53 & 20 & 77.22 & 0.259\end{array}$

22
27
25
22
24
25
22
24
21
25
26
23
23
26

Conditions for dewatering are $50 \mathrm{psig}$ and $4.0 \mathrm{gpm}$

Chiller reset to $27.0 \mathrm{C}$, waste temp down to $20.8 \mathrm{C}$

$\begin{array}{llrrrr} & \text { DW } & 2: 12 & 26.1 & 25.7 & 3.88 \\ \text { Reset to 26.0 C } & \text { DW } & 2: 24 & 27.9 & 27.3 & 4.08 \\ \text { Sample DF-11 } & \text { DW } & 2: 33 & 25.2 & 24.2 & 4.03 \\ \text { Maxed Air Out } & \text { DW } & 2: 44 & \text { NA } & 25.4 & 3.74 \\ \text { Pressure \& crossflow down } & \text { DW } & 2: 50 & \text { NA } & 29.4 & 3.62\end{array}$

47
48
46
45
44

3:15 CUF shut down and drained

51
53
49
47

20
20
20
NA
20

$\begin{array}{ll}50.45 & 0.396 \\ 61.03 & 0.328 \\ 81.57 & 0.245\end{array}$

25.7

27.3

$81.69 \quad 0.245$

25.4
2.695

1.718

1.590

1.525

1.365

1.236

1.155

2.280

1.651

1.370

1.336

1.165

1.161

1.163
0.798

0.519

0.466

0.447

0.400

0.362

0.332

0.675

0.479

0.406

0.387

0.345

0.337

0.334
0.0459

0.0293

0.0271

0.0260

0.0233

0.0211

0.0197

0.0389

0.0281

0.0234

0.0228

0.0199

0.0198

0.0198 


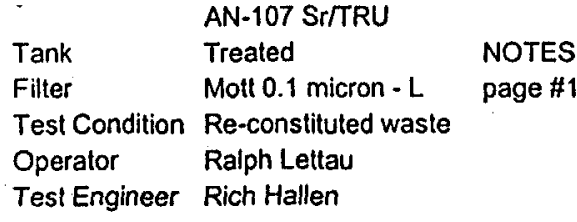

Backpulsed 2 times

\begin{tabular}{ll} 
Date & \multicolumn{1}{c}{$9 / 30 / 99$ Sheet \#2 } \\
Tank & AN-107 Sr/TRU diluted \\
Filter & Mott 0.1 micron $-L$ \\
Test Condition & $-25 \%$ dilution \\
Operator & Ralph Lettau \\
Test Engineer & Rich Hallen
\end{tabular}

Backpulsed 2 times -65 psi

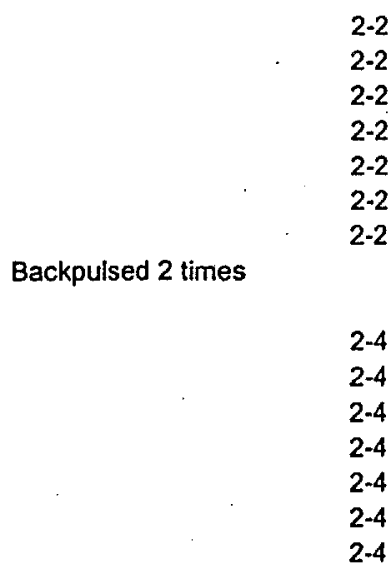

Backpulsed 2 limes

\section{Slurry}

Loop Filter Filter Filtrate Filtrate

$\begin{array}{llllll} & \text { Loop Filter } & \text { Filter } & \text { Filtrate } & \text { Flow Temp. } & \text { Plow } \\ \text { Chilleability Run }\end{array}$

Temp Slurry Rate Pressure Pressure Volume Collection Rate (C) Filtrate Flux (m/day/bar) Time

Filtrate Flux

Number Time C Temp C $(\mathrm{gpm})(\mathrm{psig}) \quad(\mathrm{psig}) \quad(\mathrm{mL}) \quad(\mathrm{Sec}) \quad(\mathrm{mL} / \mathrm{sec}) \quad$ (m3/m2/day)

(gpm/tt2)

$\begin{array}{llllllllllll}\text { rerun of 1- } & 8: 12 & 26.2 & 26.8 & 4.2 & 45 & 50 & 20 & 62.16 & 0.322 & 26.8 & 1.449 \\ \text { rerun of 1- } & 8: 23 & 26.8 & 26.5 & 4.1 & 46 & 50 & 20 & 70.23 & 0.285 & 26.5 & 1.293\end{array}$

refun of 1 - $8.23 \quad 26.8 \quad 26.5 \quad 4.1$

$\begin{array}{lrrrr}\text { rerun of 1- } & 8.34 & 24 & 23.3 & 4.1\end{array}$

$\begin{array}{lllll}\text { rerun of 1- } & 8: 44 & 26.3 & 26.6 & 4.1\end{array}$

$\begin{array}{lllll}\text { rerun of 1- } & 8: 54 & 27.3 & 27.2 & 4.2\end{array}$ $\begin{array}{ccrr}\text { rerun of 1- } & 9: 09 \quad 24.3 \quad 23.5 & 4.2 \\ & \text { ave total flow } & 4.15\end{array}$

45
46

$\begin{array}{llll}50 & 20 & 70.23 & 0.285\end{array}$

$\begin{array}{llll}70.23 & 0.285 & 26.5 & 1.293 \\ 84.86 & 0.236 & 23.3 & 1.171\end{array}$

$\begin{array}{llll}84.38 & 0.237 & 26.6 & 1.073\end{array}$

$\begin{array}{llll}80.93 & 0.247 & 27.2 & 1.101\end{array}$

\section{.15}

Ave TMP 47.9167

\begin{tabular}{rrrr}
$9: 45$ & 26.8 & 27.2 & \\
$9: 52$ & 27.2 & 27.1 & 4.1 \\
$10: 11$ & 23.7 & 23 & 4.1 \\
$10: 24$ & 27.2 & 27.6 & 4.1 \\
$10: 35$ & 26.6 & 26.2 & 4.1 \\
$10: 46$ & 23.9 & 23.2 & 4.1 \\
\multicolumn{4}{c}{ ave total flow }
\end{tabular}

\begin{tabular}{|c|c|c|}
\hline $10: 58$ & 24.3 & 23.9 \\
\hline $11: 09$ & 27.1 & 27.3 \\
\hline $11: 22$ & 24.8 & 23.9 \\
\hline $11: 34$ & 22.6 & 21.7 \\
\hline $11: 46$ & 26 & 26 \\
\hline $11: 54$ & 26.9 & 26.4 \\
\hline $12: 08$ & 22.6 & 21.4 \\
\hline
\end{tabular}
ave total flow 4.186

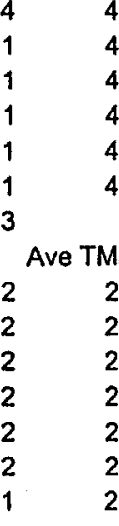

$\begin{array}{ll}47 & 51 \\ 47 & 49 \\ 47 & 50 \\ 47 & 50 \\ 47 & \end{array}$

5130

1.046

$\begin{array}{llll}55.59 & 0.540 & 27.2 & 2.404\end{array}$

$\begin{array}{llll}71.09 & 0.422 & 27.1 & 1.885\end{array}$

$\begin{array}{cccc}60.05 & 0.333 & 23 & 1.670\end{array}$

$\begin{array}{llll}56.07 & 0.357 & 27.6 & 1.571\end{array}$

$\begin{array}{llll}60.62 & 0.330 & 26.2 & 1.511\end{array}$

$\begin{array}{llll}68.35 & 0.293 & 23.2 & 1.458\end{array}$

$\begin{array}{ll}50 & 20 \\ 50 & 20\end{array}$

.458

$\begin{array}{llll}59.73 & 0.335 & 23.9 & 1.636\end{array}$

$\begin{array}{llll}59.23 & 0.338 & 27.3 & 1.500\end{array}$

$\begin{array}{llll}70.81 & 0.282 & 23.9 & 1.380\end{array}$

$\begin{array}{llll}67.56 & 0.296 & 21.7 & 1.540\end{array}$

$\begin{array}{llll}70.67 & 0.283 & 26 & 1.303\end{array}$

$\begin{array}{llll}69.66 & 0.287 & 26.4 & 1.308\end{array}$

$\begin{array}{llll}84.39 & 0.237 & 21.4 & 1.244\end{array}$

Ave TMP 28.2143

$\begin{array}{rrrr}12: 23 & 24.8 & 24.7 & 3.1 \\ 12: 32 & 27.6 & 27.6 & 3.1 \\ 12: 44 & 24 & 23.1 & 3.1 \\ 12: 56 & 23.8 & 23.4 & 3.1 \\ 13: 05 & 26.8 & 27.1 & 3.1 \\ 13: 20 & 24.7 & 23.9 & 3.1 \\ 13: 33 & 23.4 & 22.9 & 3.1\end{array}$

ave total flow

$\begin{array}{ll}50 & 52 \\ 47 & 51 \\ 47 & 50 \\ 47 & 5 \\ 48 & 5 \\ 46 & 49 \\ 46 & 49\end{array}$

20
20
20
20
20
20
20

$\begin{array}{lll}42.06 & 0.476 & \\ 56.89 & 0.352 & \\ 73.31 & 0.273 & 23 \\ 78.65 & 0.254 & 23 \\ 75.38 & 0.265 & 27 \\ 89.74 & 0.223 & 23 \\ 95.63 & 0.209 & \end{array}$

24.7
27.6
23.1
23.4
27.1
23.9
22.9

2.271

1.549

.1 .364

1.260

1.185

1.089

1.051
$0.442 \quad 4$

0.391

0.354

0.324

0.316

0.711

0.570

0.499

0.470

0.452

0.436

0.847
0.763

0.715

0.798

0.675

0.665

0.633

0.646

0.458

0.408

0.373

0.347

0.332

0.321

ave w/o
0.025

0.022

0.020

0.018

0.019

0.018

0.020

0.041

0.032

0.028

0.027

0.026

0.025

ave w/o $\quad 0.028$

$$
\begin{array}{ll}
0 & 0.0279 \\
11 & 0.0256
\end{array}
$$

$11 \quad 0.0256$

$24 \quad 0.0235$

$36 \quad 0.0263$

$70 \quad 0.0223$

ave w/o $\quad 0.024$

$\begin{array}{ll}0 & 0.0387\end{array}$

0.0264
21

$21 \quad 0.0232$

$33 \quad 0.0215$

$42 \quad 0.0202$

$57 \quad 0.0186$

$\begin{array}{ll}70 & 0.0179\end{array}$

$223 / 00$
$48 \quad 0.0222$ 


\section{Date $\quad 9 / 30 / 99$ Sheet $\# 3$ \\ Tank diluted AN-107 DF.
Mott 0.1 micron - L \\ Fitter \\ Test Condition diluted}

Operator

Test Engineer Rich Hallen

$\begin{array}{rrrrrr}13: 48 & 27.9 & 28.5 & 4.1 & 47 & 51 \\ 14: 00 & 27.3 & 27 & 4.1 & 46 & 50 \\ 14: 10 & 24.8 & 24 & 4.06 & 47 & 50 \\ 14: 21 & 24.3 & 23.9 & 4 & 47 & 51 \\ 14: 31 & 27.4 & 27.7 & 4.17 & 47 & 51 \\ 14: 40 & 26.7 & 26.4 & 4.14 & 47 & 51 \\ 14: 51 & 24.8 & 24.2 & 4.11 & 46 & 50\end{array}$
ave total flow $\quad 4.097$

Backpulsed 2 times

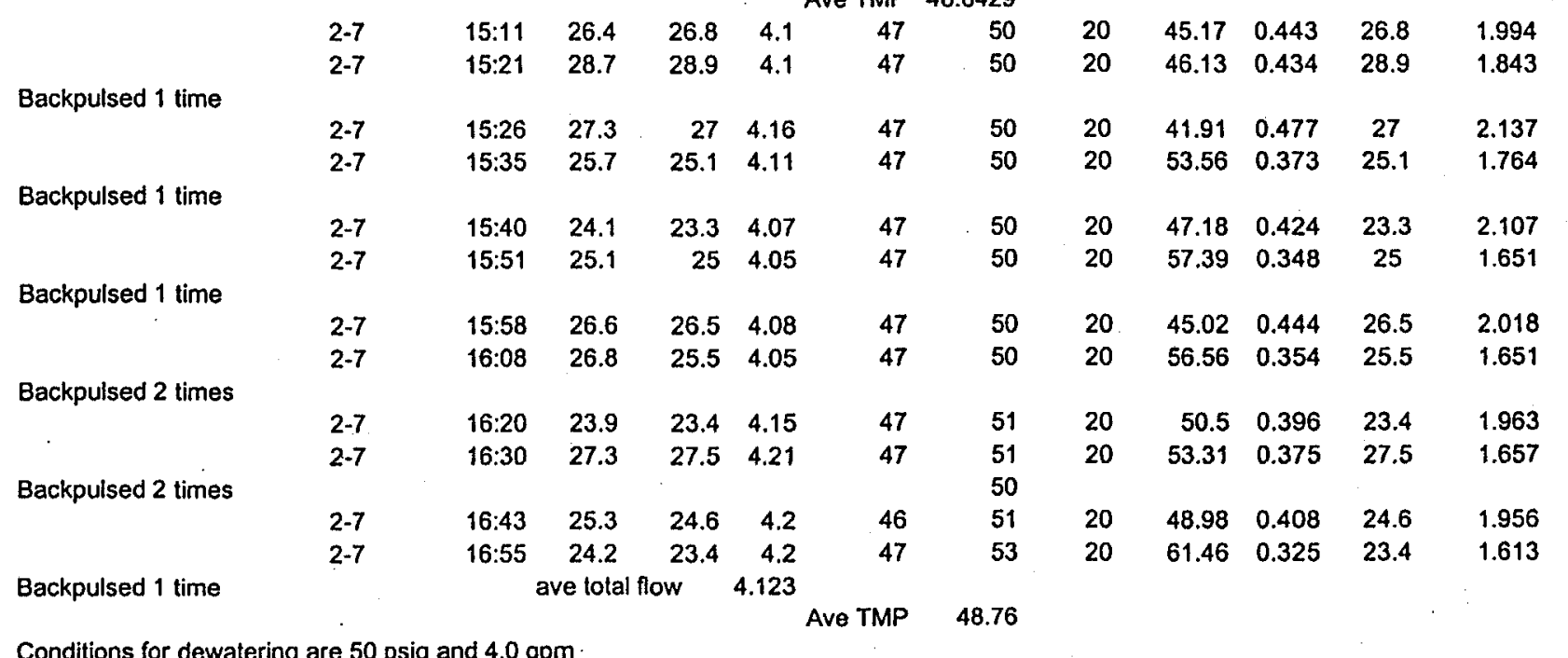

Conditions for dewatering are $50 \mathrm{psig}$ and $4.0 \mathrm{gpm}$

\begin{tabular}{lllrrrr} 
DW & $17: 07$ & 24.6 & 24.5 & 4 & 47 & 52 \\
DW & $17: 19$ & 28.9 & 29 & 4.2 & 47 & 51 \\
DW & $17: 32$ & 26.2 & 25.6 & 4.25 & 47 & 51 \\
DW & $17: 45$ & 24.3 & 23.4 & 4.2 & 47 & 52 \\
DW & $18: 04$ & 26.6 & 26.3 & 3.48 & 43 & \\
\multicolumn{5}{c}{ ave total flow } & 4.026 &
\end{tabular}

Test 2-Diluted

Ave TMP 48.8571

Ave TMP 48.6429

$\begin{array}{llll}39.69 & 0.504 & 28.5 & 2.165\end{array}$

$\begin{array}{lllll}51.04 & 0.392 & 27 & 1.755\end{array}$

$\begin{array}{ll}61.15 & 0.327\end{array}$

$\begin{array}{ll}60.91 & 0.328\end{array}$

$\begin{array}{lll}59.43 & 0.337 & 27\end{array}$

$\begin{array}{lll}63.91 & 0.313\end{array}$

1.594

1.604

1.478

1.425

1.343

9 843

0.551

0.639

0.527

0.630

0.494

0.603

0.494

0.581

0.491

0.585

0.468

Ave TMP

52
51
51
52
47

20.

$\begin{array}{llll}57.38 & 0.349 & 24.5\end{array}$

$\begin{array}{lll}57.81 & 0.346\end{array}$

$\begin{array}{lll}66.65 & 0.300 & 25.6\end{array}$

$\begin{array}{lll}77.16 & 0.259 & 23.4\end{array}$

$\begin{array}{lll}89.52 & 0.223 & 26.3\end{array}$

Ave TMP

Page 2

0.0369

0.0299

0.0272

0.0273

0.0252

0.0243

0.0229

ave w/o $\quad 0.026$

2-BP

0.0340

0.0314

1-BP

$\begin{array}{ll}9 & 0.0301\end{array}$

1-BP

$\begin{array}{ll}0 & 0.0359\end{array}$

$\begin{array}{ll}11 & 0.0281\end{array}$

$1-B P$

0.0344

0.0282

2-BP

0.0335

0.0283

2-BP

$\begin{array}{ll}0 & 0.0333\end{array}$

0.0275

0.032

AN-107 CUF Results

$2 / 23 / 00$ 


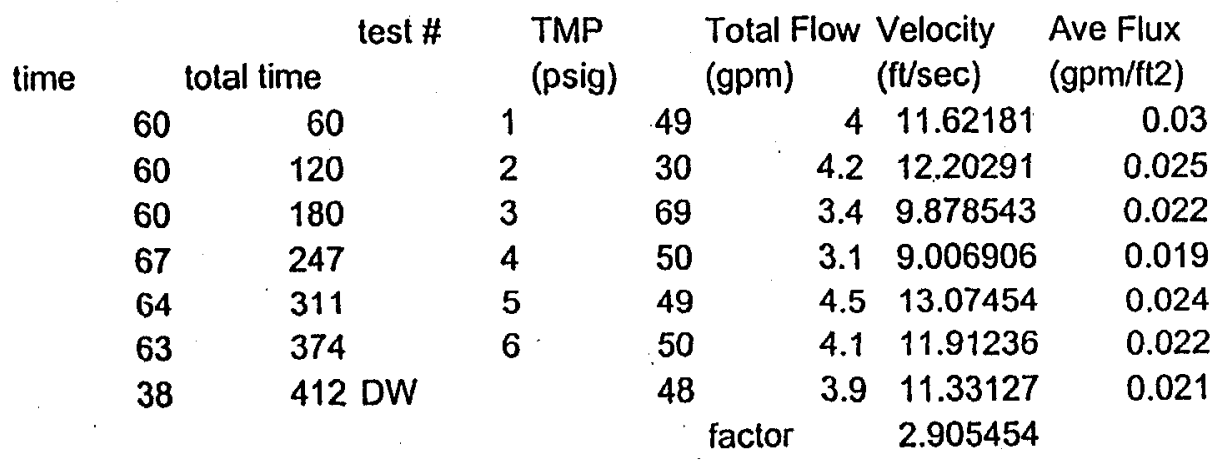

\begin{tabular}{lrrrr} 
test \# & \multicolumn{3}{c}{ Ave Flux $\%$ Change } \\
& 1 & 60 & 0.030 & \\
& 2 & 120 & 0.028 & $5.75 \%$ \\
& 3 & 180 & 0.027 & $5.75 \%$ \\
& 4 & 247 & 0.025 & $6.40 \%$ \\
& 5 & 311 & 0.023 & $6.13 \%$ \\
& 6 & 374 & 0.022 & $6.03 \%$ \\
DW & & 412 & 0.021 & $3.68 \%$
\end{tabular}

$\begin{array}{llr}\text { so a } & 63.33 \% \text { pressure increase }= & 13.09 \% \text { flux increase } \\ \text { and a } & 29.03 \% \text { velocity increase }= & 31.26 \% \text { flux increase } \\ \text { and a } & 12.50 \% \text { velocity increase }= & 2.52 \% \text { flux increase } \\ \text { test \#3 } & 17.65 \% & 21.11 \% \text { flux increase }\end{array}$




\section{APPENDIX E: STAFF AND ROLE/RESPONSIBILITY}

E.1 


\begin{tabular}{|l|l|}
\hline \multicolumn{1}{|c|}{ Staff Member } & \multicolumn{1}{|c|}{ Role/Responsibility } \\
\hline Richard Hallen & Scientist/Technical Leader - Sr/TRU Precipitation \\
\hline Paul Bredt & Scientist/Physical and Rheological Properties \\
\hline Kriston Brooks & Engineer/CUF System and Solids Removal \\
\hline Lynette Jagoda & Engineer/CUF System Cleaning \\
\hline Don Rinehart & Technician/Hot Cell Tests-Sr/TRU PPT/CUF Operation \\
\hline Ralph Lettau & Technician/Hot Cell Tests-Sr/TRU PPT/CUF Operation \\
\hline Dave Ortiz & Technician/Hot Cell CUF Operation and Cleaning \\
\hline Vaughn Hoopes & Technician/Hot Cell CUF cleaning and sample prep. \\
\hline Mike Mann & Technician/Hot Cell Filtrate Composite \\
\hline Mac Zumhoff & Technician/Hot Cell Operations \\
\hline
\end{tabular}


PNWD-3035

BNFL-RPT-027, Rev: 0

\section{Distribution}

$\begin{aligned} & \text { No. of } \\ & \text { Copies }\end{aligned}$
OFFSITE
$2 \quad \begin{aligned} & \text { DOE/Office of Scientific and Technical } \\ & \text { Information }\end{aligned}$

No. of

Copies

ONSITE

$5 \quad$ British Nuclear Fuels, Limited M. E. Johnson (4)

A. Thompson

BN-FL

BN-FL

11 Pacific Northwest National Laboratory

\begin{tabular}{ll}
\hline P. R. Bredt & P7-25 \\
K. P. Brooks & K6-24 \\
R. T. Hallen & K2-12 \\
L. K. Jagoda & K6-24 \\
D. E. Kurath & P7-28 \\
E. V. Morrey & P7-28 \\
Technical Report Files (5) K1-06
\end{tabular}

Distr.1 